
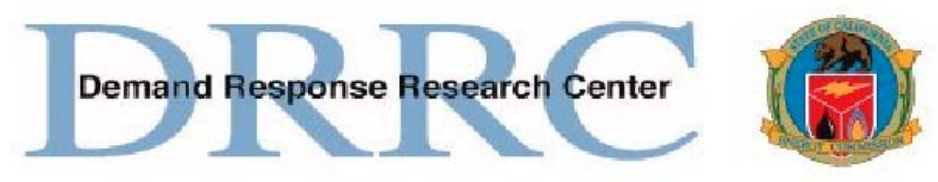

\title{
Customer Strategies for Responding to Day-Ahead Market Hourly Electricity Pricing
}

\author{
Prepared for the \\ California Energy Commission \\ Principal Authors \\ C. Goldman, N. Hopper and R. Bharvirkar \\ Lawrence Berkeley National Laboratory \\ B. Neenan, R. Boisvert, P. Cappers, D. Pratt, and K. Butkins \\ Neenan Associates \\ Ernest Orlando Lawrence Berkeley National Laboratory \\ 1 Cyclotron Road, MS 90R4000 \\ Berkeley CA 94720-8136
}

August 2005

The work described in this report was coordinated by the Demand Response Research Center and funded by the California Energy Commission, Public Interest Energy Research Program, under Work for Others Contract No. 500-03-026 and by the U.S. Department of Energy under Contract No. DE-AC02-05CH11231. 


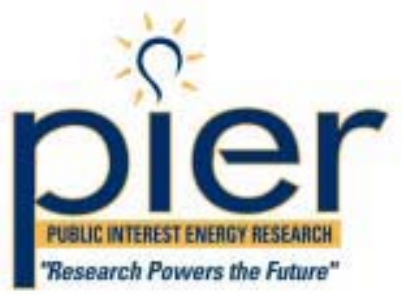

Research Powers the Future"
Prepared By: Charles A. Goldman

Lawrence Berkeley National Laboratory

Berkeley, California

Contract No. 500-03-026

Prepared For:

California Energy Commission

Public Interest Energy Research (PIER)

Program

Dave Michel

Contract Manager

Mark Rawson

Program Area Team Lead

Martha Krebs

Deputy Director

ENERGY RESEARCH AND DEVELOPMENT

DIVISION

\section{B.B. Blevins \\ Executive Director}

The work described in this report was coordinated by the Demand Response Research Center and funded by the California Energy Commission, Public Interest Energy Research Program, under Work for Others Contract No. 500-03-026 and by the U.S. Department of Energy under Contract No. DEAC02-05CH11231.

\section{DISCLAIMER}

This report was prepared as the result of work sponsored by the California Energy Commission. It does not necessarily represent the views of the Energy

Commission, its employees or the State of California. The Energy Commission, the State of California, its

employees, contractors and subcontractors make no warrant, express or implied, and assume no legal liability for the information in this report; nor does any party represent that the uses of this information will not infringe upon privately owned rights. This report has not been approved or disapproved by the California Energy

Commission nor has the California Energy Commission passed upon the accuracy or adequacy of the information in this report. 


\section{PREFACE}

The Public Interest Energy Research (PIER) Program supports public interest energy research and development that will help improve the quality of life in California by bringing environmentally safe, affordable, and reliable energy services and products to the marketplace.

The PIER Program, managed by the California Energy Commission (Commission), annually awards up to \$62 million to conduct the most promising public interest energy research by partnering with Research, Development, and Demonstration (RD\&D) organizations, including individuals, businesses, utilities, and public or private research institutions.

PIER funding efforts are focused on the following six RD\&D program areas:

- Buildings End-Use Energy Efficiency

- Industrial/Agricultural/Water End-Use Energy Efficiency

- Renewable Energy

- Environmentally-Preferred Advanced Generation

- Energy-Related Environmental Research

- Energy Systems Integration

What follows is one of two final reports for the Program and Tariffs Research Project, 500-03-026 Task 3.2, conducted by the Lawrence Berkeley National Laboratory. The report is entitled "Customer Strategies for Responding to Day-Ahead Market Hourly Electricity Pricing”. This project contributes to the Energy Systems Integration Program.

For more information on the PIER Program, please visit the Commission's Web site at: http://www.energy.ca.gov/research/index.html or contact the Commission's Publications Unit at 916-654-5200. 


\section{Acknowledgements}

The work described in this report was coordinated by the Demand Response Research Center and funded by the California Energy Commission, Public Interest Energy Research Program, under Work for Others Contract No. 500-03-026 and by the U.S. Department of Energy under Contract No. DE-AC02-05CH11231.

We would like to acknowledge the assistance and support from Michael Kelliher, Catherine McDonough and Art Hamlin of Niagara Mohawk, A National Grid Company, without which this study would have been impossible. We also thank the following individuals and organizations for their support of this research project: Laurie Ten Hope (California Energy Commission), Mary Ann Piette (LBNL/CEC PIER Demand Response Research Center), the New York Public Service Commission (NYPSC), the New York Independent System Operator (NYISO), New York State Energy Research and Development Authority (NYSERDA), and the SC-3A customers that voluntarily participated in this study.

We also thank the members of our Academic Advisory Committee, Severin Borenstein (University of California Energy Institute), Richard Schuler and Tim Mount (Cornell University), Peter Schwarz (University of North Carolina, Charlotte) and Mike Jaske and David Hungerford (CEC) for their critical input on demand modeling work, and our Technical Advisory Committee members, Bruce Kaneshiro (CPUC), Scott Cauchois (California Office of Ratepayer Advocates), Mike Jaske and David Hungerford (CEC), Glen Perez (CAISO), Andrew Bell and Dewey Seeto (PG\&E), Mark Wallenrod (SCE), Suzie Sides and Paul Borkovich (SDG\&E), Barbara Barkovich (CLECA), Karen Lindh (CMA), Jim Gallagher and Doug Lutzy (NYPSC), Dave Coup and Peter Douglas (NYSERDA), Dave Lawrence and Aaron Breidenbaugh (NYISO), Catherine McDonough and Arthur Hamlin (National Grid), Larry Dewitt (Pace University), and Bob Loughney (Multiple Interveners) for their input, suggestions and comments. Finally, we thank the following individuals for reviewing and providing comments on a draft of this report: Barbara Barkovich (CLECA), Larry Dewitt (Pace University), Roger Levy (DRRC), Peter Schwarz (UNC Charlotte), Richard Schuler (Cornell University), Steven Braithwait and Ross Hemphill (Christensen Associates) and Mary Ann Piette (DRRC). 


\section{Table of Contents}

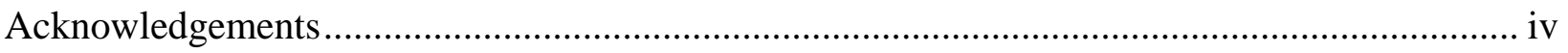

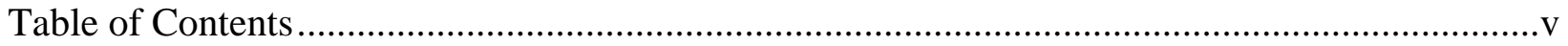

List of Figures ....................................................................................................................... vii

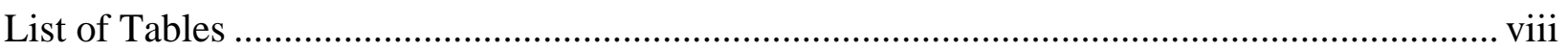

Acronyms and Abbreviations ……………………............................................................... ix

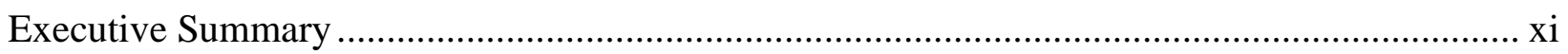

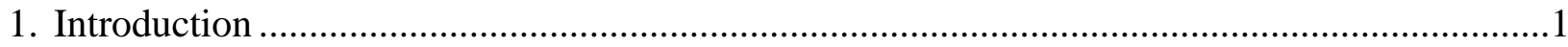

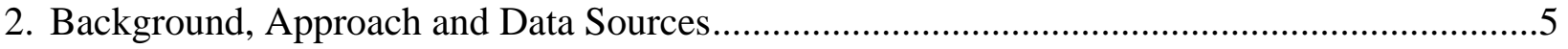

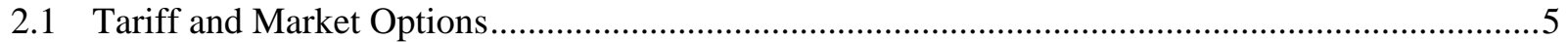

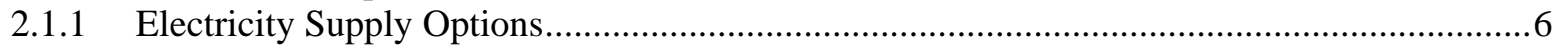

2.1.2 Additional Products and Services ......................................................................................

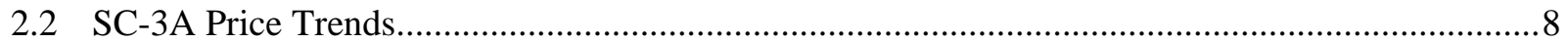

2.3 Weather in Upstate New York ……………………………………………………………....12

2.4 Customer Research..........................................................................................................12

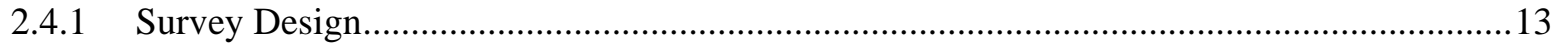

2.4.2 Survey Administration................................................................................................

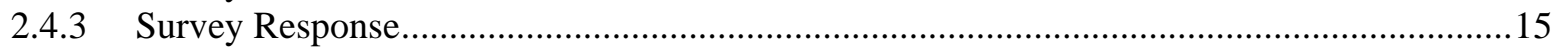

2.5 NMPC Billing Data and Tariff History ………………………………………………………....16

3. Quantifying and Characterizing Price Response.....................................................................18

3.1 Measuring Price Response - The Theory of the Firm.................................................................18

3.1.1 Interpreting Elasticity of Substitution Results .................................................................21

3.2 The Specification of Customer Response to Daily Electricity Price Changes ................................24

3.2.1 The Indirect Generalized Leontief Input Demand Model...................................................25

3.2.2 Implementation of Demand Models ..........................................................................26

3.3 Response to Market-Based Default Service Electricity Prices......................................................22

3.3.1 Price Responsiveness and the Length of the Peak Period.....................................................30

3.3.2 Intensity of Price Response ...........................................................................................

3.3.3 Distribution of Individual Customer Elasticities .....................................................................32

3.3.5 Impact of Weather on Peak Load and Price Response ..........................................................34

3.3.6 Some Customers Can be "Priced-Out" of Peak Electricity Usage .........................................35

3.3.7 The Character of Price Response.........................................................................................36

3.3.8 Drivers to Price Response.................................................................................................38

3.4 Aggregate Load Response ................................................................................................4

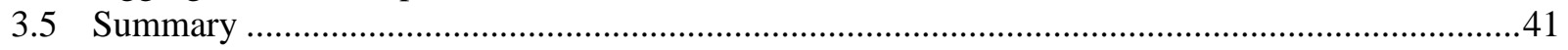

4. Customer Adaptation to Default RTP Service ……………………….......................................43

4.1 Self-Reported Response Strategies and Use of Enabling Technologies ........................................43

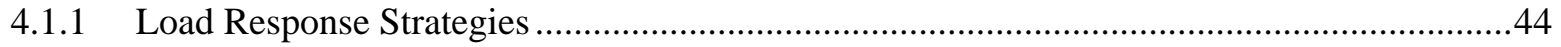

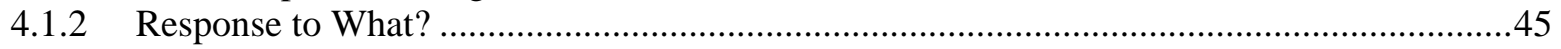




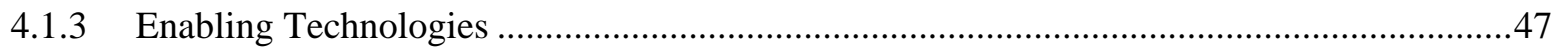

4.2 Linking Customer Characteristics and Circumstances to Estimated Price Response ...................49

4.3 Barriers to Price Response ...................................................................................................54

4.4 Customer Migration and the Search for a Hedge .......................................................................57

4.4.1 SC-3A Customer Migration Trends.................................................................................57

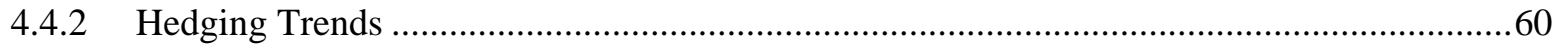

4.4.3 Why Don’t Customers Hedge More? ...............................................................................61

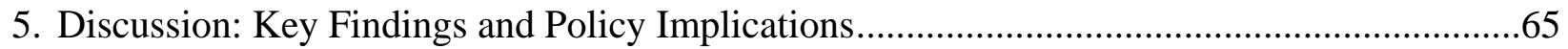

5.1 Deriving and Interpreting the Elasticity of Substitution............................................................66

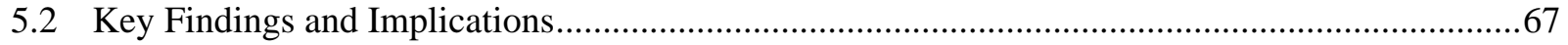

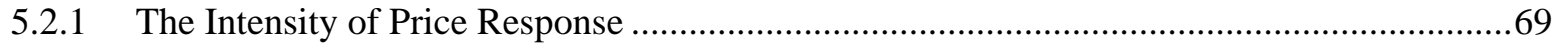

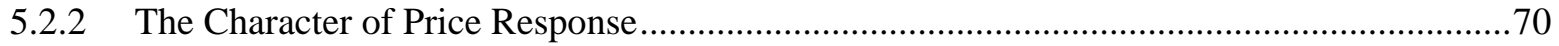

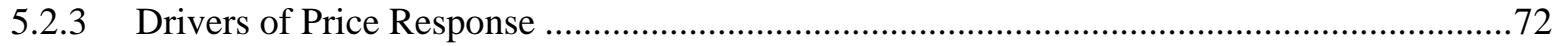

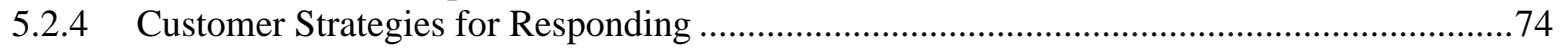

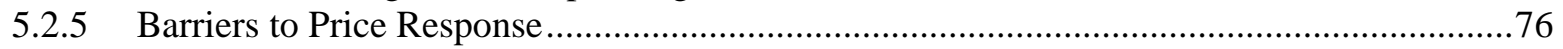

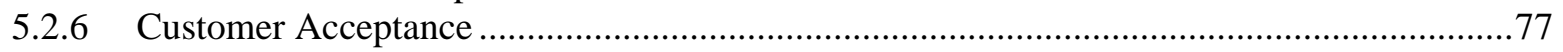

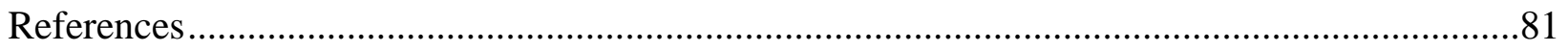

Appendix A. 2004 SC-3A Customer Survey ………………................................................ A-3

Appendix B. The Generalized Leontief Demand Model, Theoretical and Empirical Specifications and Interpretations ..................................................................... A-15

Appendix C. Empirical Estimates of NMPC’s SC-3A Customers’ Response to DayAhead Market Electricity Prices ………………………..................................... A-41 


\section{List of Figures}

Figure ES-1. Choices Available to SC-3A Customers .......................................................... xii

Figure ES-2. Distribution of Customers by their Substitution Elasticity Estimates ................... xiv

Figure ES-3. Price Responsiveness by Business Category .................................................. Xv

Figure ES-4. Self-Reported Load Response Strategies ...................................................... xix

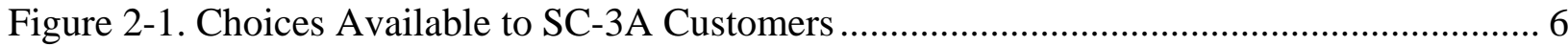

Figure 2-2. Major Price Regions in NMPC Service Territory ................................................. 9

Figure 2-3. Average Peak Prices by Region .................................................................... 9

Figure 2-4. Volatility of Peak Prices by Region ................................................................ 10

Figure 2-5. Trends in Average Summer SC-3A Prices: East Region ....................................... 10

Figure 2-6. Trends in Summer SC-3A Price Volatility: East Region...................................... 11

Figure 2-7. Price Duration Curve: East Region, 2000-2004 Summer Weekdays ....................... 11

Figure 3-1. Implementation of Generalized Leontief and Regression Models........................... 27

Figure 3-2. Impact of Peak Period Specification on Average Elasticities of Substitution ........... 30

Figure 3-3. Distribution of Accounts by Elasticity of Substitution .......................................... 32

Figure 3-4. Distribution of Load by Elasticity of Substitution ................................................. 33

Figure 3-5. Distribution of Accounts by Elasticity of Substitution and NYISO DR

Program Participation................................................................................................ 33

Figure 3-6. Reduction in 119 SC-3A Customers' Peak Demand at Various Price Ratios ........... 41

Figure 4-1. Self-Reported Load Response Strategies ......................................................... 44

Figure 4-2. Self-Reported Response Strategies by Business Classification ............................. 45

Figure 4-3. Price Responsiveness by Business Category ................................................. 51

Figure 4-4. Frequency of Monitoring Hourly Prices ......................................................... 55

Figure 4-5. Barriers to Price Response by Business Classification .......................................... 57 


\section{List of Tables}

Table ES-1. Elasticity of Substitution Results........................................................................... xiii

Table ES-2. Reasons for Responding to NYISO Emergency Events.......................................... xvii

Table ES-3. Barriers to Price Response ........................................................................................ xxi

Table 2-1. Representative Summer Weekday Temperatures in NMPC Service Territory:

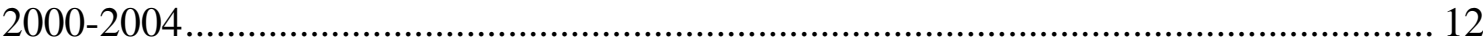

Table 2-2. Question Topics Included in 2004 SC-3A Customer Survey........................................ 14

Table 2-3. 2004 SC-3A Survey Response by Customer Account .................................................... 15

Table 2-4. Characteristics of SC-3A Customers and 2004 Survey Respondents .......................... 16

Table 3-1. Character of Customer Response: Possible Substitution Elasticity Scenarios .............. 22

Table 3-2. Empirical Price Response Models Used in this Study ………………………............. 25

Table 3-3. Phase 1 and Phase 2 Elasticity of Substitution Results ................................................. 31

Table 3-4. Significance of Weather in Influencing Customers' Load and Price Response........... 34

Table 3-5. Impact of Weather on Price Response by Business Sector ........................................... 35

Table 3-6. Characteristics of Customers that can be "Priced Out" of Peak Usage........................ 36

Table 3-7. Character of Price Response: Regression Results ........................................................ 37

Table 3-8. Marginal Changes in Elasticities of Substitution by Business Category ...................... 38

Table 3-9. Drivers to Price Response: Regression Results.............................................................. 39

Table 3-10. Price-responsiveness of Customers by Sector............................................................. 42

Table 4-1. Reasons for Responding to NYISO Emergency Events................................................ 47

Table 4-2. How SC-3A Customers Use Enabling Technologies...................................................... 48

Table 4-3. Characteristics of Price-Responsive and Non-Responsive Customers ......................... 49

Table 4-4. Selected Characteristics of Moderately and Highly Responsive Customers................. 50

Table 4-5. Barriers To Price Response ......................................................................................... 55

Table 4-6. Reasons for Not Monitoring Hourly Prices Routinely ................................................. 56

Table 4-7. Trends in SC-3A Customers' Supply Choices ................................................................ 58

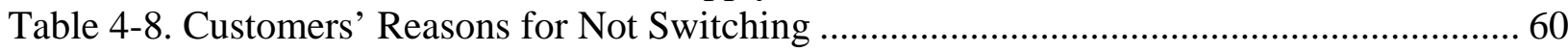

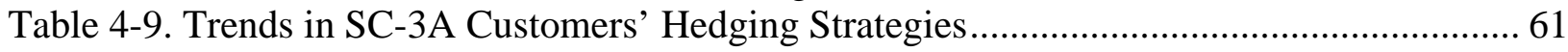

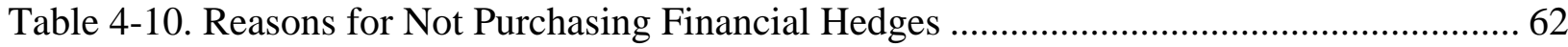

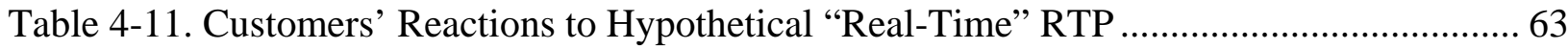

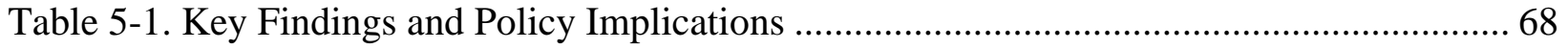




\section{Acronyms and Abbreviations}

$\begin{array}{ll}\text { CEC } & \text { California Energy Commission } \\ \text { CES } & \text { constant elasticity of substitution } \\ \text { CPP } & \text { critical peak pricing } \\ \text { DADRP } & \text { (NYISO) Day Ahead Demand Response Program } \\ \text { DAM } & \text { day-ahead market } \\ \text { DR } & \text { demand response } \\ \text { DRRC } & \text { Demand Response Research Center } \\ \text { EDRP } & \text { (NYISO) Emergency Demand Response Program } \\ \text { ESCO } & \text { energy service company } \\ \text { GL } & \text { Generalized Leontief } \\ \text { ICAP/SCR } & \text { (NYISO) Installed Capacity/ Special Case Resources Program } \\ \text { kW } & \text { kilowatt } \\ \text { kWh } & \text { kilowatt-hour } \\ \text { LBNL } & \text { Lawrence Berkeley National Laboratory } \\ \text { MW } & \text { Megawatt } \\ \text { MWh } & \text { Megawatt-hour } \\ \text { NMPC } & \text { Niagara Mohawk (Power Corporation), A National Grid Company } \\ \text { NYISO } & \text { New York Independent System Operator } \\ \text { NYPA } & \text { New York Power Authority } \\ \text { PIER } & \text { Public Interest Energy Research } \\ \text { RTP } & \text { real-time pricing } \\ \text { THI } & \text { temperature heat index } \\ \text { TOU } & \text { time-of-use } \\ & \end{array}$





\section{Executive Summary}

Real-time pricing (RTP) has been advocated as an economically efficient means to send price signals to customers to promote demand response (DR) (Borenstein 2002, Borenstein 2005, Ruff 2002). However, limited information exists that can be used to judge how effectively RTP actually induces DR, particularly in the context of restructured electricity markets. ${ }^{1}$

This report describes the second phase of a study of how large, non-residential customers' adapted to default-service day-ahead hourly pricing. The customers are located in upstate New York and served under Niagara Mohawk, A National Grid Company (NMPC)'s SC-3A rate class. The SC-3A tariff is a type of RTP that provides firm, day-ahead notice of hourly varying prices indexed to New York Independent System Operator (NYISO) day-ahead market prices. The study was funded by the California Energy Commission (CEC)'s PIER program through the Demand Response Research Center (DRRC).

NMPC's is the first and longest-running default-service RTP tariff implemented in the context of retail competition. The mix of NMPC's large customers exposed to day-ahead hourly prices is roughly $30 \%$ industrial, $25 \%$ commercial and $45 \%$ institutional. They have faced periods of high prices during the study period (2000-2004), thereby providing an opportunity to assess their response to volatile hourly prices. The nature of the SC-3A default service attracted competitive retailers offering a wide array of pricing and hedging options, and customers could also participate in demand response programs implemented by NYISO.

The first phase of this study examined SC-3A customers' satisfaction, hedging choices and price response through in-depth customer market research and a Constant Elasticity of Substitution (CES) demand model (Goldman et al. 2004). This second phase was undertaken to answer questions that remained unresolved and to quantify price response to a higher level of granularity. We accomplished these objectives with a second customer survey and interview effort, which resulted in a higher, 76\% response rate, and the adoption of the more flexible Generalized Leontief (GL) demand model, which allows us to analyze customer response under a range of conditions (e.g. at different nominal prices) and to determine the distribution of individual customers' response.

\section{Customer Choices}

Figure ES-1 provides an overview of the choices available to SC-3A customers since RTP became the default service in late 1998. Customers can purchase their electric commodity from a competitive retailer and they have opportunities to hedge with financial derivatives to offset the risks associated with paying hourly varying energy

\footnotetext{
${ }^{1}$ Zarnikau (1990), Herriges et al. (1993), Braithwait and O’Sheasy (2001), Schwarz et al. (2002), and Boisvert et al. (2004) examined large customer response to voluntary RTP programs at vertically integrated, regulated utilities and Goldman et al. (2004), the first phase of this study, characterized large customer response to RTP in a competitive retail environment. Charles River Associates (2005) recently examined small customers' response to a critical peak pricing (CPP) pilot.
} 
prices. In addition, since 2001, these customers have had opportunities to earn curtailment incentives by participating in demand response programs offered by the New York Independent System Operator (NYISO). Enabling technology incentives and technical assistance through NYSERDA programs have also been available through most of the study period to assist customers in developing price responsive behaviors.

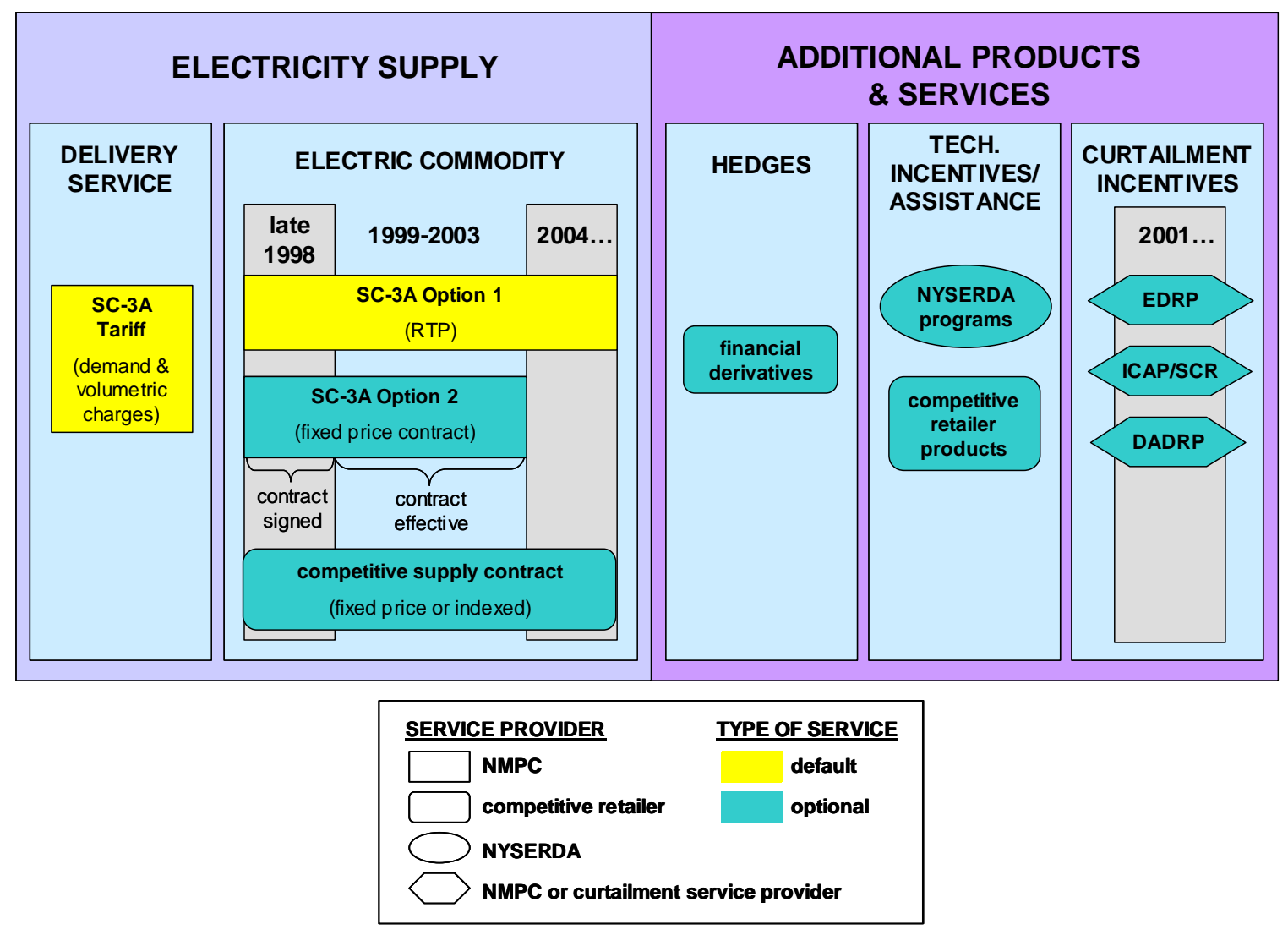

Figure ES-1. Choices Available to SC-3A Customers

\section{Deriving and Interpreting the Elasticity of Substitution}

Niagara Mohawk's SC-3A customers use electricity as an input to processes that produce intermediate or final consumer goods, or to provide services to consumers or society. Consequently, we hypothesize that these customers make electricity usage decisions in the short run, from day-to-day, based on the value electricity contributes to the customer's overall profit (or, in the case of a government/educational customer, the reduction of overall operating expenses) and information available to them about prevailing hourly electricity prices.

The distribution of NYISO day-ahead electricity prices, which are the basis for SC-3A prices, is such that the majority of days are characterized by a fairly constant pattern of hourly prices (of typically \$50-60/MWh for mid-day hours), with high peak period prices (exceeding \$300/MWh) occurring only on isolated days. Consequently, we portray SC3A customers' price response as primarily involving the decision to reallocate business 
activity from an established routine on those days when prices are high. This response involves using less electricity during the high-priced (peak) hours of the day and more during the lower priced (off-peak) hours to meet the day's expected level of business. ${ }^{2}$ Accordingly, the appropriate measure of price response is the elasticity of substitution, defined as the percentage change in daily peak electricity usage (relative to off-peak usage) in response to a one percent change in relative peak prices. ${ }^{3}$

Substitution elasticities take on values of zero or greater. Non-zero elasticities indicate price response, and the higher the elasticity, the greater the response. We estimated substitution elasticities from customers' hourly load and price data using a Generalized Leontief (GL) model. We also characterized other dimensions of price response, such as the effects of weather, load and nominal prices, and drivers to price response, by regressing elasticity of substitution results against these factors.

\section{The Intensity of Price Response}

We evaluated the intensity of price response using substitution elasticities derived from the GL model. The following key findings follow from this analysis.

Price response is modest overall - the average elasticity is 0.11

As a group, SC-3A customers' price response is modest - the load-weighted average substitution elasticity of 119 customers included in the model is 0.11 (see Table ES-1), which means that their combined ratio of peak to off-peak electricity usage declines by $11 \%$ in response to a doubling of peak prices (relative to off-peak prices). This result is consistent with other studies of large customers facing similar pricing circumstances (Herriges et al. 1993, Schwarz et al. 2002, Boisvert et al. 2004).

\section{Table ES-1. Elasticity of Substitution Results}

\begin{tabular}{|l|l|l|}
\hline Business Category & N & $\begin{array}{l}\text { Average } \\
\text { substitution } \\
\text { elasticity }\end{array}$ \\
\hline Government/education & 34 & 0.10 \\
\hline Public Works & 17 & 0.02 \\
\hline Commercial/retail & 16 & 0.06 \\
\hline Healthcare & 8 & 0.04 \\
\hline Manufacturing & 44 & 0.16 \\
\hline Total & $\mathbf{1 1 9}$ & $\mathbf{0 . 1 1}$ \\
\hline
\end{tabular}

At the highest prices observed during the study period, in which the peak price was about five times the off-peak price, we estimate that the 119 customers, as a group, reduced

\footnotetext{
${ }^{2}$ For customers that respond by curtailing load during peak periods but do not make up usage in the offpeak period, our model underestimates the corresponding peak load reduction (see section 3.1).

${ }^{3}$ This notion of elasticity differs from the more familiar own-price elasticity, but its interpretation is similar, and it is the most appropriate and feasible characterization of price response for large customers, for which electricity is an input. Moreover, estimating own-price elasticities would have required gathering output data from SC-3A customers, which was beyond the scope of this study (see section 3.1).
} 
their peak usage by $50 \mathrm{MW}$, about $10 \%$ of their combined non-coincident summer peak demand.

Manufacturing customers are most price- responsive, followed by government/education - other sectors have very low elasticities

Manufacturing firms, as a group, are $45 \%$ more price responsive than the SC-3A average, with a sector elasticity of 0.16 (Table ES-1). This comports with the conventional wisdom that these customers are good candidates for price response, though there is substantial variation within this group. The government/education sector is also quite price-responsive, with an average elasticity value of 0.10 . The commercial/retail, healthcare and public works sectors are relatively unresponsive.

Two-thirds of customers have positive substitution elasticities

Figure ES-2 shows the distribution of SC-3A customers according to their substitution elasticity estimates. Almost two-thirds (65\%) exhibit some price response (elasticities > 0.01). The other third appear to use peak and off-peak electricity in fixed proportions, regardless of prices (i.e. zero elasticity). Eighteen percent of customers exhibit relatively high price response ( $>0.10$ ), and account for $75-80 \%$ of the aggregate demand response.

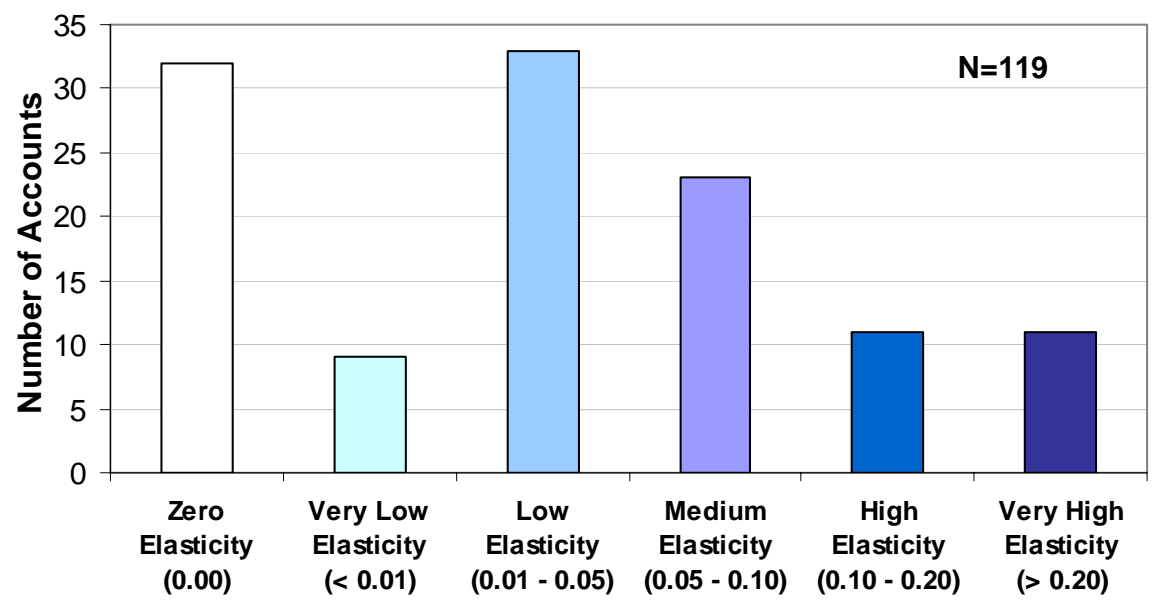

Figure ES-2. Distribution of Customers by their Substitution Elasticity Estimates

Individual customer elasticities vary substantially within sectors - most manufacturing customers are either highly responsive or not at all

An important finding of this study is that elasticity results are not uniform within business sectors (see Figure ES-3). This is most pronounced for manufacturing customers.

Twenty-seven percent are highly price responsive, with elasticities above 0.10 . But $63 \%$ are largely non-responsive (elasticities $<0.05$ ), including $27 \%$ with zero elasticities. The high average level of price response for this sector is provided by a few, very responsive, customers. 
The government/education sector, which has a lower overall elasticity, has almost as many highly responsive customers as the manufacturing sector (24\%) and proportionally fewer non-responsive customers (42\%) (Figure ES-3). The majority of commercial/retail, healthcare and public works customers are non-responsive, although there are exceptions in each of these business sectors.

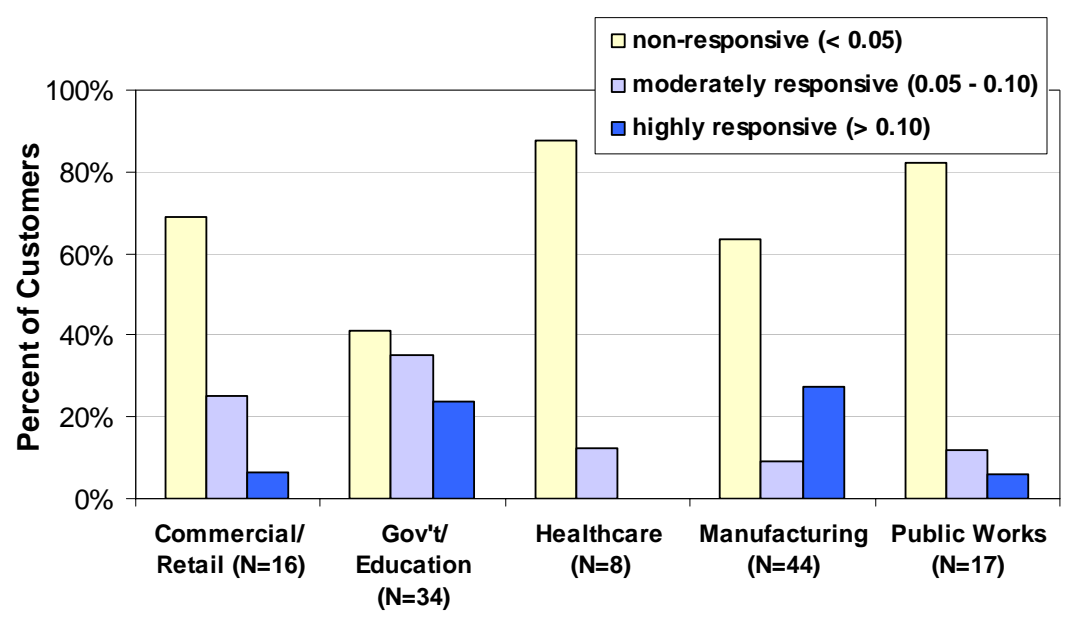

Figure ES-3. Price Responsiveness by Business Category

\section{Policy Implications}

The heterogeneity of price response, both among and within business sectors, should be explicitly recognized by policymakers. The common presumption that manufacturing customers are highly price responsive is true for some of these customers, but our results suggest that for many this is not the case at all; this comports with the findings of Taylor et al. (2005) studying similar circumstances. Furthermore, there is significant price response potential from a wide base of government/education customers that should not be ignored. Given that a large proportion of the response ( $80 \%)$ comes from a small proportion of customers ( $\sim 20 \%)$, policymakers need to expect that a large proportion of customers will not be able to respond at all, at least under the pricing conditions observed in this study and should ensure that hedged alternatives to dynamic pricing are available.

\section{The Character of Price Response}

We evaluated the character of price response in a regression model that examined the impact of nominal prices and load on price response. Key findings from this research are as follows.

Government/education and commercial/retail customers respond more when nominal prices are higher; manufacturing customers respond more when peak/off-peak price ratios are higher

We find that government/education and commercial/retail customers exhibit higher price response when nominal prices are higher - many of these customers tell us they forego load when prices are high (see section 5, below). Manufacturing firms appear to respond 
primarily to the peak to off-peak price ratio. Many of these customers report that they shift load rather than forego. The price response of public works and health care customers declines slightly as nominal prices increase.

Government/education customers' response declines slightly as they reach their peak demand

We find that government/education customers' average sector-level elasticity declines slightly (about 3\%) when they are operating close to their peak demand. No other sectors exhibited this correlation.

\section{Policy Implication}

The finding that government/education and commercial/retail customers tend to increase their response when prices are high is encouraging: it implies that RTP can be expected to provide the most response when it is most needed. It is also encouraging that although there is a reduction in government/education customers' response as they reach their maximum demand, this effect is relatively small. ${ }^{4}$ However, we caution that New York's summer climate is moderate relative to other parts of the U.S., and the prices customers faced were seldom high for more than a few hours during the study period. Prolonged hot weather accompanied by high prices could result in response fatigue.

Government/education and commercial/retail customers' response increases on hot days

Government/education customers, on average, increase their price response by about $20 \%$ on hot days compared to cooler days and commercial/retail customers' average elasticity doubles. For the other business sectors, there is no or negligible difference in sector-level elasticities between hot and cool days.

\section{Policy Implication}

Hot days are correlated with both high SC-3A prices and NYISO DR program events in NMPC service territory. Under the weather and price conditions experienced in upstate New York during our study period, these signals appear to have overridden customers' increased cooling needs on hot days. This suggests that service-oriented customers are willing to put up with a certain amount of discomfort in order to respond to high hourly prices or participate in ISO DR programs. However, we caution that summer weather conditions in upstate New York are less extreme than in other areas, such as inland California.

\section{Drivers of Price Response}

We investigated drivers to price response - customers' characteristics and circumstances - using a regression model and by examining trends among price responsive and nonresponsive customers. Few factors had statistically significant impacts on price response

\footnotetext{
${ }^{4}$ The peak demand of these customers is not correlated with hot weather, so this and the previous result are not contradictory.
} 
in the regression, partly due to a relatively small sample size. ${ }^{5}$ Nonetheless, we highlight several intuitive relationships that provide insights into the factors associated with price response.

NYISO emergency programs enhance price response, in large part by providing coincident signals to curtail

Participation in NYISO's Emergency Demand Response Program (EDRP) has a statistically significant positive correlation with price response. Because EDRP events were coincident with high day-ahead prices during our study period, it is not possible to extricate customers' response to these two signals. Based on survey and interview results, we know that many customers are aware of this coincidence and may look to NYISO events as a signal that prices are high (see Table ES-2). In addition, for many customers, response to emergency programs is motivated by a "good citizen" factor and is viewed more as an obligation to the community than an economic response.

Table ES-2. Reasons for Responding to NYISO Emergency Events

\begin{tabular}{|l|l|}
\hline Reason & $\begin{array}{l}\text { Percent of } \\
\text { Respondents } \\
\text { (N=46) }\end{array}$ \\
\hline To earn EDRP or ICAP/SCR curtailment incentive payments & $63 \%$ \\
\hline To avoid paying penalties for not responding to ICAP/SCR events & $9 \%$ \\
\hline My organization considers it a civic duty to help keep the electric system secure & $59 \%$ \\
\hline NYISO emergencies coincide with high SC-3A prices & $30 \%$ \\
\hline
\end{tabular}

${ }^{a}$ Customers were asked to check all reasons that applied, so responses do not add up to $100 \%$.

Contrary to expectations, ICAP/SCR (another NYISO demand response program) participation does not have a discernable impact on price response. We believe that the coincidence of high SC-3A day-ahead prices and NYISO emergency events makes it impossible to identify separate effects for both NYISO programs.

\section{$\underline{\text { Policy Implication }}$}

These results suggest that NYISO EDRP complements response to SC-3A prices. For some customers, notification of events and the opportunity to help out in emergencies are more important than cost savings. Thus RTP alone may not draw out their full price response potential, and policymakers for whom demand response is a primary concern should consider complementing RTP with programs that alert and compensate them for responding to system emergencies.

Load management and energy information systems do not currently influence customer response to hourly prices

Many SC-3A customers have installed energy management control systems (EMCS), peak load management (PLM) devices and energy information systems (EIS), technologies with the potential to assist price response. However, we found no

\footnotetext{
${ }^{5}$ The sample size for this regression was limited to customers that had answered the survey - only 55 customer accounts could be included.
} 
meaningful statistical relationships between ownership of these technologies and price response. In interviews and surveys, most customers indicated that at present they use them for other purposes than short-term price response, primarily for achieving acrossthe-board energy savings (permanent load reductions) and/or managing their peak demand.

\section{Policy Implication}

Promoting dissemination of enabling technologies is not a sufficient strategy to enhance short-term price response, in part because customers may consider the savings, which are available during only a few hours per year, insufficient to justify the effort or the cost of the equipment. While recent research by Piette et al. (2005) demonstrates the potential for fully automated DR strategies, customers at present clearly need technical assistance to implement them. There may be a role for energy services companies to provide DRenabling technologies as part of a larger services and products package, with price response automation included as a value-added feature.

\section{Onsite generation can contribute to significant load response}

In the regression, the presence of onsite generation is positively correlated with price response, but this effect is not statistically significant. While over half of SC-3A customers have onsite generation equipment, the majority told us in surveys and interviews that they do not use it for price response. Many of these systems are existing, older backup generators that are wired for reliability purposes only and do not lend themselves to price response. However, among the most price responsive customers, several have onsite generation installed, and a few customers told us in interviews that they have scheduled equipment tests allowed under their operating permits when prices were high.

\section{Policy Implication}

Although few SC-3A customers have responded to hourly prices or NYISO events using onsite generation, we observe that for those that have, significant load response resulted. While environmental and health considerations must be taken into account, distributed generation has the potential to create significant new opportunities for price and load response.

\section{"Champions" are probably a significant driver to price response}

Based on two years of interviewing customers, we believe the presence of a facility manager willing to take risks to forward price response within his or her organization an internal "champion" - is a vitally important, though not easily measured, driver to price response. 


\section{Policy Implication}

While policymakers cannot directly control the presence of champions within customer organizations, programs that offer recognition to such individuals can both reward them for their efforts and promote broader awareness that price response is important. ${ }^{6}$

\section{Customer Strategies for Responding}

We explored customers' qualitative load response strategies through survey and interview questions to add context and texture to elasticity results.

Over two-thirds of customers say they can respond

In our 2004 survey, $71 \%$ of respondents indicated that they can respond in some way to high prices, NYISO events or public appeals to conserve (see Figure ES-4), compared to only $46 \%$ in the previous year's survey (Goldman et al. 2004).

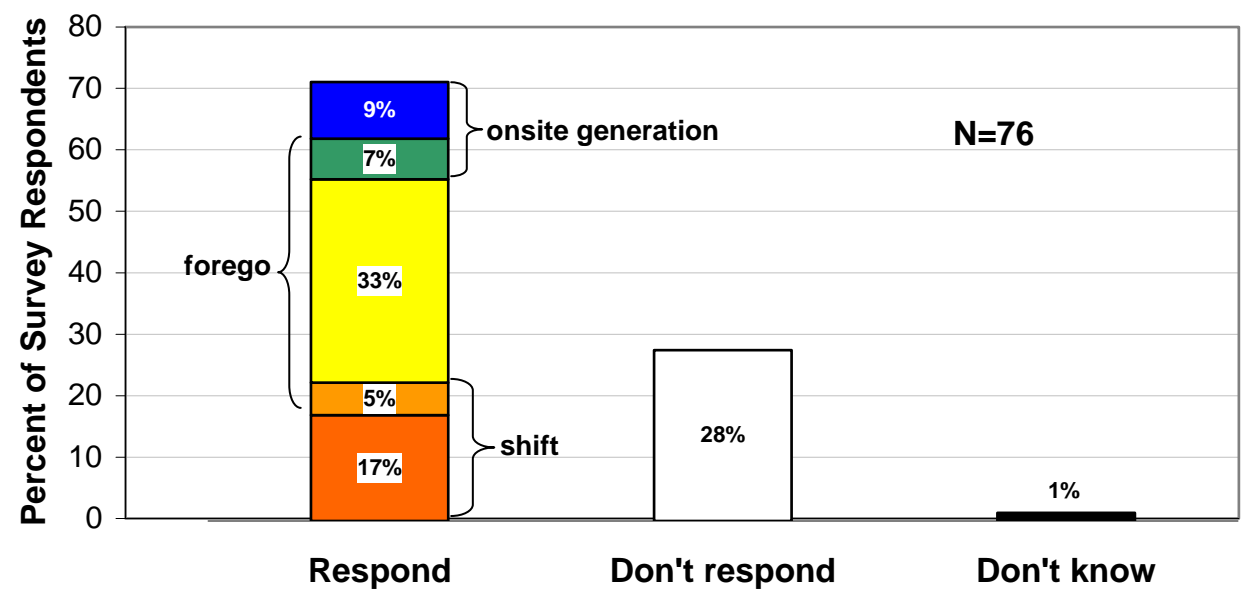

Figure ES-4. Self-Reported Load Response Strategies

Customers employ varied load response strategies - shifting, foregoing, and selfgeneration

Customers reported deploying three different load response strategies: shifting load from one time period to another (22\% of surveyed customers), foregoing discretionary usage and not making it up at another time (45\%) and supplying load with onsite generation (16\%) (Figure ES-4). Thirteen percent of customers reported more than one load response strategy.

\footnotetext{
${ }^{6}$ Similar programs have been instituted for energy-efficiency champions by Energy Star, the Federal Energy Management Program and professional engineering societies (e.g., ASHRAE, Association of Energy Engineers).
} 
Government/education customers most often forego usage; manufacturing customers are more likely to shift

Most government/education customers (83\%) report that they respond by foregoing load and not making it up later. Manufacturing customers display the most variety in the types of load response strategies reported, and report load shifting more frequently than other customer types; $40 \%$ of these customers say they can shift.

\section{Policy Implications}

There is significant latent response potential but it is diverse in nature. Price response programs and tariff options should be designed to make best use of this diversity. It should also be noted that the load response strategies reported were framed in terms of response to any of the signals SC-3A customers have faced - high SC-3A prices, NYISO events and public appeals to conserve. Thus, while there is considerable latent load response capability, it is important to remember that not all customers will necessarily exercise this capability if presented with RTP price signals alone. Other programs to elicit this potential may be necessary for some customers.

\section{What customers say they do and what they seem to do are at odds}

We found some contradictions between what some customers say they do and what their actions indicate they actually do. This arose in two critical areas in this study: customers' self-reported load response behavior (e.g., some customers told us they did not respond but had high elasticities) and their participation in NYISO demand response programs (e.g., some customers told us they had responded to events but had never been enrolled in the programs).

We offer four possible explanations for these discrepancies: (1) customers may not recall how they responded to NYISO events and high SC-3A prices, which last occurred two summers prior to the survey, (2) the individuals responding to our survey may not have been directly responsible for making decisions about price response or energy procurement, (3) customers may have answered the survey strategically, telling us what they thought we wanted to hear, or what they wanted us to hear, and (4) our ability to accurately measure customers' behavior is limited and may contribute to these discrepancies (e.g., the substitution elasticity may underestimate the response from foregoing load - see section 3.1).

\section{Policy Implications}

We urge policymakers to avoid translating the results of surveys or limited pilot analyses into hard and fast rules about customers' inclination and ability to respond to price signals. New programs should be launched with a commitment to study how customers respond over time.

\section{Barriers to Price Response}

We explored barriers to price response through survey and interview questions. We highlight the following key points from this research. 
Most customers report multiple barriers to price response - only $\sim 15 \%$ respond without obstacles

Twelve percent of survey respondents reported that they had encountered no barriers in responding to SC-3A prices (see Table ES-3). This comports, although not precisely, with our finding that $18 \%$ of customers are highly price responsive (elasticities $>0.10$ ). The rest reported up to five barriers each in responding to SC-3A prices.

Table ES-3. Barriers to Price Response

\begin{tabular}{|c|c|}
\hline Barrier & $\begin{array}{l}\text { Percent of } \\
\text { Respondents } \\
(\mathrm{N}=76)\end{array}$ \\
\hline $\begin{array}{l}\text { Organization/Business Practices } \\
\text { Insufficient time or resources to pay attention to hourly prices } \\
\text { Institutional barriers in my organization make responding difficult } \\
\text { Inflexible labor schedule }\end{array}$ & $\begin{array}{l}51 \% \\
30 \% \\
21 \%\end{array}$ \\
\hline $\begin{array}{l}\text { Inadequate Incentives } \\
\text { Managing electricity use is not a priority } \\
\text { The cost/inconvenience of responding outweighs the savings }\end{array}$ & $\begin{array}{l}22 \% \\
22 \%\end{array}$ \\
\hline $\begin{array}{l}\text { Risk Aversion/Hedging } \\
\text { My organization's management views these efforts as too risky } \\
\text { Flat-rate or time-of-use contract makes responding unimportant }\end{array}$ & $\begin{array}{l}13 \% \\
12 \% \\
\end{array}$ \\
\hline Other barriers & $3 \%$ \\
\hline No barriers encountered & $12 \%$ \\
\hline Do not know & $3 \%$ \\
\hline
\end{tabular}

Over half of large customers report not having time or resources to monitor prices

The most common barrier to price response - reported by $51 \%$ of survey respondents - is a lack of time or resources to monitor day-ahead prices (Table ES-3). Asked specifically how often they monitor prices, $70 \%$ of survey respondents indicated that they rarely or never do so. For some, this all but precludes price response. Others appear to rely on coincident signals - NYISO events or hot weather - to alert them of high prices.

\section{Inadequate incentives keep one-quarter of customers from responding}

Almost one-quarter of survey respondents cited inadequate incentives as a barrier to price response (Table ES-3). This suggests that for the other three-quarters of customers, the incentives afforded by SC-3A prices are either sufficient to justify responding, or that other barriers are of greater significance. ${ }^{7}$

\section{Policy Implications}

Despite the preponderance of barriers encountered by SC-3A customers, two-thirds have positive estimated elasticity of substitution values. Thus, we believe that some barriers

\footnotetext{
${ }^{7}$ Customers were asked to indicate all barriers that applied to them, but it is possible that they neglected to indicate inadequate incentives if, for example, they never check prices and have never evaluated them, let alone made the determination that they are not high enough to make responding worthwhile.
} 
may indeed be overcome with time. For example, targeted efforts to promote implementation of semi- or fully automated DR strategies could eliminate the need for customers to monitor prices actively. However, policymakers should expect that about half of large customers cannot or may have no intention of becoming affirmatively price responsive, regardless of whether alternatives to day-ahead pricing are available to them. Others may be price responsive under regimes of occasional high prices, but may seek to hedge their exposure if prices become too high or volatile. Some smaller fraction, perhaps 20-25\%, of highly responsive customers would probably elect to remain on dayahead pricing and respond to price spikes, even if they occurred with greater frequency than observed for SC-3A customers. This amount of price responsive load may be enough to abate the worst consequences of wholesale spot market price volatility.

\section{Customer Acceptance}

Finally, we examined customer acceptance of day-ahead market-based hourly pricing through customer survey and interview questions and by evaluating customers' supplier choice and hedging decisions.

\section{Day-ahead RTP is well accepted by large customers in New York}

In two years of administering surveys and interviews, we have heard few complaints about NMPC's default service: customers are relatively satisfied with day-ahead market pricing. Six years after its introduction, 36\% of SC-3A customers (representing 34\% of SC-3A load) still take their commodity from NMPC on the default rate. ${ }^{8}$ Survey respondents indicated that they would be more likely to leave the utility if the default service was indexed to the NYISO real-time market, which affords no advance notice of prices.

Most customers have not hedged: 45-60\% were fully exposed to day-ahead prices in 2004

Although the majority of customers interviewed told us they would prefer to hedge against price volatility, as many as $60 \%$ of SC-3A customers remain fully exposed to day-ahead market prices, either on the default SC-3A rate or a similarly indexed commodity deal with a competitive retail supplier. We believe that the main explanation for so many customers remaining un-hedged, yet not being very price responsive, is that they are "psychologically hedged": they have evaluated SC-3A prices and the market options available to them and decided that they are comfortable with the risk of remaining on day-ahead pricing and, for some, not responding. This suggests that these customers have adapted reasonably well to competitive market circumstances and are capable of assessing the inherent risks and their aversion to it.

\footnotetext{
${ }^{8}$ Customers have expressed dissatisfaction with retail market offerings in interviews, in particular an inability to find suppliers interested in serving them or hedges that they felt were reasonably priced. However, we heard fewer complaints in the second year of our study than the first. This, combined with increased customer migration in recent years, suggests that the market is maturing.
} 


\section{Policy Implications}

The acceptance of day-ahead market pricing by SC-3A customers is probably largely a function of the tariff design and price regimes these customers have faced over the past six years. In New Jersey, implementing default-service RTP indexed to the real-time market, which affords no advance notice of prices, has resulted in very high switching rates (84\% of load) over a shorter time period (two years) (Barbose et al. 2005). This suggests that most large customers require some notice of prices in order to feel comfortable. Customer acceptance of the tariff or program designed to elicit price response is critical, and subjecting them to real-time RTP may result in reduced price response if the vast majority seek out fully hedged supply contracts rather than responding by shifting or curtailing load when peak prices are high.

\section{Market penetration of financial hedges is particularly low}

Less than $10 \%$ of survey respondents indicated that they had purchased financial derivatives that hedge against electricity price volatility. ${ }^{9}$ About half of the rest either could not articulate why they had not or were not sure what a financial hedge is.

\section{Policy Implication}

Many large customers are apparently unfamiliar with financial hedging products as they relate to energy even after being exposed to day-ahead hourly pricing and competitive retail markets for six years. Policymakers concerned with ensuring adequate hedging options exist initially for customers exposed to default-service RTP should consider efforts to educate customers about financial hedge products and possibly having the default utility offer a hedged alternative during a transition period.

\footnotetext{
${ }^{9}$ The types of financial hedge products purchased by SC-3A customers are discussed in Goldman et al. (2004).
} 



\section{Introduction}

This report describes the second phase of a study of large non-residential customer response to default-service day-ahead hourly pricing. The customers, located in upstate New York, are served under Niagara Mohawk, A National Grid Company (NMPC)'s SC3A rate class. ${ }^{10}$ The SC-3A tariff is a type of "real-time pricing" (RTP) that provides firm, day-ahead notice of hourly varying prices indexed to the New York Independent System Operator (NYISO) Day-Ahead Market. It is the first and longest-running defaultservice RTP tariff implemented in the context of retail competition. With six years of experience on this tariff, NMPC customers provide a unique opportunity to study relatively long-term response to default-service RTP.

RTP has been advocated as an economically efficient means to send price signals to customers to promote demand response (DR) (Borenstein 2002, Borenstein 2005, Ruff 2002). DR is increasingly recognized as critical to ensuring efficient wholesale electricity market operation, signaling the proper timing and form of investments in new capacity, mitigating price spikes and abating the exercise of market power (Boisvert and Neenan 2003, FERC 2002). ${ }^{11}$ The relative paucity of DR in most electricity markets as they are currently designed is attributable to the preponderance of fixed retail electricity rates. In theory, if customers paid prices for electricity that reflected the short-term (typically hourly) variations observed in wholesale market prices, which by design are the marginal supply cost, they would have both the information and incentives required to respond to high prices by reducing their demand. It is this theoretical basis that motivates current interest in RTP and other pricing signals as vehicles for delivery of DR.

While this theory is compelling, few customers have actually been exposed to RTP and limited information exists that can be used to judge how effectively it actually induces DR. Not only is customers' latent price response potential not well understood, but in restructured retail electricity markets customers face a variety of choices that complicate the incentives they face. For example, in New York, customers may select supply options or financial derivatives that limit or eliminate their exposure to price volatility, thereby limiting their price response potential (either by eliminating their exposure to price signals altogether or by limiting their interest by providing some price protection). On the other hand, SC-3A customers are also allowed to participate in NYISO's statewide DR programs that pay customers to curtail load when prices are high (economic programs) or when system emergencies are declared (emergency programs). These DR programs may enhance customers "price" response if curtailment events are coincident with high prices. Sorting out these often confounding incentives is challenging.

Prior to 2003, few studies of customers' response to dynamic pricing were available in the public domain, in part because very few customers had ever been exposed to dynamic prices. The notable exceptions were Zarnikau (1990), Herriges et al. (1993), Braithwait

\footnotetext{
10 The company was formerly named "Niagara Mohawk Power Corporation”, thus the acronym "NMPC”.

${ }^{11}$ Another important benefit of price responsive load is that it obviates a certain amount of generation capacity that would otherwise be needed to meet unresponsive demand, thereby reducing overall resource costs (Braithwait 2005).
} 
and O’Sheasy (2001), Schwarz et al. (2002) and Taylor et al. (2005). All of these studies estimated price response of large commercial and industrial customers that had volunteered for optional RTP programs at regulated, vertically integrated utilities and they all found modest overall load response, the majority of which was typically provided by a minority of customers. Schwarz et al. (2002) and Taylor et al. (2005) found that customers with onsite generation were particularly price-responsive. However, extension of these results to today's restructured markets is problematic because these customers faced RTP in isolation; switching suppliers, purchasing hedges, and participating in DR programs - factors that can confound the incentives created by RTP - were not options for these customers.

Three recent studies published in the public domain address this information gap by analyzing customers' price response. First, as part of a statewide proceeding on demand response, a critical peak pricing (CPP) experiment was designed through a working group process and administered to 2500 small commercial and residential customers of California's three large investor-owned electric utilities, Pacific Gas \& Electric, Southern California Edison and San Diego Gas \& Electric. ${ }^{12}$ The resulting evaluation report estimated elasticities and found measurable reductions in energy usage associated with the observed shifting behavior (Charles River Associates 2005). For residential customers, peak demand reductions were estimated at $\sim 10-15 \%$ for critical-peak to offpeak price differentials of up to 10:1. Peak demand reductions for small commercial and industrial customers were smaller ( 6-9\%). While these results provide insights into small customers' demand for electricity, they do not speak to the behavior of large commercial, industrial and institutional customers, which use electricity as an input to business activity or service provision.

Second, Boisvert et al. (2004) quantified the price response of over 50 large commercial and industrial customers that had volunteered for a two-part RTP tariff at several Central and Southwest Services' utilities in the late 1990s. The class average substitution elasticity was estimated at $\sim 0.14$.

Third, in 2003, the California Energy Commission (CEC) Public Interest Energy Research (PIER) program commissioned the first phase of this case study of NMPC customers' response to default-service day-ahead market electricity pricing to address the following policy questions:

- Are customers satisfied with default-service RTP?

- Does RTP deliver demand response?

- What customer characteristics and circumstances drive price response?

- How do RTP and ISO DR programs interact?

\footnotetext{
${ }^{12}$ Critical peak pricing is another type of dynamic pricing tariff which resembles a time-of-use rate, with previously set prices for electricity, in most hours, but with higher "critical-peak" prices that are communicated to customers when price spikes are experienced in wholesale markets or system emergencies are called (the trigger event is determined by the particular tariff design).
} 
- Do enabling technologies enhance customers' responsiveness?

- To what extent do customers take steps to hedge against price volatility?

This first phase focused on the regulatory context for RTP adoption, customer satisfaction, customers' preferences and choices for hedges and competitive electric commodity supply arrangements, enabling technologies and response strategies, and substitution elasticity estimates based on a Constant Elasticity of Substitution (CES) demand model. The results, published in Goldman et al. (2004), showed modest overall response to prices and found that government/education customers were most responsive, followed by industrial customers. Customer market research indicated that customers were generally satisfied with default-service RTP, but had been somewhat disappointed with retail market offerings. Some factors were found to have a significant impact on elasticity - in particular, participation in the New York Independent System Operator (NYISO) demand response programs greatly enhanced industrial customers' estimated price response, and we found that response from curtailing, rather than shifting, load was significant.

However, several questions remained unanswered in the first phase of this study or had not been clearly elucidated. This second phase, also commissioned by the CEC PIER program, and coordinated by the Demand Response Research Center (DRRC), was designed to:

- further disaggregate price response by business sector,

- identify the characteristics of highly price-responsive customers and attempt to understand differences in price responsiveness within business classifications,

- disentangle customers' response to high hourly prices from response to coincident signals to curtail, such as NYISO DR program events and public appeals to conserve,

- clarify the impact of enabling technologies, particularly onsite generation, on customers' empirical price response estimates and self-reported response strategies,

- characterize the impact of price levels on response in order to look for threshold effects (e.g., customers may increase their response at higher prices or may exhaust their response capability),

- identify important barriers to price response, and

- update customer switching and hedging trends and better understand why customers make the choices they do (e.g., why they stay with default RTP pricing or why they switch).

To accomplish these goals, we developed and administered a second customer survey that targeted these research questions and collected two more years of load and price data from NMPC (2003 and 2004) allowing us to include five summers in our analysis. We also estimated a different demand model in this phase - a Generalized Leontief (GL) model - that is theoretically consistent with electricity usage as an input to firms' or 
organizations' business activity and is more flexible than the CES model in that it allows for price response to vary as a function of nominal prices. ${ }^{13}$

This report is organized as follows. Chapter 2 provides background on the customers that are the subject of this study, the choices available to them, and the prices they have faced, and describes survey design and administration and other data sources for this study. ${ }^{14}$ Chapter 3 focuses on modeling and estimating customer response to hourly prices - it introduces our methodology and treatment of data in the demand model and presents key results, including disaggregated substitution elasticity estimates and factors that influence price response. In Chapter 4, we present customer survey and interview results, including self-reported load response strategies, enabling technology usage, characteristics of priceresponsive and unresponsive customers, barriers to price response, and customer migration and hedging choices. In Chapter 5, we synthesize key findings from this study and discuss their implications for policymakers interested in default-service RTP as a strategy for encouraging DR in competitive retail markets. The customer survey, a discussion of the theory of customer electricity demand and the specific equations we estimated, and detailed model results are included as appendices.

\footnotetext{
${ }^{13}$ A major restriction of the CES model is that customers' price response is assumed to be constant at all prices. This makes the model simpler to estimate and interpret, but does not provide information on threshold responses that many customers report in interviews (Goldman et al. 2004).

${ }^{14}$ Additional background on the context for NMPC's RTP tariff, including the regulatory process and goals, is published in Goldman et al. (2004).
} 


\section{Background, Approach and Data Sources}

In this chapter, we provide an overview of the Niagara Mohawk customers and the tariff and market options and price regimes they have faced during the study period, which covers the summers of 2000 through 2004. It provides a foundation for understanding the results of models and analyses of customer behavior under default service RTP in Chapters 3 and 4. Furthermore, characterizing these customers and circumstances provides a basis for determining the applicability of these results, especially with regard to price response, to electricity customers in other jurisdictions. Goldman et al. (2004) provides a more extensive discussion of the context and motivations for NMPC's dayahead market tariff and the process under which it was adopted. We limit the discussion in this chapter to the factual and contextual information necessary to evaluate and extend the results of the analyses presented in this report.

Also in this chapter, we review price and weather trends over the five years of our study period to lay the foundation for quantifying price response, discuss customer survey and interview objectives, administration, response rates and representation by business category and other characteristics, and briefly describe other data sources for this study.

\subsection{Tariff and Market Options}

NMPC's day-ahead hourly pricing tariff was adopted as the default service for its largest customers - the "SC-3A" class of customers, with peak demand greater than $2 \mathrm{MW}$ - in late 1998. The tariff was part of the utility's rate case filing that inaugurated electric industry restructuring in New York. ${ }^{15}$ NMPC's service territory covers the majority of upstate New York and contains many of the state's largest manufacturing and industrial facilities. The competitive choice model adopted included divestiture by NMPC of its generation assets and unbundling of commodity from wires costs to facilitate customer switching and achieve greater pricing efficiency.

The RTP-based default service, employing day-ahead hourly price schedules, was proposed by NMPC and received favorably by large customer representatives and regulators (Goldman et al. 2004). Customers' subsequent acceptance of the tariff is due in large part to its implementation as part of the transition to a competitive market: SC-3A customers have several alternative choices to default-service RTP for their commodity service. ${ }^{16}$ Figure 2-1 provides an overview of the choices available to SC-3A customers since RTP became the default service in late 1998. Customers can purchase their electric commodity from a competitive retailer and they have opportunities to hedge with financial derivatives to offset the risks associated with paying hourly varying energy prices. In addition, since 2001, these customers have had opportunities to earn curtailment incentives by participating in demand response programs offered by the New York Independent System Operator (NYISO). Enabling technology incentives and

\footnotetext{
${ }^{15}$ New York is somewhat unique in that electricity market restructuring was implemented utility-by-utility by the Public Service Commission, rather than as part of a statewide legislative mandate. NMPC was one of the first utilities to undertake this transition.

${ }^{16}$ Almost a third of these customers had previously participated in voluntary RTP-style programs during the early to mid-1990s and were thus fairly comfortable with the concept of hourly pricing.
} 
technical assistance through NYSERDA programs have also been available through most of the study period to assist customers in developing price responsive behaviors. We discuss these choices in more detail below.

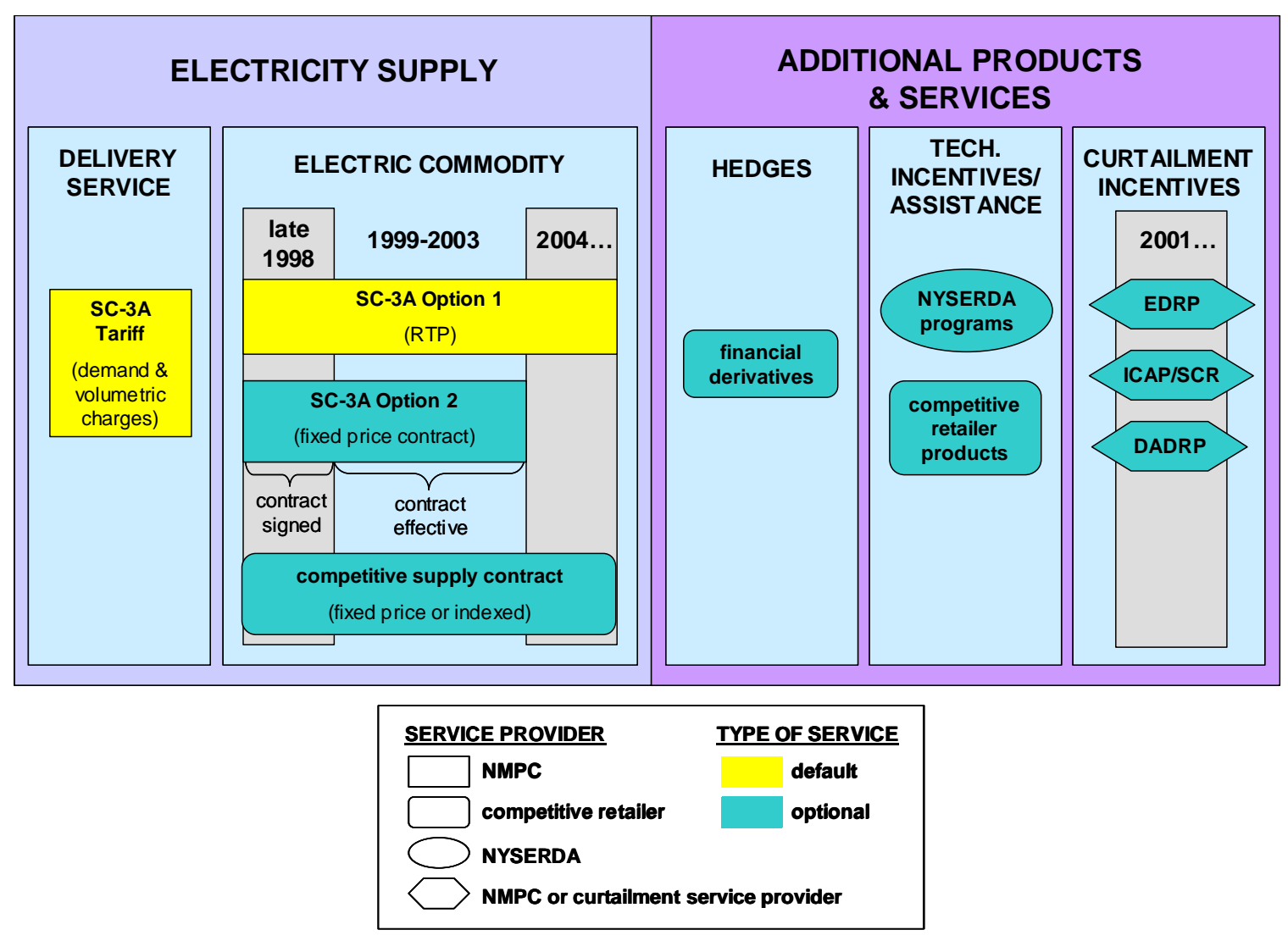

Figure 2-1. Choices Available to SC-3A Customers

\subsubsection{Electricity Supply Options}

SC-3A customers, regardless of their choice of electric commodity supplier, pay common delivery service rates specified in the SC-3A tariff that consist of demand and volumetric charges (see Figure 2-1). Their choices for electric commodity are as follows.

SC-3A Option 1. The default-service commodity tariff, “Option 1", is indexed to the New York Independent System Operator (NYISO)'s location-based day-ahead market. SC-3A customers that do not select an alternative commodity option are billed for usage in each hour at the prevailing day-ahead price for their voltage level and location, plus an adder that includes NYISO ancillary services charges. The next day's prices are posted by 4pm on NMPC's web site. Because the day-ahead prices are firm, NMPC bears some overnight forecast risk to the extent that real-time and day-ahead prices deviate.

SC-3A Option 2. At the request of large customer representatives, NMPC offered a forward contract as a fixed-rate alternative to RTP, called "Option 2", as part of the transition toward a competitive retail market. Offered only once, just prior to the 
introduction of retail access in 1998, Option 2 was a time-of-use (TOU) rate that entailed a contractual obligation for up to five years. Customers that selected Option 2 nominated a fixed amount of load for peak and off-peak periods (in MW) in each month of the contract. A pre-determined rate schedule applied to all nominated load. The terms of Option 2 were quite restrictive. It involved a take-or-pay contract, meaning that customers were responsible for paying for all contracted load regardless of whether they used it or not. A one-time, permanent opt-out provision was available for a premium, but customers had had to elect it when the contract was signed.

About 20\% of SC-3A customers selected Option 2, and many of them were conservative in the amount of load that they nominated (Goldman et al. 2004). On average, Option 2 customers covered about $60 \%$ of their peak demand and a lower proportion of their offpeak usage. The rest of their load was either served on SC-3A Option 1 or from a competitive supply contract. The Option 2 contracts expired in 2003 and were not extended.

Competitive Supply Contracts. SC-3A customers have also had the option of purchasing electric commodity from competitive retailers (referred to as "energy service companies”, or ESCOs, in New York) since 1998. Contracts with competitive retailers may be structured as fixed-rate or TOU arrangements, or may entail hourly varying commodity prices indexed to SC-3A Option 1 prices or directly to the NYISO day-ahead market or some other source of prices.

\subsubsection{Additional Products and Services}

In addition to commodity supply options, SC-3A customers have had access to several other products and services that may impact their price responsiveness (see Figure 2-1).

Financial Hedges. SC-3A customers may purchase financial hedges, which are derivatives separate from the supply of electricity, that hedge against price volatility, usually for a specified volume of electricity. With financial hedges, customers can mitigate some degree of price risk while still facing hourly prices for marginal usage. The specific types of financial hedges taken by SC-3A customers are described in Goldman et al. (2004).

Enabling Technology Incentives and Technical Assistance. During the study period, SC-3A customers have been eligible to participate in public benefits funded programs, offered by the New York State Research and Development Agency (NYSERDA), that provide incentives for installing demand response enabling technologies such as energy management control systems, peak load control devices and energy information systems that provide near real-time access to energy usage data. These programs are designed to encourage participation in NYISO Demand Response (DR) programs. In addition, competitive retailers may offer similar technologies and/or technical assistance as part of a package of load management products and services.

NYISO Demand Response Programs. Since 2001, SC-3A customers have been eligible to participate in NYISO's three demand response programs. The Emergency Demand 
Response Program (EDRP) pays a floor price of $\$ 500 / \mathrm{MWh}$ for load curtailments when NYISO declares emergency events. EDRP curtailment is voluntary; there are no penalties for enrolled customers that fail to curtail when called. Customers that participate in the Installed Capacity/ Special Case Resources (ICAP/SCR) program receive capacity payments for load reduction commitments, and since 2003 energy payments for load curtailed when NYISO declares events. Unlike EDRP, the ICAP/SCR program includes penalties for customers that fail to curtail when program events are called. The Day Ahead Demand Response Program (DADRP), an economic program in which customers bid load curtailments directly into the NYISO day-ahead market, has seen low enrollment by SC-3A customers.

\subsection{SC-3A Price Trends}

The level and volatility of the prices customers face has a direct impact on how they decide to respond to those prices - by finding a hedge, by managing their electricity usage and responding to price changes, or by taking no action. Here, we describe trends in SC-3A prices on weekdays during the five summers covered by this study: 2000-2005. Where we show average peak and off-peak prices, the peak period is defined as 2-5 p.m. to be consistent with the hours used in our final customer demand model (see section 3.3.1).

Higher, More Volatile Prices in the East. The NMPC service territory covers much of up-state New York and is comprised of two non-contiguous areas (see Figure 2-2). The region is characterized by rather mild summer weather with daily summer highs seldom reaching 90 degrees. The service territory, which spans four NYISO load zones, may be divided into three distinct regions - Eastern, Central and Western - that encompass these pricing zones (see Figure 2-2). The Central and Eastern regions are divided by a transmission interface, which periodically becomes congested. At such times the Eastern region, which is closest to downstate New York, experiences relatively high prices and greater volatility than the other NMPC regions (see Figure 2-3 and Figure 2-4). This was a factor particularly in 2000. In later years, peak prices and price volatility have converged in the three regions, though prices remain slightly higher in the East. The Western region, which is physically separated from the rest of NMPC service territory, and where there is an abundance of generation capacity, has experienced similar price patterns to the Central region. 


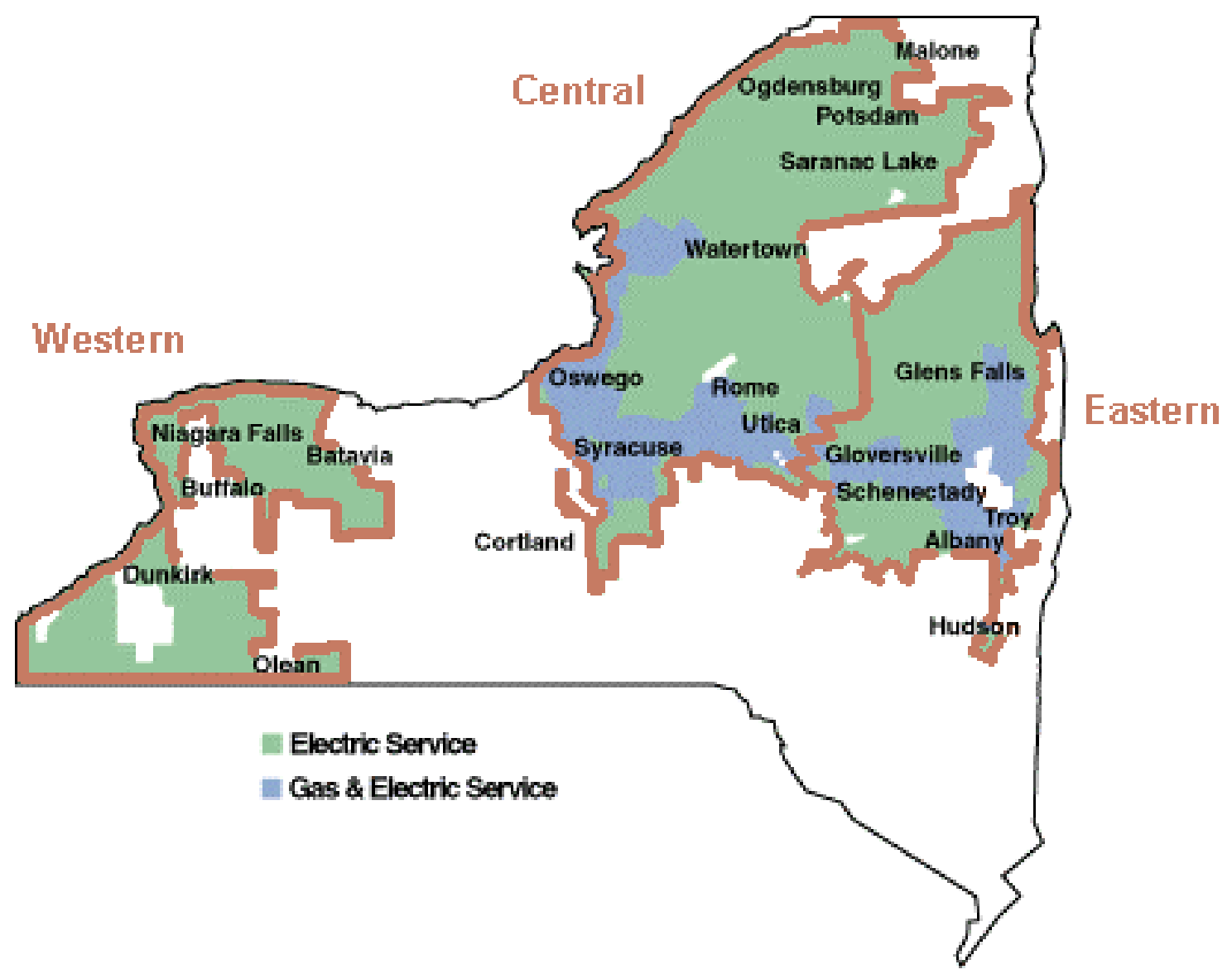

Figure 2-2. Major Price Regions in NMPC Service Territory

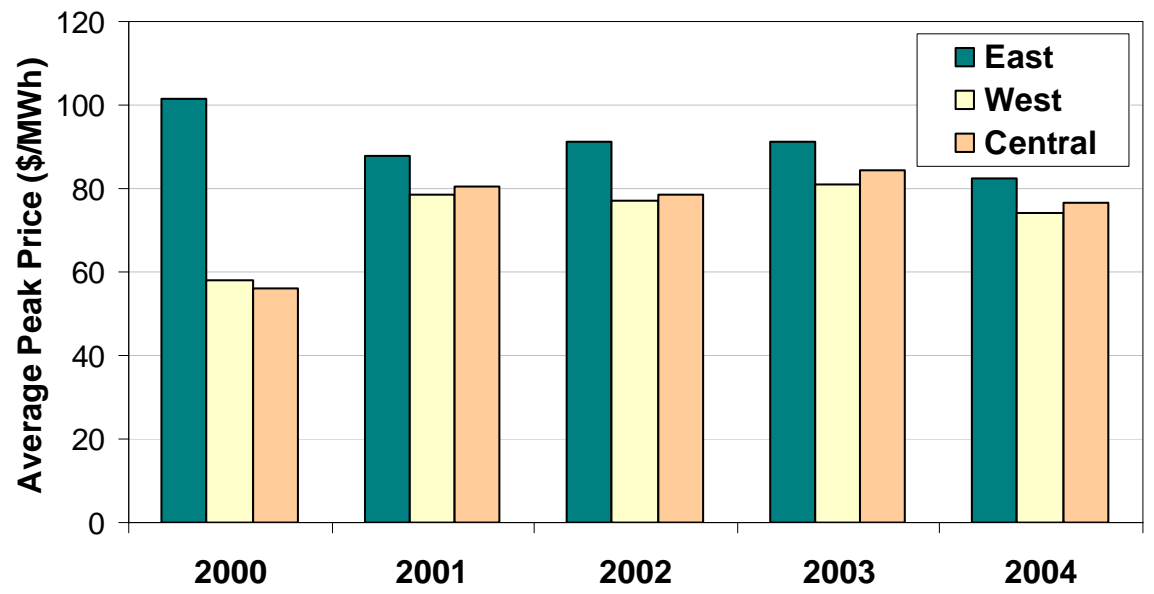

Note: Prices are averaged for primary delivery voltage customers and include weekdays during June, July and August only. The on-peak period is defined as 2pm to 5pm.

Figure 2-3. Average Peak Prices by Region 


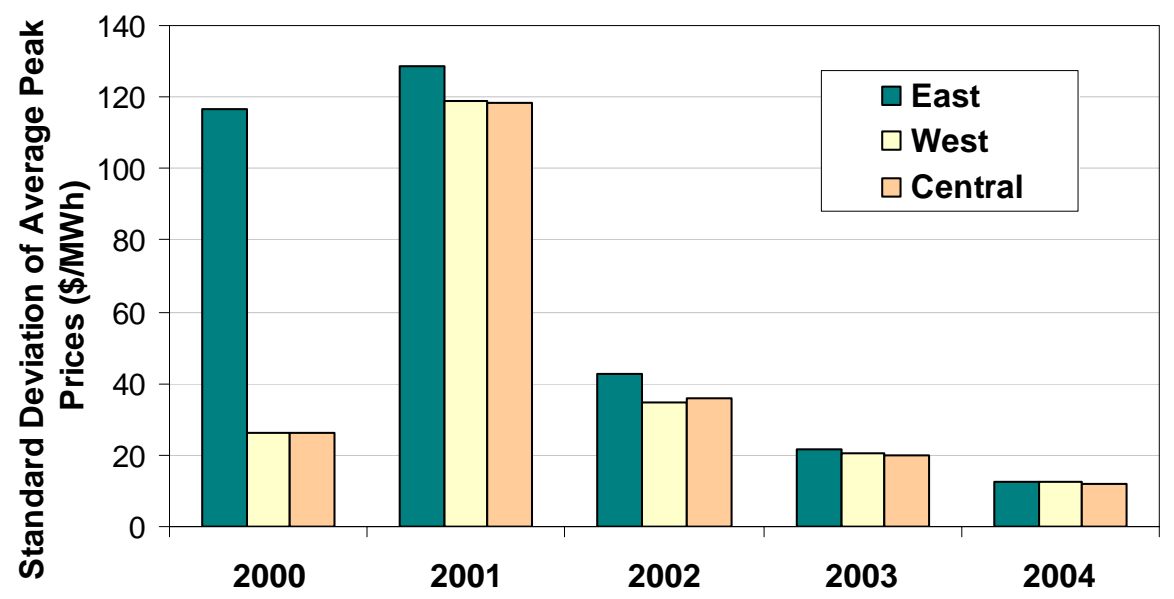

Note: Prices are averaged for primary delivery voltage customers and include weekdays during June, July and August only. The on-peak period is defined as 2pm to $5 \mathrm{pm}$.

\section{Figure 2-4. Volatility of Peak Prices by Region}

Stability in Average Prices. Average peak and off-peak SC-3A prices over the five summers of our study (2000-2005) have been relatively stable and peak prices have even declined slightly (see Figure 2-5). The difference in average summer peak and off-peak prices has diminished over time. The average peak price was $68 \%$ higher than the average off-peak price in the summers of 2000 and 2001. By 2004, the average summer peak price was only $48 \%$ higher than the average summer off-peak price.

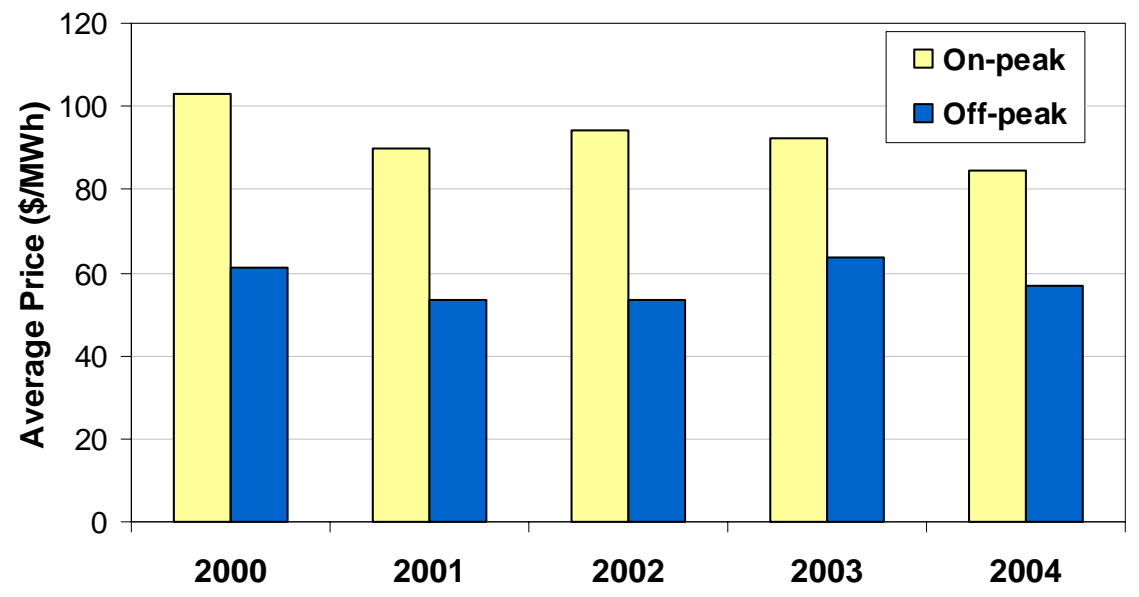

Note: Prices are averaged for primary and secondary delivery voltage customers and include weekdays during June, July and August only. The on-peak period is defined as 2pm to 5pm.

\section{Figure 2-5. Trends in Average Summer SC-3A Prices: East Region}

Declining Price Volatility. Price volatility has declined substantially in the last three years of our study (2002-2004) (see Figure 2-6). There have consequently been very few price spikes in recent years, limiting our ability to model customers' response to the type of high-price events that motivate many policymakers' interest in RTP. 


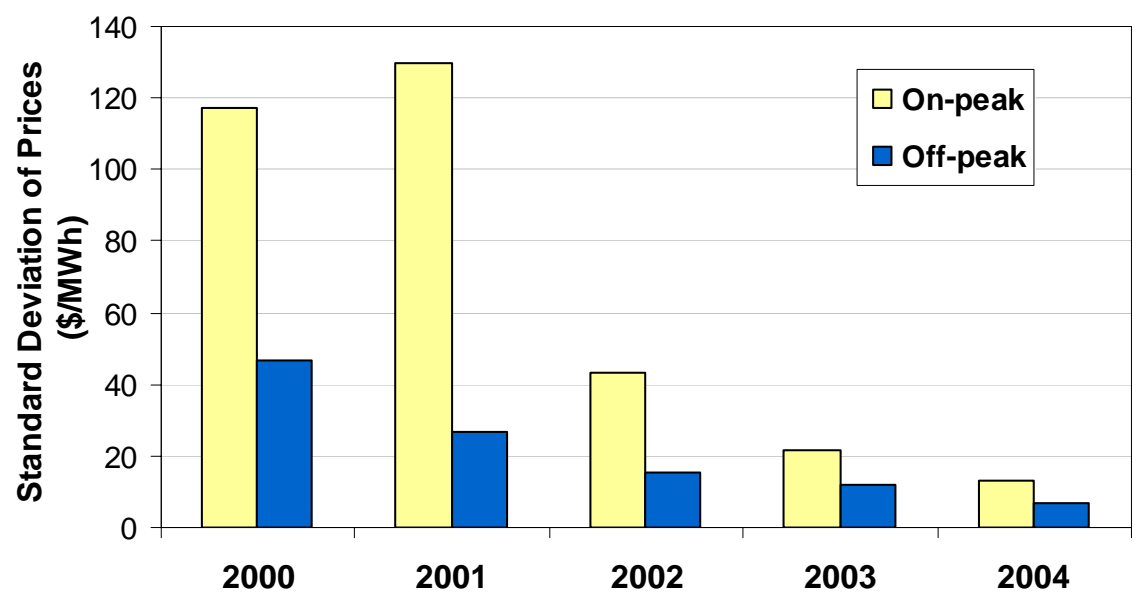

Note: Prices are averaged for primary and secondary delivery voltage customers and include weekdays during June, July and August only. The on-peak period is defined as 2pm to 5pm.

Figure 2-6. Trends in Summer SC-3A Price Volatility: East Region

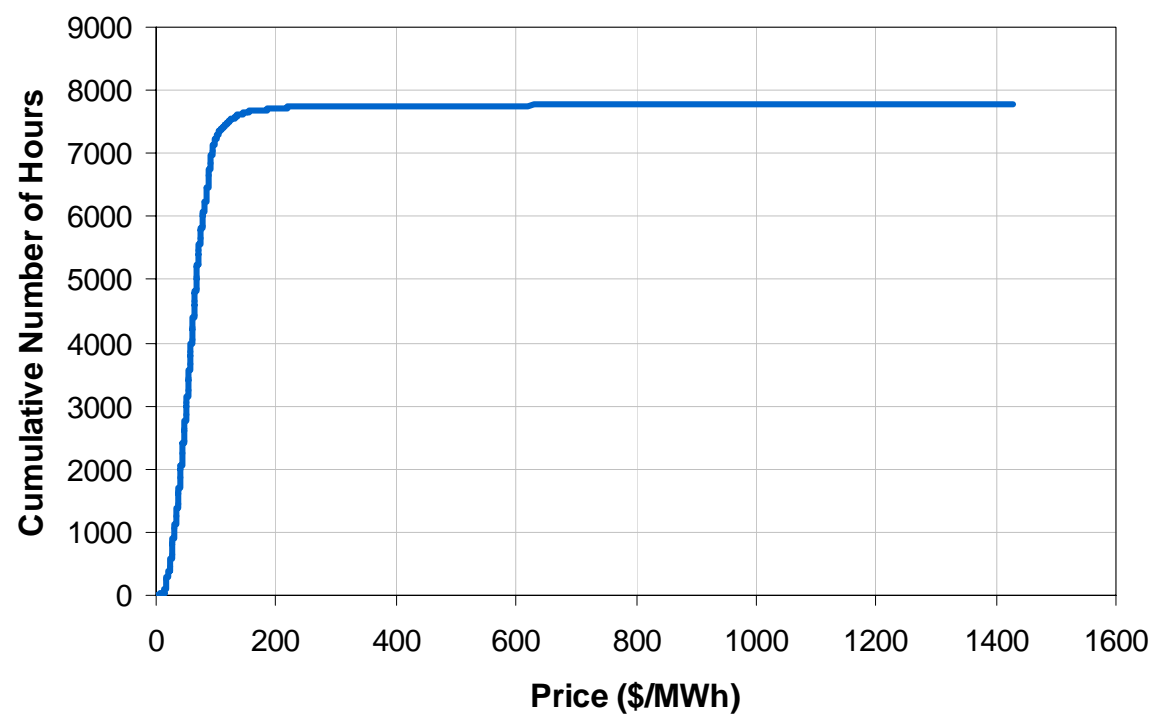

Note: Prices are averaged for primary and secondary delivery voltage customers and include weekdays during June, July and August only for the 2000-2004 period.

\section{Figure 2-7. Price Duration Curve: East Region, 2000-2004 Summer Weekdays}

Isolated High-Price Events. Over the past five summers, SC-3A customers have been faced with relatively few hours of high prices. In Figure 2-7, hourly 2000-2004 summer weekday prices for primary and secondary voltage customers in the Eastern region are averaged and ordered along the y-axis from lowest to highest. In 93\% of the hours, prices were below $\$ 100 / \mathrm{MWh}$, and prices were below $\$ 200 / \mathrm{MWh}$ for $99 \%$ of the hours. Prices were between $\$ 200 / \mathrm{MWh}$ and $\$ 500 / \mathrm{MWh}$ in only 49 hours over these five summers, and between \$500/MWh and \$1000/MWh during only ten hours. Prices exceeded 
$\$ 1,000 / \mathrm{MWh}$ in eight hours. The highest price observed was approximately $\$ 1,400 / \mathrm{MWh}$. All of the prices above \$250/MWh occurred in 2000 and 2001. Customers in the Central and Western regions have faced fewer high-priced hours than customers in the Eastern region; prices in these regions did not exceed $\$ 1,000 / \mathrm{MWh}$ during our study period.

\subsection{Weather in Upstate New York}

Weather conditions are an important factor to account for in evaluating electricity demand and price response. Hot weather may affect customers' loads, to the extent that they are driven by cooling needs, and may also affect customers' price response, to the extent that cooling loads are discretionary or that customers associate hot weather with high electricity prices. Furthermore, these impacts may vary under different weather conditions. Summer weather in NMPC's service territory is mild relative to other regions of the U.S., and this may influence the transferability of the results of this study. ${ }^{17}$

The Temperature Heat Index (THI), a metric that combines temperature and relative humidity effects, provides context for the weather patterns experienced in upstate New York over the five summers of our study period. ${ }^{18}$ Table $2-1$ shows the distribution of average THI values for the hours from $2-5$ p.m. at a representative weather station in the Eastern region of NMPC's service territory. On $87 \%$ of days, the index was below 90 , and it rose above 100 on only four days in five summers. The highest recorded THI was 111.

Table 2-1. Representative Summer Weekday Temperatures in NMPC Service Territory: 2000-2004

\begin{tabular}{|l|l|}
\hline THI $^{\mathbf{a}}$ Value & $\begin{array}{l}\text { Number of Days } \\
(\mathbf{N}=\mathbf{3 2 1})\end{array}$ \\
\hline$<70$ & 34 \\
\hline $70-80$ & 121 \\
\hline $80-90$ & 125 \\
\hline $90-100$ & 37 \\
\hline$>100$ & 4 \\
\hline${ }^{\mathrm{a}} \mathrm{THI}=$ Temperature Heat Index, daily average for the hours from 2-5 p.m.
\end{tabular}

There is a strong coincidence between hot days, high prices and the NYISO events called during our study period. Eight of the top-ten warmest days were in 2001 and 2002. On four of these days, EDRP events were declared (three in 2001 and one in 2002).

\subsection{Customer Research}

A major component of the first phase of this study was an in-depth customer survey and follow-up interviews that provided information on customer characteristics and

\footnotetext{
${ }^{17}$ The empirical aspects of this study concentrates on price response during the summer months as price volatility has been low during the rest of the year (see section 3.2.2).

${ }^{18}$ See section 3.2.2 for a discussion of how this weather metric was used in our analysis of customers' price response.
} 
circumstances. This information was used to develop variables to describe and model price response. Despite the large amount of information collected, several aspects of customer behavior and experience remained unclear. Moreover, due to survey nonresponse and missing information on key questions, only 32 customers could be included in the final customer demand model in the first phase of this study.

As part of this second phase, we undertook another customer research initiative with two objectives in mind: (1) to improve survey response, both in terms of the overall response rate and in ensuring adequate representation of customer market segments, and (2) to obtain more detail on questions that hadn't been fully answered in the first phase of this project.

\subsubsection{Survey Design}

In designing the second-phase survey, we addressed our goal of improving customer response by developing a relatively short survey that included only the most essential information. We also offered financial incentives to each customer that answered the survey (see section 2.4.2).

One of the main questions we attempted to clarify in this year's survey is which signals customers respond to (e.g., high SC-3A prices, NYISO emergency events) and why they respond to them. In the 2003 survey, we had asked customers about their response but did not directly ask what they were responding to. Given the various signals that SC-3A customers have faced, we felt that more information was needed to disentangle their response to high SC-3A prices from their response to other, coincident signals. In addition, if customers responded to some signals but not others, we wanted to find out why they did so.

A second key question that we focused on was the impact of enabling technologies on price response. Enabling technologies are equipment and devices, like energy management systems, peak load control devices, and energy information system gateways that help customers devise and execute price response strategies. In the 2003 survey, we had asked customers whether they had installed certain technologies at their facilities that could enable price response, and found no clear correlation between these investments and estimated price response. In this phase of our research, we asked more targeted questions about when the technologies were installed and how they were used.

We also designed the survey to better clarify customers' load response strategies by asking them explicitly about their use of onsite generation as a load response strategy and asking them how they curtail various end uses.

Finally, we asked several questions about barriers to price response, reasons why customers had stayed with NMPC, and their plans for responding to SC-3A prices going forward. The question topics covered by the survey are shown in Table 2-2. The complete survey is included in Appendix A. 
Table 2-2. Question Topics Included in 2004 SC-3A Customer Survey

\begin{tabular}{|l|l|}
\hline Category & Question Topic \\
\hline \multirow{3}{*}{ Electricity Usage } & Timing of usage \\
\cline { 2 - 2 } & How often customers check prices and, if they don't, why not \\
\cline { 2 - 2 } & Major changes in electricity usage (e.g., production changes) \\
\hline \multirow{5}{*}{ Enabling Technologies } & Response to what signals? \\
\cline { 2 - 2 } & Reasons for response and impact on facility operations \\
\cline { 2 - 2 } & Response strategies \\
\cline { 2 - 2 } & Barriers to price response \\
\cline { 2 - 2 } & Which technologies installed \\
\cline { 2 - 2 } & Purpose for which equipment is used \\
\hline Electricity Supply & Electricity intensity \\
\cline { 2 - 2 } & Rate history \\
\cline { 2 - 2 } & Reasons for staying with NMPC \\
\hline Hedging & Details of competitive supply arrangements \\
\cline { 2 - 2 } & Financial hedges and reasons for not purchasing them \\
\hline Future Outlook & Plans for future response to SC-3A prices \\
\cline { 2 - 2 } & $\begin{array}{l}\text { Reactions to hypothetical default service tariff indexed to real- } \\
\text { time energy markets }\end{array}$ \\
\hline
\end{tabular}

\subsubsection{Survey Administration}

This year's survey was administered in two phases: a set of telephone interviews followed by a self-administered web survey. NMPC supported both phases by providing updated customer contact information and asking its account representatives to personally contact their SC-3A customers to encourage them to participate in the survey.

Telephone Interviews. The in-depth interviews were designed to test the survey instrument prior to implementing the web survey and to obtain additional information on several topics of interest, including specific response strategies, usage of enabling technologies, and specific obstacles to price response. We identified customer attributes that we felt were important to sample representatively and established the population of each among the full survey population of 133 customer accounts. We then identified customers to target for interviews to ensure representation by these groups, outlined as follows:

- customers who hadn't answered the survey in 2003

- customers who we identified as potentially "price responsive" and "not price responsive” as predicted by the demand model estimated in Goldman et al. (2004)

- proportional representation by each of five business categories (described in section 2.4.3)

- customers that had stayed on the NMPC commodity tariff and customers that had switched to competitive retailers

The telephone interviews were conducted between October 19 and November 4, 2004. Prior to scheduling interviews, we emailed the survey to customers along with a cover 
letter explaining the project and encouraging them to participate. We offered customers a $\$ 50$ incentive for participating. ${ }^{19}$ Altogether, 20 customers were interviewed. Their responses were recorded and included with those of the customers that answered the web survey described below.

Web Survey. This year's web survey was administered initially from December 2 through 20, 2004. We sent letters to each SC-3A customer that had not already been interviewed. ${ }^{20}$ Customers were offered a $\$ 50$ incentive for filling out the survey, and each respondent was entered in a drawing for a $\$ 500$ prize. The response during this window was less than hoped for. We believe this is due in part to the time of year (just prior to the holiday season) and also to survey "fatigue" as our web survey followed directly after NMPC’s annual customer satisfaction survey.

To improve response, we re-opened the survey from January 13 through 28, 2005 and offered each respondent an incentive of $\$ 75$ as well as a chance to win a second $\$ 500$ prize. ${ }^{21}$ To improve representative coverage and to increase overall response to our goal of 50\%, we telephoned selected customers directly and administered the survey orally between February 4 and 16, 2005, offering the same \$75 incentive. This last effort was successful: we exceeded our survey response target rate and achieved our targeted market segment representation.

\subsubsection{Survey Response}

Response to this year's customer survey was extraordinarily high for this type of market research: $57 \%$ of our survey population of 133 accounts responded (see Table 2-3). Forty of the 76 accounts represented by this year's survey had also answered our previous survey in 2003.

Table 2-3. 2004 SC-3A Survey Response by Customer Account

\begin{tabular}{|l|l|l|l|l|l|}
\hline Business Category & $\begin{array}{l}\text { Total SC-3A } \\
\text { Customer } \\
\text { Accounts }\end{array}$ & $\begin{array}{l}\text { Survey } \\
\text { Population* }\end{array}$ & $\begin{array}{l}\text { Survey } \\
\text { Responses }\end{array}$ & $\begin{array}{l}\text { Response } \\
\text { Rate* }\end{array}$ & $\begin{array}{l}\text { Answered } \\
\text { 2003 } \text { and } \\
\text { 2004 Surveys }\end{array}$ \\
\hline Manufacturing & 47 & 40 & 25 & $63 \%$ & 10 \\
\hline Public works & 24 & 22 & 10 & $45 \%$ & 7 \\
\hline Commercial/retail & 17 & 16 & 8 & $50 \%$ & 5 \\
\hline Healthcare & 17 & 15 & 10 & $67 \%$ & 3 \\
\hline Government/education & 44 & 40 & 23 & $58 \%$ & 15 \\
\hline Total & $\mathbf{1 4 9}$ & $\mathbf{1 3 3}$ & $\mathbf{7 6}$ & $\mathbf{5 7 \%}$ & $\mathbf{4 0}$ \\
\hline
\end{tabular}

* Several customers indicated in advance that they did not wish to be surveyed. The survey population and response rates correspond to those customers who were approached with the survey.

\footnotetext{
${ }^{19}$ Customers had the option of taking the incentive themselves or having us donate it to a charity of their choice.

${ }^{20}$ A few customers had indicated to NMPC that they did not wish to be surveyed, and were not approached.

${ }^{21}$ Due to limited response during this phase, we included all customers who had answered the survey or been interviewed up to this point in this second prize drawing.
} 
Based on SIC codes provided by NMPC, we classified customers into five business categories: manufacturing, public works, commercial/retail, healthcare and government/education. We expanded these categories from the three utilized in Goldman et al. (2004) to provide a more detailed characterization of customers by market segment. ${ }^{22}$ The response rates for each of these categories range from $45 \%$ for public works to $67 \%$ for healthcare facilities (Table 2-3).

The full SC-3A population includes 149 customer accounts with a combined noncoincident peak demand of $642 \mathrm{MW}$. The survey respondents represent this population quite well on the basis of geographic location, supplier choice, customer size, and participation in NYISO DR programs (see Table 2-4).

Table 2-4. Characteristics of SC-3A Customers and 2004 Survey Respondents

\begin{tabular}{|c|c|c|c|}
\hline \multirow{2}{*}{\multicolumn{2}{|c|}{ Customer Characteristic }} & \multicolumn{2}{|c|}{ Percent of Customer Accounts } \\
\hline & & \multirow{2}{*}{$\begin{array}{l}\text { All SC-3A } \\
\text { Customer } \\
\text { Accounts } \\
(\mathbf{N}=149) \\
33 \%\end{array}$} & \multirow{2}{*}{$\begin{array}{l}\text { 2004 Survey } \\
\text { Respondents } \\
\text { (N=76) }\end{array}$} \\
\hline Region & East & & \\
\hline & Central & $30 \%$ & $33 \%$ \\
\hline & West & $37 \%$ & $30 \%$ \\
\hline \multirow{2}{*}{$\begin{array}{l}\text { Electric Commodity } \\
\text { Supplier (summer 2004) }\end{array}$} & NMPC & $37 \%$ & $37 \%$ \\
\hline & Competitive Retailer & $63 \%$ & $63 \%$ \\
\hline \multirow{3}{*}{$\begin{array}{l}\text { NYISO DR Program } \\
\text { Enrollment (any } \\
\text { summers) }\end{array}$} & EDRP & $33 \%$ & $37 \%$ \\
\hline & ICAP/SCR & $24 \%$ & $18 \%$ \\
\hline & DADRP & $3 \%$ & $3 \%$ \\
\hline \multirow[t]{3}{*}{ Maximum Peak Demand } & $<2.5 \mathrm{MW}$ & $40 \%$ & $37 \%$ \\
\hline & $2.5-5 \mathrm{MW}$ & $40 \%$ & $42 \%$ \\
\hline & $>5 \mathrm{MW}$ & $19 \%$ & $20 \%$ \\
\hline
\end{tabular}

\subsection{NMPC Billing Data and Tariff History}

For the second phase of this study, we worked with NMPC staff to obtain updated SC-3A customer interval meter and price data and tariff history. The interval meter and price data are hourly and cover the period from January 1, 2000 to September 30, 2004. The tariff history data indicates whether a customer was on Option 1, Option 2, or with a competitive supplier for each month from the spring of 1999 to the fall of 2004. Not only does the data in this phase cover a longer time period than the 2003 study, but the information is more complete, and we undertook a considerable effort to ensure data quality.

We also made use of customer characteristics data that we had received from NMPC in the first phase of this study. This information includes SIC codes, which we used to classify customers into business categories, geographic location, and delivery voltage level.

\footnotetext{
${ }^{22}$ In Goldman et al. (2004), public works customers were included in the government/education category and healthcare customers were included in the commercial/retail category.
} 


\section{Quantifying and Characterizing Price Response}

A major goal of this study is to quantify how large commercial, industrial and institutional customers paying day-ahead market-based electricity prices adjust their usage in response to short-term price changes. In particular, we are interested in the intensity, character and major drivers of this response. We accomplish this by estimating substitution elasticities for the SC-3A customers that faced hourly varying prices over five summers (2000-2004), comparing these estimates by customer and business classification, and by developing models that quantify the impact of various factors that we hypothesized could impact customers' response. In particular, we focus on weather effects, peak prices, and a variety of customer characteristics and circumstances, including enabling technology adoption and participation in NYISO DR programs, as drivers for price response.

Quantifying price response assists policymakers and market participants in several important ways. First, substitution elasticity results provide direct empirical evidence of the overall magnitude of price responsive load that can be expected. This provides a basis for developing price-responsive load programs and evaluating what additional DR options may be necessary. Second, understanding the distribution of price response among customers allows public benefits program administrators to identify promising targets for programs that assist with price response. Third, disaggregated elasticity estimates can be the basis for utilities or competitive retailers to anticipate the amount of load response they can expect from their customers at different price levels. This information allows them to bid price-responsive loads into wholesale power markets, thereby allowing DR to compete with supply (Braithwait 2005). Finally, elasticity results can also help policymakers forecast the impact from critical peak pricing (CPP) rate designs.

This chapter begins with a brief discussion of the theoretical basis for the demand model used in this analysis, the interpretation of the substitution elasticity, an overview of the models used in this study, how they were estimated and the data sources included. We then present the results of this research, beginning with the intensity of price response: average substitution elasticity estimates for SC-3A customers overall and for each business category, and the distribution of elasticities within each sector. Next, we describe the character of price response: weather, price and demand impacts on customers' substitution elasticities. Drivers to price response are then presented and discussed. Finally, we estimate the aggregate demand reduction potential of SC-3A customers based on their substitution elasticity estimates.

\subsection{Measuring Price Response - The Theory of the Firm}

The model for electricity demand used in this study is consistent with the modern economic theory of the firm. According to this theory, firms - or SC-3A customers, in our case study - are assumed to minimize the cost of producing a given level of output by trading off production inputs based on their relative prices. Output, in this case, refers to the customer's business activity - the production of intermediate or final consumer goods or the provision of services to consumers or society - at levels demanded by their 
customers or clients. Inputs are any goods or services needed to produce this output. Electricity is one such input to SC-3A customers’ business activities.

Under hourly electricity pricing, the cost of electricity varies considerably during the day, with the highest prices typically occurring during the afternoon, peak-period hours. We therefore model electricity as two inputs - "peak" and "off-peak" electricity - that can be substitutes or complements, depending on how they are used to support a customer's productive process. In either case, the model assumes that customers decide how much peak and off-peak electricity to use in order to meet their daily output obligations. ${ }^{23}$

During our study period, NYISO day-ahead electricity prices, which are the basis for SC3A prices, were distributed such that the majority of days are characterized by a fairly constant pattern of hourly prices (of typically \$50-60/MWH for mid-day hours), with high peak period prices (exceeding \$300/MWh) occurring only on isolated days (see section 2.2). Consequently, we portray SC-3A customers' price response as primarily involving the decision to reallocate business activity on those days when prices are high from an established routine followed on "normal" days.

The established routine of normal business practices require electricity expenditures derived from the operation of machines, lighting, safety, space conditioning and other requirements. According to the economic theory of the firm, these requirements in turn are derived from proscribed or anticipated levels of business activity. Implicitly or explicitly, customers allocate electricity use in each hour of the day according to its value as an input during those hours. This usage pattern might change in response to factors that change the business intensity or schedule, but on a day-to-day basis electricity usage is derived by the expected, and planned for, level of business activity.

The theory of the firm also predicts that the level of peak and off-peak energy used on any day may be adjusted depending on the relative prices for that day. On days with high peak prices, we expect customers to use less electricity during the high-priced hours of the day and more during the lower priced hours to meet the day's expected level of business. In other words, the decision involves substitution of off-peak electricity use for peak usage. It is this relationship - the substitution of off-peak for peak energy - that is explicitly modeled in this study.

To evaluate this response, we estimate elasticities of substitution for SC-3A customers exposed to day-ahead hourly prices from their hourly-integrated load and price data. The substitution elasticity is a very specific characterization of electricity demand and price response that is consistent with this portrayal of how customers use and value electricity. Mathematically, it is defined as the percentage change in the ratio of daily peak to offpeak electricity usage in response to a one percent change in the ratio of off-peak to peak electricity prices. It indicates the degree to which a customer minimizes costs by adjusting electricity usage between times of the day, based on relative electricity prices.

\footnotetext{
${ }^{23}$ This peak vs. off-peak distinction is consistent with how other empirical evaluations of RTP-type tariffs have treated electric commodity (Caves, et al. 1984, King and Shatrawka 1994, Schwarz et al. 2000, Bosivert et al. 2004, Goldman et. al. 2004).
} 


\section{Own-Price vs. Substitution Elasticities}

Readers of this report may be more familiar with the own-price elasticity of demand than the substitution elasticity measured in this study. Own-price elasticities are somewhat more intuitive - they measure the reduction in a customer's overall consumption in response to an increase in the nominal price of electricity (rather than changes in the customer's relative peak and off-peak electricity consumption due to relative price changes) - and provide a direct means to predict load reductions at specific prices.

However, there are two important reasons for estimating substitution rather than own-price elasticities to characterize large commercial and industrial customers' price response: theoretical consistency and data limitations.

\section{Theoretical Consistency}

SC-3A customers are large industrial and commercial firms and institutions. All of them use electricity as an input to their business activity in some form. We observe that their daily electricity usage patterns are relatively well defined and comport with prices (high loads during high prices, low loads during low prices); this coincidence between prices and load provides a logical basis for analyzing price response in terms of changes in peak and off-peak usage. Moreover, we observe that customers make short-term decisions about how to adjust their electricity usage. Thus, it makes sense to use the theory of the firm, and the resulting elasticity of substitution, to analyze the relationship between prices and usage during peak and off-peak periods of the day. Although it is possible to derive own-price (Allen partial) elasticities from the GL model, they would restrict "output" to remain constant as electricity consumption patterns change. This makes their interpretation very difficult. The more traditional Marshallian own-price elasticity, which does not hold output constant, cannot be estimated here due to data limitations (see below).

Customer interviews and surveys conducted in both phases of this study indicate that customers employ a variety of load curtailment strategies. Many say they respond to price increases by reducing discretionary usage during peak periods without making it up later or by serving load with onsite generation, and a few report that they indeed shift usage, but to another day. We acknowledge that input substitution is not the only type of response observed. However, the substitution elasticity is structurally consistent with all these load response strategies because they all result in a reduction in the ratio of peak to off-peak usage in response to higher peak prices (see the inset, How the Substitution Elasticity Characterizes Foregoing and Other Load Response Strategies, below). The substitution elasticity cannot separately and consistently account for each of these effects, but neither could the own-price elasticity, which would incorrectly capture the effect of shifting behavior, resulting in precisely the opposite problem. To the extent that SC-3A customers adopt non-shifting response strategies, the substitution elasticity underestimates the associated reduction in peak demand. The implication is that the elasticity estimates in this study are conservative.

\section{Data Limitations}

Estimating Marshallian own-price elasticities would require information on either customers' demand in the absence of RTP (e.g., a customer baseline load) or their daily production output (e.g., number of widgets produced each day or some estimate of end-use service characteristics or changes in worker productivity for institutional or commercial buildings). The former is not possible (given constraints on the availability of historic hourly interval data), since SC-3A customers have faced RTP for the last six years and no control group is available. The latter, collecting output data, is not practical. Not only would it be beyond the scope of this study, but most customers would not be willing to disclose such sensitive information at any meaningful level of detail. Furthermore, for customers that produce multiple goods or provide services, defining a reliable output metric would be problematic.

The concept of a price elasticity of demand is a useful way to quantify price response. It provides a normalized, relative measure of the change in input intensity in response to 
prices. Normally, as prices rise, other factors held constant, we expect that electricity usage will decline. The higher the elasticity estimated for a given customer, the greater that customer's response to price changes. The elasticity measure also accommodates comparing the price responsiveness of different business sectors, customers of different sizes, and even drawing comparisons among individual customers.

This measure of price response has been used in a number of previous studies of large customers' response to dynamic electricity prices. Herriges et al. (1993) used substitution elasticities to quantify the price response of participants in Niagara Mohawk's voluntary RTP program, implemented in 1988, which involved some of the same customers in this study. This approach was subsequently used to evaluate other RTP programs that offer similar incentives to adjust loads (hourly prices quoted dayahead) and involved customers of similar circumstances and character as SC-3A customers (King and Shatrawka 1994, Christensen Associates 1995, Schwarz et al. 2002, Boisvert et al. 2004). The first phase of this study also estimated substitution elasticities from a derived electricity demand model (Goldman et al. 2004).

\subsubsection{Interpreting Elasticity of Substitution Results}

The elasticity of substitution provides insight into the intensity of a customer's response to high hourly prices as well as a means to compare the response of different groups of customers. The elasticity of substitution takes on values of zero or greater - the higher the elasticity, the greater the customer's intensity of price response. For example, a substitution elasticity of 0.15 means the customer's peak to off-peak usage ratio changes by $15 \%$ in response to a $100 \%$ change in the off-peak to peak price ratio. A value of one 
signifies that the shifting of electricity is in exactly in the same proportion as the change in relative prices. Previous studies have found sector-level substitution elasticities ranging from zero to 0.30 , although individual customer elasticities in excess of one have been reported (Schwarz et al. 2002).

In this study, we adopt a flexible model for estimating substitution elasticities that allows us to compare individual customers' response on different days (see section 3.2.1). This provides a means to evaluate whether and how their response differs under a range of conditions. Accordingly, several patterns of response that customers might exhibit are identified in Table 3-1 and described, with examples, below. ${ }^{24}$

Table 3-1. Character of Customer Response: Possible Substitution Elasticity Scenarios

\begin{tabular}{|l|l|l|l|}
\hline & \multicolumn{2}{|l|}{ Scenario } & Implication \\
\hline 1. & \multicolumn{2}{|l|}{ Substitution elasticity equals zero } & $\begin{array}{l}\text { Customer is not price responsive under any } \\
\text { circumstances }\end{array}$ \\
\hline 2. & $\begin{array}{l}\text { Substitution } \\
\text { elasticity depends } \\
\text { on the price ratio }\end{array}$ & $\begin{array}{l}\text { a. constant over all } \\
\text { price ratios }\end{array}$ & $\begin{array}{l}\text { Customer's price response increases proportionate to } \\
\text { increases in the price ratio }\end{array}$ \\
\cline { 3 - 4 } & & $\begin{array}{l}\text { b. varies with the } \\
\text { level of the price } \\
\text { ratio }\end{array}$ & $\begin{array}{l}\text { Customer's response is disproportionately high at } \\
\text { higher price ratios, or }\end{array}$ \\
\cline { 3 - 4 } & & $\begin{array}{l}\text { c. peak usage can } \\
\text { be “priced out” }\end{array}$ & $\begin{array}{l}\text { Above a threshold price ratio, customer's peak usage is } \\
\text { all but eliminated }\end{array}$ \\
\hline 3. & \multirow{2}{*}{$\begin{array}{l}\text { Substitution elasticity depends on } \\
\text { nominal prices }\end{array}$} & $\begin{array}{l}\text { Customer's response increases as nominal prices } \\
\text { increase, or }\end{array}$ \\
\cline { 3 - 4 } & & & Customer's response drops off at higher nominal prices \\
\hline
\end{tabular}

1. Substitution elasticity equals

zero. Customers with zero

substitution elasticities use

electricity in fixed proportions. This

means that relative electricity prices

have no impact on their electricity

consumption. This may be due to

the nature of their production

process (see example) or may

simply indicate that they have

explicitly or implicitly made a

decision not to respond, regardless

of electricity prices.

\section{Zero Substitution Elasticity Example}

A bakery that bakes cakes in the morning (using electric mixers and ovens) and frosts them in the afternoon (using mixers and refrigeration) is an example of a customer that uses electricity in fixed proportions due to the nature of its production process. Every kWh used in the morning to produce a cake requires an additional and fixed level of electricity in the afternoon to frost and store it. The baker cannot avoid high electricity prices by substituting morning electricity usage to bake more cakes and then save on electricity by not frosting them in the afternoon. For such a customer, there is no possibility for substitution.

2. Substitution elasticity depends on the price ratio. This scenario encompasses a variety of situations in which customers' price elasticities are greater than zero and where response is a function of the ratio of peak to off-peak prices (not nominal prices). For example, a customer's response on a day where the peak price is $\$ 0.10 / \mathrm{kWh}$ and the off-peak price is $\$ 0.05 / \mathrm{kWh}$ is the same as on a day where peak

${ }^{24}$ Appendix B provides a graphical depiction of these alternative substitution trade-off possibilities. 
and off-peak prices are $\$ 1.00$ and $\$ 0.50 / \mathrm{kWh}$ respectively. This is because on both days the price ratio is $2: 1$. There are three sub-cases of this type of response:

a. Substitution elasticity is constant over all price ratios. In this case, a customer's response increases in the same proportion with the price ratio over all possible levels of electricity usage. For example, if a customer's response to the price ratio doubling from 2:1 to 4:1 resulted in a 15\% increase in the customer's off-peak to peak usage ratio (an elasticity of 0.15 ), another doubling of the price ratio, from $4: 1$ to $8: 1$, would result in another $15 \%$ increase in the off-peak to peak usage ratio. $^{25}$

b. Substitution elasticity varies with the level of the price ratio. Some customers may exhibit different degrees of response on days with higher or lower price ratios. For some, as peak usage is reduced, further reductions may become increasingly difficult to achieve (see example). For others, the opposite may be true - they may exhibit some threshold price ratio above which response is deemed worthwhile, resulting in higher elasticities on days with higher price ratios. Example of Declining Elasticity with Increasing
Price Ratios

Consider a firm that uses electricity to run conveyor belts, lighting and power to support laborers assembling a product, runs two eight-hour shifts (with a shift change at noon), has some excess capacity and stockpiled parts, and can add labor to increase plant output if needed. If the peak to off-peak electricity price ratio rises, the firm can reassign some labor from the afternoon to the morning shift and still maintain output. To a point, the greater the peak price, the more the firm shifts production. But as the morning production increases, it eventually reduces the overall efficiency of electricity usage, and each increment of shifted production becomes smaller. Nonetheless, marginal substitution of off-peak for peak electricity is always possible.

c. Peak usage can be "priced out". Some customers may not be able to substitute peak for off-peak energy over all ranges of production. At some threshold peak usage level, they may encounter a production indivisibility that makes the decision regarding any further peak usage curtailment “all-or-nothing”. For example, some customers may simply need to shut down production altogether if peak-period labor drops below some critical level. Others may switch from grid electricity to onsite generation when a critical price ratio is met. The result, in either case, is that peak usage (as seen by the utility) is suspended.

3. Substitution elasticity depends on nominal prices. Some customers, particularly those that forego load rather than shift (see section 4.1.1), may respond to nominal prices rather than peak to off-peak price ratios. For example, a customer that responds very little on a day where the peak price is $\$ 0.10 / \mathrm{kWh}$ and the off-peak price is $\$ 0.05 / \mathrm{kWh}$ might have a very large response on a day with the same 2:1 price ratio but where peak and off-peak prices are $\$ 1.00$ and $\$ 0.50 / \mathrm{kWh}$ respectively. For some,

\footnotetext{
${ }^{25}$ This type of response is assumed for all customers in the CES model employed in Goldman et al. (2004).
} 
this may reflect a nominal price threshold at which response is deemed worthwhile. ${ }^{26}$ For others, this behavior may reflect response to NYISO DR programs, which could result in higher elasticities during high-priced hours. ${ }^{27}$ Still others may have specific production processes that are amenable to increasing response when nominal prices are high (see example). The opposite may also be the case for some customers: as prices rise, their ability to respond to prices declines. This is plausible for customers whose loads are coincident with high prices (e.g., cooling loads).

\begin{tabular}{|l|}
\hline \multicolumn{1}{|c|}{$\begin{array}{c}\text { Example of Increased Response at Higher Nominal } \\
\text { Prices }\end{array}$} \\
Consider a customer with a backup production process that \\
affords a greater rate of substitution of off-peak for peak \\
consumption than is possible under the customer's primary \\
production process, but that is employed only when \\
electricity prices are high enough to make it cost-effective \\
to do so. The customer's primary process may also allow \\
for input substitution, but at a lower level, and we may \\
observe a substitution elasticity that holds for the range of \\
prices below which the backup process is deployed. But \\
when nominal peak prices reach a threshold level, the \\
customer's price response, and accordingly its substitution \\
elasticity, increases as it switches to the backup production \\
process.
\end{tabular}

In summary, a customer's ability to respond to prices can be characterized not only by the level of the substitution elasticity, but also by its dynamic character over a range of price and peak load conditions. This is accomplished by estimating elasticities for all customers and relating differences in them to selected customer characteristics and other circumstances. Our methodology for accomplishing this is described in the next section.

\subsection{The Specification of Customer Response to Daily Electricity Price Changes}

We adopted three models to study SC-3A customers' price response (see Table 3-2). First, substitution elasticities were estimated using an Indirect Generalized Leontief (GL) model. This provides an indicator of the intensity of price response that can be used to explore trends among customers and business sectors. Weather impacts were also an integral part of this model. Substitution elasticity estimates were then used as a dependent variable in two linear regression models designed to answer questions about the character of price response: (1) how price response changes with nominal prices and load and (2) which customer characteristics and circumstances have a statistical correlation with price response.

In the sections that follow, we provide background on the GL model specification, focusing on its strengths and limitations in characterizing price response, and we describe how the three models used in this study were implemented, focusing on the scope of the customers and days included, key data inputs and output indicators. A detailed discussion of the model specifications, including estimated equations, is provided in Appendix B.

\footnotetext{
${ }^{26}$ Several customers told us in interviews that they would only bother responding if prices reached very high levels.

${ }^{27}$ During our study period, program events have been coincident with high prices, and for EDRP participants we considered the $\$ 0.50 / \mathrm{kWh}$ floor price paid for curtailments to be the "price" they saw during those hours.
} 
Table 3-2. Empirical Price Response Models Used in this Study

\begin{tabular}{|l|l|l|l|}
\hline & Model & Goal & Questions asked \\
\hline 1. & $\begin{array}{l}\text { Indirect } \\
\text { Generalized } \\
\text { Leontief }\end{array}$ & $\begin{array}{l}\text { Determine } \\
\text { intensity of } \\
\text { price response }\end{array}$ & $\begin{array}{l}\text { What is the distribution of price response among customers? } \\
\text { What are average elasticities by business sector? } \\
\text { What is the overall average elasticity of SC-3A customers? } \\
\text { What is the impact of weather on price response? }\end{array}$ \\
\cline { 3 - 4 } Can some customers be "priced out" of peak usage? \\
\hline 2. & $\begin{array}{l}\text { Linear } \\
\text { regression }\end{array}$ & $\begin{array}{l}\text { Determine } \\
\text { character of } \\
\text { price response }\end{array}$ & $\begin{array}{l}\text { Do customers respond more when prices are high? } \\
\text { Do customers respond less when they are operating close to } \\
\text { their peak demand? }\end{array}$ \\
\hline 3. & $\begin{array}{l}\text { Linear } \\
\text { regression }\end{array}$ & $\begin{array}{l}\text { Identify drivers } \\
\text { to price } \\
\text { response }\end{array}$ & $\begin{array}{l}\text { Which customer characteristics and circumstances are statistical } \\
\text { predictors of price response? }\end{array}$ \\
\hline
\end{tabular}

\subsubsection{The Indirect Generalized Leontief Input Demand Model}

The Indirect Generalized Leontief (GL) cost model was chosen to estimate substitution elasticities in this second phase of this study. It provides a highly flexible representation of cost-minimization behavior that places very few restrictions on the nature of the substitution elasticities. However, its mathematical interpretation is complex, as the elasticities must be derived indirectly from the parameter estimates. By contrast, the Constant Elasticity of Substitution (CES) model, which we estimated in the first phase of this study, is appealing because the estimated model parameters are the substitution elasticities (Goldman et al. 2004). This facilitates deriving elasticities and testing their significance. However, it embodies the assumption that elasticity is constant over all price ranges (scenario 2.a in Table 3-1). This is highly restrictive and contradicts some customers' reported behavior. ${ }^{28}$

In the first phase of this study, we estimated average elasticities for business sectors, and found substantial differences between sectors (Goldman et al. 2004). But based on customer interviews, we knew that price response varied considerably among customers within each sector. In other words, business activity is not a sufficient predictor of how individual customers respond to daily electricity price changes. The GL model allows us to estimate substitution elasticities for individual customers. ${ }^{29}$ This affords greater granularity of results and allows us to look within business sectors at the distribution of non-responsive, moderately responsive and highly responsive customers.

Employing a flexible characterization of input substitution does, however, come at a price. The mathematical complexity of the model makes it difficult to include variables that represent customer characteristics and circumstances on price response directly in the

\footnotetext{
${ }^{28}$ In both phases of this study we found that SC-3A customers' reaction to peak price increases encompasses a wide variety of behaviors that a CES specification does not capture.

${ }^{29}$ Other efforts to model demand response have also relied on estimated demand models for individual firms, although the functional forms have been different than the one used here (e.g., Schwarz et al. 2002, Taylor et al. 2005, Patrick and Wolak 2001). Certain other studies were based on functional forms that did not allow the substitution elasticities to vary across days for each firm (e.g. Caves et al. 1984, Charles River Associates 2005).
} 
GL demand model. ${ }^{30}$ Yet this is one of the major objectives of this study. ${ }^{31}$ We were only able to include the effects of price and weather in the GL model. To study the influence of other factors on price response, we took an indirect approach, first estimating the GL model for individual customers on individual days, and then regressing the results against other factors that we hypothesized would impact the character of response or serve as drivers to price response (models 2 and 3 in Table 3-2). ${ }^{32}$ The way in which these models were implemented is described below.

\subsubsection{Implementation of Demand Models}

The GL model was estimated on summer weekdays (not including holidays or the two days of the 2003 northeast blackout) over the five summers, 2000 through 2004, for which we had load and price data. ${ }^{33}$ We included customers for all summers in which we knew they had faced hourly varying prices - either NMPC's SC-3A Option 1 tariff or a similarly indexed commodity supply contract with a competitive supplier - for at least some portion of their load. ${ }^{34}$ We combined tariff history data with survey responses about commodity supply options to classify customers in each summer of the study - customers that were either fully hedged or had unknown commodity supply arrangements (due to survey non-response) in any period were omitted from the model for those periods. Altogether, 119 customer accounts were included in the GL model for at least one summer each.

The implementation of the three models, including data sources and key outputs, is depicted in Figure 3-1. The models were estimated to achieve our analysis goals as follows.

Intensity of Price Response. We began by estimating the GL model iteratively for each of the 119 customers on each of the 321 days included in the study period for which we had determined that they faced hourly prices. ${ }^{35}$ This resulted in a separate elasticity of substitution estimate for each customer on each day - over 30,000 estimates altogether (see Figure 3-1). For customers enrolled in the NYISO EDRP program, we replaced the SC-3A price with the $\$ 0.50 / \mathrm{kWh}$ EDRP floor price during program event hours.

\footnotetext{
${ }^{30}$ The algebraic specification of the GL model's arguments is highly non-linear , even after a logarithmic transformation.

${ }^{31}$ In the CES model estimated in Goldman et al. (2004) several such variables were found to be significant drivers of price response.

${ }^{32}$ This estimation strategy is similar to the one used by Schwarz (1990). Schwarz used a GL demand model to estimate household demand response by customer, and used a second regression to relate customer characteristics to the degree of price responsiveness.

${ }^{33}$ The study was restricted to the summer months because that is when NYISO day-ahead prices vary the most and reach their highest levels. Adding additional months of data to the analysis would have worked against the study interests. While prices vary little during these months, loads still vary. Without any additional explanatory variables (such as firm output) to explain these variations, the overall quality of the substitution elasticity estimates would be reduced.

${ }^{34}$ Including customers that were fully hedged and did not see hourly varying prices for marginal usage would have been inconsistent with the GL model specification.

${ }^{35}$ Because some customers took hedged or unspecified contracts for some summers, not all customers were included in the model for the full 321 days.
} 


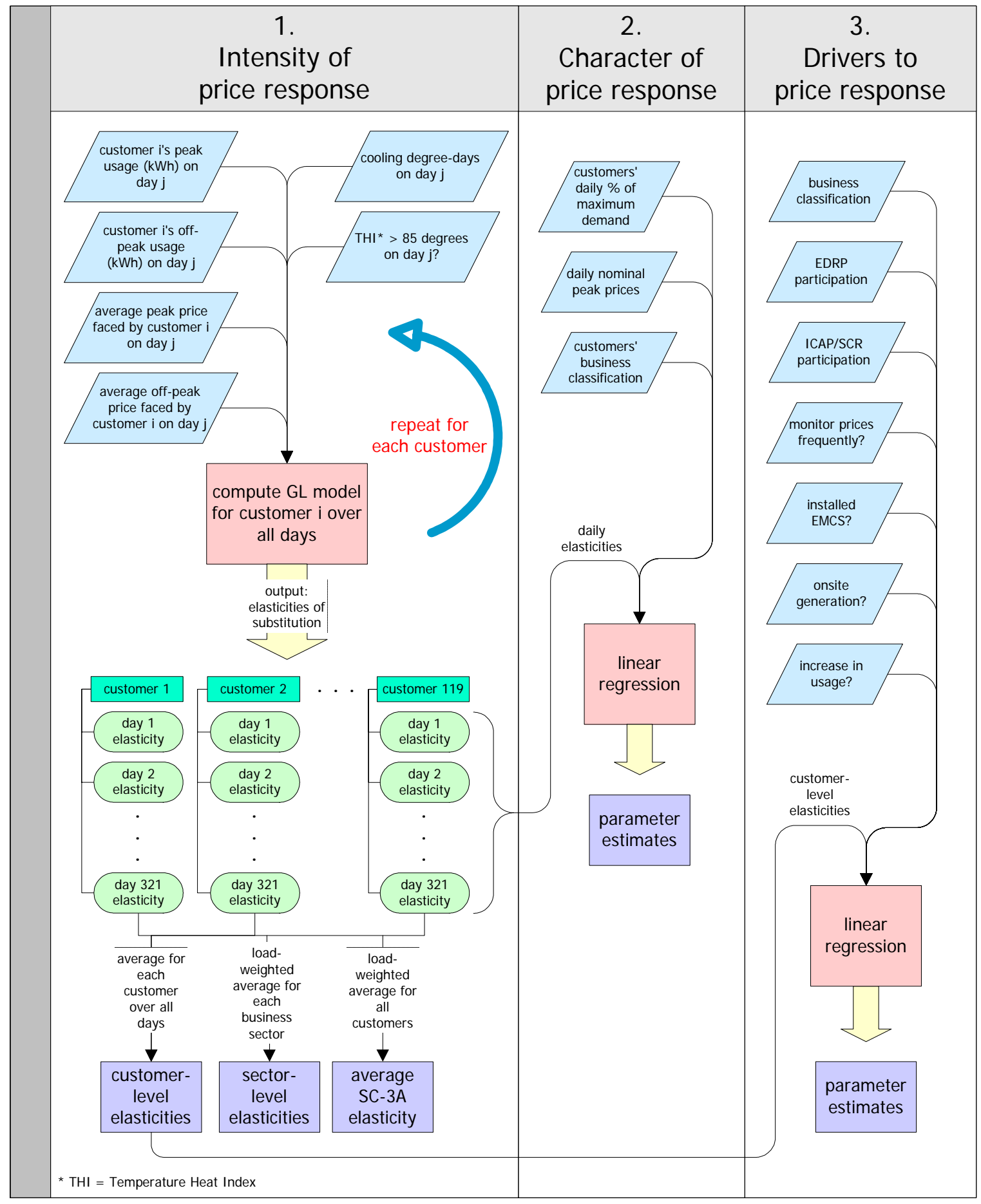

Figure 3-1. Implementation of Generalized Leontief and Regression Models

One problem that we addressed at this stage was determining the length and timing of the peak period. Rather than arbitrarily assign a peak period, we estimated the GL model (as described above) for three possible peak-period definitions - 12-5 p.m., 1-5 p.m. and 2-5 p.m. - to see which provided the most robust elasticity estimates. These results are 
presented in section 3.3.1. We then selected the best-fit peak period and used it for all subsequent analyses.

To evaluate the intensity of price response, we averaged the daily elasticity estimates in three ways: by customer (average of daily elasticities for each customer), by business sector (load-weighted average of customer elasticities grouped into five business sectors), and for all SC-3A customers (load-weighted average of all customers' elasticities) (see Figure 3-1). These customer-level, sector-level and overall SC-3A results are presented in section 3.3.2.

Two variables were included in the GL model to account for the effect of weather on customers' electricity usage and price response. For some customers, the primary driver of marginal electricity usage is weather - hot summer days cause increased peak loads to serve air conditioning and other cooling needs. Hot days are also coincident with high NYISO day-ahead market prices. To the extent that higher prices are associated with higher loads, the associated upward-sloping demand curve for electricity could confound efforts to identify input substitution in response to relative prices. We corrected for this by including a continuous variable reflecting cooling degree-days as an intercept shifter to control for differences in peak and off-peak electricity usage on summer days that are unusually warm. ${ }^{36}$

Weather can also have the opposite effect on price response. Some customers may be more price-responsive at higher loads if their marginal loads are discretionary. The comfort and convenience they realize from air conditioning, for example, may be foregone if the price is right. To test for this effect, a second, binary weather variable based on the average Temperature Heat Index (THI) was used to distinguish hot from cool days. ${ }^{37}$ It was included as a shifter variable on the price ratio and peak usage intensity parameters. The impact of weather on price response, based on these two variables, is discussed in section 3.3.5.

We also used GL parameter estimates to identify customers with the potential to be "priced out" of peak electricity usage (see section 3.1.1). The methodology for doing so is presented in Appendix B, and the results are in section 3.3.6.

Character of Price Response. To evaluate the character of SC-3A customers' price response, we regressed the daily customer elasticities derived from the GL model against the price ratio on each day and the amount of load used by each customer on each day

\footnotetext{
${ }^{36}$ The study team acknowledges Drs. Borenstein (University of California Energy Institute) and Schuler (Cornell University) for emphasizing the need to employ a specification that lets the data determine the extent of this effect, while exonerating them from responsibility for the method employed. In the first phase of the study, weather was not a significant determinant in the CES specification, although many firms reported having weather-sensitive loads.

${ }^{37}$ The Temperature Heat Index (THI), derived by the National Weather Service during the hours of noon to 5 p.m. is based on daily temperature and dew point values for five weather stations located in the utility's service territory. See Goldman et al. (2004) for details on the construction of the index.
} 
relative to their summer peak demand over the entire study period (see Figure $3-1) .{ }^{38} \mathrm{We}$ also included customers' business classification in the model to evaluate differences in the character of price response by business sector. The resulting parameter estimates describe how customers' elasticities change on different days in response to these factors. These results are presented in section 3.3.7.

Drivers to Price Response. We also regressed the customer-level elasticities derived from the GL model against a variety of customer characteristics and circumstances that we hypothesized were drivers to price response. The input explanatory variables shown in Figure 3-1 are those that were included in the final model. ${ }^{39}$ Survey responses, along with other customer records, provided data on the presence and use of energy management equipment and on-site generation, participation in NYISO demand response programs, overall increases in electricity usage over the study period, and the reported frequency of monitoring SC-3A prices. Because of this, the sample of customers included in this model is limited to those that provided answers to the associated survey questions: we were able to include 55 customers. With the exception of healthcare and public works customers, these 55 customers proportionally represent the other business sectors compared to the 119 customers included in the first two models in terms of both customer numbers and non-coincident peak demand.

The associated parameter estimates describe the impact and significance of these factors in explaining differences in customers' elasticities. These results are presented in section 3.3.8.

\subsection{Response to Market-Based Default Service Electricity Prices}

In this section, we present and discuss results of this empirical analysis of SC-3A customers' price response. We begin with a discussion of the timing and length of the peak period definition and how this affects elasticity estimates. Then, we present overall and sector-level elasticity of substitution estimates derived from the separate GL demand models estimated for each customer, examine the distribution of customers by their elasticity estimates and discuss the impacts of weather on customers' substitution elasticities. Next, we present results of the two regression models, discussing the impacts of load and price levels on price response and customer characteristics as drivers to price response. Finally, we estimate the aggregate load response of the modeled SC-3A customers at various price levels.

\footnotetext{
${ }^{38}$ The price ratio and relative peak demand variables are specified in the model as both intercept and slope shifters to account for the possible interaction among these characteristics (e.g., interaction between relative electricity prices and relative peak usage). In addition to an auto-regressive correction that was used in the GL model estimation, the second-stage model is also corrected to account for heteroskedasticity, a condition where the error term depends on the size of the substitution elasticity rather than being identically and independently distributed. The reasons for these two corrections are discussed in Appendix B.

${ }^{39}$ We tested a several other customer characteristics, including customer size, that displayed no discernable relationship with customer elasticities and could not be included in the model.
} 


\subsubsection{Price Responsiveness and the Length of the Peak Period}

Substitution elasticities were estimated for three alternative peak period definitions - 125 p.m., 1-5 p.m. and 2-5 p.m. - to observe how this specification influences price response estimates (see section 3.2.2). The resulting load-weighted average elasticity of substitution over all accounts ranges between 0.05 (12-5 p.m.) and 0.11 (2-5 p.m.).

Figure 3-2 illustrates the load-weighted elasticity estimates for each peak period by business sector. For all sectors but healthcare, the estimates increase as the peak period duration decreases. This difference is most dramatic for the sectors with the highest estimated elasticities - the manufacturing, government/education and commercial/retail sector elasticities for the 2-5 p.m. peak are more than double the estimates for 12-5 p.m. SC-3A prices generally reach their daily high between 2 p.m. and 5 p.m., so it is not surprising that this period reflects customers' highest inducements to respond to prices.

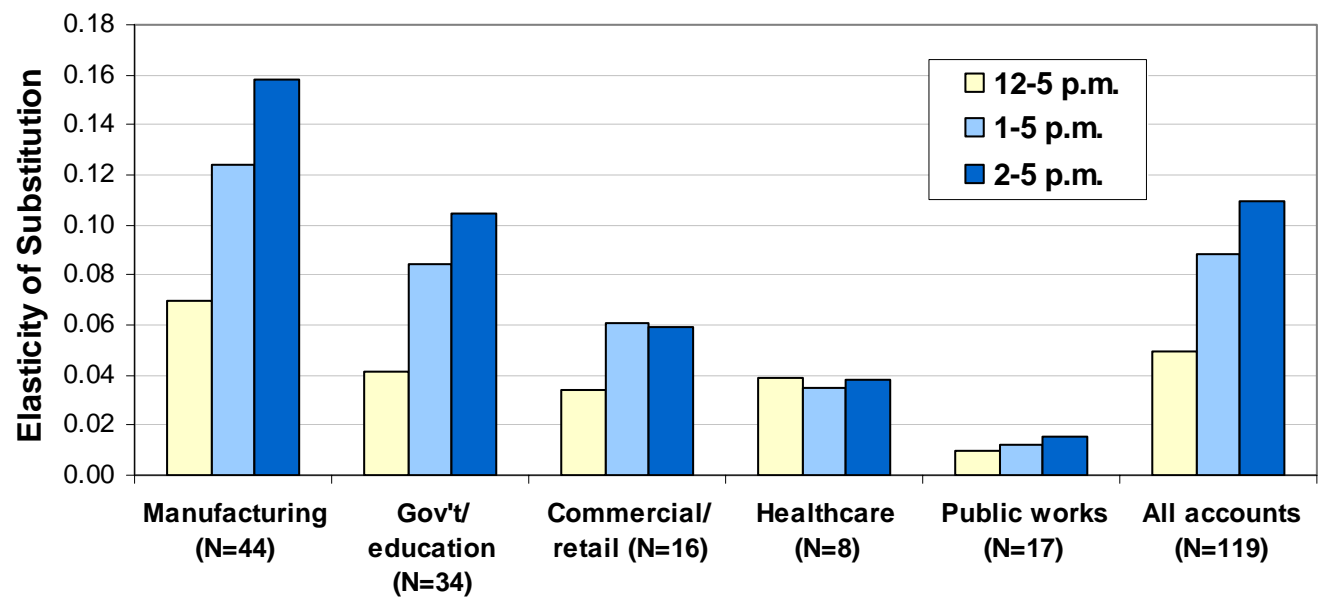

Figure 3-2. Impact of Peak Period Specification on Average Elasticities of Substitution

Based on these results, we designated the hours from 2 p.m. to 5 p.m. as the peak period (and the remaining hours of the day as the off-peak period) for all subsequent results reported in this chapter.

\subsubsection{Intensity of Price Response}

The overall average elasticity of substitution for the 119 customer accounts included in the GL model is 0.11 . This means that a doubling of the peak price ratio, other factors held constant, would result in an $11 \%$ reduction in the ratio of their peak to off-peak electricity usage. This value is within the range of portfolio substitution elasticity estimates for commercial and industrial customers reported elsewhere (Herriges et al. 1993, Schwarz et al. 2002, Boisvert et al. 2004). However, these other studies focused on customers that were served under a two-part, base-load hedged rate offered by vertically integrated utilities quoting top-of-stack marginal prices. The differences in the design of these services from that of Niagara Mohawks' SC-3A tariff, which prices all metered 
usage at transparent market prices, led many to speculate that customer price response would be different. Overall, these tariff design differences do not seem to be very influential.

Overall, the model explains 50\% of the variation in usage, measured as changes in the ratio of peak to off-peak energy. This is a robust result considering that the only explanatory variables included in the GL model are the price ratio and weather. A test of significance rejects the hypothesis that all estimated parameters are equal to zero. The estimated model parameters and statistical properties are discussed in full in Appendix C.

The sector-level elasticities of substitution derived from the GL model are displayed in Table 3-3 along with corresponding results from the CES model estimated in the first phase of this study (Goldman et al. 2004). The GL estimates generally comport with the earlier results. The biggest difference is that the manufacturing sector has the highest substitution elasticity value under the GL specification, followed by the government/education sector, the converse of what we found previously. This difference can be explained as follows:

1) a GL model was used, in contrast to the more restrictive CES functional form,

2) the GL model was estimated at the individual customer level, while the CES model was only estimated at the sector level in the first phase,

3) more customers were included in this phase (119 compared to 30 in the final phase 1 model), ${ }^{40}$ and

4) a longer time series of data was available (the summers of 2000 through 2004, compared to only 2001 through 2003 in the first phase).

Table 3-3. Phase 1 and Phase 2 Elasticity of Substitution Results

\begin{tabular}{|c|c|c|c|c|}
\hline \multirow[t]{2}{*}{ Business Category } & \multicolumn{2}{|c|}{$\begin{array}{l}\text { Phase 1: } \\
\text { CES model }^{\mathrm{a}}\end{array}$} & \multicolumn{2}{|c|}{$\begin{array}{l}\text { Phase 2: } \\
\text { GE model }\end{array}$} \\
\hline & $\mathbf{N}$ & $\begin{array}{l}\text { Average } \\
\text { substitution } \\
\text { elasticity }\end{array}$ & $\mathbf{N}$ & $\begin{array}{l}\text { Average } \\
\text { substitution } \\
\text { elasticity }\end{array}$ \\
\hline Government/education & \multirow{2}{*}{11} & \multirow{2}{*}{0.16} & 34 & 0.10 \\
\hline Public Works & & & 17 & 0.02 \\
\hline Commercial/retail & \multirow{2}{*}{9} & \multirow{2}{*}{0.07} & 16 & 0.06 \\
\hline Healthcare & & & 8 & 0.04 \\
\hline Manufacturing & 10 & 0.12 & 44 & 0.16 \\
\hline Total & 30 & 0.14 & 119 & 0.11 \\
\hline
\end{tabular}

${ }^{\mathrm{a}} \mathrm{CES}=$ Constant Elasticity of Substitution

${ }^{\mathrm{b}} \mathrm{GL}=$ Generalized Leontief

We speculate that restricting the substitution elasticity to be constant over all price ranges in the CES analysis obscured underlying price response behavior, which the GL model

\footnotetext{
${ }^{40}$ Because of the model specification used in Phase 1, only customers with both usage and survey data available could be included in the analysis.
} 
captures more effectively. ${ }^{41}$ Moreover, the GL specification provides for a more robust characterization of how customers respond to prices.

\subsubsection{Distribution of Individual Customer Elasticities}

The distribution of elasticity estimates among the 119 modeled customers is shown in Figure 3-3. About 27\% of the customers are completely non-responsive - their elasticities are zero. Such customers use peak and off-peak electricity in fixed proportions, regardless of electricity prices (see section 3.1.1). Another $8 \%$ have elasticities that are very small (less than 0.01 ).

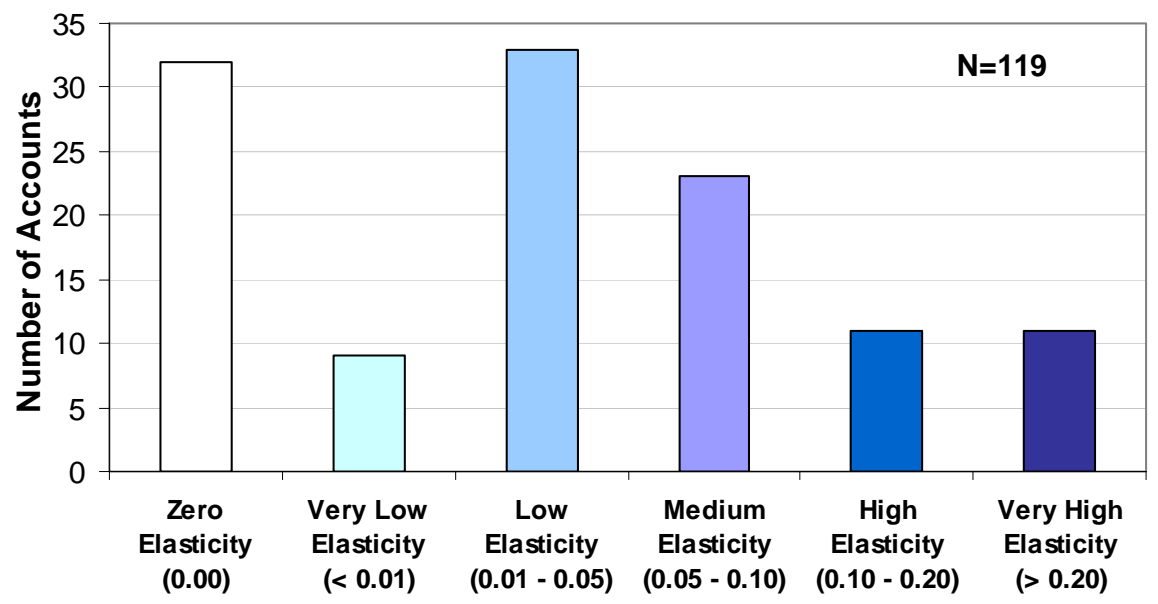

Figure 3-3. Distribution of Accounts by Elasticity of Substitution

Another 28\% of customers exhibit very modest response - their elasticities are between 0.01 and 0.05 . The remaining $37 \%$ have elasticities above 0.05 . Nearly half of this group (20 customers, or $18 \%$ of the 119 customer population) exhibit average elasticities of substitution above 0.10 . This small group of customers provides $75-80 \%$ of the overall price response.

SC-3A customers' price-responsiveness is distributed in almost equivalent proportions in terms of load (Figure 3-4) as in customer numbers (Figure 3-3). This finding - that there is no discernable correlation between customer size and price responsiveness - refutes the notion that larger customers are more price response than smaller customers within the large commercial/industrial class. Some customers with high peak demand are nonresponsive, and some with relatively low peak demand are quite responsive. ${ }^{42}$

\footnotetext{
${ }^{41}$ A comparison of the GL estimates with those of the CES specification using the same 119 firms reveals that at the mean of the data the differences are minor.

${ }^{42}$ SC-3A customers' summer maximum demands range from about $2 \mathrm{MW}$ to over 20MW. The average maximum demand is $\sim 4.3 \mathrm{MW}$.
} 


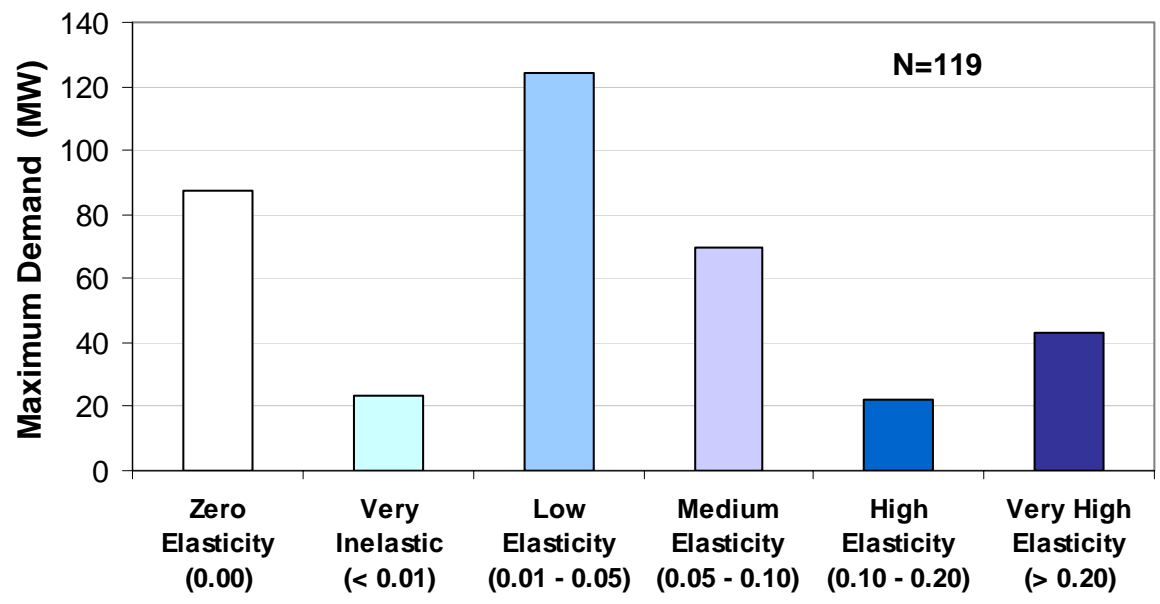

Figure 3-4. Distribution of Load by Elasticity of Substitution

Some SC-3A customers, in addition to facing daily prices, were enrolled in NYISO demand response programs that pay them to reduce load on very short (two-hour) notice. Categorizing customers by NYISO program enrollment and substitution elasticity (Figure 3-5) provides insights into whether particularly price-responsive customers are more likely to be attracted to these programs. The results are somewhat surprising. The customers with the highest elasticities of substitution show disproportionately high levels of participation, as we might expect. However, some customers with relatively low elasticities of substitution (under 0.05) enrolled in the NYISO programs, as did a few with no measured price response at all.

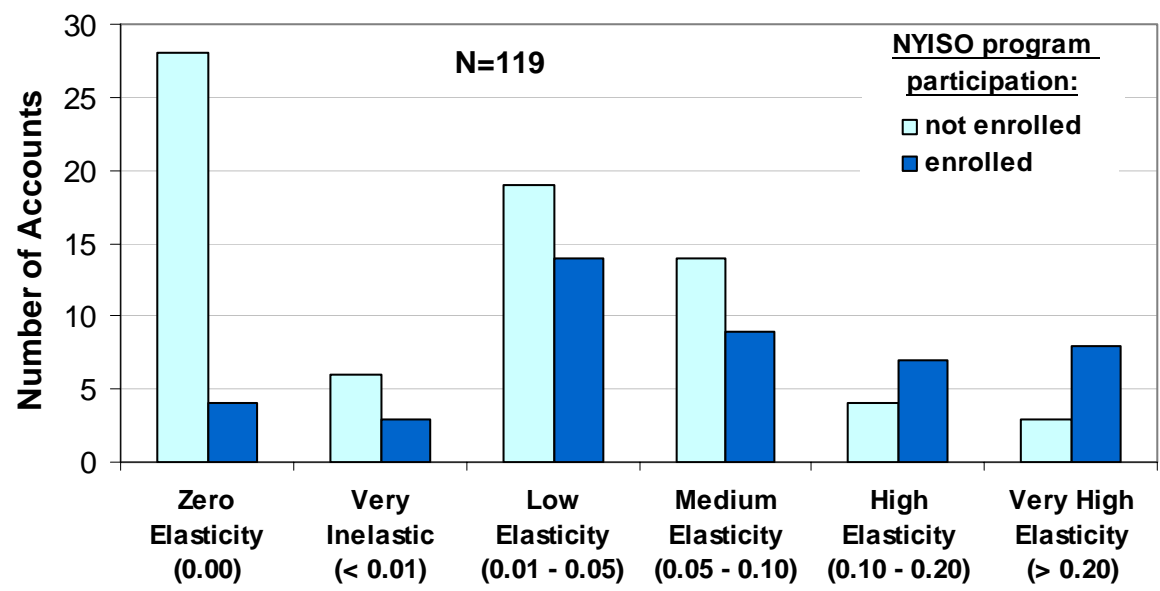

Figure 3-5. Distribution of Accounts by Elasticity of Substitution and NYISO DR Program Participation

These somewhat contradictory results may be explained in several ways. First, if customers respond by foregoing load (rather than shifting), we might observe low elasticities due to the nature of the substitution elasticity, which underestimates response from discretionary load curtailments (see section 3.1). Second, some customers may be 
enrolled in the NYISO EDRP program but not have curtailed when events were called during the study period, and not have responded to SC-3A prices either. Third, others may have responded to isolated NYISO events but not to SC-3A prices on other days, resulting in small elasticity estimates. Some analysts have advocated against paying for load curtailments through DR programs, arguing that customers on RTP face the same financial incentives to curtail when prices rise high enough. Yet we know from two years of surveys and interviews that some SC-3A customers that respond to NYISO events do not respond to prices. For some, the additional price incentive makes responding worthwhile when the SC-3A price alone does not. But many are willing to respond to NYISO events for other reasons altogether (e.g., to help preserve system reliability) and are less interested in monitoring and responding to SC-3A prices. This is discussed in more detail in Chapter 4. Finally, NYISO events and high SC-3A are highly coincident and may confound results (see section 3.3.8).

\subsubsection{Impact of Weather on Peak Load and Price Response}

As described in section 3.2.2, we included two weather variables in the GL model. Table 3-4 indicates the number of customers for which these variables are significant and the sign of the parameter estimates for those that are significant. The results are somewhat mixed. The weather intercept variable, which describes correlations between weather and customers' electricity demand, was statistically significant for about half of the 119 customers, and most of the significant parameters were positive. The slope shifter variable, which measures the effect of weather on the intensity of price response, was significant for $\sim 27 \%$ of customers and in most cases was negative.

Table 3-4. Significance of Weather in Influencing Customers' Load and Price Response

\begin{tabular}{|c|c|c|c|c|c|c|}
\hline \multirow[t]{3}{*}{ Business Category } & \multicolumn{3}{|c|}{$\begin{array}{l}\text { Impact of Weather on Demand } \\
\text { (weather intercept variable) }\end{array}$} & \multicolumn{3}{|c|}{$\begin{array}{l}\text { Impact of Weather on Price } \\
\text { Response } \\
\text { (weather slope shifter variable) }\end{array}$} \\
\hline & \multicolumn{2}{|c|}{$\begin{array}{l}\text { statistically } \\
\text { significant }^{\mathrm{a}}\end{array}$} & \multirow[t]{2}{*}{$\begin{array}{l}\text { statistically } \\
\text { insignificant }\end{array}$} & \multicolumn{2}{|c|}{$\begin{array}{l}\text { statistically } \\
\text { significant }^{\mathrm{a}}\end{array}$} & \multirow[t]{2}{*}{$\begin{array}{l}\text { statistically } \\
\text { insignificant }\end{array}$} \\
\hline & positive & negative & & positive & negative & \\
\hline Manufacturing & 7 & 3 & 34 & 2 & 7 & 35 \\
\hline Government/education & 22 & 1 & 11 & 0 & 8 & 26 \\
\hline Commercial/retail & 12 & 1 & 4 & 3 & 4 & 10 \\
\hline Healthcare & 6 & 0 & 2 & 1 & 3 & 4 \\
\hline Public works & 5 & 1 & 10 & 0 & 4 & 12 \\
\hline Total & 52 & 6 & 61 & 6 & 26 & 87 \\
\hline
\end{tabular}

a $10 \%$ level of statistical significance

The impact of these estimated parameter values on the substitution elasticity is not straightforward. The elasticities are derived from a complex formulation of the GL estimated parameters, and are calculated for each customer and each day; they depend on daily price and customer load quantities, not average values. Consequently, the effect of a 
positive weather parameter estimate could be positive or negative, depending on the other parameters in the model. ${ }^{43}$

We can, however, illustrate the combined, overall effect of weather on price response. Table 3-5 shows elasticities for each business sector on normal (cool) days and on hotter than normal days (defined by an average THI value greater than 85 during the 2-5 p.m. peak period). Overall, hot weather is associated with an increase in the average elasticity of 0.109 to 0.113 (about 3.5\%). But the sector-level results show that this difference in response is largely due to government/education and commercial/retail customers that typically operate in office buildings or campus settings with substantial cooling loads. For the other business sectors, there is no or negligible difference in sector-level elasticities between hot and cool days.

Table 3-5. Impact of Weather on Price Response by Business Sector

\begin{tabular}{|l|l|l|l|}
\hline Business Category & \multirow{2}{*}{} & \multicolumn{2}{|l|}{$\begin{array}{l}\text { Average Elasticity of } \\
\text { Substitution }\end{array}$} \\
\cline { 3 - 4 } & & cool days & hot days $^{\mathrm{b}}$ \\
\hline Manufacturing & 44 & 0.16 & 0.15 \\
\hline Government/education & 34 & 0.10 & 0.12 \\
\hline Commercial/retail & 16 & 0.05 & 0.10 \\
\hline Healthcare & 8 & 0.04 & 0.04 \\
\hline Public works & 17 & 0.02 & 0.02 \\
\hline Total & $\mathbf{1 1 9}$ & $\mathbf{0 . 1 0 9}$ & $\mathbf{0 . 1 1 3}$ \\
\hline
\end{tabular}

${ }^{a}$ Average Temperature Heat Index (THI) from 2-5 p.m. $<85$

${ }^{\mathrm{b}}$ Average THI from 2-5 p.m. > 85

Government/education customers, on average, increase their price response by about 20\% on hot days compared to cooler days and commercial/retail customers' average elasticity doubles. Thus, while these service-oriented customers may indeed be temperaturesensitive and increase their loads on hot days (to meet greater cooling requirements), their increased price response outweighs this effect substantially. Hot days are correlated with both high SC-3A prices and NYISO DR program events and these signals appear to override these customers' need for increased cooling, at least within the range of temperature and prices observed in upstate New York.

\subsubsection{Some Customers Can be "Priced-Out” of Peak Electricity Usage}

The flexibility of the GL model enables us to identify customers that reach a relative price threshold at which their usage of peak electricity is effectively eliminated, or "priced out". ${ }^{44}$ In other words, at some point, as prices rise, no more substitution is possible, and the price ratio drives peak usage to zero (see section 3.1.1). Five customers

\footnotetext{
${ }^{43}$ See Appendix B for the specification of the derivation of substitution elasticities from estimated GL model parameters. The complexity of the relationship does not allow us to test for significance using the conventional tests. Moreover, even proxy, bootstrap estimation techniques are computationally burdensome.

${ }^{44}$ See Appendix B for a discussion of how such customers can be identified and their price-out ratios estimated from their GL model parameters.
} 
in our sample exhibit this characteristic - one commercial/retail firm and four government/education customers (Table 3-6).

Table 3-6. Characteristics of Customers that can be "Priced Out" of Peak Usage

\begin{tabular}{|l|l|l|l|l|}
\hline Customer & Business Category & Elasticity & $\begin{array}{l}\text { Onsite } \\
\text { Generation? }\end{array}$ & $\begin{array}{l}\text { Peak to off-peak } \\
\text { price ratio } \\
\text { threshold }\end{array}$ \\
\hline 1. & Commercial/retail & Very high & Yes & 7 \\
\hline 2. & Government/education & Very high & Yes & 15 \\
\hline 3. & Government/education & Very high & Yes & 95 \\
\hline 4. & Government/education & Very high & Yes & $>100$ \\
\hline 5. & Government/education & Very high & Yes & $>100$ \\
\hline
\end{tabular}

All five customers exhibit high levels of price response (average elasticities over 0.20). The commercial/retail firm is priced out at a peak to off-peak price ratio of seven. Over the study period, the price ratio never exceeded five, but it is possible for NYSIO prices to reach $\$ 1,000 / \mathrm{MWh}$. Under these conditions the price ratio could well reach 10 . Based on the character of its estimated average substitution elasticity, this commercial/retail firm would be expected to reduce its peak electricity usage to virtually nothing if this occurred.

The four government/education facilities show a wide range in their "price-out" price ratios, from 15 to well over 100 . All of these customers report having on-site generation, but not all indicated that they use it to respond to prices (see section 4.1.3). The very high prices that would be necessary for these four customers to be priced out are unlikely under the current NYISO market structure (e.g., \$1,000/MWh cap).

\subsubsection{The Character of Price Response}

The first of the two regression models we estimated used the price ratio and customers' usage as a percentage of maximum demand as variables to explain differences in customers' estimated elasticities on different days. By including interactive terms made up of the product of business sector dummy variables with these factors, the effects of nominal prices and customers' demand levels on price response were estimated for each business sector (see Appendix B for details). ${ }^{45}$

Data for all 119 customers were used to estimate the parameters of this model. The results are provided in Table 3-7. Because the equation in its initial specification exhibited autocorrelation, an AR(1) process was incorporated into the model. The high degree of fit $\left(\mathrm{R}^{2}=0.99\right)$ is due in large part to this correction for autocorrelation. The estimated coefficients are all significantly different from zero $(t>1)$.

\footnotetext{
${ }^{45}$ In each case, only four business-sector parameters are reported - the omitted sector serves as the reference case. We deliberately chose the sector with the lowest parameter estimate as the reference case to facilitate comparison of results (all estimated parameters are positive).
} 
Table 3-7. Character of Price Response: Regression Results

\begin{tabular}{|l|l|l|}
\hline Variable & $\begin{array}{l}\text { Parameter } \\
\text { estimate }\end{array}$ & t-Statistic \\
\hline Peak/off-peak price ratio (PR) & -0.0028 & -8.92 \\
\hline Manufacturing * PR & 0.0016 & 2.34 \\
\hline Government/education * PR & 0.0241 & 3.44 \\
\hline Commercial/retail * PR & 0.0199 & 4.22 \\
\hline Public works * PR & 0.0010 & 2.80 \\
\hline Customer's daily \% of maximum demand (MD) & -0.0513 & -1.99 \\
\hline Manufacturing * MD & 0.0487 & 1.89 \\
\hline Commercial/retail * MD & 0.0646 & 2.43 \\
\hline Healthcare * MD & 0.0514 & 2.00 \\
\hline Public works * MD & 0.0509 & 1.97 \\
\hline AR(1) & 0.4657 & 8.82 \\
\hline $\begin{array}{l}\mathrm{N}=119 \text { customer accounts } \\
\mathrm{R}^{2}=0.99 \\
\text { Durbin Watson statistic = 2.13 }\end{array}$ & \\
\hline
\end{tabular}

${ }^{\mathrm{a}} \mathrm{AR}(1)$ is an autocorrelation correction

Using the estimated coefficients from Table 3-7, the effects of changes in the price ratio and in usage relative to maximum demand are summarized in Table 3-8. For each business sector, the change in elasticity in response to a unit increase in the price ratio (e.g., from 2:1 to 3:1) and a unit increase in customers' load as a percent of their summer peak demand are shown relative to each sector's un-weighted average elasticity. ${ }^{46}$ This provides an indication of the extent to which elasticities are larger for higher nominal peak prices than for lower ones. Positive percentage changes indicate that price response increases as the nominal level of peak prices increases or as customers' approach their peak demand. Negative percentage changes indicate that price responsiveness falls in response to these factors.

The commercial/retail and government/education sectors both exhibit increased price responsiveness at higher price ratios: the former increases by $14.8 \%$ and the latter by $13.4 \%$ for a $50 \%$ increase in the price ratio. Because high price ratios are correlated with high nominal prices in our study period, these customers can be expected to decrease peak usage more at very high market prices than at moderately high prices. ${ }^{47}$ Healthcare and public works customers, on the other hand, show the opposite result; their price response drops by $8.1 \%$ and $9.5 \%$, respectively, as the price ratio increases by $50 \%$. The manufacturing sector's price response appears to be almost immune to changes in the price ratio.

\footnotetext{
46 The un-weighted sector-level elasticities are somewhat different from the load-weighted values reported in section 3.3.2. This reflects differing distributions of customers with respect to elasticity and peak demand within each sector. For the purposes of evaluating load response from various business sectors, the load-weighted values in section 3.3.2 should be used.

${ }^{47}$ We also estimated a similar regression using nominal peak prices rather than the price ratio as a variable, and found similar results, though the model parameters were of less significance. These results are included in Appendix C.
} 
Table 3-8. Marginal Changes in Elasticities of Substitution by Business Category

\begin{tabular}{|c|c|c|c|c|c|c|}
\hline \multirow[t]{2}{*}{ Business Category } & \multirow[t]{2}{*}{$\mathbf{N}$} & \multirow[t]{2}{*}{$\begin{array}{l}\text { Average } \\
\text { elasticity }\end{array}$} & \multicolumn{2}{|c|}{$\begin{array}{l}\text { Marginal change in } \\
\text { peak to off-peak } \\
\text { price ratio }^{\text {a }}\end{array}$} & \multicolumn{2}{|c|}{$\begin{array}{l}\text { Marginal change in } \\
\text { customers' demand } \\
\text { relative to their } \\
\text { maximum }^{\text {b }}\end{array}$} \\
\hline & & & elasticity & $\begin{array}{l}\text { \% diff. } \\
\text { from } \\
\text { average }\end{array}$ & elasticity & $\begin{array}{l}\text { \% diff. } \\
\text { from } \\
\text { average }\end{array}$ \\
\hline Commercial/retail & 17 & 0.115 & 0.132 & $14.8 \%$ & 0.116 & $1.2 \%$ \\
\hline Government/education & 34 & 0.159 & 0.180 & $13.4 \%$ & 0.154 & $-3.2 \%$ \\
\hline Healthcare & 8 & 0.035 & 0.032 & $-8.1 \%$ & 0.035 & $0.0 \%$ \\
\hline Manufacturing & 44 & 0.087 & 0.086 & $-1.4 \%$ & 0.087 & $-0.3 \%$ \\
\hline Public works & 16 & 0.018 & 0.017 & $-9.5 \%$ & 0.018 & $-0.2 \%$ \\
\hline
\end{tabular}

${ }^{a}$ E.g., a change in the price ratio from 2:1 to $3: 1$

${ }^{b}$ E.g., a change in a customer's demand from $60 \%$ to $70 \%$ of its maximum demand measured over the study period.

As a result, we infer that on days with very high peak prices, government/education and commercial/retail customers curtail peak usage more than they would on a moderately priced day. From another perspective, if the objective were to induce these customers to curtail (e.g., under a critical peak pricing program), higher price differentials would achieve a greater response. Conversely, higher peak prices seem to reduce the response of the healthcare and public works customers, so using the same prices to induce peak load reductions may work somewhat against this objective for these sectors, which already exhibit relatively low elasticities.

The impact on customers' elasticities of the size of their load relative to their summer peak usage is very small for all sectors. The greatest impact is observed for government/education customers, whose ability to respond is reduced by only $3 \%$ for each incremental $10 \%$ increase in their demand. ${ }^{48}$ This overall result is in contrast to the notion that as customers approach their peak demand they become less price-responsive.

\subsubsection{Drivers to Price Response}

Our second regression quantifies the impact of several customer characteristics and circumstances on estimated price response (see section 3.2.2). Table 3-9 presents the estimated parameters for this relationship. The $\mathrm{R}^{2}$ value indicates that the explanatory variables included in this equation account for about a third of the variation in the average elasticities of substitution for the 55 customers included in the regression. ${ }^{49}$

\footnotetext{
${ }^{48}$ These incremental changes are additive, so an average government/education customer is $15 \%$ less responsive when operating at $50 \%$ of peak demand than at $100 \%$ of peak demand. Taken in aggregate, these results seem counterintuitive in that government/education customers are more responsive on hot days and as prices rise, but are less responsive as they approach their maximum demand. This can be rationalized by observing the lack of coincidence of high prices, hot days, and high loads for these customers - a finding that runs counter to conventional wisdom for this class of customers.

${ }^{49}$ White's statistic indicates that the error terms do not exhibit heteroskedasticity, so no correction was required.
} 
Table 3-9. Drivers to Price Response: Regression Results

\begin{tabular}{|l|l|l|}
\hline Variable & $\begin{array}{l}\text { Parameter } \\
\text { estimate }\end{array}$ & t-Statistic \\
\hline Intercept & 0.1976 & 0.88 \\
\hline Manufacturing & 0.0155 & 0.17 \\
\hline Government/education & 0.1227 & 1.09 \\
\hline Commercial/retail & 0.1640 & 1.34 \\
\hline Healthcare & 0.0590 & 0.37 \\
\hline EDRP $^{\mathrm{a}}$ participant & 0.1794 & 2.53 \\
\hline ICAP/SCR $^{\mathrm{b}}$ participant & -0.0610 & -0.63 \\
\hline Monitor prices frequently & 0.0579 & 0.52 \\
\hline Installed EMCS & -0.1489 & -2.46 \\
\hline Installed onsite generation & 0.0262 & 0.45 \\
\hline Increase in usage over last 5 years & 0.0811 & 1.34 \\
\hline Average peak to off-peak load ratio & -1.3114 & -0.94 \\
\hline White's test statistic & 52 & 0.10 \\
\hline $\mathrm{N}=55$ customer accounts & \\
$\mathrm{R}^{2}=0.31$ & \multicolumn{2}{|l}{} \\
\hline
\end{tabular}

${ }^{a}$ EDRP = Emergency Demand Response Program

${ }^{\mathrm{b}}$ ICAP/SCR = Installed Capacity/ Special Case Resource Program

${ }^{\mathrm{c}}$ EMCS $=$ energy management control system

In general, the estimated parameter values yield limited insight into the factors that explain differences in customers' ability to reduce peak load in response to price. While many of the coefficients are of the expected sign, only two - EDRP participation and the presence of energy management control systems (EMCS) at customers' facilities - are statistically different from zero $(\mathrm{t}>2)$. The lack of significance of other factors could either indicate that they have no effect on customers' elasticities or that the sample size was simply too small to derive a statistically robust model.

The negative coefficient for the EMCS variable is counterintuitive. It suggests that customers with these systems are less able to shift load in response to higher relative peak prices, on average, than customers that do not. This result, however, has been consistent throughout this study (Goldman et al. 2004), and comports with other studies of price response among customers participating in NYISO demand response programs statewide (Neenan et al. 2003). In surveys and interviews, many customers indicated that, for them, the primary purpose for installing an EMCS system is to control maximum demand or achieve energy-efficiency objectives, not short-term price response (see section 4.1.3). While these systems could be adapted, in many cases quite easily, to accommodate responding to SC-3A hourly prices, most customers either do not realize that capability, or have not found exercising it to be worthwhile.

The coefficients on the variables for participation in NYISO's two demand response programs are of different signs. The results for EDRP are intuitive: participation has a positive and significant impact on elasticity, indicating that EDRP participation is correlated with higher than average price responsiveness. However, because of the coincidence of NYISO events with high SC-3A prices during the study period, it is difficult to disentangle how much of the observed response is attributable to EDRP and how much to RTP. But we can infer from the parameter estimate that EDRP, through its 
financial incentives or the opportunity to help avoid system emergencies (see section 4.1.2), supplements the price response elicited by SC-3A prices.

NYISO calls on EDRP participants with two hours' notice and pays those that curtail the greater of $\$ 0.50 / \mathrm{kWh}$ or the prevailing market price. Response is voluntary, so no penalty applies for failure to curtail. We expected ICAP/SCR participation to result in at least the same, if not greater, price response than that afforded by EDRP participation because the program not only offers curtailment payments (like EDRP), but levies penalties for customers that do not meet their curtailment obligations. Yet the estimated coefficient on the variable for participation in ICAP/SCR is negative and insignificant. In other words, the specification finds no (or at best a weak) relationship between the imposition of high penalty prices and price response. For ICAP/SCR, the coincidence of the curtailment inducement and the SC-3A prices is even higher than for EDRP. Enrolled customers receive SCR event alerts at about the same time they receive SC-3A prices - midafternoon the previous day. We suspect that while in practice the SCR inducement actually increases price response (because it carries a non-compliance penalty), the effects are so intermingled with coincident price signals that separating them is not possible in a statistical sense.

In summary, the coincidence of high day-ahead prices and the declaration of NYISO demand response program events makes it impossible to sort out the relative effects of these signals. Yet we make the following observation: the NYISO programs are operated to preserve system reliability, while SC-3A prices provide economic signals. Concerns about providing double payments to customers that are simultaneously enrolled in NYISO programs and face market prices, under the presumption that they had already planned to curtail, are unwarranted because these programs elicit complementary yet distinct responses that serve equally distinct objectives (avoiding blackouts and reducing wholesale market prices). Moreover, excluding customers from NYISO programs that routinely face and respond to prices may encourage them to hedge against price volatility if the cost of doing so is less than the expected benefits of NYISO program participation. This would only serve to remove the economic benefits of their everyday price response from the system.

\subsection{Aggregate Load Response}

To portray the overall impact of SC-3A customers' price response, the elasticities of substitution for individual customers were used to simulate their aggregate peak load reductions at various price ratios. ${ }^{50}$ The results are illustrated in Figure 3-6. At the highest peak to off-peak price ratio observed in the SC-3A price data - 5:1 - the 119 modeled customers are estimated to reduce their peak-period usage by about $50 \mathrm{MW}$, a $10 \%$ reduction from their typical usage. SC-3A customers' aggregate load response is nonlinear - it increases as the price ratio increases but at a decreasing rate, especially at ratios above 3:1. This occurs primarily because the relationship between price ratios and the elasticity of substitution is negative for $\sim 57 \%$ of the customers (see Table $3-8$ ). As the price ratio increases, the elasticity of substitution decreases modestly among

\footnotetext{
${ }^{50}$ See Appendix B for a discussion of how load reductions were derived from substitution elasticities.
} 
manufacturing, healthcare, and public works customers. The overall level of load response therefore increases for higher price ratios, but the rate of change for higher and higher price ratios becomes smaller and smaller.

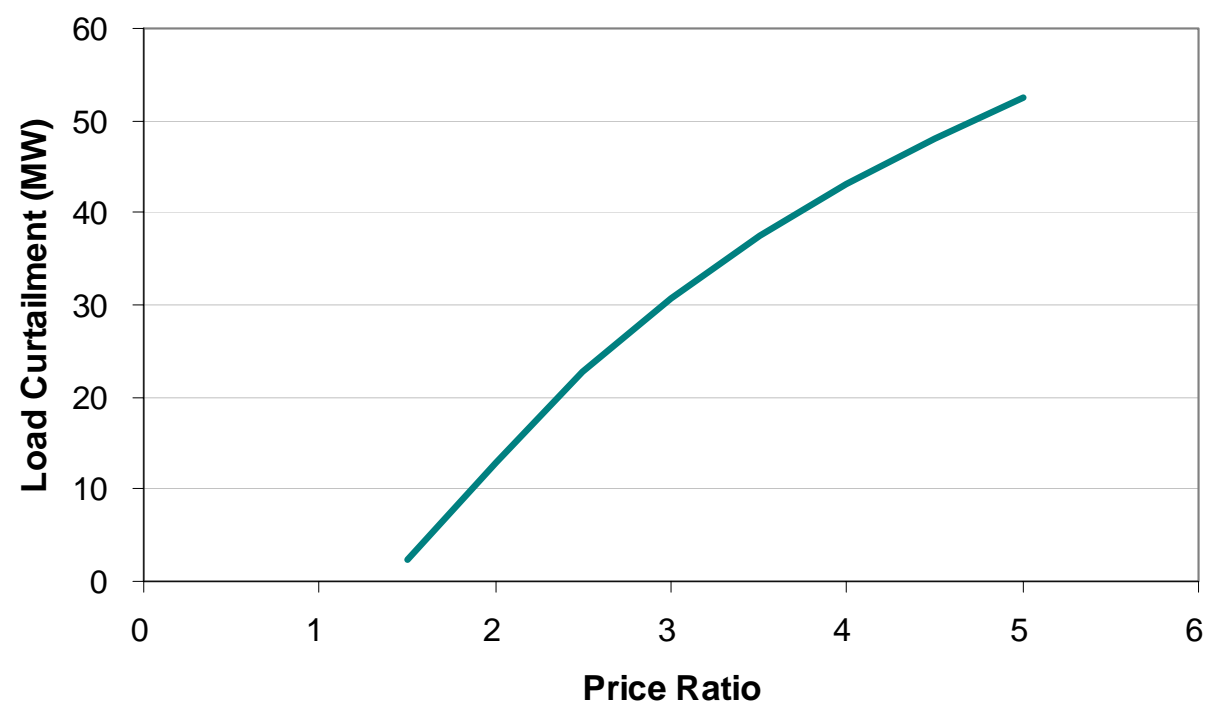

Figure 3-6. Reduction in 119 SC-3A Customers' Peak Demand at Various Price Ratios

What would the response be if prices were much higher (i.e., if the NYISO price cap of $\$ 1,000 / \mathrm{MWh}$ were raised or eliminated, resulting in price ratios of 10 or more)? The shape of the aggregate response curve suggests that price response would increase with higher price ratios. However, as the price climbs higher, certain customers' elasticities would be further reduced resulting in fewer and fewer additional megawatts of load reduction. At some price level, these customers would approach the point where they would simply exhaust their potential and thereafter be unable to provide additional load reductions. In addition, if price volatility increased, it is conceivable that more customers might decide to fully hedge themselves, reducing or eliminating their incentives to respond to high prices and offsetting some or all of the increases in aggregate demand response at higher price levels.

\subsection{Summary}

The results of this empirical research indicate that the traditional classification of customer price response according to business sector can be misleading. While manufacturing customers have the largest sector-level elasticity, and 24\% have elasticity values above 0.10 (see Table 3-10), individual manufacturing customers' elasticities are distributed over all response intensity categories, including $27 \%$ that are not able to respond at all. 
Table 3-10. Price-responsiveness of Customers by Sector

\begin{tabular}{|l|l|l|l|l|l|l|l|}
\hline Business Category & $\mathbf{N}$ & \multicolumn{6}{|l|}{ Price Response (elasticity): } \\
\cline { 3 - 9 } & & $\begin{array}{l}\text { none } \\
(0.00)\end{array}$ & $\begin{array}{l}\text { very low } \\
(0.00- \\
0.01)\end{array}$ & $\begin{array}{l}\text { low } \\
\left(\begin{array}{l}0.01- \\
0.05)\end{array}\right.\end{array}$ & $\begin{array}{l}\text { moderate } \\
\left(\begin{array}{l}0.05- \\
0.10)\end{array}\right.\end{array}$ & $\begin{array}{l}\text { high } \\
(0.10- \\
0.20)\end{array}$ & $\begin{array}{l}\text { very } \\
\text { high } \\
(>0.20)\end{array}$ \\
\hline Manufacturing & 44 & $27 \%$ & $11 \%$ & $25 \%$ & $9 \%$ & $16 \%$ & $11 \%$ \\
\hline Government/education & 34 & $18 \%$ & $3 \%$ & $21 \%$ & $35 \%$ & $9 \%$ & $15 \%$ \\
\hline Commercial/retail & 16 & $31 \%$ & $13 \%$ & $25 \%$ & $25 \%$ & $6 \%$ & $0 \%$ \\
\hline Healthcare & 8 & $13 \%$ & $13 \%$ & $63 \%$ & $13 \%$ & $0 \%$ & $0 \%$ \\
\hline Public works & 17 & $35 \%$ & $12 \%$ & $35 \%$ & $12 \%$ & $0 \%$ & $6 \%$ \\
\hline
\end{tabular}

Government/education customers show a wide range in price responsiveness. Eighteen percent of individual customers have elasticities of zero, yet one-quarter exhibit elasticities above 0.10 , almost as many as in the manufacturing sector. The healthcare and public works sectors have the lowest sector-level substitution elasticities, and there are no customers in these sectors with elasticities over 0.10 . Clearly, estimating the price response potential of large customers by business activity alone misrepresents the inherent price response potential for many individual customers.

Statistical model results indicate that customers in the government/education and commercial/retail sectors are more responsive as peak prices increase relative to off-peak prices. In the other sectors, the reverse is true, although the size of the effect is not as large. There is also limited evidence that the ability to respond to price is abated as customers approach their maximum demand.

Our efforts to distinguish customer characteristics that are drivers to price response were less productive, in part due to the relatively small sample of customers that could be modeled. However, the data collected from surveys administered to these customers provide another, qualitative, means to characterize who responds to prices, and why. That inquiry is taken up further in Chapter 4. 


\section{Customer Adaptation to Default RTP Service}

In Chapter 3, we quantified customer's price responsiveness using a customer demand model specification and characterized some of the factors that influence their elasticities of substitution of off-peak for peak electricity. However, the empirical model cannot fully characterize the complexity of customer behavior, as it does not account for some important aspects of price response. Some factors that are basically qualitative in nature (such as barriers to price response) are not easily quantified. Moreover, the practical limitations on gathering information on customer characteristics, operating practices and firm output, along with survey non-response, constrains the empirical specification of the customer demand model.

In this chapter, we supplement model results with information that addresses these issues and provides context for empirical results. This is accomplished using data on customer adaptation to RTP synthesized from two years of customer surveys and interviews. We begin with customers' self-reported load response strategies, the signals they respond to and the deployment and use of enabling technologies. Next, we link individual customers' estimated substitution elasticities to their specific circumstances, focusing on the attributes and strategies of customers that are particularly price-responsive compared to those that are not price-responsive. Then, we discuss barriers to price response reported by customers. Finally, we discuss trends in SC-3A customer's commodity supply choices and hedging options over time as they relate to customer's actions undertaken to reduce or eliminate exposure to hourly prices.

\subsection{Self-Reported Response Strategies and Use of Enabling Technologies}

In Chapter 3, we estimated price response quantitatively using a GL model and linked elasticity estimates to various customer characteristics and circumstances. However, the GL model does not describe price response qualitatively - it does not describe how customers respond. Rather, it assumes that customers respond in one specific way - by shifting load that would otherwise have been scheduled during peak hours to the off-peak hours of the same day. As a result, price response from other possible load response strategies, shifting load to subsequent days, foregoing consumption altogether (without making it up later), or transferring load from the grid to onsite generation, may be underestimated by the GL model (see section 3.1). In addition, the model assumes that all response is to prices, yet SC-3A customers have seen other signals to curtail, including declared NYISO emergencies and, on one occasion during our study period, a call from the state Governor's office to curtail.

We explored these qualitative aspects of load response through the analysis of survey questions and customer interviews. Together, these results provide context for empirical load response results, and also provide a means to compare how well the model's predictions about individual customers' price response match customers' self-reported behavior (see section 4.2). 


\subsubsection{Load Response Strategies}

In our customer survey, customers self-reported three types of load response strategies: shifting load from one time period to another (22\% of surveyed customers), foregoing electricity use completely and not making it up at another time (45\%) and supplying load with onsite generation (16\%) (see Figure 4-1). ${ }^{51}$ Some customers report more than one response strategy $-6 \%$ have both shifted and foregone load and $7 \%$ have both foregone load and used onsite generation. Almost 30\% of the 76 customers surveyed indicate that they are unable to respond at all. This is substantially lower than the $54 \%$ of survey respondents that indicated they could not curtail in our previous survey (Goldman et al. 2004).

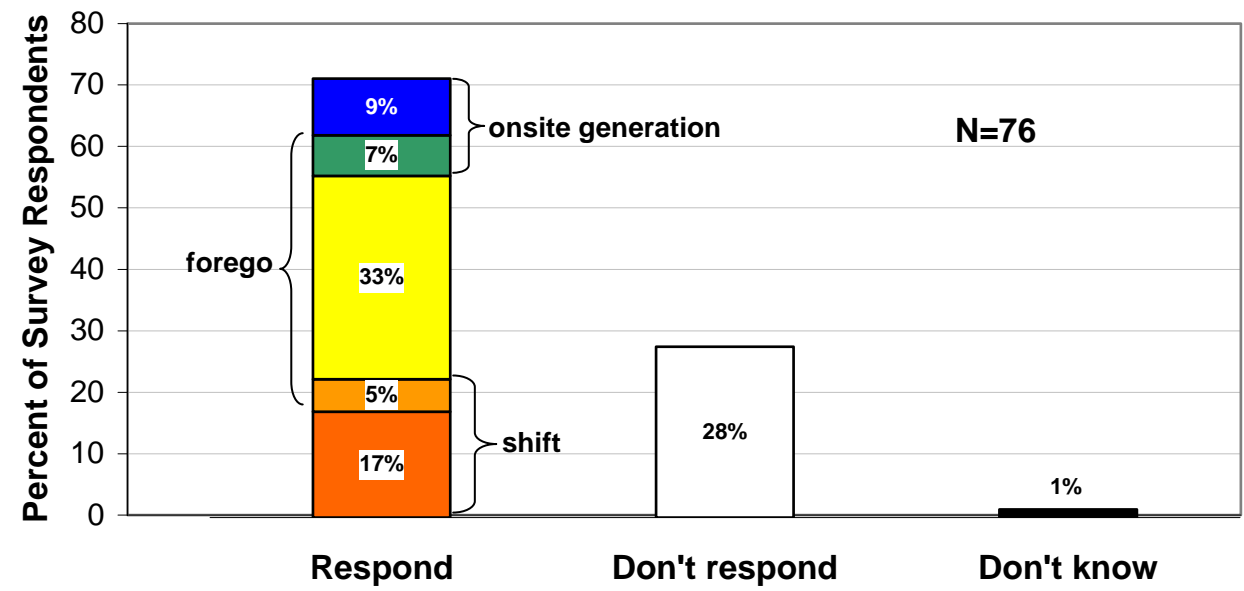

Figure 4-1. Self-Reported Load Response Strategies

Of the 17 customers that reported responding to prices by shifting load, 65\% told us that they typically reschedule that load to the next day (47\%) or a subsequent day (18\%). Only six customers (35\%) said they typically shift to another time the same day. Therefore, among our sample of 76 survey respondents, only $8 \%$ indicated that they respond in the way implicitly assumed by the GL model - by shifting load within the same 24-hour period. This suggests that the GL model results in Chapter 3 may underestimate the actual reduction in peak usage from SC-3A customers' load response on high-priced days.

Among the 34 customers that reported foregoing load, 65\% told us that foregoing discretionary usage has minimal or no impact on their facility’s operations. ${ }^{52}$ Twenty percent reported significant inconvenience or employee discomfort and 9\% indicated that they have to adjust their business operations to accommodate this load response. ${ }^{53}$

\footnotetext{
${ }^{51}$ The question asked about customers' response to any of hourly SC-3A prices, NYISO Emergencies or public appeals to reduce electricity consumption.

52 Twenty-one customers reported slight inconvenience or employee discomfort and one indicated no impact at all.

${ }^{53}$ The remaining 6\% answered "don’t know" to this question.
} 
Different types of customers appear to have adopted different response strategies (see Figure 4-2). Government/education customers are most likely to respond by foregoing load and not making it up later - almost all (83\%) report that they respond in this way. This, along with earlier survey results reported in Goldman et al. (2004) suggest that these customers are typically willing to respond by curtailing lighting, HVAC or plug loads that often do not require rescheduling. Manufacturing customers display the most variety in the types of load response strategies reported, reflecting the diversity of customers included in this category. About one-third of manufacturing customers report that they cannot respond at all.

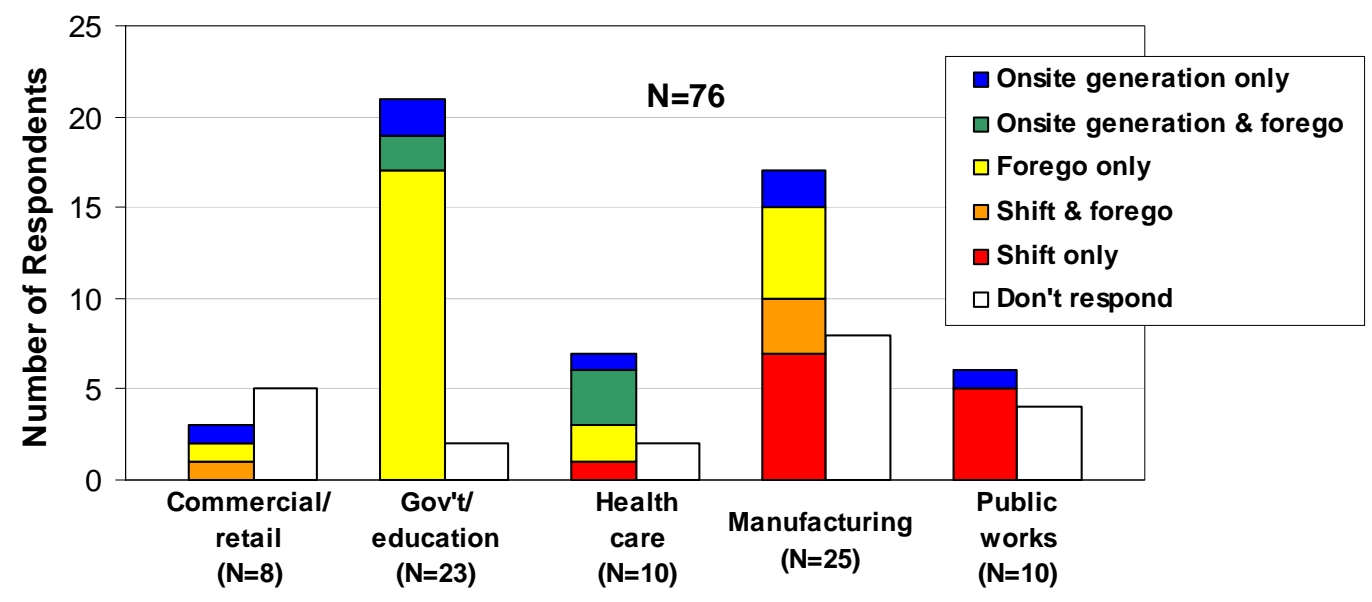

Figure 4-2. Self-Reported Response Strategies by Business Classification

Load shifting is primarily reported by manufacturing customers, but several public works facilities indicated that they can shift load. Based on customer interviews, it appears that most of this response is by water or wastewater treatment facilities that can reschedule pumping operations when prices are high or NYISO calls for emergency curtailments. Onsite generation is reported as a load response strategy by half of healthcare customers; these facilities typically have backup generators installed for power reliability purposes. While some may make use of them when prices are high or NYISO emergencies are called, the elasticities computed for these customers are low (see section 3.3.2). Consistent with their low elasticities, commercial/retail customers are the least likely to report undertaking any response behavior.

\subsubsection{Response to What?}

Day-ahead hourly prices are not the only signals that SC-3A customers were exposed to during the study period. Since 2001, 42\% of SC-3A customers have enrolled in EDRP or ICAP/SCR, NYISO's DR programs that offer customers payments for reducing load when called, for at least one summer (see section 2.1.2). Even customers that are not enrolled in the NYISO programs may be aware of NYISO emergency events, by monitoring the NYISO website or through news broadcasts or public appeals to conserve, and may contribute additional load curtailments. 
We asked customers to tell us which conditions - high hourly prices, NYISO emergency events, public appeals to conserve, or major changes in their facility operations - had caused them to change their electricity use from normal levels or serve load with onsite generation. Of the 76 survey respondents, only 5\% claimed to have responded to high hourly prices; $80 \%$ said they had not and 15\% did not know. Self-reported response to NYISO emergency events was much higher: $60 \%$ claimed to have responded to NYISO events, 37\% said they had not, and 3\% didn't know. ${ }^{54}$ These findings support the significance of EDRP enrollment in explaining price response, but also reveal inconsistencies between self-reported data and other information available to us. For example, only 35\% of surveyed customers have enrolled in NYISO programs, yet $60 \%$ say they respond to calls for curtailments specific to these programs. It is also interesting that while only $5 \%$ of survey respondents say they respond to high prices, we find statistically that almost 50\% have altered load patterns when prices are high. These disparities may indicate that the individuals participating in our survey do not know or do not remember important aspects of their response or are answering the survey strategically. The interplay of coincident signals - high prices, NYISO events and hot weather - probably confuse the matter.

We asked the 46 customers that attested to responding to NYISO emergencies to tell us why they had done so. The most commonly cited reason, not surprisingly, is to earn incentive payments; 29 customers (63\%) gave this reason (see Table 4-1). Here too, their responses contradict what we know about their experience with these programs. Only about half (14) of these customers were enrolled in NYISO programs in 2001, 2002 or 2003, the years when NYISO events were called. Twelve customers that cited this reason were not enrolled in the program during these years. Another three were enrolled but did not receive curtailment payments. ${ }^{55}$ Helping to keep the electric system secure appears to be almost as important to customers as receiving payments; $44 \%$ of enrolled respondents indicated that their organization considers it their civic duty to do so. It is also notable that $44 \%$ of customers responding to NYISO emergencies said they do so at least in part because they coincide with high SC-3A prices. This suggests that some customers may look for external signals that prices are high, rather than specifically monitoring and responding to high SC-3A prices. ${ }^{56}$ Thus, some response appears to be attributable to customers simply being made aware that prices are high through other, coincident events. $^{57}$

\footnotetext{
${ }^{54}$ Fifty-three percent of respondents said they had responded to public appeals. However, since there was only one such event during our study period, and we believe the question may have elicited strategic responses, we are cautious in interpreting this result.

${ }^{55}$ Nonetheless, these customers may have tried to reduce load but not been successful at earning payments.

${ }^{56}$ The results in section 4.3, which deal with how customers monitor prices, support this finding.

${ }^{57}$ In other words, the NYISO programs serve to alert customers that prices are high and thereby trigger reductions. This raises the prospect that price response might be increased by simply providing customers with a way to chose a trigger price, one at which they intend to respond, and sending notice on days when the next day's prices exceed that threshold.
} 
Table 4-1. Reasons for Responding to NYISO Emergency Events

\begin{tabular}{|l|l|}
\hline Reason & $\begin{array}{l}\text { Percent of } \\
\text { Respondents } \\
\text { (N=46) }\end{array}$ \\
\hline To earn EDRP or ICAP/SCR curtailment incentive payments & $63 \%$ \\
\hline To avoid paying penalties for not responding to ICAP/SCR events & $9 \%$ \\
\hline My organization considers it a civic duty to help keep the electric system secure & $59 \%$ \\
\hline NYISO emergencies coincide with high SC-3A prices & $30 \%$ \\
\hline
\end{tabular}

${ }^{a}$ Customers were asked to check all reasons that applied, so responses do not add up to $100 \%$.

\subsubsection{Enabling Technologies}

In the survey, we asked customers about three types of technologies that have been supported by NYSERDA's peak-load reduction programs and that have the potential to assist customers with load response: (1) energy management control systems (EMCS) and/or peak load management (PLM) devices, (2) energy information systems (EIS) that provide near real-time access to facility electricity usage data and (3) onsite generation. Forty-nine percent of customers reported having installed EMCS/PLM devices. Most (59\%) of these systems were installed in 2000 or earlier. EMCS/PLM devices are most commonly installed by government/education facilities. EIS systems were installed by $41 \%$ of survey respondents. Adoption of this technology has been quite recent; $75 \%$ of EIS systems were installed in 2002-2004. Fifty-five percent of customers told us they have onsite generation capacity installed. This technology is most common among healthcare customers, where it is in many cases required by statute or practical considerations.

Despite the potential for these technologies to facilitate price response, their impact on estimated price response is not clearly discernable (see section 3.3.8). While the presence of onsite generation does contribute to higher elasticities, customers that had installed EMCS and/or PLM devices actually had lower substitution elasticities than those that didn't and EIS installation did not appear to contribute one way or another to price response. ${ }^{58}$ These apparently contradictory results are explained by customers' survey responses regarding how they actually use these technologies (see Table 4-2). Only a small number of respondents (7\% to $23 \%$ of customers installing each of the three enabling technology categories) reported using these technologies to respond to high hourly prices.

For example, only $16 \%$ of respondents with EMCS or PLM devices indicated that they use them for short-term price response. The most common uses for these technologies are facility/process automation and reducing overall electricity bills (76\% and 65\% respectively). Many customers also use these systems specifically to reduce peak demand charges. EIS systems are also commonly used for these purposes, as well as for monitoring and analysis of process energy usage to identify potential savings. Only $23 \%$ of customers with these systems use them to respond to high hourly prices.

\footnotetext{
58 The result pertaining to onsite generation is not statistically significant.
} 
Table 4-2. How SC-3A Customers Use Enabling Technologies

\begin{tabular}{|l|l|l|l|}
\hline \multirow{2}{*}{} & \multicolumn{2}{|l|}{$\begin{array}{l}\text { Percent of Respondents Using Technology for Specific } \\
\text { Purpose }\end{array}$} \\
\cline { 2 - 4 } & $\begin{array}{l}\text { EMCS or PLM } \\
\text { Devices } \\
\text { (N=37) }\end{array}$ & $\begin{array}{l}\text { Energy } \\
\text { Information } \\
\text { Systems (EIS) } \\
(\mathbf{N = 3 1 )}\end{array}$ & $\begin{array}{l}\text { Onsite Generation } \\
\text { (N=42) }\end{array}$ \\
\hline To respond to high hourly prices & $16 \%$ & $23 \%$ & $7 \%$ \\
\hline To reduce overall electricity bills & $65 \%$ & $37 \%$ & $5 \%$ \\
\hline To reduce peak demand charges & $41 \%$ & $39 \%$ & $2 \%$ \\
\hline Facility/process control automation & $76 \%$ & $35 \%$ & - \\
\hline Monitoring and analysis & - & $29 \%$ & - \\
\hline Emergency backup/reliability & - & - & $95 \%$ \\
\hline Cogeneration & - & - & $5 \%$ \\
\hline
\end{tabular}

${ }^{\mathrm{a}}$ Customers were asked to check all purposes that applied to each technology, so responses do not add up to $100 \%$.

${ }^{\mathrm{b}}$ EMCS = Energy management control systems; PLM = Peak load management

Although onsite generation could be a significant factor influencing elasticities of substitution, customers indicated that they primarily use this technology for other purposes than short-term price response. The majority of customers owning self-supply equipment (95\%) cited emergency backup or reliability as its purpose, with only $7 \%$ reporting that they use their generators to respond to high electricity prices. ${ }^{59}$ Evidence from customer interviews suggests that, for some, this strategy involves running permitted tests on their emergency generators during high-price events. ${ }^{60}$

We believe that the majority of the onsite generation equipment currently in place at SC3A customers' facilities was installed prior to default-service hourly pricing being introduced. A current NYSERDA program designed to encourage “clean generation”, particularly combined heat and power applications (cogeneration), is accelerating deployment of a new wave of onsite generation technology that is more amenable to short-term price response than legacy systems that are often wired for emergency backup purposes. ${ }^{61}$ Several of the most price responsive SC-3A customers have onsite generation installed (see section 4.2) - further dissemination of newer, more flexible technologies may improve opportunities for price response.

\footnotetext{
59 This result appears to contradict the $16 \%$ of customers reporting load response strategies involving onsite generation (Figure 4-1). However, the load response question was framed more broadly, asking about strategies for responding to any of high hourly prices, NYISO emergencies or public appeals to conserve. ${ }^{60}$ Environmental permits for emergency generators in New York allow them to be run a specified number of hours per year for testing purposes.

${ }^{61}$ However, standby charges for onsite generation will limit the amount of new generation installed, even with support from NYSERDA. In interviews, several customers noted that they are interested in selfgeneration but feel that standby charges make it uneconomical. A report commissioned by NYSERDA also noted standby charges as the greatest barrier to distributed generation in New York state in general (Hedman et al. 2002).
} 


\subsection{Linking Customer Characteristics and Circumstances to Estimated Price Response}

In Chapter 3 we explored the link between customers' substitution elasticities and their characteristics and circumstances with the help of a heuristic regression model. This specification was less fruitful than we had hoped, in part due to too few observations, and in part due to the inherent co-linearity of many factors. Furthermore, the regression analysis focuses on the quantitative influence customer characteristics exert on the substitution elasticity estimate. Our extended study of these customers has revealed that a wide range of factors influence price response, many of which are not amenable to quantification.

In this section, we supplement that analysis by categorizing the customers into different groups based on their GL elasticity estimates and looking for trends that further explain which customer characteristics are associated with price responsiveness. While not all of these associations meet the statistical test of significance, they do provide insights to policymakers about which customers are most likely to respond to hourly prices.

Table 4-3. Characteristics of Price-Responsive and Non-Responsive Customers

\begin{tabular}{|c|c|c|c|}
\hline \multirow{3}{*}{\multicolumn{2}{|c|}{ Characteristic/Circumstance }} & \multirow{2}{*}{\multicolumn{2}{|c|}{ Percent of customers that are... }} \\
\hline & & & \\
\hline & & $\begin{array}{l}\text { Price } \\
\text { Responsive } \\
(>0.05)\end{array}$ & $\begin{array}{l}\text { Non- } \\
\text { Responsive } \\
(<0.05)\end{array}$ \\
\hline \multicolumn{2}{|c|}{ Information available for all 119 customers in GL model } & $N=45$ & $N=74$ \\
\hline \multirow{3}{*}{$\begin{array}{l}\text { Business } \\
\text { Category }\end{array}$} & Manufacturing & $36 \%$ & $38 \%$ \\
\hline & Government/education & $44 \%$ & $19 \%$ \\
\hline & Commercial/Healthcare/Public Works & $20 \%$ & $43 \%$ \\
\hline \multirow{3}{*}{$\begin{array}{l}\text { Geographic } \\
\text { Location }\end{array}$} & East & $31 \%$ & $42 \%$ \\
\hline & Central & $29 \%$ & $31 \%$ \\
\hline & West & $40 \%$ & $27 \%$ \\
\hline \multirow[t]{2}{*}{ Delivery Voltage } & Transmission or sub-transmission & $60 \%$ & $46 \%$ \\
\hline & Primary or secondary & $40 \%$ & $54 \%$ \\
\hline \multirow[t]{2}{*}{ NYISO EDRP } & Enrolled & $47 \%$ & $23 \%$ \\
\hline & Received incentive payments & $27 \%$ & $19 \%$ \\
\hline \multicolumn{2}{|c|}{ Information based on survey responses } & $N=25$ & $N=36$ \\
\hline \multirow{4}{*}{$\begin{array}{l}\text { Load Response } \\
\text { Strategy }\end{array}$} & Shift load & $24 \%$ & $25 \%$ \\
\hline & Operate DG & $20 \%$ & $11 \%$ \\
\hline & Forego load & $52 \%$ & $33 \%$ \\
\hline & None & $16 \%$ & $42 \%$ \\
\hline \multirow{3}{*}{$\begin{array}{l}\text { Enabling } \\
\text { Technology }\end{array}$} & EMCS or PLM devices available & $56 \%$ & $36 \%$ \\
\hline & EIS available & $40 \%$ & $33 \%$ \\
\hline & Onsite generation available & $60 \%$ & $56 \%$ \\
\hline
\end{tabular}

We classified the 119 customers included in the GL model into two categories: "priceresponsive" customers, with estimated substitution elasticities greater than or equal to 0.05, and "non-responsive" customers, with elasticities less than 0.05 (see Table 4-3). We also identified customer characteristics and circumstances that we hypothesized could distinguish these two groups of customers. Forty-five of the 119 customers fall into the price-responsive category. The remaining 74 customers have either zero or very low 
elasticities. To gain further insights into the more explanatory factors we also segregate the price-responsive customers into "highly responsive" (>0.10) and "moderately responsive" (0.05 to 0.10$)$ customers (Table $4-4)$. The factors summarized in the two tables are discussed in terms of their influence on price-responsiveness below.

Table 4-4. Selected Characteristics of Moderately and Highly Responsive Customers

\begin{tabular}{|c|c|c|c|}
\hline \multirow{3}{*}{\multicolumn{2}{|c|}{ Characteristic/Circumstance }} & \multirow{2}{*}{\multicolumn{2}{|c|}{ Percent of customers that are... }} \\
\hline & & & \\
\hline & & $\begin{array}{l}\text { Highly } \\
\text { Responsive } \\
(>0.10)\end{array}$ & $\begin{array}{l}\text { Moderately } \\
\text { Responsive } \\
(0.05-0.10) \\
\end{array}$ \\
\hline \multicolumn{2}{|c|}{ Information available for all 119 customers in GL model } & $N=22$ & $N=23$ \\
\hline \multirow{3}{*}{$\begin{array}{l}\text { Business } \\
\text { Category }\end{array}$} & Manufacturing & $55 \%$ & $17 \%$ \\
\hline & Government/education & $36 \%$ & $52 \%$ \\
\hline & Commercial/Healthcare/Public Works & $9 \%$ & $30 \%$ \\
\hline \multirow[t]{2}{*}{ Delivery Voltage } & Transmission or sub-transmission & $77 \%$ & $43 \%$ \\
\hline & Primary or secondary & $23 \%$ & $57 \%$ \\
\hline \multirow[t]{2}{*}{ NYISO EDRP } & Enrolled & $59 \%$ & $35 \%$ \\
\hline & Received incentive payments & $36 \%$ & $17 \%$ \\
\hline \multicolumn{2}{|c|}{ Information based on survey responses } & $N=9$ & $N=16$ \\
\hline \multirow{4}{*}{$\begin{array}{l}\text { Load Response } \\
\text { Strategy }\end{array}$} & Shift load & $33 \%$ & $19 \%$ \\
\hline & Operate DG & $22 \%$ & $19 \%$ \\
\hline & Forego load & $22 \%$ & $69 \%$ \\
\hline & None & $22 \%$ & $13 \%$ \\
\hline
\end{tabular}

Business Category. Price-responsive customers (those with elasticities greater than 0.05) are more likely to be government/education facilities than any other business category (see Table 4-3). On the surface, this appears to contradict the finding in Chapter 3 that manufacturing customers, not government/education ones, provide the most price response. However, although there are more price-responsive government/education customers overall, they are more likely to be moderately than highly responsive, constituting 52\% and 36\% of these groups respectively (see Table 4-4). Manufacturing customers represent roughly the same share of both price-responsive and non-responsive customers (36\% and 38\%, respectively), but those that are price-responsive tend to be very price responsive and account for over half (55\%) of this group of customers.

Figure 4-3 shows the proportional breakdown of customers by these same responsiveness categories in each business category. The government/education sector has the most price-responsive customers (59\%), with a large proportion of moderately responsive customers (35\%), and a significant proportion of highly responsive customers as well (24\%). Manufacturing customers exhibit a "bipolar" distribution: 64\% are nonresponsive, $27 \%$ are highly responsive, and only $9 \%$ are moderately responsive. These findings coupled with the larger number of manufacturing customers explain the overall higher elasticities for this business category $(0.16)$ than for government/education $(0.11)$. 


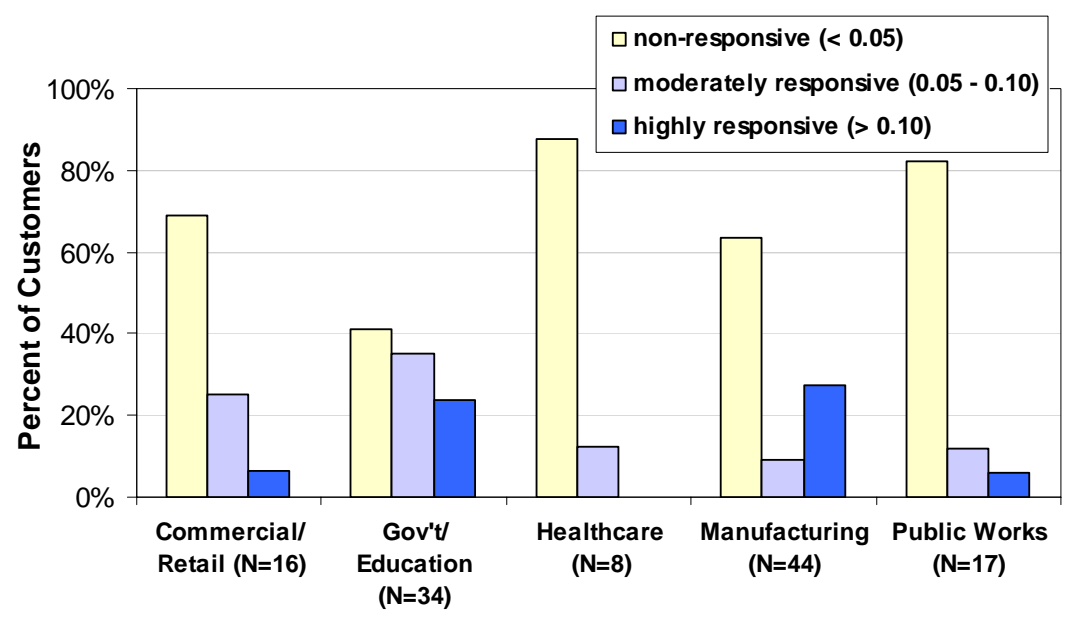

Figure 4-3. Price Responsiveness by Business Category

Non-responsive customers are most highly represented by commercial, healthcare, and public works facilities (43\%) (Table 4-3). The results in Figure 4-3 support this - most of the customers in these groups are nonresponsive, although there are some exceptions. The low sector-level elasticity results in Chapter 3 for these business categories are thus not surprising.

Geographic Location. We expected to see more priceresponsive customers in the eastern region of NMPC's service territory because prices were higher and more volatile in this region, particularly in 2000, 2001 and 2002. Instead, we find that price-responsive customers are slightly more likely to be located in the western region (40\% versus $\sim 30 \%$ of customers in each of the other regions) (see Table 4-3). Conversely, non-

\section{A Closer Look at Manufacturing Customers}

To explain why some manufacturing customers have very high elasticities while others show very little response, we examined customer characteristics within this group.

While enabling technologies do not correlate with price responsiveness among SC-3A customers overall (see sections 3.3.8 and 4.1.3), fifty percent of highly responsive manufacturing customers told us they have EMCS/PLM devices installed compared to only $25 \%$ of non-responsive manufacturing customers. Similarly, EIS owners comprise $75 \%$ of the highly responsive manufacturing customers but only $47 \%$ of non-responsive ones. We find no such correlation with onsite generation.

Self-reported load response strategies are also well correlated with responsiveness among manufacturing customers. Three quarters of highly responsive manufacturing customers indicated shifting as their only response strategy. Only $29 \%$ of non-responsive manufacturing customers indicated that they shift load. These results comport in part with the conventional wisdom that industrial customers may be able to shift production processes in response to high prices, but demonstrates that this is true for only a subset of these customers.

Highly responsive manufacturing customers also tend to be large: $75 \%$ had peak demand greater than $2.5 \mathrm{MW}$. All of them are served at the transmission or sub-transmission voltage level, compared to $68 \%$ of non-responsive manufacturing customers. They are also more likely to have been enrolled in EDRP and to have responded to EDRP events in 2001 and 2002.

In summary, large manufacturing customers that own EMCS/PLM devices and/or EIS, are served at transmission or sub-transmission levels and enroll/participate in EDRP are more likely to be highly responsive than those who do not have these characteristics. 
responsive customers are somewhat more likely to be located in the eastern region than the other two regions.

This result does not seem to be explained by more customers hedging in the eastern region than other regions. More than $80 \%$ of eastern region customers were exposed to SC-3A prices during all three years of high prices (2000-2002). The lack of correlation between higher prices and responsiveness either indicates that the difference in prices between these regions was insufficient to provide significantly different price incentives, or it may indicate other differences between customers located in the different parts of upstate New York, with more responsive ones located in the western region.

Voltage Level. Delivery voltage level is highly correlated with customers' price responsiveness. Customers that receive electricity at transmission or sub-transmission voltages are more likely to be price-responsive than not (see Table 4-3), and this is particularly so for highly responsive customers (Table 4-4). Delivery voltage can be viewed as a proxy for customer size - customers with higher peak demand are significantly more likely to take transmission or sub-transmission level delivery (p-value $<0.01$ ) - but customers must be located near high voltage transmission lines to take advantage of this service, which provides a substantial discount over primary and secondary voltage service.

Participation in EDRP. Because the NYISO EDRP program provides additional financial incentives to participants to reduce usage during NYISO-called emergency events and promotes awareness of coincident high prices, we expect to see a correlation between EDRP participation and price responsiveness. Not surprisingly, price-responsive customers are more likely to have been enrolled in EDRP (47\%) than non-responsive customers (27\%) (see Table 4-3). Highly responsive customers are also much more likely to have been enrolled (59\%) than moderately responsive customers (36\%) (see Table 4-4).

Curtailing during events and receiving payments for EDRP curtailments is less correlated with responsiveness: $27 \%$ of price-responsive customers received payments compared to $19 \%$ of non-responsive customers, and $36 \%$ of highly responsive customers received payments compared to $17 \%$ of moderately responsive customers. ${ }^{62}$ If we look at only EDRP-enrolled customers, the results are non-intuitive: 57\% of EDRP-enrolled priceresponsive customers received payments from NYISO compared to more than three quarters (76\%) of EDRP-enrolled non-responsive customers.

These results indicate that EDRP enrollment is an important factor in customers' responsiveness, but actual incentive payments are less well correlated. This suggests that ISO DR programs may enhance price response in other ways than just paying for

\footnotetext{
${ }^{62}$ The somewhat counter-intuitive result that customers who responded to EDRP events are not responsive may be explained, at least in part, by our imputing of the \$500/MWh EDRP floor price during events for these customers - this reduces the elasticity estimate for these customers relative to others that paid a lower SC-3A price and had the same load response.
} 
curtailments. Simply by making customers more aware of electricity costs, markets and reliability issues, DR programs may make customers more priceresponsive in general.

An additional consideration is the "good citizen" factor. In surveys of NYISO demand response program participants, many indicate that responding to calls for curtailment by the ISO is viewed as a corporate obligation that is not seen as price response but an obligation to the community (Neenan et al. 2003). Such customers may rationalize curtailing in response to an incentive when system reliability is apparently at stake, but do not do so for essentially the same remuneration in the form of avoided high SC-3A prices.

\section{Load Response Strategies.} Matching up customers' selfreported load response strategies to their estimated elasticities produces some interesting results. First, we find that $58 \%$ of "nonresponsive" customers indicated some type of load curtailment strategy. Conversely, $17 \%$ of "priceresponsive" customers reported that they do not respond at all (see Table 4-3). Among price-responsive customers, the most common strategy is foregoing electricity usage; this was indicated by more than half of these customers. Looking within the price-responsive customers, it appears that moderately responsive customers are most likely to forego load (Table 4-4). Highly responsive customers are slightly more likely to shift load than use other load response strategies. A

\section{Portrait of the "Top Ten” Price Responders}

Eleven of the 119 customers included in the GL model have average elasticity estimates that are very high (greater than 0.20 ). We examined the characteristics of these "top ten" customers to see if we could determine what drives their extremely priceresponsive behavior.

All except one of these facilities have been exposed to hourlyvarying prices for at least four of the past five years. None of them elected the hedged alternative tariff offered by NMPC at the inception of customer choice in 1998. Most of these customers (64\%) have also never bought their electricity from a competitive supplier. Very high elasticities coupled with being on the default hourly-varying tariff when other options such as flat rates are available suggests that these customers have chosen to be exposed to hourly varying prices. Furthermore, they have demonstrated their ability to respond to high, volatile prices through substantial changes in their intra-day usage patterns.

Four of the eleven customers are public order and safety facilities, one is a college, one is a recreational facility, and the remaining five customers are manufacturing facilities in the paper, cement and milling industries. One feature common to these eleven customers is that nine of them are served at the sub-transmission or transmission voltage level. Eight have been enrolled in EDRP for at least two of the four years that the program has been administered. Those that were enrolled in EDRP during 2001 and 2002, when events were called, responded to those events. Two have enrolled in ICAP/SCR.

Only four of these eleven customers responded to our 2004 survey, limiting what we can infer about their self-reported response strategies. Of these four, two indicated that they have onsite generation capability, one has an EIS system and the other has both EMCS/PLM devices and EIS. However, none of these customers indicated that they used these technologies for responding to high prices. One of them claimed to have no load response strategy at all, yet appears to be responding affirmatively to prices or other curtailment inducements.

To summarize, the most highly responsive SC-3A customers are typically (but not exclusively) manufacturing and government facilities that take their power at the transmission level, and that have enrolled in EDRP. This lends at least some credence to the proposition that NYISO programs supplement price response from default service RTP pricing. 
surprising number of "highly responsive" customers indicated in their survey responses that they do not respond. This discrepancy between what some customers tell us and what we measure from their load and price data may either indicate that their electricity demand varies due to some factor correlated with prices that we are unable to account for, or that these customers understated their response capabilities. This could be because the individuals answering the survey were not aware of their facilities' actual response strategies - when we conducted the survey in late 2004, it had been over two years since they had seen significant price spikes. Finally, this anomaly may be the result of strategic survey response - customers may have told us what they wanted us to hear, or what they thought we needed to hear.

Enabling Technologies. In Chapter 3, we noted based on regression results that enabling technologies did not enhance SC-3A customers' price responsiveness, and discussed potential explanations in section 4.1.3. Nonetheless, we do see a slight positive correlation between price-responsiveness and enabling technologies in Table 4-3. Priceresponsive customers are somewhat more likely to own all three types of enabling technologies than non-responsive customers, though these results are not statistically significant. We conclude that for the most part, many customers with the technical capability to manage loads against hourly prices do not (or do not know how to) utilize that capability.

\subsection{Barriers to Price Response}

A number of barriers to price response were expressed by SC-3A customers in interviews and surveys. In the survey, we specifically asked customers to indicate barriers they had encountered in responding to high hourly prices. Only $12 \%$ of respondents indicated that they had not encountered any barriers at all (see Table 4-5). The remaining $88 \%$ reported anywhere from one to five barriers to price response. The pervasiveness of barriers cited by customers is consistent with individual customer-level demand model results, which indicate that a significant number of customers (27\%) are not price responsive at all (zero elasticities), and another $36 \%$ have low elasticities of substitution $(<0.05)$.

We categorized the barriers reported by customers into three broad areas: organization/business practices, inadequate incentives and customers being risk averse and/or having hedged (Table 4-5). Each of these is discussed below.

Organization/Business Practices. Over two-thirds of surveyed customers indicated that they have encountered at least one barrier related to their organization's or business' practices or structure (Table 4-5). Twenty-one percent indicated inflexible labor schedules as a barrier to price response, and 30\% cited institutional barriers. In interviews, several customers mentioned complaints from building occupants as a major barrier. This was particularly prevalent for customers with landlord-tenant relationships. As one put it, "re-setting the thermostats too frequently would drive tenants nuts." 
Table 4-5. Barriers To Price Response

\begin{tabular}{|l|l|}
\hline Barrier & $\begin{array}{l}\text { Percent of } \\
\text { Respondents } \\
\text { (N=76) }\end{array}$ \\
\hline $\begin{array}{l}\text { Organization/Business Practices } \\
\text { Insufficient time or resources to pay attention to hourly prices } \\
\text { Institutional barriers in my organization make responding difficult } \\
\text { Inflexible labor schedule }\end{array}$ & $\begin{array}{l}51 \% \\
30 \% \\
21 \%\end{array}$ \\
\hline $\begin{array}{l}\text { Inadequate Incentives } \\
\text { Managing electricity use is not a priority }\end{array}$ & $22 \%$ \\
The cost/inconvenience of responding outweighs the savings & $22 \%$ \\
\hline $\begin{array}{l}\text { Risk Aversion/Hedging } \\
\text { My organization's management views these efforts as too risky } \\
\text { Flat-rate or time-of-use contract makes responding unimportant }\end{array}$ & $13 \%$ \\
\hline Other barriers & $3 \%$ \\
\hline No barriers encountered & $12 \%$ \\
\hline Do not know & $3 \%$ \\
\hline a Customers were asked to check all barriers that applied, so responses do not add up to 100\%.
\end{tabular}

Over half of survey respondents cited insufficient time to monitor hourly prices as a barrier to price response (Table 4-5). When asked specifically how often they monitor day-ahead hourly prices, $70 \%$ indicated that they rarely or never monitor day-ahead SC3A prices (see Figure 4-4). Only 14\% told us that they monitor day-ahead hourly prices routinely. Thirteen percent indicated they check day-ahead prices only when other factors suggest that they may be high (e.g., when the weather is hot or NYISO emergency events are called), and $3 \%$ said they check prices on a weekly basis.

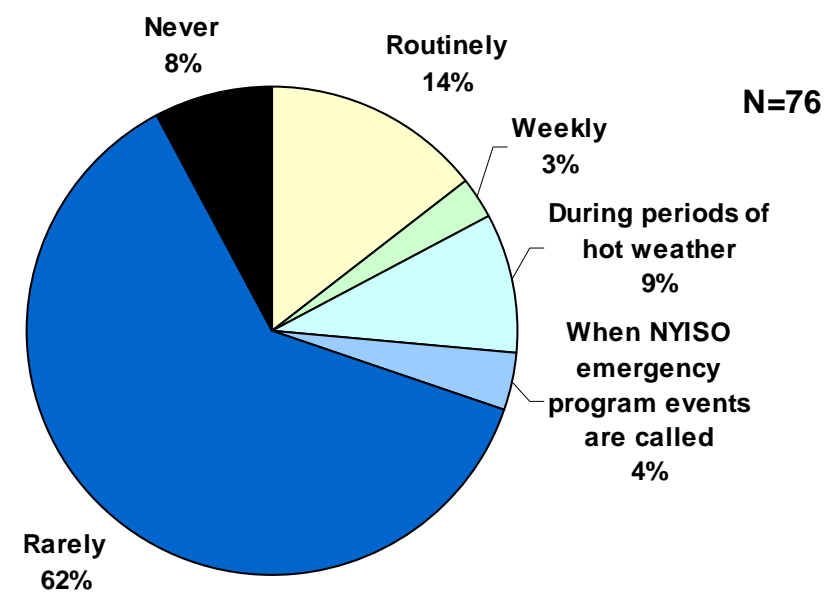

Figure 4-4. Frequency of Monitoring Hourly Prices

The $86 \%$ of customers that indicated that they do not monitor prices routinely were asked for their primary reason for not doing so. Over one-third cited resource or technology limitations (Table 4-6). For 28\%, having procured a hedged commodity contract made this exercise irrelevant. Almost 20\% said that another party is responsible for monitoring prices on their behalf. 
Table 4-6. Reasons for Not Monitoring Hourly Prices Routinely

\begin{tabular}{|l|l|}
\hline Reason & $\begin{array}{l}\text { Percent of } \\
\text { Respondents } \\
\text { (N=65) }\end{array}$ \\
\hline Limited resources to do so & $34 \%$ \\
\hline Limited technology to do so & $3 \%$ \\
\hline Hedged commodity contract makes monitoring prices irrelevant & $28 \%$ \\
\hline Another party is responsible for monitoring prices & $18 \%$ \\
\hline Electricity prices are not a high priority & $3 \%$ \\
\hline Unable to respond, so don't check prices & $3 \%$ \\
\hline Unaware that prices change hourly & $2 \%$ \\
\hline Other & $3 \%$ \\
\hline Do not know & $6 \%$ \\
\hline
\end{tabular}

In interviews, we asked customers if they would monitor prices more frequently if they were higher or more volatile. Six out of 20 interviewees said they would consider doing so, and one said he definitely would. Another customer said it would depend on how high prices were, and how often, noting that a single-day, short duration price spike would not change his behavior. Four customers told us they do worry about high prices even though they do not monitor them routinely - their strategy is to try to check prices during severe weather or NYISO emergency events.

Inadequate Incentives. One third of customers cited barriers related to inadequate price incentives to respond (Table 4-5). Twenty-two percent indicated that managing electricity use is not a priority - for these customers, electricity costs may not be a large enough portion of their bottom line to invest the time necessary to manage them. An equal number of customers felt that the cost or inconvenience of responding was greater than the potential savings. In interviews, some customers told us they would only respond if prices stayed high for several hours. As one put it, "a single hour does not ruin it for us. The financial impact is much greater if high prices continue for several hours.” Another told us, "it's not worth the effort for just one hour".

Both of these barriers are related to the fact that electricity price volatility in NMPC's service territory has historically been relatively low and that price volatility has been declining for the last three years (see section 2.2). Even in the Eastern region, with the highest prices during our study period, prices were above \$500/MWh in only 18 hours. Under this price regime, it appears that some customers do not see sufficient opportunity for savings from curtailing load relative to the costs of responding.

Risk Aversion/Hedging. Seventeen percent of customers cited risk aversion or having taken a hedge as a barrier to price response (Table 4-5). Thirteen percent of survey respondents indicated that their organization's management views price response as too risky. Twelve percent said they had hedged their electricity costs either physically or financially, and did not see price response as necessary. ${ }^{63}$

\footnotetext{
63 Three of the seven customers who responded that "flat rate or TOU contracts makes responding unimportant” were partially or fully hedged according to their survey responses.
} 
The types of barriers to price response reported differ substantially among business classifications (see Figure 4-5). For government/education customers, the most common barriers are related to organization/business practices; $96 \%$ of these customers reported at least one such barrier. Though also common among manufacturing and public works customers, other barriers are also important. For these and commercial customers inadequate incentives were cited by $40-60 \%$ of customers. This result suggests that the organization's bottom line factors into the decision to respond to prices more for these customers than for government/education customers. Barriers related to risk aversion and/or hedging are most common among manufacturing customers.

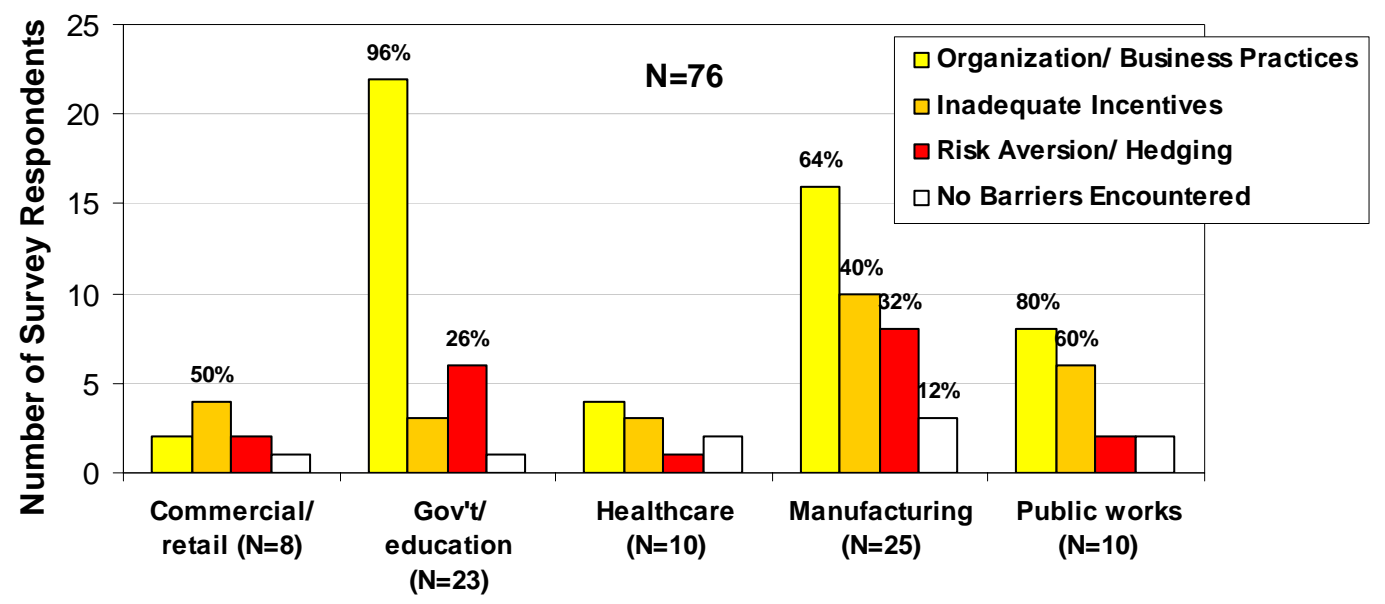

Note: Customers were asked to check all barriers that applied, so responses do not add up to $100 \%$.

Figure 4-5. Barriers to Price Response by Business Classification

\subsection{Customer Migration and the Search for a Hedge}

NMPC's day-ahead market commodity tariff was implemented in a complex environment. In interpreting customers' response to RTP, it is important to consider the interacting incentives afforded by their retail market choices. SC-3A customers have been free to leave NMPC at any time since RTP was implemented as the default service tariff, and have also had the option of purchasing financial hedges to reduce their exposure to price risk from SC-3A or similarly indexed commodity prices. In this section, we examine trends in SC-3A customers' migration patterns between the regulated utility and competitive retail suppliers over the last five years. We also describe customers' hedging choices over the same time period, drawing on tariff history data complemented by survey and interview results.

\subsubsection{SC-3A Customer Migration Trends}

The combinations of electric commodity supply choices available to SC-3A customers and the number choosing them over time are shown in Table 4-7 (the data are for summers only). In addition to day-ahead hourly pricing (“Option 1”), NMPC offered a fixed rate supply contract ("Option 2") that expired in 2003. Customers selecting Option 
2 could nominate some or all of their load on this rate - any residual power requirements could be met with a competitive supply contract or under SC-3A Option 1.

Table 4-7. Trends in SC-3A Customers' Supply Choices

\begin{tabular}{|c|c|c|c|c|c|c|c|}
\hline \multirow{2}{*}{\multicolumn{3}{|c|}{ Supply Option }} & \multicolumn{5}{|c|}{$\begin{array}{l}\text { Number of Customer Accounts in } \\
\text { Summer of... }\end{array}$} \\
\hline & & & 2000 & 2001 & 2002 & 2003 & 2004 \\
\hline \multicolumn{3}{|c|}{ Only SC-3A Option 1} & 90 & 99 & 87 & 66 & 54 \\
\hline \multirow{5}{*}{$\begin{array}{l}\text { SC-3A } \\
\text { Option } 2\end{array}$} & \multicolumn{2}{|c|}{ Full load } & 2 & 1 & 1 & 1 & \multirow[t]{5}{*}{$\mathrm{N} / \mathrm{A}$} \\
\hline & \multirow{4}{*}{$\begin{array}{l}\text { Partial } \\
\text { load } \\
\text { with: }\end{array}$} & SC-3A Option 1 & 11 & 7 & 5 & 4 & \\
\hline & & competitive supply - fixed rate & 5 & 4 & 5 & 3 & \\
\hline & & competitive supply - indexed rate & 0 & 0 & 0 & 2 & \\
\hline & & competitive supply - unknown rate & 3 & 5 & 6 & 6 & \\
\hline \multicolumn{3}{|l|}{ All NMPC } & 111 & 116 & 104 & 82 & 54 \\
\hline \multirow{3}{*}{$\begin{array}{l}\text { Competitive } \\
\text { supply }\end{array}$} & \multicolumn{2}{|c|}{ Fixed-rate contract } & 8 & 6 & 11 & 11 & 16 \\
\hline & \multicolumn{2}{|c|}{ Indexed contract } & 1 & 1 & 3 & 10 & 10 \\
\hline & \multicolumn{2}{|c|}{ Unknown contract type } & 28 & 25 & 30 & 45 & 68 \\
\hline \multicolumn{3}{|c|}{ All Competitive Supply } & 37 & 32 & 44 & 66 & 94 \\
\hline \multicolumn{3}{|c|}{ Information not available } & 1 & 1 & 1 & 1 & 1 \\
\hline \multicolumn{3}{|c|}{ Total } & 149 & 149 & 149 & 149 & 149 \\
\hline
\end{tabular}

Customer migration rates were quite modest until 2002, ranging from $21 \%$ to $30 \% .{ }^{64}$ In the last two years, however, there has been a marked increase in the number of customers leaving the utility; as of the summer of 2004, 63\% had left. ${ }^{65}$ The sunset of Option 2 probably explains this increase to a large extent, as customers that had made nominations began to search for other options. Though there appears to have been an increase in the number of hedged competitive supply contracts over time, the share of hedged contracts among known agreements has declined (see Table 4-7). The majority of new competitive supply contracts are indexed, not hedged. Based on these results and customer interviews, we believe that switching is probably driven by the desire to hedge for the most riskaverse customers. Others are taking advantage of the shopping credit defined in NMPC's restructuring agreement and, possibly, more attractive indexing arrangements. ${ }^{66}$

The observed increase in customers leaving NMPC Option 1 default service for the competitive market in 2003 and 2004 probably reflects a combination of two additional factors: (1) customers may have watched the market play out for a few years before deciding to switch, or (2) the number of suppliers and the variety of contract options appears to have taken off in recent years, primarily due to a maturing retail market as several adjacent states have also adopted RTP-type default service (Barbose et al., 2005).

\footnotetext{
64 These percentages count customers with Option 2 nominations in combination with a competitive supply contract as still being served by the regulated utility.

${ }^{65}$ An equivalent proportion of SC-3A customers' load had switched as of $2004-66 \%$ - indicating that switching rates are unrelated to customer size.

${ }^{66}$ NMPC adds NYISO ancillary services charges it incurs for serving SC-3A customers to NYISO dayahead hourly prices. Some competitive retail suppliers may be able to offer a lower price if their exposure to NYISO uplift costs is less than NMPC's.
} 
We asked customers who had remained with the utility for any period during the last five years why they had not switched. The most commonly reported reasons were institutional barriers within their organizations and the inability to find a competitive supply contract that was preferable to the default service; almost a third of customers provided each of these reasons for not switching (Table 4-8). Among the latter group, some reported difficulty finding a competitive supplier to serve them, some did not find the type of contract they were looking for (long term or hedged contracts), and a significant number of customers appear to have evaluated offers and decided that they were too expensive or did not provide enough savings to justify the switch. The observed increase in

\section{Overcoming Institutional Barriers to Switching}

A large number of government/education and public works customers cited institutional barriers, usually procurement rules that allocate decision-making authority to an overseeing agency or that require lengthy requests for proposals (RFP) and bid evaluation processes that make it difficult or impossible to switch to a competitive supplier, even when doing so would save the institution money.

One such customer, frustrated by rules that were ill-suited to procuring electricity, took the initiative to have them changed. He approached his facility's governing agency with a proposal to revise procurement rules for energy, arguing that the RFP process in place took too long to lock in electricity prices offered by competitive suppliers. His proposal included establishing an energy advisory group with representatives from both the overseeing agency and his facility that has the authority to lock in energy prices. The change required the governing legislative body to pass a resolution, but, as this interviewee put it, "I just had to demonstrate that we would save $\$ 80,000$ per year and they listened”.

This customer's story demonstrates that it is possible to overcome seemingly intractable barriers, in this case to switching, but it may also be possible to address barriers to price response in this way. More importantly, it underscores the importance of having a "champion" within an agency, someone who is willing to take the initiative to overcome obstacles. customer migration is likely attributable to customers becoming more comfortable evaluating retail market offers and overcoming internal procurement barriers over time, as well as retailers providing more and possibly better-priced options to customers as the market has matured. An example of a customer that took steps to overcome institutional barriers is described in the adjacent inset (Overcoming Institutional Barriers to Switching).

Even though switching is on the increase, 37\% of SC-3A customers still remain on default-service hourly pricing, six years after its introduction (see Table 4-7). Another large group of customers has switched to competitive suppliers and signed contracts that are indexed to the SC-3A rate. This group could represent $7 \%$ to $25 \%$ of the NMPC SC3A accounts (depending on assumptions regarding customers with unknown supply contract types) ${ }^{67}$. Relative to other jurisdictions that have implemented default-service RTP and experienced very high switching rates, the number of SC-3A customers willing

\footnotetext{
${ }^{67}$ Ten of 26 survey respondents (7\% of the total 149 SC-3A accounts) indicated that they had an indexed contract with a competitive retail supplier in 2004. If we assume that the 68 customers known to buy commodity from a competitive supplier (but for whom we don't know the type of contractual arrangement) have similar contractual arrangements as survey respondents (i.e., 38\% have contracts indexed to dayahead hourly prices), then 36 customers (or $24 \%$ of SC-3A accounts) may be exposed to day-ahead hourly prices.
} 
to remain on SC-3A hourly pricing is extraordinarily high (Barbose et al. 2005). We believe that the major reason for this difference is that NMPC's tariff involves day-ahead prices, while other states that have implemented default-service RTP have indexed these tariffs to real-time markets. In the following sections, we will discuss hedging by SC-3A customers and will argue that the combination of day-ahead firm price notice and low volatility relative to real-time markets represents a "hedge" in the SC-3A default service rate compared to "real-time” RTP.

Table 4-8. Customers' Reasons for Not Switching

\begin{tabular}{|l|l|}
\hline Reason for staying with NMPC & $\begin{array}{l}\text { Percent of } \\
\text { Respondents } \\
\text { (N=54) }\end{array}$ \\
\hline Institutional barriers in my organization make switching difficult & $31 \%$ \\
\hline Could not find a preferred alternative & $31 \%$ \\
Could not find an ESCO ${ }^{b}$ willing to serve my organization & $4 \%$ \\
Could not find a hedged (flat-rate) contract & $2 \%$ \\
Unavailability of long-term contracts & $11 \%$ \\
ESCO offers have been too expensive & $15 \%$ \\
The savings offered by ESCOs have not been enough to justify the switch & $26 \%$ \\
\hline My organization has signed a long-term contract with NMPC & $4 \%$ \\
\hline Prefer NMPC's prices, reputation or service & $6 \%$ \\
\hline My organization has a NYPAc allocation & $4 \%$ \\
\hline My organization made Option 2 nominations & $7 \%$ \\
\hline My organization buys power directly from NYISO & $13 \%$ \\
\hline Other & $4 \%$ \\
\hline Do not know & $26 \%$ \\
\hline a Customers were asked to check all reasons that applied, so responses do not add up to 100\%. \\
b Competitive retail electricity suppliers are termed “ESCOs” in New York. \\
c The New York Power Authority (NYPA) provides low-cost power allocations under economic \\
development rationale. \\
\hline
\end{tabular}

\subsubsection{Hedging Trends}

SC-3A customers have had three alternatives for hedging against electricity price volatility. First, in 1998, customers had the one-time choice of nominating some or all of their projected load on NMPC's fixed rate forward contract, Option 2, for up to 5 years (these contracts expired in August 2003). Second, at any time during the study period, customers could switch to a competitive supplier that offered a fixed-price commodity contract (e.g., a flat rate or time-of-use rate contract). Third, customers could purchase financial hedge products, separate from the delivery of electricity, that functionally hedge against some degree of price volatility.

We classified customers by combining rate history information with survey responses on the types of commodity contracts and financial hedges entered into by customers in each of the last five summers (Table 4-9). We considered customers to be "fully hedged" if they had either taken their full load on Option 2 or signed a hedged commodity contract. We considered them to be "partially hedged" if they had taken Option 2 for only part of their load (with either Option 1 or an indexed contract for residual power) or if they had purchased a financial hedge in conjunction with Option 1 or an indexed commodity 
contract. Customers on Option 1 or indexed commodity contracts that saw hourly varying prices for their entire load were classified as "not hedged". For many customers, survey non-response or incomplete survey information prevented us from making a definitive classification of their hedging behavior (“unknowns” in Table 4-9). ${ }^{68}$

Table 4-9. Trends in SC-3A Customers' Hedging Strategies

\begin{tabular}{|l|l|l|l|l|l|}
\hline \multirow{2}{*}{ Hedging Strategy } & \multicolumn{5}{|l|}{ Number of Customer Accounts in Summer of... } \\
\cline { 2 - 6 } & $\mathbf{2 0 0 0}$ & $\mathbf{2 0 0 1}$ & $\mathbf{2 0 0 2}$ & $\mathbf{2 0 0 3}$ & $\mathbf{2 0 0 4}$ \\
\hline Hedged & 29 & 27 & 31 & 29 & 19 \\
Fully & 15 & 11 & 17 & 15 & 16 \\
Partially & 11 & 11 & 8 & 8 & 3 \\
Unknown degree & 3 & 5 & 6 & 6 & 0 \\
\hline Not Hedged & 53 & 56 & 50 & 46 & 35 \\
\hline Unknown & 67 & 66 & 68 & 74 & 95 \\
\hline Total & $\mathbf{1 4 9}$ & $\mathbf{1 4 9}$ & $\mathbf{1 4 9}$ & $\mathbf{1 4 9}$ & $\mathbf{1 4 9}$ \\
\hline
\end{tabular}

Overall, the percentage of customers that are fully or partially hedged has remained fairly constant over the last five years at 33-39\% of accounts with enough information to make this determination (Table 4-9). The number of customers known to be fully hedged has also remained fairly constant over time. It appears that fewer customers were partially hedged in the most recent years - this may be related to the sunset of Option 2. The majority of customers that are hedged do so with electricity supply arrangements (Option 2 or fixed-rate competitive supply contracts). The number of customers taking financial hedges, separate from the supply of electricity, has increased over the last five years; nonetheless, it appears that this strategy is still adopted by less than $10 \%$ of customers that provided information about these products. ${ }^{69}$ Finally, it should be noted that the number of customers with missing information has increased over time ("unknowns" in Table 4-9).

\subsubsection{Why Don’t Customers Hedge More?}

In interviews with SC-3A customers it was clear that many customers would prefer to hedge than be exposed to price volatility. Other research also suggests that large electricity customers want to hedge. For example, in market research performed by Tractebel Energy Services (2004, 2005) among commercial and industrial customers in the Northeast and Texas, $80-85 \%$ indicated that they would prefer hedged to indexed electricity pricing. Why, then, have so few SC-3A customers actually done so? We propose two reasons for the observed difference between what customers say they want

\footnotetext{
${ }^{68}$ Customers were included in the GL model if they were either not hedged or partially hedged (see section 3.2.2). Altogether, 119 customer accounts met these criteria in at least one summer of our study. These customers are classified as "partially hedged”, "not hedged” or "unknown” in Table 4-9; some of the "unknowns" could be identified as either not hedged or partially hedged, so we were able to include them in the model, but could not distinguish them in the table.

${ }^{69}$ We believe that some customers misinterpreted our survey questions about financial hedges, in part because most customers that said they had financial hedges also indicated they had fully hedged supply contracts (and having both would be redundant), and also because some customers that were interviewed were not familiar with the concept of a financial hedge. Thus, these results should be interpreted with caution.
} 
and what they actually do: (1) some customers have been unable to find suitable hedges, and (2) given the market circumstances that SC-3A customers have faced, they are what we call "psychologically" hedged.

Difficulty Finding Hedges. In both years of this study, a number of customers indicated in interviews that they had experienced difficulties finding hedged supply contracts.

Some told us they couldn't find them at all, and others that the offers they received were too high priced for them to consider. These complaints were noted somewhat less frequently in the second year of our survey, suggesting either that there are more or better priced offers on the table in recent years, or that customers have re-evaluated their desire to hedge given their market experience.

SC-3A customers have also had the option to purchase financial hedges, but relatively few customers have done so. In a survey question, we asked customers why they had not. A few customers (7\%) indicated they had searched for a financial hedge but found the risk premium too expensive (Table 4-10). Twenty-two percent cited institutional barriers, and about one-third of customers had already hedged with a supply contract. Over $50 \%$ of the customers that had not entered into a financial hedge either did not know why they hadn't purchased one or were not sure what a financial hedge is. This may reflect a culture within firms and institutions that sees financial products as distinct from energy supply contracts or under which the two products may be procured by different departments and people. ${ }^{70}$

Table 4-10. Reasons for Not Purchasing Financial Hedges

\begin{tabular}{|l|l|}
\hline Reason for not purchasing financial hedge & $\begin{array}{l}\text { Percent of } \\
\text { Respondents }^{\text {a }} \\
\text { (N=60) }\end{array}$ \\
\hline Offered hedges were too expensive & $7 \%$ \\
\hline Institutional barriers in my organization make procuring financial hedges difficult & $22 \%$ \\
\hline My facility already has a hedged supply contract & $27 \%$ \\
\hline My organization is comfortable managing risk without a financial hedge & $7 \%$ \\
\hline Not sure what a financial hedge is or why I would need one & $23 \%$ \\
\hline Other & $3 \%$ \\
\hline Do not know & $27 \%$ \\
\hline${ }^{\text {a }}$ Customers were asked to check all reasons that applied, so responses do not add up to $100 \%$. \\
${ }^{b}$ Includes fixed-rate competitive supply contracts, Option 2, and NYPA allocations.
\end{tabular}

"Psychological" Hedging. Based on our market research with SC-3A customers, we propose that some customers that have not taken steps to hedge against electricity price volatility are in fact "psychologically" hedged. What we mean by this is that customers have observed SC-3A prices over the last six years, along with the hedging options available to them, and are apparently comfortable managing day-ahead market price risk without a hedge. In part, this can be explained by the price regimes they have faced. Relatively few price spikes and declining volatility in summer peak prices have probably led customers to conclude that the risk of remaining on the SC-3A rate or an indexed

\footnotetext{
${ }^{70}$ The majority of the people that answered our surveys were energy or facility managers or people responsible for procuring energy.
} 
supply contract is small. In interviews, some customers have told us that "there aren't enough high prices to worry about”. So, when high prices are encountered, they do not set off any alarm because such occurrences were anticipated and factored into their decision to not hedge or make plans to respond.

This level of comfort may also reflect the fact that SC-3A prices are indexed to the dayahead market. By contrast, in New Jersey, implementing default-service RTP indexed to the PJM real-time market in which prices are revealed after the fact resulted in high customer migration rates in a very short time frame (Barbose et al. 2005). Because realtime market prices tend to be more volatile than day-ahead prices, and because they afford no advance notice of prices, day-ahead hourly prices may be seen by customers as less risky. ${ }^{71}$

We specifically asked SC-3A customers what they would do if the default SC-3A rate were indexed to the real-time market, with no advance price notice. Only 5\% said they would remain on the SC-3A rate for commodity service (see Table 4-11). Twenty-eight percent said they would switch or consider offers from competitive retail suppliers for commodity service. Almost half of customers said they did not know what they would do.

Table 4-11. Customers' Reactions to Hypothetical "Real-Time" RTP

\begin{tabular}{|l|l|}
\hline $\begin{array}{l}\text { Action Customer Would Take if SC-3A Default } \\
\text { Service Was Based on NYISO Real-Time Market }\end{array}$ & $\begin{array}{l}\text { Percent of } \\
\text { Respondents } \\
\text { (N=76) }\end{array}$ \\
\hline Continue buying commodity service from NMPC & $5 \%$ \\
\hline Continue buying commodity service from an ESCO & $18 \%$ \\
\hline Switch to an ESCO for commodity service & $13 \%$ \\
\hline Consider offers from an ESCO for commodity service & $15 \%$ \\
\hline Do not know & $49 \%$ \\
\hline
\end{tabular}

\footnotetext{
${ }^{71}$ Moreover, Taylor and Schwarz (2000) quantified the welfare benefits from providing advance notice of prices and found that the benefits of providing customers with time to react to price changes outweighed the cost to the utility of bearing forecast risk.
} 



\section{Discussion: Key Findings and Policy Implications}

This study was initiated three years ago to provide insight into how customers adapt to market-based default service electricity pricing. In 1998, Niagara Mohawk Power Corporation (NMPC) became the first utility in the U.S. to incorporate day-ahead, hourly ISO market based prices into an unbundled default service tariff. Our study group consists of many of NMPC's largest customers: the SC-3A service classification of 150 commercial, industrial and institutional customers with peak demands in excess of 2 MW. However, from the onset, competitive retailers have provided alternatives.

This study was funded by the California Energy Commission (CEC)'s PIER program through the Demand Response Research Center (DRRC). Since the 2000-2001 electricity crises, policymakers in California have been considering means of increasing price response by retail customers to mitigate extreme prices. Day-ahead hourly pricing, often referred to generically as real-time pricing (RTP), is one of the tariff structures under consideration. Another is critical-peak pricing (CPP), which differs from RTP in that dynamic price changes are invoked only under specified circumstances (not in every hour as is the case for RTP), and are usually triggered by system conditions (e.g., forecasted or actual shortfalls in operating reserves) or very high prices to elicit response when it is most needed.

SC-3A customers have faced short periods of high prices on several occasions over the study period (2000-2004), thereby providing an opportunity to assess customers' abilities to respond to volatile hourly prices. The mix of NMPC's large customers exposed to dayahead hourly prices - roughly 30\% industrial, $25 \%$ commercial and $45 \%$ institutional - is also comparable to that of California, although the types of industrial facilities are not identical. The nature of the SC-3A default service attracted competitive retailers offering a wide array of pricing options, from fully hedged flat rates, to financial hedges, to prices indexed to the NYISO day-ahead prices. These customers also had opportunities to receive payments for curtailments under demand response programs implemented by NYISO.

These attributes of SC-3A customers - the wide range of customer circumstances, load sizes and profiles, business activity, experience with dynamic pricing, availability of enabling technologies, retail market choices and NYISO DR program opportunities - are conducive to quantifying the intensity of price response (the price elasticity) and characterizing the factors that drive it. They also provide an opportunity to study how customers decide when and how to hedge against price volatility, and to determine if default RTP and ISO demand response initiatives are complementary forces, or redundant incentives to reduce load.

We begin this chapter with a brief discussion of the model used to estimate price response and how to interpret elasticity of substitution results. The next section identifies and describes key findings, organized around several themes, and discusses their implications for policymakers interested in price response from RTP in the context of retail competition, or who are considering dynamic pricing as default service for other reasons. 


\subsection{Deriving and Interpreting the Elasticity of Substitution}

Niagara Mohawk's SC-3A customers use electricity as an input to processes that produce intermediate or final consumer goods, or to provide services to consumers or society. Consequently, we hypothesize that these customers make electricity usage decisions in the short run, from day-to-day, based on the value electricity contributes to the customer's overall profit (or, in the case of a government/educational customer, the reduction of overall operating expenses) and information available to them about prevailing hourly electricity prices.

The distribution of NYISO day-ahead electricity prices, which are the basis for SC-3A prices, is such that the majority of days are characterized by a fairly constant pattern of hourly prices (of typically \$50-60/MWh for mid-day hours), with high peak period prices (exceeding \$300/MWh) occurring only on isolated days. Consequently, we portray SC3A customers' price response as primarily involving the decision to reallocate business activity from an established routine on those days when prices are high. This response involves using less electricity during the high-priced, peak hours of the day and more during the lower priced, off-peak hours to meet the day's expected level of business. In other words, the decision involves substitution of off-peak electricity use for peak usage. Accordingly, the appropriate measure of price response is the elasticity of substitution, defined as the percentage change in daily peak electricity usage (relative to off-peak usage) in response to a one percent change in relative peak prices.

This notion of elasticity differs from the more familiar own-price elasticity, but its interpretation is similar, and it is an appropriate and feasible characterization of price response for large customers. (Moreover, estimating own-price elasticities would have required gathering output data from customers, which was beyond the scope of this study. ${ }^{72}$ ) The model we employ is conducive to estimating own-price response as well as substitution elasticities, though it is conservative. ${ }^{73}$

Substitution elasticities take on values of zero or greater. A value of zero has a special interpretation. It indicates that relative electricity prices have no impact on electricity consumption due to the nature of how electricity is used by the customer during the day. Positive elasticities indicate price response, and the higher the elasticity, the greater the response. We expect individual customers to exhibit a variety of price response intensities, even within the same general line of business, due to subtle but important differences in how electricity contributes to business activity.

\footnotetext{
72 To calculate an own-price elasticity, which measures the reduction in demand in response to a price increase in absolute terms, information on either customers' demand in the absence of RTP (e.g., a customer baseline load) or their total production output (e.g., number of widgets produced each day) would have been necessary. The former is simply not possible, since SC-3A customers have faced RTP for the last six years and no control group is available. The latter is not practical, as collecting firm output data would require resources beyond the scale of this project and would be unacceptable to customers.

73 The substitution elasticity underestimates the response from customers that forego electricity usage without making it up later or respond with onsite generation (see section 3.1).
} 
The substitution elasticity provides a means to compare the intensity of price response among different customers and customer groups. We employ a Generalized Leontief (GL) model of firm behavior that estimates substitution elasticities from customers' load and price data over the study period. We also characterized other dimensions of price response, such as the effects of weather, load and nominal prices and drivers to price response by regressing elasticity of substitution results against various factors. We hypothesize that a customer's ability and inclination to respond cannot be predicted by its business activity or size alone.

Customer interviews and surveys conducted in both phases of this study indicate that customers employ a variety of load curtailment strategies and behaviors. Many customers say they respond to price increases by reducing discretionary usage during peak periods without making it up later, and a few report that they indeed shift usage, but to another day. We acknowledge that input substitution is not the only type of response observed. However, the substitution elasticity is structurally consistent with all these load response strategies - foregoing load, using onsite generation, and shifting usage to other days because they all result in a reduction in the ratio of peak to off-peak usage in response to higher peak prices. Our model specification cannot separately and consistently account for each of these effects, but no model can. To the extent that these behaviors are present, our model underestimates the reduction in peak demand from these other response strategies. ${ }^{74}$ The implication is that our elasticity estimates are conservative.

\subsection{Key Findings and Implications}

We highlight several key findings and policy implications from this second-phase case study of SC-3A customers' response to default-service, day-ahead market RTP. Table 5-1 summarizes these findings and the related policy implications. Each of these findings and implications are discussed in detail in the following sections.

\footnotetext{
${ }^{74}$ To illustrate, for a customer that foregoes load and does not make it up later, we observe a reduction in peak usage and no corresponding change in off-peak usage. This results in a reduction in the peak to offpeak usage ratio, but one of lesser magnitude than for a customer that reduced the same amount of load and made it up in the off-peak period. Thus, the model captures but underestimates the response from foregoing usage. Similar results occur for inter-day shifting and self-generation.
} 
Table 5-1. Key Findings and Policy Implications

\begin{tabular}{|c|c|c|}
\hline \multicolumn{2}{|c|}{ Key Findings } & \multirow{2}{*}{$\begin{array}{l}\text { Policy Implications } \\
\text { Business activity alone is not an accurate } \\
\text { predictor of price response. }\end{array}$} \\
\hline $\begin{array}{l}\text { Intensity of } \\
\text { Price }\end{array}$ & $\begin{array}{l}\text { Price response is modest overall - the average } \\
\text { elasticity is } 0.11\end{array}$ & \\
\hline \multirow{3}{*}{$\begin{array}{l}\text { Price } \\
\text { Response }\end{array}$} & $\begin{array}{l}\text { Two-thirds of customers have positive substitution } \\
\text { elasticities }\end{array}$ & \multirow{3}{*}{$\begin{array}{l}\text { Policymakers should recognize the } \\
\text { heterogeneity of response and ensure that } \\
\text { hedging opportunities exist for customers that } \\
\text { cannot respond. Public benefits technical } \\
\text { assistance programs should be targeted to those } \\
\text { that need it most }\end{array}$} \\
\hline & $\begin{array}{l}\text { Manufacturing customers are most price- responsive } \\
(0.16) \text {, followed by government/education }(0.10)- \\
\text { other sectors have very low elasticities }\end{array}$ & \\
\hline & $\begin{array}{l}\text { Individual customer elasticities vary substantially } \\
\text { within sectors - most manufacturing customers are } \\
\text { either highly responsive or not at all }\end{array}$ & \\
\hline \multirow[t]{3}{*}{$\begin{array}{l}\text { Character } \\
\text { of Price } \\
\text { Response }\end{array}$} & $\begin{array}{l}\text { Government/education and commercial/retail } \\
\text { customers respond more when nominal prices are } \\
\text { higher }\end{array}$ & \multirow[t]{2}{*}{$\begin{array}{l}\text { RTP can be expected to provide the most } \\
\text { response when it is most needed. }\end{array}$} \\
\hline & $\begin{array}{l}\text { Government/education customers' response declines } \\
\text { slightly as they reach their peak demand }\end{array}$ & \\
\hline & $\begin{array}{l}\text { Government/education and commercial/retail } \\
\text { customers' response increases on hot days }\end{array}$ & $\begin{array}{l}\text { Weather effects may be even more important in } \\
\text { areas such as inland California }\end{array}$ \\
\hline \multirow[t]{4}{*}{$\begin{array}{l}\text { Drivers of } \\
\text { Price } \\
\text { Response }\end{array}$} & $\begin{array}{l}\text { NYISO emergency programs enhance price response, } \\
\text { in part by providing coincident signals to curtail }\end{array}$ & $\begin{array}{l}\text { For some customers, notification of events and } \\
\text { fulfilling a perceived community obligation to } \\
\text { curtail are more important than cost savings - } \\
\text { RTP should be complemented with DR } \\
\text { programs that alert and compensate customers } \\
\text { for responding to system emergencies }\end{array}$ \\
\hline & $\begin{array}{l}\text { Load management and information technologies do not } \\
\text { influence customer response to hourly prices at the } \\
\text { present time }\end{array}$ & $\begin{array}{l}\text { Disseminating information gateway } \\
\text { technologies is not enough - large customers } \\
\text { need assistance to develop load response } \\
\text { strategies }\end{array}$ \\
\hline & $\begin{array}{l}\text { Onsite generation can contribute to significant load } \\
\text { response }\end{array}$ & $\begin{array}{l}\text { Distributed generation can create opportunities } \\
\text { for price and load response }\end{array}$ \\
\hline & $\begin{array}{l}\text { "Champions” are probably a significant driver to price } \\
\text { response }\end{array}$ & $\begin{array}{l}\text { Programs to recognize the efforts of champions } \\
\text { can promote price response }\end{array}$ \\
\hline \multirow{4}{*}{$\begin{array}{l}\text { Customer } \\
\text { Strategies } \\
\text { for } \\
\text { Responding }\end{array}$} & Over two-thirds of customers say they can respond & \multirow{3}{*}{$\begin{array}{l}\text { There is significant latent response potential but } \\
\text { it is diverse in nature - programs and/or tariff } \\
\text { options should be designed to make best use of } \\
\text { this diversity }\end{array}$} \\
\hline & $\begin{array}{l}\text { Customers employ varied load response strategies - } \\
\text { shifting, foregoing, and self-generation }\end{array}$ & \\
\hline & $\begin{array}{l}\text { Government/education customers most often forego } \\
\text { usage; manufacturing customers are more likely to shift }\end{array}$ & \\
\hline & $\begin{array}{l}\text { What customers say they do and what they seem to do } \\
\text { are at odds }\end{array}$ & $\begin{array}{l}\text { Policymakers should avoid making hard and fast } \\
\text { rules based on surveys or pilots }\end{array}$ \\
\hline \multirow{3}{*}{$\begin{array}{l}\text { Barriers to } \\
\text { Price } \\
\text { Response }\end{array}$} & $\begin{array}{l}\text { Most customers report multiple barriers to price } \\
\text { response - only } \sim 15 \% \text { respond without obstacles }\end{array}$ & \multirow{3}{*}{$\begin{array}{l}\text { Some barriers may be overcome with time with } \\
\text { customer education and technical assistance, but } \\
\text { policymakers should expect that about half of } \\
\text { large customers cannot or have no intention of } \\
\text { responding to prices, at least under current } \\
\text { pricing conditions }\end{array}$} \\
\hline & $\begin{array}{l}\text { Over half of large customers report not having time or } \\
\text { resources to monitor prices }\end{array}$ & \\
\hline & $\begin{array}{l}\text { Inadequate incentives keep one quarter of NMPC } \\
\text { customers from responding }\end{array}$ & \\
\hline \multirow[t]{3}{*}{$\begin{array}{l}\text { Customer } \\
\text { Acceptance }\end{array}$} & $\begin{array}{l}\text { Day-ahead RTP is well accepted by large customers in } \\
\text { New York }\end{array}$ & \multirow{2}{*}{$\begin{array}{l}\text { Default service based on day-ahead prices is an } \\
\text { acceptable compromise for most large } \\
\text { customers; it affords greater notice of prices, and } \\
\text { may result in higher demand response than real- } \\
\text { time RTP }\end{array}$} \\
\hline & $\begin{array}{l}\text { Most customers have not hedged: } 45-60 \% \text { were fully } \\
\text { exposed to day-ahead prices in } 2004\end{array}$ & \\
\hline & $\begin{array}{l}\text { Market penetration of financial hedges is particularly } \\
\text { low }\end{array}$ & $\begin{array}{l}\text { Many customers are unfamiliar with financial } \\
\text { products as they relate to energy and may } \\
\text { require education if this market is to develop }\end{array}$ \\
\hline
\end{tabular}




\subsubsection{The Intensity of Price Response}

We evaluated the intensity of price response using substitution elasticities derived from a GL model (see sections 3.2 and 5.1). We draw the following key findings from these results.

\section{Price response is modest overall - the average elasticity is 0.11}

As a group, SC-3A customers' price response is modest - the load-weighted average substitution elasticity is 0.11 , which means that their combined ratio of peak to off-peak electricity usage declines by $11 \%$ in response to a doubling of peak prices (relative to offpeak prices). This level of price response is consistent with other studies that have evaluated of the behavior of large customers facing similar pricing circumstances (Herriges et al. 1993, Schwarz et al. 2002, Boisvert et al. 2004).

At the highest prices observed during the study period, in which the peak price was five times the off-peak price, we estimate that these customers, as a group, reduced their peak usage by $~ 50 \mathrm{MW}$, about $10 \%$ of their combined summer peak demand of about 500 MW.

\section{Two-thirds of customers have positive substitution elasticities}

Almost two-thirds of SC-3A customers (65\%) exhibit some price response (elasticities > 0.01 ), but for many of them the response is small. The other third, with zero elasticities, appear to use peak and off-peak electricity in fixed proportions, regardless of prices. Eighteen percent of customers exhibit relatively high price response $(>0.10)$, accounting for $\sim 75-80 \%$ of the aggregate demand response.

\section{Manufacturing customers are most price- responsive (0.16), followed by government/education (0.10) - other sectors have very low elasticities}

Not all sectors exhibit the same intensity of price response. Manufacturing firms, as a group, are $45 \%$ more price responsive than the average, with a sector elasticity of 0.16 . This comports with the conventional wisdom that these customers are good candidates for price response, though there is substantial variation within this group. The government/education sector was also found to be quite price-responsive, with an average elasticity value of 0.10 . The commercial/retail, healthcare and public works sectors are relatively unresponsive, with respective elasticities of $0.06,0.04$, and 0.02 .

\section{Individual customer elasticities vary substantially within sectors - most manufacturing customers are either highly responsive or not at all}

An important finding of this study is that elasticity results are not uniform within business sectors. This is most pronounced for manufacturing customers. Twenty-seven percent of manufacturing firms are highly price responsive, with elasticities above 0.10 . But $63 \%$ are largely non-responsive (elasticities $<0.05$ ), including $27 \%$ with zero elasticities. 
Thus, the high average elasticity for this sector is provided by a few, very responsive, customers.

The government/education sector, which has a lower overall elasticity, has almost as many highly elastic customers as the manufacturing sector (24\%) and proportionally fewer non-responsive customers (42\%). The majority of commercial/retail, healthcare and public works customers are non-responsive, although there are some price-responsive customers in each group.

\section{Policy Implications}

The heterogeneity of price response, both among and within business sectors, should be explicitly recognized by policymakers. The common presumption that manufacturing customers are highly price responsive is true for some of these customers, but our results suggest that for many this is not the case at all. Furthermore, there is significant price response potential from a wide base of government/education customers that should not be ignored. Given that a large proportion of the response ( $80 \%)$ comes from a small proportion of customers ( $\sim 20 \%$ ), policymakers need to expect that a large proportion of customers will not be able to respond at all, at least under the pricing conditions observed in this study and should ensure that hedged alternatives to dynamic pricing are available. Disaggregated customer characteristics and elasticity information can be used to target public benefits programs toward those customers with the greatest need for priceresponse assistance. Competitive retailers may also use this information to identify and target price-responsive customers.

\subsubsection{The Character of Price Response}

We evaluated the character of price response in a regression model that examined the impact of nominal prices and load on price response (see section 3.3.7). Key findings from this research are as follows.

\section{Government/education and commercial/retail customers respond more when nominal prices are higher; manufacturing customers respond more when peak/off-peak price ratios are higher}

We find that government/education and commercial/retail customers exhibit higher price response when nominal prices are higher. For government/educational customers, who tend to respond by foregoing load (and not making it up in the off-peak period), this makes intuitive sense. Manufacturing firms appear to respond primarily to the peak to off-peak price ratio. These customers tend to respond by shifting load rather than curtailing, so it makes sense that their response is motivated by the daily price ratio. The price response of public works and healthcare customers declines slightly as nominal prices increase. 


\section{Government/education customers' response declines slightly as they reach their peak demand}

We find that government/education customers' average sector-level elasticity declines slightly (about 3\%) when they are operating close to their peak demand. No other sectors exhibited this correlation.

\section{$\underline{\text { Policy Implication }}$}

The finding that government/education and commercial/retail customers tend to increase their response when prices are high is encouraging: it implies that RTP can be expected to provide the most response when it is most needed. It is also encouraging that although there is a reduction in government/education customers' response as they reach their maximum demand this effect is relatively small. ${ }^{75}$ However, we caution that New York's summer climate is moderate relative to other parts of the U.S., and the prices study customers faced were seldom high for more than a few hours during the study period. Prolonged hot weather accompanied by high prices could result in response fatigue.

These results also have implications for the design of CPP tariffs for large commercial and industrial customers, in which an arbitrary high price is used to elicit price response when it is needed. The conventional thinking is that a very high price is needed, but our results suggest that this is true for only some customers, while excessively high prices may be punitive for others. If feasible, the most efficient design would discriminate among sectors to achieve predictable load reduction results.

\section{Government/education and commercial/retail customers' response increases on hot days}

Government/education customers, on average, increase their price response by about 20\% on hot days compared to cooler days and commercial/retail customers' average elasticity doubles. For the other business sectors, there is no or negligible difference in sector-level elasticities between hot and cool days.

\section{Policy Implication}

Hot days are correlated with both high SC-3A prices and NYISO DR program events in NMPC service territory. Under the weather and price conditions experienced in upstate New York during our study period, these signals appear to have overridden government/education and commercial/retail customers' need for increased cooling on hot days. This suggests that some service-oriented customers are willing to put up with a certain amount of discomfort in order to respond to high hourly prices or participate in ISO emergency DR programs. However, we caution that summer weather conditions in upstate New York are less extreme than in other areas, such as inland California. Whether the promise of greater price response as temperatures rise suggested by our results would

\footnotetext{
${ }^{75}$ The peak demand of these customers is not correlated with hot weather, so this and the previous result are not contradictory.
} 
hold up under more extreme conditions is unclear. The importance of accounting for weather effects in modeling price response should not be understated.

\subsubsection{Drivers of Price Response}

We investigated drivers to price response - customers' characteristics and circumstances - using a heuristic regression model (section 3.3.8) and by examining trends qualitatively among price responsive and non-responsive customers (section 4.2). The model results were somewhat disappointing - few factors had statistically significant impacts on price response - partly because the sample size was limited to customers that had answered the survey. Nonetheless, we highlight several intuitive relationships that provide insights into the factors that cause customers to be price responsive or not.

\section{NYISO emergency programs enhance price response, in large part by providing coincident signals to curtail}

In the regression model, participation in NYISO’s Emergency Demand Response Program (EDRP) has a significant positive correlation with price response. This statistical finding is supported by survey responses that indicate that customers are more accustomed to respond to NYISO emergency events than SC-3A prices directly. Because EDRP events have been coincident with high day-ahead prices during our study period, it is not possible to extricate customers' response to these two signals. Based on survey and interview results, we know that many customers are aware of this coincidence and may look to NYISO events as a signal that prices are high. In addition, for many customers, response to emergency programs is motivated by a "good citizen" factor and therefore is viewed more as an obligation to the community than an economic response.

Not surprisingly then, there is a strong correspondence between customers' price responsiveness and EDRP participation. Almost $60 \%$ of highly responsive customers (with elasticities $>0.10$ ) were enrolled in EDRP. By contrast, only 36\% of moderately responsive customers $(0.05-0.10)$ and $27 \%$ of non- or somewhat responsive customers $(<0.05)$ were enrolled.

Contrary to expectations, ICAP/SCR (another NYISO demand response program) participation does not appear to have a discernable impact on price response, statistical or otherwise. One would think that the threat of penalty for not curtailing that goes with ICAP/SCR would result in measurable price response from this program. We believe that the coincidence of high SC-3A day-ahead prices and the incidence of NYISO demand response program curtailment events makes it impossible to identify separate effects for both NYISO programs.

\section{$\underline{\text { Policy Implication }}$}

These results suggest that NYISO EDRP complements SC-3A prices in eliciting price response in important ways. For some customers, notification of events and the opportunity to help out in emergencies are more important than cost savings. Thus RTP alone may not draw out their full price response potential, and policymakers for whom 
demand response is a primary concern should consider complementing RTP with DR programs that alert and compensate them for responding to system emergencies.

\section{Load management and energy information systems do not currently influence customer response to hourly prices}

Many SC-3A customers have installed energy management control systems (EMCS), peak load management (PLM) devices and energy information systems (EIS), technologies that have the potential to assist with price response. However, we found no meaningful statistical relationships between use of these technologies and price response. In interviews and surveys, most customers indicated that, at present, they use them for other purposes than short-term price response, primarily for achieving across-the-board energy savings (permanent load reductions) and/or managing their peak demand.

\section{$\underline{\text { Policy Implication }}$}

Promoting dissemination of enabling technologies is not a sufficient strategy to enhance short-term price response, in part because customers may consider the savings, which are available during only a few hours per year, as insufficient to justify the effort or the cost of the equipment. While recent research by Piette et al. (2005) demonstrates the potential for fully automated DR strategies, customers at present clearly need technical assistance to implement them. There may be a role for energy services companies to provide DRenabling technologies to customers as part of a larger package of products and services, with price response automation included as a value-added feature.

\section{Onsite generation can contribute to significant load response}

In the demand model, the presence of onsite generation is positively correlated with price response, but this effect is not statistically significant. While over half of SC-3A customers have onsite generation equipment, the majority told us in surveys and interviews that they do not use it for price response. Many of these systems are existing, older backup generators that are wired for reliability purposes only and do not lend themselves to price response. However, among the most price responsive customers, several have onsite generation installed, and a few customers told us in interviews that they have scheduled equipment tests allowed under their operating permits when prices were high.

\section{$\underline{\text { Policy Implication }}$}

Although few SC-3A customers have responded to hourly prices or NYISO events using onsite generation, we observe that for those that have, significant load response resulted. While environmental and health considerations must be taken into account, distributed generation has the potential to create significant new opportunities for price and load response. $^{76}$

\footnotetext{
${ }^{76}$ Some distributed generation technologies may increase overall pollutant emission levels if they emit more than the marginal generation units they replace. In addition, even if overall emissions from onsite
} 


\section{“Champions" are probably a significant driver to price response}

Because we found few characteristics of statistical significance in describing price response, we know there must be other, more subtle, factors that explain why customers that are otherwise "identical" - in size, business practice and other easily observed factors - exhibit substantially different degrees of price responsiveness. Based on two years of interviewing customers, we believe the presence of a facility manager willing to take risks to forward price response within his or her organization - an internal "champion" is vitally important, though not easily measured. While the savings from price response might be a small fraction of total electricity costs, and an even smaller portion of an organization's total operating costs, committed energy managers often direct their efforts toward areas they can influence and, for many, price response is such an opportunity.

\section{Policy Implication}

While policymakers cannot directly control the presence of champions within customer organizations, programs that offer recognition to such individuals can both reward them for their efforts and promote broader awareness that price response is important. Similar programs have been instituted for energy-efficiency champions by Energy Star, the Federal Energy Management Program and professional engineering societies (e.g., ASHRAE, Association of Energy Engineers).

\subsubsection{Customer Strategies for Responding}

We explored customers' qualitative load response strategies through survey and interview questions to add context and texture to elasticity results (see section 4.1.1). The following findings demonstrate the diversity of responses, as well as the mismatch between some customers' self-reported behavior and the price response we observe.

\section{Over two-thirds of customers say they can respond}

In our 2004 survey, $71 \%$ of respondents indicated that they can respond in some way to high prices, NYISO events or public appeals to conserve. This is substantially higher than the $46 \%$ that said they could respond in the previous year's survey (Goldman et al. 2004). This comports with the empirical finding that about two-thirds of customers exhibit positive elasticity of substitution values.

\section{Customers employ varied load response strategies - shifting, foregoing, and self- generation}

Customers reported deploying three different load response strategies: shifting load from one time period to another (22\% of surveyed customers), foregoing discretionary usage

generation are lower than for the marginal units, the relative proximity of onsite generation units to residences and workplaces may result in higher rates of human pollutant exposure. 
and not making it up at another time (45\%) and supplying load with onsite generation (16\%). Thirteen percent of customers reported more than one load response strategy.

\section{Government/education customers most often forego usage; manufacturing customers are more likely to shift}

Most government/education customers (83\%) report that they respond by foregoing load and not making it up later. Manufacturing customers display the most variety in the types of load response strategies reported, and report load shifting more frequently than other customer types; $40 \%$ of these customers say they can shift.

\section{Policy Implications}

There is significant latent response potential but it is diverse in nature. Price response programs and tariff options should be designed to make best use of this diversity. It should also be noted that the load response strategies reported were framed in terms of response to any of the signals SC-3A customers have faced - high SC-3A prices, NYISO events and public appeals to conserve. Thus, while there is considerable latent load response capability, it is important to remember that not all customers will necessarily exercise this capability if presented with RTP price signals alone. Other programs to elicit this potential may be necessary for some customers.

\section{What customers say they do and what they seem to do are at odds}

In this and similar studies of price response that we have conducted, we have been confronted with a discrepancy between what some customers say they do and what their actions indicate they actually do. This arose in two critical areas in this study: customers' self-reported load response behavior and their participation in NYISO demand response programs. ${ }^{77}$ We found that six out of nine survey respondents who were very price responsive (elasticity $>0.10$ ) said they could not respond, while one customer that claimed to respond had a low substitution elasticity $(<0.05)$. Nine of the twenty-nine customers that attested to having curtailed load to earn NYISO DR program incentive payments had never been enrolled in the programs. Twenty-four of the forty-three customers that we verified had received payments for program curtailments claimed that they had not responded to any signals at all (prices, NYISO emergencies or public appeals to conserve). ${ }^{78}$

There are a number of possible explanations for these discrepancies. When we conducted the survey, it had been two summers since NYISO events and high SC-3A prices had occurred. Our questions were framed over the entire study period (five years previous), and it is likely that some customers did not accurately remember if or how they had

\footnotetext{
${ }^{77}$ We also encountered inconsistencies regarding customers' supplier histories. Some customers told us that they'd been with a competitive supplier for periods when their billing information indicated they'd been with NMPC. The converse was also true in some cases.

${ }^{78}$ We observed the same phenomenon in evaluating the performance of ISO-based demand response programs, where customers that were paid for curtailing during events reported that they had not responded to any requests to curtail (Neenan et al. 2003).
} 
responded. In some cases, we believe that the individuals responding to our survey were not directly responsible for making decisions about adjusting usage in response to prices or about energy procurement and consequently may not have been able to accurately describe their organization's experience. Strategic survey response is another possibility - some customers may have provided answers that reflected what they thought we wanted to hear, or what they wanted us to hear.

Finally, we acknowledge that our ability to accurately measure customers' behavior is limited and may contribute to these discrepancies. For example, the elasticity of substitution underestimates the load response from customers that forego discretionary usage (see section 5.1). In some cases, particularly where the foregoing response is small, this may lead us to conclude that a customer that actually does provide some load response is not responsive at all.

\section{Policy Implications}

In light of these issues, we urge policymakers to be creative and not translate the results of surveys or limited pilot analyses into hard and fast rules about customers' inclination and ability to respond to price signals. New initiatives should be launched with a commitment to study how customers react to opportunities to participate. This should include efforts to quantify, to a high degree of resolution, how customers that face hourly prices actually respond, as well as to collect qualitative information from customers to provide interpretive context for empirical results.

\subsubsection{Barriers to Price Response}

We explored barriers to price response through survey and interview questions. We highlight the following key points from this research.

\section{Most customers report multiple barriers to price response - only 15\% respond without obstacles}

Twelve percent of survey respondents reported that they had encountered no barriers in responding to SC-3A prices. This comports, although not precisely, with our finding that $18 \%$ of customers are highly price responsive (elasticities $>0.10$ ). The rest of the respondents each reported one to five barriers to responding to SC-3A prices.

\section{Over half of large customers report not having time or resources to monitor prices}

The most common barrier to price response - reported by $51 \%$ of survey respondents - is a lack of time or resources to monitor day-ahead prices. Asked specifically how often they monitor prices, $\sim 70 \%$ of survey respondents indicated that they rarely or never do so. ${ }^{79}$ For some, this all but precludes price response. Others appear to rely on coincident signals - NYISO events or hot weather - to alert them of high prices.

\footnotetext{
${ }^{79}$ Another implication of this finding is that customers may not pay attention to off-peak prices and consequently do not take advantage of load-building opportunities when prices are low. This is in contrast
} 


\section{Inadequate incentives keep one-quarter of customers from responding}

Another barrier of concern to policymakers designing dynamic pricing tariffs is the size of the incentives created by high hourly prices. Almost one-quarter of survey respondents cited inadequate incentives as a barrier to price response. This suggests that for the other three-quarters of customers, the incentives afforded by SC-3A prices are either sufficient to justify responding, or it may be that other barriers are of greater significance. ${ }^{80}$ If the incentives were much higher, it is not clear if price response would be more widespread, or if rigidities in customers' electricity usage are so entrenched in business practices that price response would not be practical, regardless of how high prices became.

\section{Policy Implications}

Despite the preponderance of barriers encountered by SC-3A customers, two-thirds of them have positive estimated elasticity of substitution values. It appears that some customers have been able to overcome many of these barriers, at least during the isolated occurrences of high prices and NYISO events of the last few years. Thus, we believe that some barriers may indeed be overcome with time. For example, targeted efforts to promote implementation of semi- or fully automated DR strategies could eliminate the need for customers to monitor hourly prices actively.

However, policymakers should expect that about half of large customers cannot or may have no intention of becoming affirmatively price responsive, regardless of whether alternatives to day-ahead pricing are available to them. Others may be price responsive under regimes of occasional high prices, but may seek to hedge their exposure if prices become too high or too volatile. Some smaller fraction, perhaps $20-25 \%$, of highly responsive customers would probably elect to remain on day-ahead pricing and respond to price spikes, even if they occurred with greater frequency than observed for SC-3A customers. This amount of price responsive load may be enough to abate the worst consequences of wholesale spot market price volatility.

\subsubsection{Customer Acceptance}

Finally, we examined customer acceptance of day-ahead market-based hourly pricing through customer survey and interview questions and by evaluating customers' supplier choice and hedging decisions.

\section{Day-ahead RTP is well accepted by large customers in New York}

In two years of administering surveys and interviews, we have heard few complaints about NMPC's default service: customers are relatively satisfied with day-ahead market

to how many predecessor voluntary RTP programs have been promoted to customers: as a tradeoff between paying occasional high prices in return for load-building during low-priced hours.

${ }^{80}$ Customers were asked to indicate all barriers that applied to them, but it is possible that they neglected to indicate inadequate incentives if, for example, they never check prices and have never evaluated them, let alone made a determination about the incentives they afford. 
pricing. Six years after day-ahead market pricing was introduced, 36\% of SC-3A customers (representing 34\% of SC-3A load) still take their commodity from NMPC on the default rate. ${ }^{81}$ Survey respondents indicated that they would be more likely to leave the utility if the default service was indexed to the NYISO real-time market, which affords no advance notice of prices.

\section{Most customers have not hedged: 45-60\% were fully exposed to day-ahead prices in 2004}

Although the majority of customers interviewed told us they would prefer to hedge against price volatility, as many as $60 \%$ of SC-3A customers remain fully exposed to day-ahead market prices, either on the default SC-3A rate or a similarly indexed commodity deal with a competitive retail supplier. We believe that the main explanation for so many customers remaining un-hedged, yet not being very price responsive, is that they are "psychologically hedged": they have evaluated SC-3A prices and the market options available to them and decided that they are comfortable with the risks associated with day-ahead market pricing. Many of these customers may not be price responsive, having already rationalized and accepted a certain degree of price risk as part of their decision not to hedge.

\section{Policy Implications}

The acceptance of day-ahead market pricing by SC-3A customers is probably largely a function of the tariff design and price regimes these customers have faced over the past six years. In New Jersey, implementing default-service RTP indexed to the real-time market, which affords no advance notice of prices, has resulted in very high switching rates (84\% of load) over a shorter time period (two years) (Barbose et al. 2005). This suggests that most large customers require some notice of prices in order to feel comfortable. Day-ahead RTP is seen as less risky by customers than real-time RTP and is therefore much more likely to be accepted by them. Ultimately, policymakers must rely on customers to provide price response. It follows that their acceptance of the tariff or program designed to elicit this response is critical, and subjecting them to real-time RTP may result in reduced price response if the vast majority seek out fully hedged supply contracts rather than responding by shifting or curtailing load when peak prices are high.

\section{Market penetration of financial hedges is particularly low}

We asked customers to indicate whether they had purchased financial derivatives that hedge against electricity price volatility and found that less than $10 \%$ of survey respondents had done so. About half of the rest either could not articulate why they had not or were not sure what a financial hedge is. This may reflect a culture within firms and

\footnotetext{
${ }^{81}$ Customers have expressed dissatisfaction with retail market offerings in interviews, in particular an inability to find suppliers interested in serving them or hedges that they felt were reasonably priced. However, we heard fewer complaints in the second year of our study than the first. This, combined with increased customer migration in recent years, suggests that the market is maturing.
} 
institutions that sees financial products as distinct from energy supply contracts or under which the two products may be procured by different departments and people. ${ }^{82}$

\section{$\underline{\text { Policy Implication }}$}

Many large customers are apparently unfamiliar with financial hedging products as they relate to energy. This lack of awareness, observed among large customers exposed to day-ahead pricing and competitive retail markets for six years, strongly suggests that customers require education if a robust market for these products is to develop.

Policymakers that are concerned about ensuring adequate hedging options exist initially for customers exposed to default-service RTP should consider efforts to educate customers about financial hedge products and possibly having the default utility offer a hedged alternative (such as NMPC’s Option 2) during the transition period.

${ }^{82}$ In addition, some customers may have institutional rules preventing them from purchasing derivatives this too can be a barrier to financial hedging. 



\section{References}

Barbose, G., C. Goldman, and B. Neenan, 2004, "Real Time Pricing Tariffs: A Survey of Utility Program Experience”, Lawrence Berkeley National Laboratory: LBNL-54238, March.

Barbose, Galen, Chuck Goldman, Ranjit Bharvirkar, Nicole Hopper, Mike Ting and Bernie Neenan, 2005, "Real Time Pricing as a Default or Optional Service for C\&I Customers: A Comparative Analysis of Eight Case Studies” report to the Calfornia Energy Commission, Lawrence Berkeley National Laboratory: LBNL-57661, forthcoming.

Boisvert, Richard N. and Bernard F. Neenan, 2003, "Social Welfare Implications of Demand Response Programs in Competitive Electricity Markets”, report to Lawrence Berkeley National Laboratory: LBNL-52530, April.

Boisvert, Richard, Peter Cappers, Bernie Neenan and Bryan Scott, 2004, "Industrial and Commercial Customer Response to Real Time Electricity Prices”, December, available online at http://eetd.lbl.gov/ea/EMS/drlm-pubs.html.

Borenstein, Severin, 2002, “The Theory of Demand-Side Price Incentives”, in Dynamic Pricing, Advanced Metering and Demand Response in Electricity Markets, Hewlitt Foundation Energy Series, San Francisco CA, October.

Borenstein, Severin, 2005 (revised), “The Long-Run Efficiency of Real-Time Electricity Pricing”, Center for the Study of Electricity Markets (CSEM) Working Paper 133r, February.

Braithwait, Steven, 2005, Christensen Associates Energy Consulting, personal communication, August 10.

Braithwait, Steven and Michael O'Sheasy, 2001, "RTP Customer Demand Response Empirical Evidence on How Much You Can Expect”, Chapter 12 in Electricity Pricing in Transition, A. Faruqui and K. Eakin, editors, Kluwer Academic Publishers.

Caves, D., L. Christensen and J. Herriges, 1984, “Consistency of Residential Response in Time of Use Pricing Experiments”, Journal of Econometrics 26(1984):179-203.

Charles River Associates, 2005, “Impact Evaluation of the California Statewide Pricing Pilot”, final report to the California Energy Commission, March 16.

Christensen Associates, 1995, "Reaping the Benefits of RTP: Georgia Power's RTP Evaluation Case Study”, Electric Power Research Institute: EPRI TR-105044.

Goldman, C., N. Hopper, O. Sezgen, M. Moezzi, R. Bharvirkar, B. Neenan, R. Boisvert, P. Cappers, and D. Pratt, 2004, “Customer Response to Day-ahead Wholesale Market Electricity Prices: Case Study of RTP Program Experience in New York”, report to the 
California Energy Commission, Lawrence Berkeley National Laboratory: LBNL-54761, June.

Federal Energy Regulatory Commission (FERC), 2002, “Working Paper on Standardized Transmission Service and Wholesale Electric Market Design”, March 15, available online at http://www.ferc.gov/industries/electric/indus-act/smd/nopr/work-pap.PDF.

Hedman, Bruce A., Ken Darrow and Tom Bourgeois, 2002, "Combined Heat and Power Market Potential for New York State”, report to the New York State Energy Research and Development Agency, Energy Nexus Group, Onsite Energy Corporation and Pace Energy Project, October.

Herriges, J. A., S. M. Baladi, D. W. Caves and B. F. Neenan, 1993, “The Response of Industrial Customers to Electric Rates Based Upon Dynamic Marginal Costs” Review of Economics and Statistics 75(20): 446-454.

King, K. and P. Shatrawka, 1994, "Firm Response to Real-Time Pricing in Great Britain", in the proceedings of the American Council for an Energy Efficient Economy (ACEEE) 1994 Summer Study on Energy Efficiency in Buildings, Panel 2: Demand and Load Shapes, pp. 2194-2203.

Neenan, B., D. Pratt, P. Cappers, J. Doane, J. Anderson, R. Boisvert, C. Goldman, O. Sezgen, G. Barbose, R. Bharvirkar, M. Kintner-Meyer, S. Shankle and D. Bates, 2003, "How and Why Customers Respond to Electricity Price Variability: A Study of NYISO and NYSERDA 2002 PRL Program Performance”, report to the New York Independent System Operator (NYISO) and New York State Energy Research and Development Agency (NYSERDA), January.

Patrick, Robert H. and Frank A. Wolak (2001). "Estimating the Customer-Level Demand for Electricity Under Real-Time Market Prices”, National Bureau of Economic Research (NBER) Working Paper 8213, April.

Piette, M. A., O. Sezgen, D. Watson, N. Motegi, C. Shockman, and L. ten Hope, 2005, "Development and Evaluation of Fully Automated Demand Response in Large Facilities”, California Energy Commission: CEC-500-2005-013, January.

Ruff, Larry E., 2002, “Economic Principles of Demand Response in Electricity”, report to the Edison Electric Institute, October.

Schwarz, P. M., T. N. Taylor, M. Birmingham and S. L. Dardan, 2002, "Industrial Response to Electricity Real-Time Prices: Short Run and Long Run” Economic Inquiry 40(4): 597-610.

Taylor, Thomas N. and Peter M. Schwarz, 2000, "Advance Notice of Real-Time Electricity Prices” Atlantic Economic Journal 28(4): 478-488. 
Taylor, Thomas N., Peter M. Schwarz and James E. Cochell, 2005, “24/7 Hourly Response to Real-Time Pricing with up to Eight Summers of Experience” Journal of Regulatory Economics 27(3): 235-262.

Tractebel Energy Services, Inc., 2004, “Texas 2004 Energy Usage and Sourcing Trend Survey Analysis”, October 26, available online at http://www.tractebelenergy.com/Ourexp/documents/TXTrendSurveCompleteResults.pdf.

Tractebel Energy Services, Inc., 2005, “NE Trend Survey”, January 24.

Zarnikau, Jay, 1990, “Customer responsiveness to real-time pricing of electricity.” The Energy Journal 11(4): 99-116. 

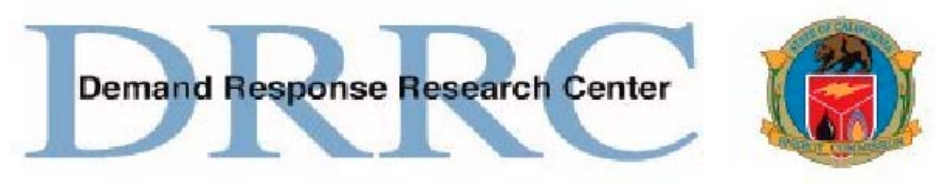

LBNL-57128

\title{
Customer Strategies for Responding to Day-Ahead Market Hourly Electricity Pricing: Appendices
}

\author{
Prepared for the \\ California Energy Commission \\ Principal Authors \\ C. Goldman, N. Hopper and R. Bharvirkar \\ Lawrence Berkeley National Laboratory \\ B. Neenan, R. Boisvert, P. Cappers, D. Pratt, K. Butkins and L. Scholle \\ Neenan Associates \\ Ernest Orlando Lawrence Berkeley National Laboratory \\ 1 Cyclotron Road, MS 90R4000 \\ Berkeley CA 94720-8136
}

August 2005

The work described in this report was coordinated by the Demand Response Research Center and funded by the California Energy Commission, Public Interest Energy Research Program, under Work for Others Contract No. 500-03-026 and by the U.S. Department of Energy under Contract No. DE-AC03-76SF00098. 
Prepared By: Charles A. Goldman

Lawrence Berkeley National Laboratory

Berkeley, California

Contract No. 500-03-026

Prepared For:

California Energy Commission

Public Interest Energy Research (PIER)

Program

Dave Michel

Contract Manager

Mark Rawson

Program Area Team Lead

Martha Krebs

Deputy Director

ENERGY RESEARCH AND DEVELOPMENT

DIVISION

B.B. Blevins

Executive Director

The work described in this report was coordinated by the Demand Response Research Center and funded by the California Energy Commission, Public Interest Energy Research Program, under Work for Others Contract No. 500-03-026 and by the U.S. Department of Energy under Contract No. DEAC02-05CH11231.

\section{DISCLAIMER}

This report was prepared as the result of work sponsored by the California Energy Commission. It does not

necessarily represent the views of the Energy

Commission, its employees or the State of California. The

Energy Commission, the State of California, its

employees, contractors and subcontractors make no

warrant, express or implied, and assume no legal liability

for the information in this report; nor does any party

represent that the uses of this information will not infringe

upon privately owned rights. This report has not been

approved or disapproved by the California Energy

Commission nor has the California Energy Commission

passed upon the accuracy or adequacy of the information

in this report. 


\section{Appendix A. 2004 SC-3A Customer Survey}

1. Please confirm your contact information.
1. Name
2. Organization
3. Title
4. Address

5. Phone

6. Fax

7. Email

The following questions pertain to your facilities that receive electricity service from Niagara Mohawk Power Corporation (NMPC) under the SC-3A rate classification.

2. On a normal summer weekday, during which of the following time periods is your facility's electricity use highest? (CHECK ONLY ONE)
口 1. 8 a.m. -12 noon
$\square$ 2. 12 noon -6 p.m.
口 3. 6 p.m. -10 p.m.
$\square$ 4. 10 p.m. -8 a.m.

$\square$ 5. Do not know

3. Which of the following best describes how often you monitor the next day's hourly electricity prices? (CHECK ONLY ONE)
$\square$ 1. Routinely, most days
Skip to Question 5
$\square$ 2. Weekly
$\square$ 3. Only during periods of hot weather
$\square$ 4. Only during NYISO emergency program events - EDRP and/or ICAP/SCR
$\square$ 5. Rarely
6. Other (please specify):
7. Do not know 
4. Why do you not monitor prices more frequently? (CHECK ONLY ONE)

1. Unaware that prices change hourly

2. Limited resources to do so

3. Limited technology to do so

4. My electric service contract with a competitive supplier (ESCO) makes monitoring hourly prices irrelevant

- 5. Other (please specify):

口 6. Do not know

\section{Questions 5 through 12 refer to your facility's experience over the past five years during summer weekdays.}

5. If you have reduced electricity use or turned on on-site generation in response to high hourly electricity prices, how high were prices when you responded? (check only one)

\begin{tabular}{|c|c|c|c|c|c|c|}
\hline $\begin{array}{c}\$ 0.10 / \\
\mathrm{kWh}\end{array}$ & $\begin{array}{c}\$ 0.20 / \\
\mathrm{kWh}\end{array}$ & $\begin{array}{c}\$ 0.50 / \\
\mathrm{kWh}\end{array}$ & $\begin{array}{c}\$ 0.75 / \\
\mathrm{kWh}\end{array}$ & $\begin{array}{c}\$ 1.00 / \\
\mathrm{kWh}\end{array}$ & $\begin{array}{c}\text { Have not } \\
\text { responded } \\
\text { to prices }\end{array}$ & $\begin{array}{c}\text { Do not } \\
\text { know }\end{array}$ \\
\hline$\square$ & $\square$ & $\square$ & $\square$ & $\square$ & $\square$ & $\square$ \\
\hline
\end{tabular}

6. If you have reduced electricity use or turned on on-site generation in response to NYISO emergency program events, why have you done so? (check all that apply)

1. To earn EDRP or ICAP/SCR curtailment incentive payments

口 2. To avoid paying penalties for not responding to ICAP/SCR events

口 3. My organization considers it a civic duty to help keep the electric system secure

4. NYISO emergencies coincide with high SC-3A prices

$\square$ 5. Other (please specify):

6. My facility has not responded to NYISO emergency events

․ Do not know

7. If you have reduced electricity use or turned on on-site generation in response to public appeals and/or mandates to reduce electricity consumption, why have you done so? (CHECK ALL THAT APPLY)

1. My organization is required or expected to comply with public appeals

2. My organization considers it a civic duty to respond to public appeals 
3. Public appeals coincide with high SC-3A prices

4. Other (please specify):

5. My facility has not responded to public appeals

6. Do not know

8. When you have reduced electricity use or turned on on-site generation, how has your facility changed its electricity use (check all that apply):

1. Electricity use was shifted: consumption was reduced and made up at another time (e.g., equipment use was rescheduled to later in the day or the next day)

a 2. Electricity use was foregone: consumption was reduced and not made up at another time

3. Turned on on-site generation

4. I have not reduced or shifted electricity use nor turned on on-site generation

5. Do not know

9. In the table below, please indicate which specific equipment or end-uses have been affected when you reduced electricity or turned on on-site generation and how (CHECK ALL THAT APPLY):

\begin{tabular}{|l|c|c|c|c|c|c|}
\hline \multirow{2}{*}{$\begin{array}{l}\text { Equipment and } \\
\text { End-Uses }\end{array}$} & Shifted & Foregone & $\begin{array}{c}\text { Turned on } \\
\text { on-site } \\
\text { generation }\end{array}$ & $\begin{array}{c}\text { Have } \\
\text { not } \\
\text { curtailed }\end{array}$ & $\begin{array}{c}\text { Do not } \\
\text { have this } \\
\text { equipment }\end{array}$ & $\begin{array}{c}\text { Do not } \\
\text { know }\end{array}$ \\
\hline Lighting & $\square$ & $\square$ & $\square$ & $\square$ & $\square$ & $\square$ \\
\hline Air conditioning & $\square$ & $\square$ & $\square$ & $\square$ & $\square$ & $\square$ \\
\hline $\begin{array}{l}\text { Plug loads (e.g., } \\
\text { office equipment, } \\
\text { vending } \\
\text { machines) }\end{array}$ & $\square$ & $\square$ & $\square$ & $\square$ & $\square$ & $\square$ \\
\hline $\begin{array}{l}\text { Process } \\
\text { equipment/ } \\
\text { production lines }\end{array}$ & $\square$ & $\square$ & $\square$ & $\square$ & $\square$ & $\square$ \\
\hline Water pumping & $\square$ & $\square$ & $\square$ & $\square$ & $\square$ & $\square$ \\
\hline Refrigeration & $\square$ & $\square$ & $\square$ & $\square$ & $\square$ & $\square$ \\
\hline
\end{tabular}

10. Over the past 5 years, has your facility experienced major changes in electricity consumption? (CHECK ALL THAT APPLY)

1. Yes - My facility has increased production over this time period

2. Yes - My facility has decreased production over this time period 
3. Yes - My facility has invested in equipment to reduce overall electricity consumption

4. Yes - Other changes (please describe):

$\square$ 5. No

6. Do not know

11. If some portion of your load has been shifted, which of the following time periods was it most often rescheduled to? (CHECK ONLY ONE)

$\square$ 1. The day before the curtailment

$\square$ 2. Earlier or later the same day as the curtailment

$\square$ 3. The day after the curtailment

4. Some later time

$\square$ 5. My facility has not shifted load

$\square$ 6. Do not know

12. If some portion of your load has been foregone, which best describes the impact on your facility's operations? (CHECK ONLY ONE)

$\square$ 1. No impact

$\square$ 2. Slight inconvenience or employee discomfort

$\square$ 3. Significant inconvenience or employee discomfort

$\square$ 4. Business operations must be adjusted

$\square$ 5. Other (please specify:)

6. My facility has not foregone load

$\square$ 7. Do not know

13. What barriers has your organization experienced in responding to high hourly electricity supply prices? (CHECK ALL THAT APPLY)

$\square$ 1. Insufficient time or resources to pay attention to hourly prices

$\square$ 2. Managing electricity use is not a priority

3. The cost/inconvenience of responding outweighs the savings

$\square$ 4. Institutional barriers in my organization make responding difficult

$\square$ 5. My organization's management views these efforts as too risky

$\square$ 6. Inflexible labor schedule 
7. Negative previous experience with day-ahead hourly pricing

8. Flat-rate or time-of-use (TOU) contract makes responding unimportant

9. Other (please specify):

10. No barriers have been encountered

$\square$ 11. Do not know

14. How does your facility intend to mitigate SC-3A price variability in the next two to three years? (CHECK ALL THAT APPLY)

$\square$ 1. Secure a time-of-use or flat-rate contract for electricity supply from an alternative supplier (ESCO)

$\square$ 2. Secure a financial hedge so that my facility does not have to worry about high prices

3. Continue to reduce load when prices are high, as I have in the past

$\square$ 4. Adjust operations to allow for greater capability to respond to high SC-3A prices

5. Invest in control and other load management technologies to enhance my ability to respond to high SC-3A prices

6. Invest in on-site generation to adjust electricity use

7. My facility does not intend to respond to SC-3A price variability

8. Do not know

15. In the future, how high would hourly SC-3A electricity prices have to be for your facility to reduce electricity use below normal levels or turn on on-site generation? (CHECK ONLY ONE)

\begin{tabular}{|c|c|c|c|c|c|c|c|}
\hline $\begin{array}{c}\$ 0.10 / \\
\mathrm{kWh}\end{array}$ & $\begin{array}{c}\$ 0.20 / \\
\mathrm{kWh}\end{array}$ & $\begin{array}{c}\$ 0.50 / \\
\mathrm{kWh}\end{array}$ & $\begin{array}{c}\$ 0.75 / \\
\mathrm{kWh}\end{array}$ & $\begin{array}{c}\$ 1.00 / \\
\mathrm{kWh}\end{array}$ & $\begin{array}{c}\$ 2.00 / \\
\mathrm{kWh}\end{array}$ & $\begin{array}{c}\text { Would not } \\
\text { change use } \\
\text { at any price }\end{array}$ & $\begin{array}{c}\text { Do not } \\
\text { know }\end{array}$ \\
\hline$\square$ & $\square$ & $\square$ & $\square$ & $\square$ & $\square$ & $\square$ & $\square$ \\
\hline
\end{tabular}

The following questions ask about energy management technologies installed at facilities served by NMPC, specifically:

Energy Management Control Systems (EMCS): control systems that optimize operations of end-use equipment, usually HVAC, through a series of sensors, communicators and controllers

Peak Load Management Devices: devices that control the electric demand of HVAC equipment, lighting, process loads, motors or drives Energy Information Systems (EIS): integrated systems of software, data acquisition hardware, and communication systems used to manage electricity use over a variety of end-uses in a single facility or across several remotely managed facilities 
16. Has your facility installed an Energy Management Control System (EMCS) or peak load management devices?

$\square 1$. Yes

$\square$ 2. No Skip to Question 19

口 3. Do not know Skip to Question 19

17. For what purpose(s) are your facility's EMCS and/or peak load management devices used? (CHECK ALL THAT APPLY)

$\square$ 1. To respond to high hourly prices

口 2. To reduce overall electricity bills

$\square$ 3. To reduce peak-demand charges

$\square$ 4. Facility/process control automation

$\square$ 5. Other (please specify):

6. Do not know

18. During which summers have you used your EMCS and/or peak load management devices for these purposes? (CHECK ALL THAT APPLY)

$\square$ 1. Summer of 2000

口 2. Summer of 2001

a 3. Summer of 2002

$\square$ 4. Summer of 2003

$\square$ 5. Summer of 2004

6. Do not know

19. Has your organization installed an Energy Information System (EIS) in the past five years?

$\square$ 1. Yes

$\square$ 2. No Skip to Question 22

$\square$ 3. Do not know Skip to Question 22

20. For what purpose(s) is your facility's EIS used? (CHECK ALL THAT APPLY)

1. To respond to high hourly prices 
2. To reduce overall electricity bills

․ To reduce peak-demand charges

口 4. Facility/process control automation

5. Other (please specify):

6. Do not know

21. During which summers have you used the EIS for these purposes? (CHECK ALL THAT APPLY)

ㅁ 1. Summer of 2000

2. Summer of 2001

3. Summer of 2002

口 4. Summer of 2003

口 5. Summer of 2004

․ Do not know

22. Does your facility have on-site generation (e.g., self-generation, cogeneration or emergency generators)?

- 1. Yes

2. No Skip to Question 24

3. Do not know Skip to Question 24

23. For what purpose(s) is (are) your facility's on-site generator(s) used? (CHECK ALL THAT APPLY)

1. To respond to high hourly prices

2. To reduce overall electricity bills

3. To reduce peak-demand charges

口 4. Emergency backup / reliability

a 5. Cogeneration

6. Other (please specify):

7. Do not know

The following questions pertain to how you purchase electricity at your facilities served by NMPC under the SC-3A rate classification. 
24. On average, what percent of your facility's total annual operating costs do your energy costs (e.g. electricity, natural gas, fuel oil, etc.) account for? (check only one)

(1. Less than $1 \%$

口 2 . Between $1 \%$ and $3 \%$

口 3 . Between $4 \%$ and $6 \%$

$\square$ 4. Between $7 \%$ and $10 \%$

口 5 . Between $11 \%$ and $20 \%$

6. Greater than $20 \%$

$\square$ 7. Do not know

25. On average, what percent of your facility's total annual operating costs do your electricity costs account for? (check only one)

口 1 . Less than $1 \%$

口. Between $1 \%$ and $3 \%$

口 3 . Between $4 \%$ and $6 \%$

$\square$ 4. Between $7 \%$ and $10 \%$

口 5 . Between $11 \%$ and $20 \%$

6. Greater than $20 \%$

$\square$ 7. Do not know

26. Has your facility ever purchased electricity from an alternative supplier (ESCO)?

$\square$ 1. Yes

$\square$ 2. No Skip to Question 29

$\square$ 3. Do not know Skip to Question 29

27. During which of the following summers did your facility buy electricity from an ESCO under a time-of-use or flat-rate contract? (check all that apply)

1. Summer of 2000

$\square$ 2. Summer of 2001

口 3. Summer of 2002

$\square$ 4. Summer of 2003

$\square$ 5. Summer of 2004 
6. My facility was not on this type of rate during these time periods

7. Do not know

28. During which of the following summers did your facility buy electricity from an ESCO under a contract in which prices change hourly? (check all that apply)

口 1. Summer of 2000

口 2. Summer of 2001

3. Summer of 2002

․ 4. Summer of 2003

口 5. Summer of 2004

6. My facility was not on this type of rate during these time periods

7. Do not know

29. In the last five years, if you have not bought electricity exclusively from ESCOs, please indicate why not (CHECK ALL THAT APPLY):

$\square$ 1. Could not find a hedged (flat-rate) contract

2. Could not find an ESCO willing to serve my organization

a 3. ESCO offers have been too expensive

4. The savings offered by ESCOs have not been enough to justify the switch

5. Institutional barriers in my organization make switching difficult

6. Prefer NMPC's prices

7. Prefer NMPC's reputation

8. Prefer NMPC's service

9. Unavailability of long-term contracts

10. Contract(s) with NYPA limit(s) my organization's interest

11. Believe that contracts with NYPA prevent me from choosing an ESCO

12. Other (please specify):

13. My organization has bought electricity exclusively from ESCOs since 1999

14. Do not know

30. In the future, what would prompt you to buy electricity from an ESCO? (CHECK ALL THAT APPLY)

1. More interest by ESCOs in serving my facility 
2. Better priced ESCO flat-rate or time-of-use offerings than those currently available

3. Better priced ESCO Day-Ahead Market indexed offerings than those currently available

4. More information or education on how to evaluate ESCO offers

5. More interest/support from my organization's management

6. Higher forecasted SC-3A electricity prices

7. More volatile forecasted SC-3A electricity prices

8. Other (please specify):

9. Nothing could induce my organization to switch (why?):

10. Do not know

31. Currently, the default SC-3A commodity price varies from hour to hour but is provided to you on a day-ahead basis. Suppose that in the future the default SC-3A commodity price was instead provided to you at the beginning of each hour and was effective for the load consumed in that hour (e.g. no advance notice of prices). What would you do? (CHECK ONLY ONE)

1. Continue buying commodity service from NMPC

2. Continue buying commodity service from an ESCO

3. Switch to an ESCO for an alternative commodity service

4. Consider offers from an ESCO for an alternative commodity service

5. Do not know

32. During which of the following summers did your facility purchase a financial product that hedged electricity price volatility (e.g. a contract for differences, swap, etc.)? (check all that apply)

\section{Summer of 2000 Skip to End}

2. Summer of 2001 Skip to End

3. Summer of 2002 Skip to End

4. Summer of 2003 Skip to End

5. Summer of 2004 Skip to End

6. My facility did not have a financial hedge during these time periods

7. Do not know 
33. Which of the following have influenced your decision not to buy a financial hedge? (CHECK ALL THAT APPLY)

1. Not sure what a financial hedge is or why I would need one

口 2. Could not find an institution that offered a financial hedge

․ Offered hedges were too expensive

․ Institutional barriers in my organization make procuring financial hedges difficult

5. My organization is comfortable managing risk without a financial hedge

․ My facility already had a flat-rate or TOU supply contract

7. Other (please specify):

․ 8. Do not know 



\section{Appendix B. The Generalized Leontief Demand Model, Theoretical and Empirical Specifications and Interpretations}

\section{B.1 Introduction}

The purpose of this appendix is to provide an overview of the conceptual approach and empirical model used to quantify the response in electricity usage by industrial and commercial customers to hourly varying, day-ahead electricity prices in Niagara Mohawk's SC-3A electricity rate. The conceptual model is based on the modern economic theory of the derived demand for inputs by profit maximizing and/or cost minimizing firms. This conceptual foundation is reported in detail by Goldman, et al. (2004); it is therefore only summarized in this appendix. While relying on the same conceptual model, the empirical demand specification for this current study is substantially different. It is based on a flexible Generalized Leontief (GL) cost function, rather than the more restrictive Constant Elasticity of Substitution (CES) specification.

By allowing price response to vary with the level of prevailing prices, this flexible demand model facilitates the understanding of RTP participants' response to RTP prices in two important ways. First, we are able to structure a specific statistical test for the hypothesis that a firm exhibits no price response. Second, the GL demand specification allows estimates of demand response to vary across price levels. Therefore, for those firms that are price responsive, we can also test the hypothesis that a firm's willingness to shift electricity between high-and low-priced periods increases as the prices in the highpriced periods rise. ${ }^{1}$ Once separate demand models are estimated for each customer, it is possible to test this second hypothesis by pooling the individual customer estimates of demand response and estimating two additional models. In the first of them, we model estimates of demand response as a function of the ratio of peak to off-peak prices, including additional variables that are available for all customers. In the second model, we are also able to quantify the separate effects on average price responsiveness of additional customer-specific characteristics and circumstances that were collected through a self-administered customer survey.

After a brief review of the electricity demand model, the GL model is described in detail, along with a strategy for empirical estimation and a geometric, intuitive interpretation of the range in possible demand response accommodated by the flexible specification. Finally, the econometric issues related to model specification and the testing of important hypotheses are addressed.

\section{B.2 The Electricity Demand Model}

The model for electricity demand in this study is consistent with the modern economic theory of the firm. It provides the theoretical underpinnings for the initial empirical

\footnotetext{
${ }^{1}$ In contrast to most other studies of RTP customer demand response, we define daily peak and off-peak pricing periods rather than treat electricity in every hour as a distinct commodity. Several alternative peakperiod specifications are employed in our empirical estimation in order to test which best characterizes customer behavior.
} 
evaluations of RTP-type services by Caves, et al. (1984), and more recently by King and Shatrawka (1994) and Schwarz, et al. (2002). ${ }^{2}$ According to this theory, firms are assumed to maximize profits (or minimize the cost of producing a given level of output), and electricity usage is modeled according to a sequential, three-level profit or cost function that is assumed to be separable in electricity usage. ${ }^{3}$ At the first level, weekday electricity usage is allocated between peak and off-peak time periods, which reflect differences in the price of electricity, the value of electricity, or both. The second level allocates monthly usage between weekdays and weekends. The third, and final, level determines overall electricity expenditures as a proportion of total costs, reflecting the relative demand for electricity in relation to all other inputs in the production process.

In this study, we focus the demand model specification on the first stage - the allocation of daily electricity usage between high-price (peak) and low-price (off-peak) hours. ${ }^{4}$ To facilitate an analysis of electricity demand response to RTP prices from this perspective, it is necessary to develop an appropriate definition of the electricity commodity.

\section{B.2.1. Defining the Electricity Commodity}

Because of the continuous nature of electric service and usage, defining the hours that constitute the peak and off-peak periods in electricity demand models is generally treated as an empirical question, driven by the prices customers face and the circumstances by whichthey use and value electricity. Studies of price response to time-of-use (TOU) rates typically utilize pooled data for customers participating in different TOU rates, or data are pooled across several treatments, where prices or the definition of the peak period vary by the experimental design (Caves, et al. 1984; Patrick 1990; Braithwait 2000).

To establish the definition of distinct electricity commodities in one of the most detailed studies ever undertaken, Caves, et al. (1987) identified six separate commodities for customers facing a six-hour peak-pricing period of 9 A.M - 12 noon and 1 P.M. - 4 P.M. These peak hours were then further divided into two separate commodities - one twohour commodity (11 A.M - 12 Noon and 1 P.M - 2 P.M) and one four-hour commodity (9 A.M. - 11 A.M. and 2 P.M. - 4 P.M). Other hours in the day were aggregated into four

\footnotetext{
${ }^{2}$ The model is conceptually similar to the consumer demand model discussed by Braithwait (2000).

${ }^{3}$ For a production function or utility function to be weakly separable in any partition of its arguments, the marginal rate of substitution between any two inputs or goods in a separable subset is independent of all inputs or goods that are not in the subset (Chambers 1988, pp. 45-46). In other words, any function in $n$ variables, $\mathrm{f}(\mathrm{x})=\mathrm{F}\left(\mathrm{x}_{1}, \ldots, \mathrm{x}_{\mathrm{n}}\right)$, that is separable in a partition $\mathrm{x}^{1}$ through $\mathrm{x}^{\mathrm{m}}$, where $\mathrm{x}^{\mathrm{i}}$ is a vector representing a subset of the $\mathrm{n}$ variables, can be written as $\mathrm{f}(\mathrm{x})=\mathrm{F}\left(\mathrm{f}^{\mathrm{l}}\left(\mathrm{x}^{1}\right), \ldots, \mathrm{f}^{\mathrm{n}}\left(\mathrm{x}^{\mathrm{n}}\right)\right)$. Each of the sub-functions can be treated as an aggregate input or consumption bundle - essentially a production or utility function in and of itself. Therefore, it is legitimate to think of production or consumption occurring in two steps. To use the example of a production function, inputs in the sub-vector are combined to create the aggregate inputs in the first step. In the second step, these aggregate inputs are used to produce the output from the macro production function. The practical implication is that choice of cost minimizing input levels within any sub-function depends only on prices for those inputs in the sub-function. Thus, input demands and price response elasticities can be derived from the sub-function alone.

${ }^{4}$ Caves, et al. (1984) estimate a demand model that includes all three stages of electricity demand. It is perhaps the only study that looks at all three stages of electricity demand, and one of only a handful of studies that consider more than just the within-day energy demand.
} 
separate commodities, all priced the same. They argued that this sub-aggregation of the peak is needed to characterize "needle peaking" behavior. Extending this structure to RTP-type programs with hourly prices would require 24 separate electricity commodities, one for each hour of the day.

This specification would be warranted if industrial and commercial customers could in fact adjust usage on an ongoing basis to changing hourly prices. However, there is compelling evidence that firms implicitly characterize the day as being comprised of a peak and an off-peak period (Neenan, et al. 2003). While the exact specification of the peak hours is firm specific, common business practices, driven in large part by traditional rate structures, support utilizing a single specification to capture most of the variation in usage.

Consistent with this line of reasoning, we analyze the price response behavior of NMPC's RTP customers by estimating the demand model for several alternative specifications of the peak period that differ in length. To gain insights into which hourly aggregates firms view as distinct commodities, we focus the discussion on a specification that best represents the data.

\section{B.2.2 The Model of Daily Demand for Electricity in Peak and Off-Peak Periods}

Since the focus is on the first stage in the decision process described above, our empirical demand model deals only with the allocation of daily electricity usage between high-price (peak) hours and low-price (off-peak) hours. It is generally thought that electricity use in these two periods are valued differently by the firm. In contrast, it may also be the case that peak and off-peak electricity inputs are complementary to the firm and could in fact be demanded in nearly fixed proportions. To formulate this demand model, we define a firm's production function that is separable in electricity inputs as:

$$
\mathrm{Q}=\mathrm{F}\left(\mathrm{x}_{1}, \mathrm{x}_{2}, \ldots, \mathrm{x}_{\mathrm{n}}, \mathrm{E}\left(\mathrm{k}_{\mathrm{p}}, \mathrm{k}_{\mathrm{o}}\right)\right)
$$

where $\mathrm{Q}$ is the output of the firm, $\mathrm{x}_{\mathrm{i}}$ are inputs other than electricity and $\mathrm{k}_{\mathrm{p}}$ and $\mathrm{k}_{\mathrm{o}}$ are electricity used in peak and off-peak periods, respectively.

Electricity is assumed to be separable from other production inputs. Therefore, this subfunction $\mathrm{E}=\mathrm{E}\left(\mathrm{k}_{\mathrm{p}}, \mathrm{k}_{\mathrm{o}}\right)$ represents an aggregate electricity input; a firm can produce a given level of output by combining different amounts of peak and off-peak electricity that yield a given level of the electricity aggregate, say $\mathrm{E}_{0}$, needed by the firm to produce its output. In considering the use of peak and off-peak electricity, there are four cases that should be distinguished. The particular case that applies to any individual customer depends not only on the technical aspects of certain production processes, but also on behavioral considerations. The situation can also vary depending on circumstances, such as when certain firms decide to reduce what might be termed "discretionary" energy use. In this case, the rate at which firms substitute off-peak for peak electricity could be called "state dependent". These four cases are described graphically here. In later sections, these 
individual cases are related directly to the estimated parameters of the GL demand models.

Case 1 is where peak and off-peak electricity are substitute inputs in production, depicted in Figure 1. This case is what most would think of as the normal situation regarding a firm's ability to substitute peak and off-peak electricity.

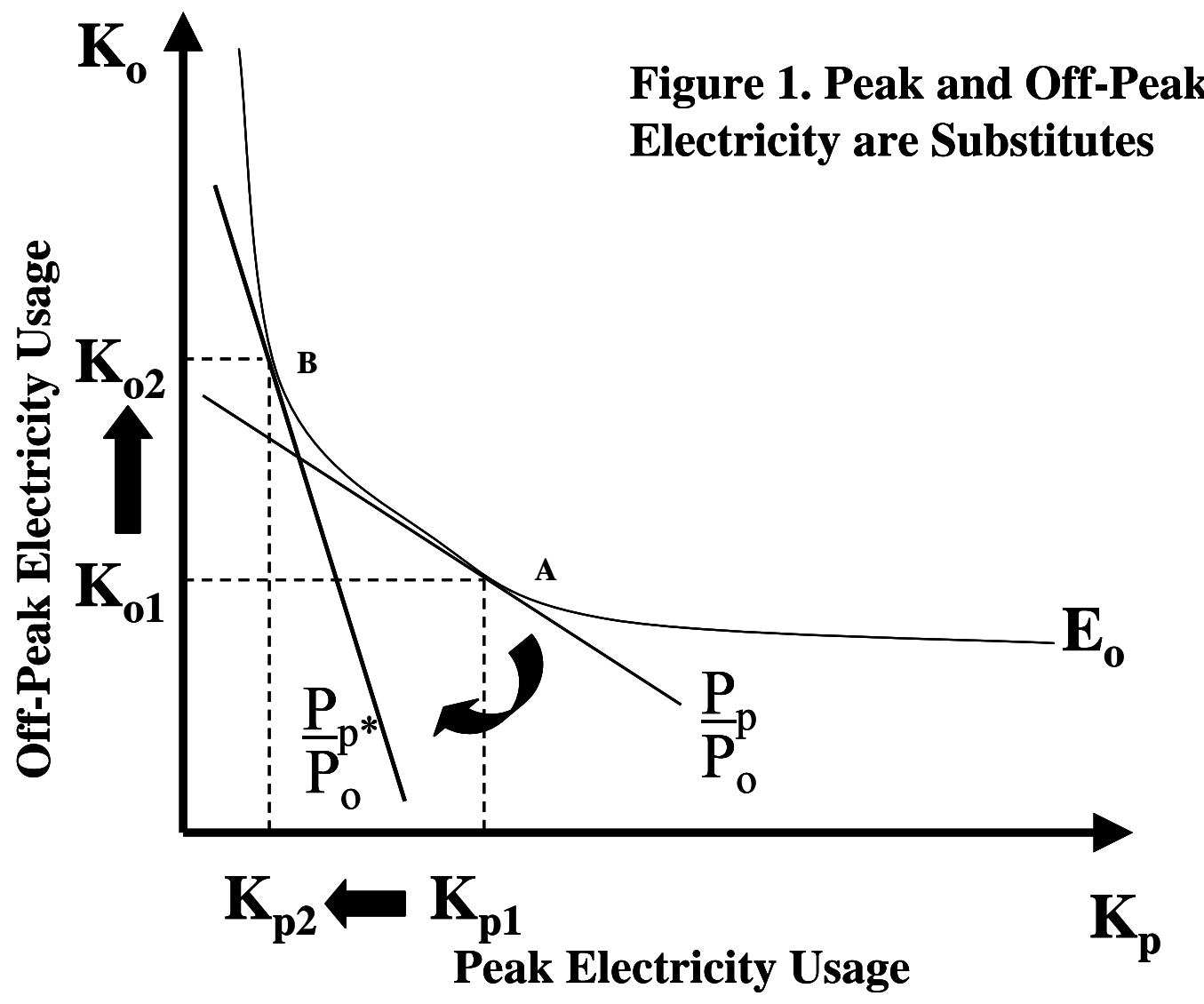

The curve $\mathrm{E}_{0}$ in Figure 1 represents those combinations of peak electricity $\left(\mathrm{K}_{\mathrm{p}}\right)$ and offpeak electricity $\left(\mathrm{K}_{\mathrm{o}}\right)$ that produce an energy aggregate, $\mathrm{E}_{0}$, needed to support the firm's desired (and constant) output. At an initial ratio of peak to off-peak electricity prices (given by the price line in Figure 1 labeled $\mathrm{P}_{\mathrm{p}} / \mathrm{P}_{\mathrm{o}}$ ), ${ }^{5}$ the firm would minimize the cost of producing $\mathrm{E}_{0}$ by using $\mathrm{K}_{\mathrm{p} 1}$ and $\mathrm{K}_{\mathrm{ol}}$ of peak and off-peak electricity, respectively. This is point $A$ in Figure 1. If there is an increase in the peak period price of electricity to $\mathrm{P}_{\mathrm{p}}{ }^{*}>$ $\mathrm{P}_{\mathrm{p}}$, the price line gets steeper and if the firm is to continue to produce $\mathrm{E}_{0}$, the minimum cost way of doing so is by using more electricity off-peak and less on-peak (e.g. $\mathrm{K}_{\mathrm{p} 2}<$ $\mathrm{K}_{\mathrm{p} 1}$ and $\mathrm{K}_{\mathrm{o} 2}>\mathrm{K}_{\mathrm{o} 1}$ ). This is at point $\mathrm{B}$ in Figure 1, and it is the increase in the peak price of electricity that leads to a decrease in the ratio of peak to off-peak electricity usage. It is this change in the ratio of peak to off-peak electricity use that measures the firm's price responsiveness. This change in input intensity is related to the slope of the curve, $\mathrm{E}_{0}$. The

\footnotetext{
${ }^{5}$ For this given set of prices. $\mathrm{P}_{\mathrm{p}}$ and $\mathrm{P}_{\mathrm{o}}$, the price line represents all combinations of $\mathrm{K}_{\mathrm{p}}$ and $\mathrm{K}_{\mathrm{o}}$ that can be purchased for a fixed budget.
} 
measure of this change in the ratio of input use in percentage terms is commonly called the elasticity of substitution, and it is often denoted by $\sigma$. In our case, $\sigma$ measures the percentage change in the ratio of peak to off-peak electricity use to a one percent change in the ratio of off-peak to peak electricity. As the curvature or slope of $E_{0}$ becomes more pronounced, a firm's price responsiveness, as measured by the elasticity of substitution falls, and as the curve $\mathrm{E}_{0}$ becomes flatter, the price responsiveness increases. Finally, in this particular case, we have drawn the curve $\mathrm{E}_{0}$ so that it never crosses either axis. Thus, regardless of how high the peak price rises relative to the off-peak price, production always requires some peak electricity. Technically, this is the case where $0<\sigma<\infty$.

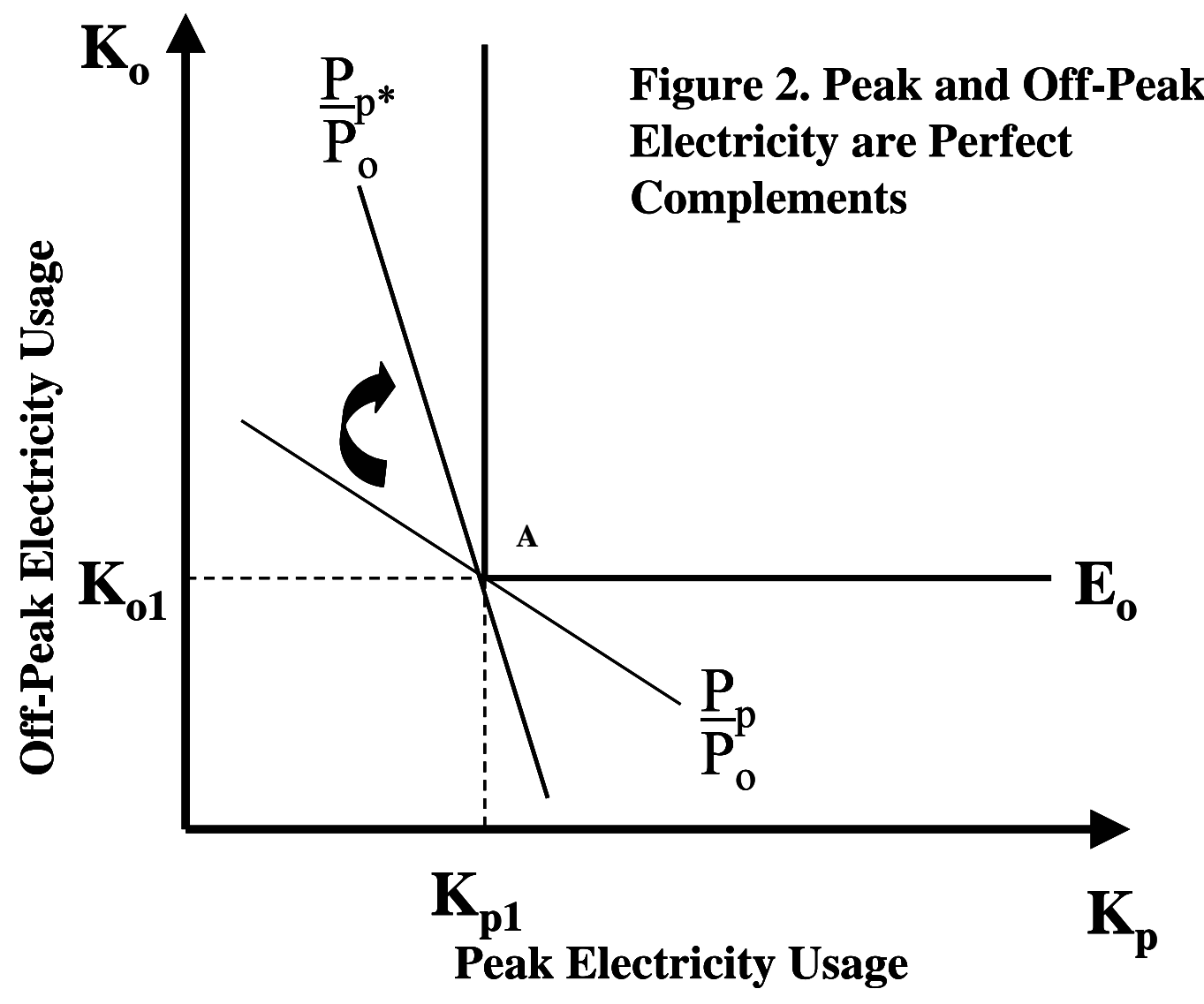

In this study, one extreme case, where $\sigma=0$, is of particular interest, and it is depicted in Figure 2. In this case, there is no possibility for substituting peak for off-peak electricity regardless of the relative prices of peak and off-peak electricity. This means that output can only be produced using these two electricity inputs in fixed proportions, and peak and off-peak electricity are called perfect complements. The equal output curve, $\mathrm{E}_{0}$, is the rectangle (Figure 2 ). At point $\mathrm{A}$ in the figure, the electricity aggregate, $\mathrm{E}_{0}$, is produced using $\mathrm{K}_{\mathrm{p} 1}$ and $\mathrm{K}_{\mathrm{o} 1}$ units of peak and off-peak electricity, respectively. The fixed proportions nature of production is reflected in the rectangular curve $\mathrm{E}_{0}$ in the following way. If $K_{p}$ is increased above the level $K_{p 1}$ while holding $K_{o}$ at $K_{o 1}$, we would move to the right horizontally along the curve $\mathrm{E}_{0}$. Since we remain on the curve $\mathrm{E}_{0}$, the electricity aggregate and output are constant, and the extra peak electricity would be of no use to the 
firm. A similar argument can be made for trying to increase output by increasing the amount of off-peak electricity without any increase in peak usage. ${ }^{6}$

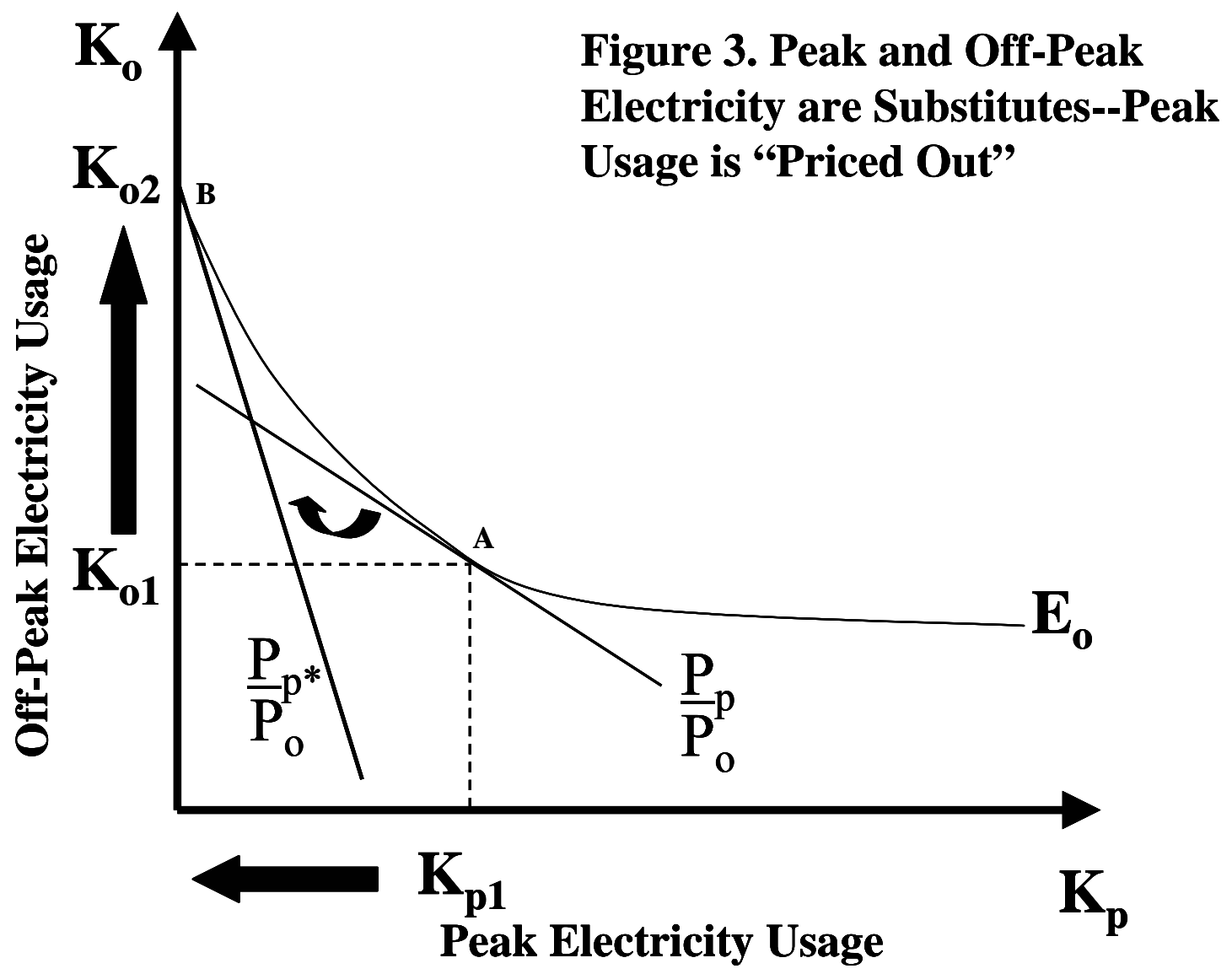

The third case is depicted in Figure 3. As in Case 1 above, peak and off-peak electricity are substitute inputs in production, and the curve $\mathrm{E}_{0}$ in Figure 3 still represents those combinations of peak electricity $\left(\mathrm{K}_{\mathrm{p}}\right)$ and off-peak electricity $\left(\mathrm{K}_{\mathrm{o}}\right)$ that produce an energy aggregate, $\mathrm{E}_{0}$, needed to support the firm's desired (and constant) output. At an initial ratio of peak to off-peak electricity prices (given by the price line in Figure 3 labeled $\mathrm{P}_{\mathrm{p}} / \mathrm{P}_{\mathrm{o}}$ ), the firm would minimize the cost of producing $\mathrm{E}_{0}$ by using $\mathrm{K}_{\mathrm{p} 1}$ and $\mathrm{K}_{\mathrm{o} 1}$ of peak

\footnotetext{
${ }^{6}$ The other extreme, where $\sigma=\infty$, is of little interest in the study of the substitutability of off-peak for peak electricity. We include a short discussion here for completeness only. This is the case where peak and offpeak electricity are called perfect substitutes. In this case, rather than the $\mathrm{E}_{0}$ curve being convex to the origin as it is in Figure 1, the $\mathrm{E}_{0}$ curve is instead a straight line with a negative slope that intersects both the horizontal and vertical axes. In this case, a certain number of units of off-peak electricity can always be substituted for one unit of peak electricity to keep the electricity aggregate at $\mathrm{E}_{0}$ and output constant. The flatter this straight line is, the fewer is the number of units of off-peak electricity needed to substitute for one unit of peak electricity. If the ratio of peak to off-peak prices happens to be the same as the slope of this line, then any point on the line represents a minimum-cost combination of peak and off-peak electricity to keep $\mathrm{E}$ at $\mathrm{E}_{0}$. However, if the price-ratio line becomes steeper, representing a relative increase in price of peak electricity, then only off-peak electricity is used in production. Alternatively, if the price-ratio line becomes less steep, representing an increase in the off-peak price, then only peak electricity would be used in production.
} 
and off-peak electricity, respectively. This is point A in Figure 3. In contrast to the situation in Figure 1, we see that in this case the $\mathrm{E}_{0}$ cuts the vertical axis at point $\mathrm{B}$. Although off-peak electricity is substituted for peak electricity as the price of peak electricity rises, there is a price (say $\mathrm{P}_{\mathrm{p}}$ ), at which peak electricity is "priced out of the market", and peak usage drops to zero (point B in Figure 3). There are perhaps a small number firms with production processes that accommodate such dramatic substitution possibilities and are able to forgo all electricity use during peak periods when peak prices are extremely high. However, we focus on this case because it may depict very well the behavior of firms with significant on-site generation. Regardless of the price of peak electricity these firms may still require peak electricity as an input, but as the price of peak electricity rises to a certain level, the demand for peak power from the grid falls to zero (point B in Figure 3). The firm continues to receive its off-peak power from the grid, but now relies completely on its on-site generation to supply its peak electricity needs. ${ }^{7}$

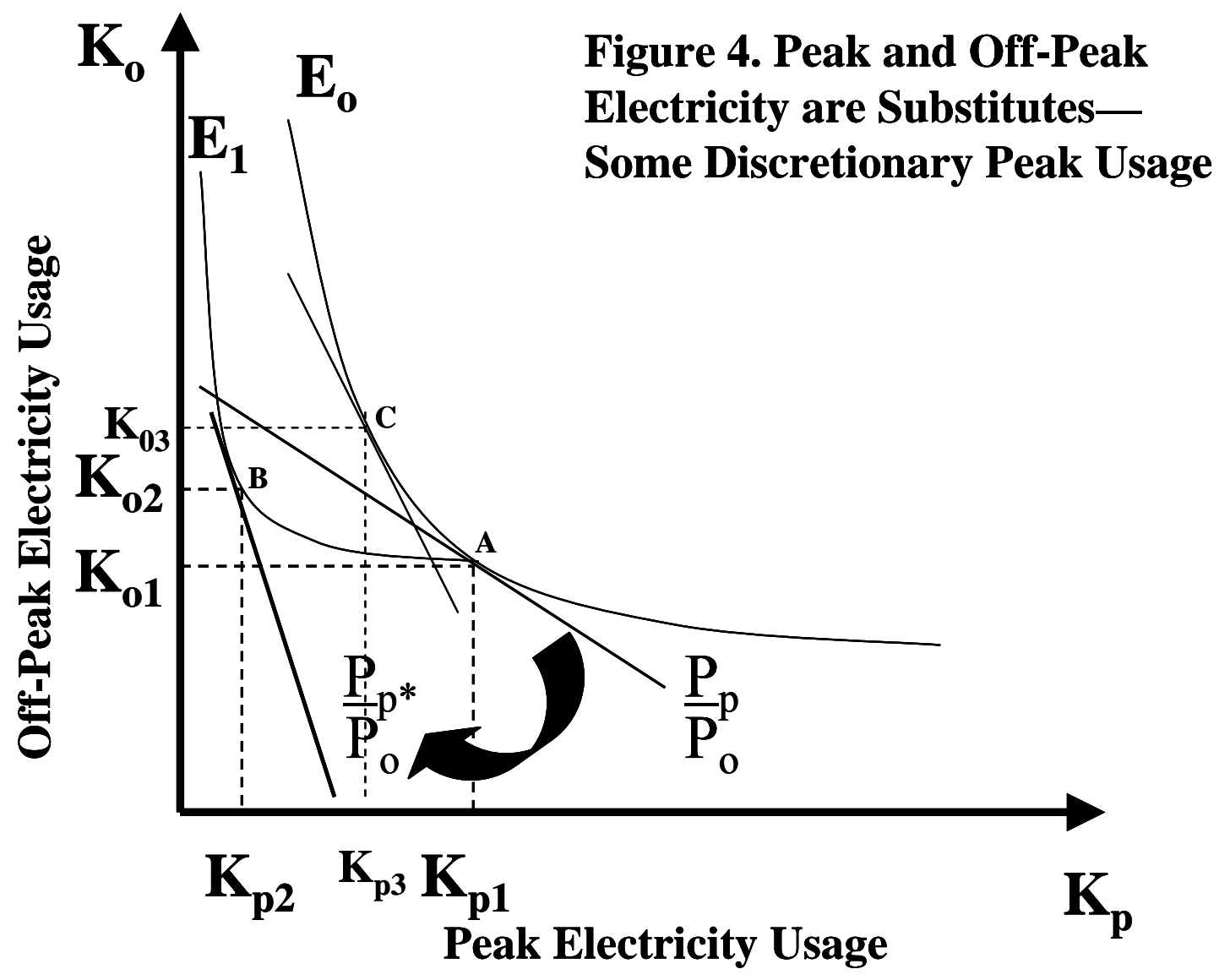

The fourth case of interest is also more descriptive of a behavioral response to high peak electricity prices than it is of a pure technical relationship usually depicted by input demand models. This case is depicted in Figure 4, and it is the case where demand for peak electricity depends on prevailing circumstances ("state dependent" if you will). For

\footnotetext{
${ }^{7}$ As is seen below, this situation is accommodated within the framework of the GL model, but it cannot be modeled by the CES function.
} 
example, there are some firms that when prices of peak electricity reach a certain point, they shed some "discretionary" load (e.g., maintain output but ask customers and employees to forgo normal comfort levels so lights and/or air conditioning can be turned down). Thus, by shedding discretionary load as the price of peak electricity rises, this firm moves from point $\mathrm{A}$ on the $\mathrm{E}_{0}$ curve to point $\mathrm{B}$ on the $\mathrm{E}_{1}$ curve, in effect shedding more peak load (from $\mathrm{K}_{\mathrm{p} 1}$ to $\mathrm{K}_{\mathrm{p} 2}$ ) than would be possible if production levels were to be maintained at normal comfort levels for customers and employees (e.g., by moving up the $\mathrm{E}_{0}$ curve to point $\mathrm{C}$ with a peak usage of $\mathrm{K}_{\mathrm{p} 3}>\mathrm{K}_{\mathrm{p} 2}$ ).

More is said about the range in elasticities of substitution below. However, based on this general discussion, it is clear that in order to estimate firm's change in peak and off-peak electricity use in response to price changes, we need only specify a functional form for $\mathrm{E}$ $=\mathrm{e}\left(\mathrm{k}_{\mathrm{p}}, \mathrm{k}_{\mathrm{o}}\right)$ and estimate it empirically. Perhaps the most critical factor in selecting a functional form is that it be able to reflect a wide range in price responsiveness as measured by the elasticity of substitution. As is seen below, both the CES and the GL models have this capacity. However, the GL model has the added flexibility of not imposing the same elasticity of substitution for a firm regardless of the firm's output level, electricity usage, and the price of electricity.

\section{B.2.2.1 The CES Specification}

In much previous literature, including two recent studies of customer demand response in new competitive markets by Neenan, et al. (2003) and Charles River Associates (2004), a constant elasticity of substitution (CES) functional form was used. It has the form:

$$
E=\left[\delta\left(k_{p}\right)^{-\rho}+(1-\delta)\left(k_{o}\right)^{-\rho}\right]^{-1 / \rho}
$$

In this function, $\mathrm{E}$ is an aggregate electricity input that exhibits constant returns to scale (Moroney 1972; and Ferguson 1969). That is, if electricity use is increased by the same proportion in both peak and off-peak periods, the value of the energy aggregate increases by that same proportion. The parameter $\delta$ reflects the natural peak Kwh intensity of production. The parameter $\rho$ is a transformation of the elasticity of substitution between peak and off-peak electricity use, $\sigma=1 /(1+\rho) .{ }^{8}$ This elasticity of substitution is constant regardless of the levels of energy use or levels of output.

Neenan et al. (2003) have shown that this elasticity of substitution is also a convenient measure of the price responsiveness of electricity demand between peak and off-peak periods. ${ }^{9}$ In particular, they show that the ratio on peak to off-peak electricity use is a function of the inverse of the price ratio (the ratio of off-peak to peak price) and the parameters $\delta$ and $\sigma$. That is:

\footnotetext{
${ }^{8}$ The algebra needed to derive this relationship, along with the derivation of the elasticity of substitution, is found in Fergurson (1969, pp. 103-04) and is not repeated here.

${ }^{9}$ This involves solving the first-order conditions to the constrained optimization problem for minimizing the cost of producing a given output for the factor demands and substituting them back into the direct cost function. This procedure allows one to write the indirect cost-minimizing cost function in terms of output and input prices only.
} 


$$
\mathrm{k}_{\mathrm{p}} / \mathrm{k}_{0}=\left\{[\delta /(1-\delta)]\left[\mathrm{p}_{0} / \mathrm{p}_{\mathrm{p}}\right]\right\}^{\sigma} .
$$

One attractive feature of this model is that we can multiply the right-hand-side of this equation by an appropriate error term $(\varepsilon)$, take the logarithms of both sides, and obtain an unbiased, minimum-variance estimate of $\sigma$ using ordinary least squares (OLS) regression:

$$
\ln \left[\mathrm{k}_{\mathrm{p}} / \mathrm{k}_{\mathrm{o}}\right]=\sigma \ln [\delta /(1-\delta)]+\sigma \ln \left[\mathrm{p}_{0} / \mathrm{p}_{\mathrm{p}}\right]+\ln \varepsilon .
$$

Furthermore, from this transformed, logarithmic relationship, it is clear that the elasticity of substitution, the parameter $\sigma$, measures the proportional change in the ratio of electricity use in peak and off-peak periods due to a percentage change in the inverse price ratio (e.g., $\partial \ln \left[k_{\mathrm{p}} / \mathrm{k}_{\mathrm{o}}\right] / \partial \ln \left[\mathrm{p}_{0} / \mathrm{p}_{\mathrm{p}}\right]=\sigma$ ). For this production function to be well behaved, Ferguson (1969) shows that the elasticity of substitution must lie between the extremes discussed above (e.g., $\infty \geq \sigma \geq 0$ ). ${ }^{10}$ To reiterate from above, if $\sigma=0$, then peak and off-peak electricity must be used in fixed proportions. The higher $\sigma$ is, the more responsive energy use is to changing in relative prices between peak and off-peak periods. For example, if $\sigma<1$, then as the price ratio changes by one percent, the ratio of peak to off-peak energy use changes by less than one percent. For $\sigma>1$, the ratio of energy use changes by more than one percent as the inverse price ratio changes by one percent.

While this CES model is easy to estimate in logarithmic form and one of its parameters has a natural interpretation as a demand response elasticity, one potential disadvantage of the CES specification is that the elasticity of substitution is constant-invariant with respect to initial peak relative to off-peak electricity usage or to the initial relative prices. This is inconsistent with the view by some that when peak usage is high relative to nonpeak usage, a customer may find it more difficult to shift load in response to a change in relative prices. It is also thought by some that a firm's ability to shift load to off-peak declines as more and more load is shifted. In addition, the CES specification is inconsistent with the view that a customer's willingness to respond to price increases at times of very high peak prices. ${ }^{11}$ Since we are interested in studying these two issues, we must turn to an alternative, more flexible Generalized Leontief (GL) specification. In doing so, however, we encounter some challenges in estimation.

\footnotetext{
${ }^{10}$ This relationship shows that $\sigma$ is the proportional change in the use of electricity in the peak period relative to the off-peak period (holding output, in this case the electricity aggregate, constant), as the inverse price ratio increases or decreases by one percent (Ferguson 1969, pp. 103-04).

${ }^{11}$ A nested extension of this CES form was used originally by Herriges, et al. (1993) to characterize customer demand for electricity, where consumption within days is weakly separable from consumption across days. Schwarz, et al. (2002) also adopted a modification of this model to obtain intra-day and interday price responses. Despite this particular feature, there are two primary reasons we gave no further consideration to this nested CES model. First, this model still forces intra-day response elasticities to be constant; thus the model does not have the needed flexibility to allow for daily differences in intra-day response elasticities. Second, we focus our attention on intra-day price response because in the responses to our customer survey, the vast majority of the customers indicated that they did not shift from one day to another.
} 


\section{B.2.2.2 The Generalized Leontief Specification}

This model of electricity demand is based on the Indirect Generalized Leontief Cost Function. To begin its development, one must, as in the case of the CES model, specify a firm's production function that is separable in electricity inputs as given in equation (1) above (i.e., $\mathrm{Q}=\mathrm{F}\left(\mathrm{x}_{1}, \mathrm{x}_{2}, \ldots, \mathrm{x}_{\mathrm{n}}, \mathrm{E}\left(\mathrm{k}_{1}, \ldots, \mathrm{k}_{\mathrm{o}}\right)\right)$, where $\mathrm{Q}$ is output, $\mathrm{x}_{\mathrm{i}}$ are inputs other than electricity and $\mathrm{k}_{1}$ through $\mathrm{k}_{\mathrm{n}}$ are electricity used in periods 1 through $\mathrm{n}$, respectively). Because production is assumed to be separable in electricity inputs, we can specify the function $\mathrm{F}$ as above, where the electricity inputs can be combined according to an aggregator function $\mathrm{E}$. This is essentially being able to specify a sub-function within $\mathrm{F}$. Any combination of $k_{p}$ and $k_{o}$ that yields the same value for $E$ is equally productive in producing Q. It is the nature of this sub-function that determines the substitutability of electricity among different periods of the day.

Appealing to duality theory (Shephard 1970), we can also, in theory, specify the indirect cost functions associated with both the production function $\mathrm{Q}$ and the sub-function $\mathrm{E}$ above. ${ }^{12}$ Because of the assumption that the function is separable in electricity inputs, we are again only concerned with the indirect cost function associated with the electricity aggregate's sub-function. From that sub-function, we can derive expressions for the elasticity of substitution among electricity use during different times of the day.

If we assume that the underlying aggregator function for $\mathrm{E}$ is linear homogeneous in the electricity inputs $\left(\mathrm{k}_{\mathrm{i}}\right)$ and that the indirect cost function $\mathrm{C}$ is a flexible generalized Leontief (GL) function, then we have for peak and off-peak periods: ${ }^{13}$

$$
\mathrm{C}=\mathrm{E}\left\{\sum_{\mathrm{i}} \sum_{\mathrm{j}} \mathrm{d}_{\mathrm{ij}}\left(\mathrm{p}_{\mathrm{i}} \mathrm{p}_{\mathrm{j}}\right)^{1 / 2}\right\}
$$

E is a measure of effective electricity as given by the electricity sub-function. This function is linear homogeneous in all prices, which is a requirement for a well behaved indirect cost function. That is, if all prices are changed in the same proportion, then $\mathrm{C}$, the cost of producing the electricity aggregate, changes in the same proportion as well. We also require that $\mathrm{d}_{\mathrm{ij}}=\mathrm{d}_{\mathrm{ji}}$, for symmetry.

Since we are interested in a model that can capture price response for only two periods, (peak, $\mathrm{p}$, and off-peak, 0 ), the corresponding GL model is given by: ${ }^{14}$

\footnotetext{
${ }^{12}$ This involves solving the first-order conditions to the constrained optimization problem for minimizing the cost of producing a given output for the factor demands and substituting them back into the direct cost function. This procedure allows one to write the indirect cost-minimizing cost function in terms of output and input prices only.

${ }^{13}$ Diewert (1974) shows that if the generalized Leontief function (or any cost function) can be decomposed is this form, then the underlying aggregator function for E reflects a constant returns to scale technology. Put differently, this implies that total cost of the electricity aggregate is equal to a unit cost function (the term in \{\} in equation (6)) multiplied by the level of the energy aggregate. Furthermore, this specification implies that the "isoclines" are linear rays out of the origin and that for a given ratio of peak to off-peak electricity prices, the ratio of peak to off-peak electricity use will be invariant with respect to the output level. Obviously, when the price ratio changes, the ratio of input use will change as well.
} 


\section{B.2.2.3 Deriving the Elasticity of Substitution}

Since the elasticity of substitution in this model is not constant as it is in the CES model, it is not equal to one of the parameters in equation (6). It must be derived in the following way. From Shepherd (1970), we know that optimal demands for peak and off peak electricity can be determined by differentiating (6) with respect to each price:

(7) $\partial \mathrm{C} / \partial \mathrm{p}_{\mathrm{p}}=\mathrm{k}_{\mathrm{p}}=\mathrm{E}\left[\mathrm{d}_{\mathrm{pp}}+\mathrm{d}_{\mathrm{p} 0}\left(\mathrm{p}_{0} / \mathrm{p}_{\mathrm{p}}\right)^{1 / 2}\right]$.

(8) $\partial \mathrm{C} / \partial \mathrm{p}_{0}=\mathrm{k}_{0}=\mathrm{E}\left[\mathrm{d}_{00}+\mathrm{d}_{\mathrm{p} 0}\left(\mathrm{p}_{\mathrm{p}} / \mathrm{p}_{0}\right)^{1 / 2}\right]$

To develop a measure for the price responsiveness in the GL indirect cost function, we must also begin by deriving what is known as the Allen (1938) partial elasticities of input substitution, which, for any indirect cost function such as the one in equation (6), are equal to: ${ }^{15}$

\footnotetext{
${ }^{14}$ In conducting this analysis, there were a number of other second-order flexible forms that might have been used in the empirical specification. One such commonly used flexible form, the translog (TL) model (Boisvert 1982 and Chambers 1988) would have avoided estimating any equations that are non-linear in the parameters. The TL model relies on estimating a set of electricity cost share equations that are linear in the model parameters and does not require observations on the electricity aggregate. While this TL form was particularly attractive from an estimation perspective, this alternative was not pursued because as Caves and Christensen (1980 a, b) point out, the TL model does not perform well when substitution elasticities are likely to be small, or when there are likely to be small shares or large relative differences among shares. This is partly true because the translog has the Cobb-Douglas form (a form that embodies considerable input substitution possibilities) as a special case. Patrick and Wolak (2001) found this to be problematic in an application of customer demand for electricity under real time pricing, and Diewert and Wales (1987) encountered similar difficulties in an earlier study using aggregate U.S. industrial data. Patrick and Wolak (2001) argue that the GL model is superior to the TL model because it has a fixed-coefficient Leontief technology as a limiting case, and therefore, it can reflect rather modest substitutions possibilities. However, these authors also note that if one imposes global concavity, the GL model loses some of its flexibility - in particular all inputs must be substitutes. To circumvent these difficulties related to both the TL and GL models, Patrick and Wolak (2001) and Taylor et al. (2005) employ a Generalized McFadden (GM) cost function that is "...second-order flexible, yet suited to capture small positive and negative elasticities of substitution between electricity demands across load periods within a day" (Patrick and Wolak, 2001, p. 27). Despite these theoretical advantages to the GM model, the computational burden is increased substantially as well. Their need to accommodate both positive and negative elasticities of substitution results from their specification of more than two demand periods. However, our empirical model specifies only two demand periods. In this case, any model in which global concavity is either assumed, or imposed, requires that the inputs be substitutes. Therefore, the primary issue that led to their selection of the GM model is of no concern in our present application of the GL indirect cost model. ${ }^{15}$ As discussed originally by Allen (1938, pp. 508-09), the partial elasticity measures the degree to which the demand for factor $\mathrm{j}$ changes as the price of factor $\mathrm{i}$ changes. If $\sigma_{\mathrm{ij}}>0$, and the price of factor $\mathrm{i}$ increases, then the use of factor $\mathrm{j}$ increases, thereby taking part in the replacement of factor $\mathrm{i}$ in production. The two factors are said to be competitive. If, on the other hand, $\sigma_{i j}<0$, the two factors are complements, and as the price of one of them rises, the demand for both falls. Competitiveness between factors is, on the whole the more general case; one factor cannot be complementary with all others. In the two-input case, direct elasticity of substitution (which measures the percentage change in factor intensities as the inverse price ratio changes by one percent) is equal to the Allen partial elasticity of substitution.
} 
(9) $\sigma_{\mathrm{p} 0}=\mathrm{C}_{\mathrm{p} 0} /\left[\mathrm{C}_{\mathrm{p}} \mathrm{C}_{0}\right]$

where the subscripts refer to the first- and second-order partial derivatives of $\mathrm{C}$ with respect to electricity inputs $\mathrm{k}_{\mathrm{p}}$ and $\mathrm{k}_{0}$. Fortunately, in the two-input case such as we have here, the direct elasticity of substitution (which measures the percentage change in factor intensities as the inverse price ratio changes by one percent, holding a firm's output constant) is also equal to the Allen partial elasticity of substitution. Thus, although denoted somewhat differently, the measure of price response given by equation (9) is directly comparable to that derived from the CES model above.

Evaluating equation (9) for the GL cost function given in equation (6), we have:

$$
\sigma_{\mathrm{p} 0}=1 / 2\left[\mathrm{C} \mathrm{d}_{\mathrm{p} 0}\left(\mathrm{p}_{\mathrm{p}} \mathrm{p}_{0}\right)^{-1 / 2}\right] /\left[\mathrm{E} \mathrm{a}_{\mathrm{p}} \mathrm{a}_{0}\right]
$$

where $a_{p}=k_{p} / E$ and $a_{0}=k_{0} / E$ are the peak and off-peak energy proportions of the electricity aggregate, which are derived by dividing the electricity demand equations in equations (7) and (8) by E. That is:

$$
\begin{aligned}
& a_{p}=k_{p} / E=d_{p p}+d_{p 0}\left(p_{0} / p_{p}\right)^{1 / 2} \\
& a_{0}=k_{0} / E=d_{00}+d_{p 0}\left(p_{p} / p_{0}\right)^{1 / 2}
\end{aligned}
$$

Finally, although they do not have a terribly meaningful interpretation in this application, we also need to estimate the Allen own partial elasticities of substitution, so that we can check to see if the underlying function is well behaved. These are given by ( $i$ and $j=p$ and 0):

$$
\sigma_{i i}=-1 / 2\left[C \sum_{j \neq i} d_{i j}\left(p_{j}^{-1 / 2} p_{i}^{-3 / 2}\right)\right] /\left[E a_{i}^{2}\right]
$$

\section{B.2.2.4 Estimating the Generalized Leontief Function}

Normally, to estimate the parameters of this cost GL function, one need only assume an additive error structure associated with the input share equations (11) and (12), and then estimate them as a system of equations where there are across-equation restrictions to ensure symmetry of the parameters. Unfortunately, because E in our case is the energy aggregate and cannot be observed directly, it is impossible to employ this strategy. However, using full information maximum likelihood (FIML) methods within PROC MODEL in SAS, one can estimate the parameters of the cost function (6) from the ratio $\mathrm{a}_{\mathrm{p}}$ and $\mathrm{a}_{0}$. That is, we can estimate:

$$
\left[\mathrm{a}_{\mathrm{p}} / \mathrm{a}_{0}\right]=\left[\mathrm{k}_{\mathrm{p}} / \mathrm{k}_{0}\right]=\left[\mathrm{d}_{\mathrm{pp}}+\mathrm{d}_{\mathrm{p} 0}\left(\mathrm{p}_{0} / \mathrm{p}_{\mathrm{p}}\right)^{1 / 2}\right] /\left[\mathrm{d}_{00}+\mathrm{d}_{\mathrm{p} 0}\left(\mathrm{p}_{\mathrm{p}} / \mathrm{p}_{0}\right)^{1 / 2}\right]
$$

In this form, the equations are extremely non-linear in the parameters, and it might be best to take the logarithms of both sides for estimation purposes. We have the following logarithmic specification: 
$\ln \left[\mathrm{a}_{\mathrm{p}} / \mathrm{a}_{0}\right]=\ln \left[\mathrm{k}_{\mathrm{p}} / \mathrm{k}_{0}\right]=\ln \left\{\left[\mathrm{d}_{\mathrm{pp}}+\mathrm{d}_{\mathrm{p} 0}\left(\mathrm{p}_{0} / \mathrm{p}_{\mathrm{p}}\right)^{1 / 2}\right] /\left[\mathrm{d}_{00}+\mathrm{d}_{\mathrm{p} 0}\left(\mathrm{p}_{\mathrm{p}} / \mathrm{p}_{0}\right)^{1 / 2}\right]\right\}$

This strategy will not get rid of the non-linearities, but it will convert each equation into the differences between two logarithms within which there are coefficients imbedded. Whether SAS deals with that kind of non-linearity better than these quotients is an empirical question. Within PROC MODEL, we can also impose the symmetry restrictions on $\mathrm{d}_{\mathrm{ij}}$, and force the adding up restrictions to $\sum_{\mathrm{i}} \sum_{\mathrm{j}} \mathrm{d}_{\mathrm{ij}}=1$ to normalize to a unit $\mathrm{E}_{0}$ curve.

\section{B.2.2.5 Calculating Elasticities of Substitution}

Regardless of which transformation is easiest to estimate, we can use the results to calculate the elasticities of substitution from equations (10) and (13). This is done by substituting the estimated parameters, denoted $d_{i j}{ }^{*}$ (for $i$ and $j=p$ and 0 ), from equation (14) or (15) into equations (11) and (12) to calculate $\left(\mathrm{a}_{\mathrm{p}}\right)_{\mathrm{fit}}$ and $\left(\mathrm{a}_{0}\right)_{\text {fit }}$ at each data point. In turn, these estimated expressions are substituted into equation (6) to obtain estimates of $(\mathrm{C} / \mathrm{E})_{\text {fit. }}$. Finally, these estimated expressions are substituted into equations (10) and (13) to obtain for each data point estimates of:

$$
\begin{aligned}
& \sigma_{\mathrm{p} 0}=1 / 2\left[(\mathrm{C} / \mathrm{E})_{\mathrm{fit}} \mathrm{d}_{\mathrm{p} 0}{ }^{*}\left(\mathrm{p}_{\mathrm{p}} \mathrm{p}_{0}\right)^{-1 / 2}\right] /\left[\left(\mathrm{a}_{\mathrm{p}}\right)_{\mathrm{fit}}\left(\mathrm{a}_{0}\right)_{\mathrm{fit}}\right] \\
& \sigma_{\mathrm{pp}}=-1 / 2\left[(\mathrm{C} / \mathrm{E})_{\mathrm{fit}} \mathrm{d}_{\mathrm{p} 0}{ }^{*}\left(\mathrm{p}_{0}{ }^{1 / 2} \mathrm{p}_{\mathrm{p}}{ }^{-3 / 2}\right)\right] /\left[\left(\mathrm{a}_{\mathrm{p}}\right)_{\mathrm{fit}}{ }^{2}\right], \text { and } \\
& \sigma_{00}=-1 / 2\left[(\mathrm{C} / \mathrm{E})_{\mathrm{fit}} \mathrm{d}_{0 \mathrm{p}}{ }^{*}\left(\mathrm{p}_{\mathrm{p}}{ }^{1 / 2} \mathrm{p}_{0}^{-3 / 2}\right)\right] /\left[\left(\mathrm{a}_{0}\right)_{\mathrm{fit}}{ }^{2}\right]
\end{aligned}
$$

As stated above, in this two-input case, the cross Allen partial elasticity of substitution (17) is equivalent to the direct elasticity of substitution which measures the proportional change in the ratio of peak to off-peak electricity use due to a one percent change in the inverse price ratio (Ferguson 1969). ${ }^{16}$ By examining equations (16) through (18), one major advantage of using the GL function is apparent. In contrast to the CES model, the elasticity of substitution for the GL model can now vary from observation to observation; it can also vary with price ratios, the energy aggregate, and the cost minimizing input levels. The trade-off necessary to gain this flexibility is that there is now no guarantee that the function is well behaved--e.g., $\infty>\sigma_{0 \mathrm{p}} \geq 0$ (Ferguson 1969).

B.2.2.6 Interpreting the Coefficients in the GL Demand Model: Their Relationship to $\sigma_{0 p}$

Whether or not the cost function is well behaved depends on the estimated values of the model parameters, $\mathrm{d}_{\mathrm{pp}}, \mathrm{d}_{0 \mathrm{p}}$, and $\mathrm{d}_{00} .{ }^{17}$ A sufficient condition for the GL function to be

\footnotetext{
${ }^{16}$ This relationship shows that $\sigma$ is the proportional change in the use of electricity in the peak period relative to the off-peak period (holding output, in this case the electricity aggregate, constant), as the inverse price ratio increases by one percent (Ferguson 1969, pp. 103-04).

${ }^{17}$ For the most general case, where the parameters $\mathrm{d}_{00}, \mathrm{~d}_{\mathrm{pp}}$ and $\mathrm{d}_{0 \mathrm{p}}$ are allowed to take on any possible value, the resulting cost function need not be non-negative for all factor prices. Thus, in this case, it is necessary to ensure that at each data point the estimated cost function is monotonically increasing and strictly quasi-concave in input prices. To do this, we must verify that the fitted values for all the input-
} 
well behaved is that all parameters be non-negative (Diewert 1974). Perhaps more important for our purposes, a necessary condition for the function to be well behaved is that $\mathrm{d}_{0 \mathrm{p}}$, must be greater than or equal to zero. There are three cases of empirical interest, given this restriction on $\mathrm{d}_{0 \mathrm{p}}$ (Diewert, pp.503-504), and they can be related to the types of demand response depicted in Figures 1 and 2 above.

Case 1: If $\mathrm{d}_{\mathrm{pp}}, \mathrm{d}_{0 \mathrm{p}}$, and $\mathrm{d}_{00}$ are all non-negative, then peak and off-peak electricity are substitutes and the substitution possibilities are characterized by the curve in Figure 1.

Case 2: If $\mathrm{d}_{0 \mathrm{p}}$ takes on an extreme value of zero, then for the function to be well-behaved, $d_{p p} \geq 0$ and $d_{00} \geq 0$, with at least one strict inequality. The significance of this case is that the GL model reduces to the ordinary two-factor Leontief production function that is characterized by fixed factor proportions as in Figure 2 above. Here, peak and off-peak electricity are perfect complements and the firm has no opportunities for input substitution. Since this situation may indeed characterize a number of firms, it is important that this GL model encompasses this possibility. Because this situation is captured by one of the coefficients in the model, we can develop a formal test of the hypothesis of fixed proportion electricity demand. The details of the test are discussed below.

Case 3: For this case, we have $d_{p p}<0, d_{0 p}>0$, and $d_{00}>0$. Here, we can still trace out the curve representing input combinations that can keep output constant, but there is a price of peak electricity, $\mathrm{p}_{\mathrm{p}}{ }^{*}$ that makes the peak to off-peak price so large that peak electricity is no longer used. This happens when $\mathrm{p}_{0} / \mathrm{p}_{\mathrm{p}}<\mathrm{d}_{\mathrm{pp}}{ }^{2} / \mathrm{d}_{00}{ }^{2}$. This situation is depicted in Figure 3 , where the constant electricity aggregate curve $\mathrm{E}_{0}$ intersects the vertical axis. This situation cannot be modeled by the CES function. While it is perhaps unlikely that many firms can forgo all electricity use during peak periods when peak prices are extremely high, the fact that the GL model can identify this type of behavior suggests that this flexible model is capable of capturing the entire range of price responsive behavior.

\section{B.3 Empirical Specification of the GL Model and Econometric Considerations}

output equations are positive and that the nxn matrix of the $\sigma_{\mathrm{ij}}$ substitution elasticities is negative semidefinite at each observation (Berndt, 1991, p. 465 and p. 493).

The test to verify that this matrix in negative semi-definite is related to a well-known adding up condition for the Allen (1938. pp.504-05) partial elasticities of substitution. In the multi-factor case, this adding up condition ensures that the substitution relationships are more numerous and more important than the complementary relationships.

For the two-factor, the inputs must be substitutes: the adding up relationship implies: $\mathrm{S}_{\mathrm{p}} \sigma_{0 \mathrm{p}}=-\mathrm{S}_{0} \sigma_{00}$ and $S_{0} \sigma_{0 p}=-S_{p} \sigma_{p p}$, where the $S$ 's are corresponding cost shares. Berndt (1991) shows that the right hand side of the second relation is equal to the negative of own price elasticity of demand for peak electricity, holding output and all other input prices constant. The left-hand term is the corresponding cross-price elasticity of off-peak demand with respect to peak price, holding output and all other input prices constant. Thus, as the peak price is increased, the percentage increase in off-peak electricity usage equals the percentage decrease in peak electricity usage. It follows that if total actual off-peak demand is greater than total on-peak demand, then as peak price is increased, the increase in total off-peak demand will be larger than the decrease in peak demand. Thus, total daily electricity usage will increase. 
In the 2004 analysis of Niagara Mohawk's SC-3A customers, a CES response function was estimated to provide empirical estimates of elasticities of substitution between peak and off-peak electricity (Goldman, et al. 2004). In that study, responses from a survey were used to determine if the elasticities of substitution differed systematically by customer characteristic. Since the CES model restricts elasticities of substitution to be constant for any individual firm, the most efficient way to identify the importance of these firm characteristics was to estimate one model for all customers by pooling the data across customers and accounting for the effects of specific firm characteristics by introducing a series of additional variables that are the product of the price ratio and a series of 0-1 "dummy variables which are assigned a value of 1 if the firm has the particular characteristic. This model estimation was accomplished in a straightforward fashion in SAS.

Because of the non-linear nature of the equations to be estimated for the GL model, it is not possible to account for these firm effects by including a series of $0-1$ "categorical" variables into a model that is estimated using the data pooled across all customers.

Furthermore, even if such a strategy were possible, it would not exploit the full flexibility of the GL model. Therefore, to exploit the flexibility of the GL model, where elasticities of substitution can differ across days for a single firm, we employ the following estimation strategy:

1) Estimate a demand model for each customer;

2) Calculate the substitution elasticities for each data point for each firm;

3) Pool the estimated elasticities for all firms and all data points; and

4) Estimate a second model from this pooled data set where the daily elasticities of substitution between peak and off-peak electricity are a function of daily peak to off-peak electricity price ratios and a variety of individual firm characteristics.

5) Estimate a third model to relate the average elasticities of substitution by firm to a number of individual firm characteristics.

In estimating the elasticities of substitution between peak and off-peak electricity use, we exploit the flexibility of the GL demand model by estimating a separate model for each firm. ${ }^{18}$ This entire estimation strategy is similar to the one used by Taylor and Schwarz (1990). In his study, Patrick used a GL demand model to estimate household demand response by customer, and used a second regression to relate customer characteristics to the degree of price responsiveness.

\section{B.3.1 Demand Model Specification}

To conduct our estimation, we specify the following GL model for each individual firm as follows:

\footnotetext{
${ }^{18}$ Other efforts to model demand response have also relied on estimated demand models for individual firms, although the functional forms have been different than the one used here (e.g., Schwartz et al., 2002, Patrick and Wolak 1997). In several cases, the analyses were based on functional forms that did not allow the substitution elasticities to vary across days for each firm (e.g. Caves, et al. 1984 and Charles River Associates 2004).
} 

$\left\{\ln \left[\left(\mathrm{h}_{0 \mathrm{f}}\right)\left(\mathrm{H}_{\mathrm{tf}}\right)+\left(\mathrm{d}_{00, \mathrm{f}}\right)+\left(\mathrm{d}_{0 \mathrm{p}, \mathrm{f}}\right)\left(\mathrm{p}_{\mathrm{pt}, \mathrm{f}} / \mathrm{p}_{0 \mathrm{t}, \mathrm{f}}\right)^{1 / 2}\right]\right\}+\varepsilon_{\mathrm{t}, \mathrm{f}}$,

where, for each weekday, $\mathrm{t}$, and firm, $\mathrm{f}$, we define: $\mathrm{k}_{\mathrm{pt}, \mathrm{f}}=$ actual peak $\mathrm{kWh} ; \mathrm{k}_{0 \mathrm{t}, \mathrm{f}}=$ actual off-peak $\mathrm{kWh} ; \mathrm{p}_{\mathrm{pt}, \mathrm{f}}=$ average hourly peak price $/ \mathrm{kWh}$; and $\mathrm{p}_{0 \mathrm{t}, \mathrm{f}}=$ average hourly off-peak price/kWh.

The effect of weather is accounted for in two distinct ways. The variable $\mathrm{W}_{\mathrm{tf}}$ is a continuous variable reflecting cooling degrees (e.g., the difference between the average peak period temperature and 65). This variable enters as an intercept shifter, thus controlling for differences in peak to off-peak usage during days that are unusually warm. The second weather variable is $\mathrm{H}_{\mathrm{tf}}$ is another weather index. It is a binary $(0,1)$ variable to distinguish hot $\left(\mathrm{H}_{\mathrm{tf}}=1\right)$ from cool days $\left(\mathrm{H}_{\mathrm{tf}}=0\right)$. We used the average Temperature Heat Index (THI) derived by the National Weather Service during the peak period hours to distinguish hot $($ Avg. THI $\geq 85)$ from cool $($ Avg. THI $<85)$ days. ${ }^{19}$ By including this variable in the model, we account for differences in the model parameters on hot vs. cool days. This happens because the estimated coefficients on this variable affect the size of the estimated parameters of the model (e.g. $\mathrm{d}_{00, \mathrm{f}}$ and $\mathrm{d}_{\mathrm{pp}, \mathrm{f}}$ ), but only on hot days. In turn, these parameters affect the size of the estimated elasticities of substitution. The process by which these coefficients are changed on hot days is discussed in the next section.

In the estimation, $\mathrm{d}_{\mathrm{p} 0, \mathrm{f}}=\mathrm{d}_{0 \mathrm{p}, \mathrm{f}}$ to ensure the required symmetry among estimated coefficients. We also require that $\mathrm{d}_{00, \mathrm{f}}+\mathrm{d}_{\mathrm{pp}, \mathrm{f}}+\mathrm{d}_{0 \mathrm{p}, \mathrm{f}}+\mathrm{d}_{\mathrm{p}, \mathrm{f}}=1$ and $\mathrm{h}_{\mathrm{pf}}=\mathrm{h}_{0 \mathrm{f}}$, which normalizes the coefficients to reflect a one unit curve for the energy aggregate. ${ }^{20}$

\section{B.3.2 Calculating Elasticities of Substitution by Firm}

Since we do not pool the data across firms, we have separate estimates for the coefficients, $\mathrm{d}_{00, \mathrm{f}}, \mathrm{d}_{\mathrm{pp}, \mathrm{f}}, \mathrm{d}_{0 \mathrm{p}, \mathrm{f}}$, and $\mathrm{d}_{\mathrm{p}, \mathrm{f}}$ for each firm, $\mathrm{f}$. We use the estimates of these individual demand model parameters to derive a set of firm-specific estimates of substitution elasticities according to equations (16), (17), and (18) and the procedures outlined in the previous section. It is important to be quite specific about how the effect of hot days is captured in these estimates of the elasticities of substitution. As above, let a * denote an estimated parameter. From equation (19), we can now think of two of the parameters to be estimated in this model as $\mathrm{d}_{\mathrm{pp}, \mathrm{f}}{ }^{*}=\left(\mathrm{h}_{\mathrm{pf}}\right)\left(\mathrm{H}_{\mathrm{tf}}\right)+\left(\mathrm{d}_{\mathrm{pp}, \mathrm{f}}\right)$ and $\mathrm{d}_{00, \mathrm{f}}{ }^{*}=\left(\mathrm{h}_{0 \mathrm{f}}\right)\left(\mathrm{H}_{\mathrm{tf}}\right)$ $+\left(\mathrm{d}_{00, \mathrm{f}}\right)$. Thus, for hot days (when $\left.\mathrm{H}_{\mathrm{tf}}=1\right)$, the coefficients that are substituted into equations $\left(16,17\right.$, and 18) for calculating the elasticities of substitution are $\mathrm{d}_{\mathrm{pp}, \mathrm{f}}{ }^{*}=\left(\mathrm{h}_{\mathrm{pf}}\right)+$ $\left(\mathrm{d}_{\mathrm{pp}, \mathrm{f}}\right)$ and $\mathrm{d}_{00, \mathrm{f}}{ }^{*}=\left(\mathrm{h}_{\mathrm{of}}\right)+\left(\mathrm{d}_{00, \mathrm{f}}\right)$. In contrast, for cool days (when $\left.\mathrm{H}_{\mathrm{ff}}=0\right)$, the estimated coefficients being used in equations $(16,17$, and 18) for calculating the elasticities of substitution are simply $\mathrm{d}_{00, \mathrm{f}}{ }^{*}=\mathrm{d}_{\mathrm{pp}, \mathrm{f}}$ and $\mathrm{d}_{\mathrm{pp}}{ }^{*}=\mathrm{d}_{00, \mathrm{f}}$.

\footnotetext{
${ }^{19}$ The weather index is constructed from temperature and dew point values for five weather stations located in the utility's service territory. See Goldman, et al. (2004) for details on the construction of the index.

${ }^{20}$ Although the parameter estimates changed if this adding up condition were set to a number different from 1 , the estimates of the elasticities of substitution were invariant to the specification.
} 


\section{B.3.3 Some Econometric Issues in Estimating the GL Function}

There are two important econometric issues that were of some concern in estimation of the GL function. The first has to do with whether or not the prices in this demand model (equation (19)) are endogenously determined with peak and off-peak loads. The second has to do with whether or not there is autocorrelation between the error terms in equation (19), and in the subsequent equations for steps 4 and 5 of the overall estimation strategy. The final issue is the extent to which there is heteroskedasticity in the error structures of the equations for steps 4 and 5 of the overall estimation strategy. Each issue is discussed in turn.

\section{B.3.3.1 Exogenous Prices and Loads}

In equation (19), the logarithm of the ratio of peak to off-peak load is the dependent variable, whereas the off-peak and peak prices of electricity appear on the right hand side as explanatory variables, often called regressors. Most econometric methods assume that the regressors in a model are exogenous, or independent of each other, and are also not simultaneously determined with the dependent variable. In our case, this would mean that prices are being determined simultaneously along with peak and off-peak load. If the regressors are not exogenous, then by including an endogenous variable (that is correlated with the equation's error term) on the right hand side of the equation, the estimated residuals of the model are affected, and the parameter estimates are no longer unbiased, and their standard errors are no longer consistent (minimum variance). This leads to an underestimation of the standard errors and could lead to the t-ratios being biased upward. The consequence would be to reject some null hypotheses when it was unwarranted.

This issue can arise in any economic model of aggregate supply and demand when, as is often believed, prices and quantities are simultaneously determined. However, the issue is not thought to be a serious one when the model is dealing with the input demand at the firm level. When firms are small relative to the total market, it is reasonable to assume that they are price takers. ${ }^{21}$ A second reason for believing that this issue is not important in this case is the fact that in making their energy use decisions, these SC-3A customers face 24-hour prices determined the day before in the day-ahead market. Thus, while their demand response decisions to high prices may affect prices on the same day in the real time market, their decisions can have no effect on the prices in the day ahead market that were determined the day before. Since customers face prices on which to base their decisions on hourly electricity usage that are established the day before, the price

\footnotetext{
${ }^{21}$ In a price dependent zonal supply model of the new unregulated New York electricity market, Cappers (2004) argues that real time load is highly correlated with the error term, and its inclusion on the right-hand side of the model would affect the estimated residuals. For this reason, he employed the method of instrumental variables by estimating real time load as a function of a heat index and some cyclical variables for each zone. The estimated loads, now uncorrelated with the supply equation's error term, were then used as regressors in the supply models.
} 
variables used in the firm-level electricity demand model specified here are truly exogenous. $^{22}$

\section{B.3.3.2 Autocorrelated Error Terms}

Standard regression models are generally based on the assumption that the error term of any observation is not influenced by the error term of any other observation. Formally, this means that the error terms are uncorrelated, and $E\left(\varepsilon_{\mathrm{I}}, \varepsilon_{\mathrm{j}}\right)=0$ for $\mathrm{j} \neq \mathrm{i}$. However, for each of our customers, we have a time series of data--the daily observations of peak and off-peak prices and loads are arrayed chronologically, and there is good reason to think that relative loads are likely to persist from day to day. Alternatively, it may also be the case that due to high prices, or other disturbances, that the effects on peak to off-peak demand may continue for a few days. In each of these cases, there may be some systematic relationship between the error terms. That is, $E\left(\varepsilon_{\mathrm{I}}, \varepsilon_{\mathrm{j}}\right) \neq 0$ for $\mathrm{j} \neq \mathrm{i}$. For this case, Gujarati (1995) shows that although the OLS estimators are unbiased and consistent, they are no longer minimum variance. In addition, even though the OLS estimators remain unbiased and consistent, the confidence intervals derived from them using the variances corrected for autocorrelation are likely to be wider than when using a GLS estimator. Thus, in our analysis, we test for autocorrelation, and apply the appropriate correction if warranted. This appropriate correction for a model that is nonlinear in the parameters is accommodated within PROC MODEL in SAS.

\section{B.3.3.3 Accounting for Heteroskedasticity}

Another usual assumption in regression analysis is that disturbance terms for all observations in the model are independently and identically distributed (i.e., $\mathrm{E}\left(\varepsilon_{\mathrm{i}}{ }^{2}\right)=\sigma^{2}$, for all i). In this application, some firms may exhibit zero or near zero estimated price responsiveness over all days, while others may exhibit quite a large average price response, but the daily variation around the mean price response may be rather large as well. Therefore, it may be reasonable to expect that the variance of the disturbance term in the equation (from step 4 of the estimation strategy) in which the estimated elasticities of substitution (pooled across all customers) are regressed on the ratio of prices and some limited firm characteristics are indeed not equal across firm or across observations within firms. That is, it may be that the elasticities of substitution are proportional to those factors that make a firm more or less price responsive on a particular day.

\footnotetext{
${ }^{22}$ The modeling framework and rationale is similar to that used by Neenan, et al. (2003) in estimating prices in the day-ahead market. In the present case, quantities demanded by firms are determined by exogenous day-ahead prices, as set out in the terms of the SC-3A contract between Niagara Mohawk and the SC-3A customers. Similarly, an analogous situation applies in the day ahead electricity market in New York due to the nature of the market rules. In the day ahead market, Load Serving Entities (LSEs) and other market participants are required to submit a fixed bid load, the load they are willing to purchase in the day ahead market at any price. Once this load for all customers has been received, the NYISO determines hourly prices in the day that minimize the cost of meeting fixed bid load by solving its day ahead unit commitment algorithm. Thus, these fixed bid loads are truly exogenous at the time the day ahead prices are determined.
} 
This characteristic of the error structure in a regression model is known as heteroskedasticity (Gujarati 1995). Although the coefficients remain unbiased, the estimators of the parameters are no longer minimum variance. That is, unless heteroskedasticity is recognized, the t-ratios associated with the coefficients may be biased, and in turn so are the t-ratios used for testing hypotheses about the significance of the effects of certain variables. Therefore, in both the second and third equations in the analysis (the regressions using pooled data to explain the effect of price levels on the elasticities of substitution and differences in average substitution elasticities), we test for heteroskedasticity using a generalized White's test (Greene 1990, pp. 399-428). In the cases where there is heteroskedasticity, we use the generalized method of moments to derive the appropriate correction and re-estimate the model. The tests and the reestimations are accomplished within SAS.

\section{B.3.4 Elasticity of Substitution Regression Model Specification}

Once we have the estimated daily elasticities of substitution from each of the individual demand models, we pool the data across customers in order to test the hypotheses that price responsiveness is related to the level of electricity prices and other individual firm characteristics.

The basic regression equation specifies that the elasticities of substitution are a function of the peak to off-peak price ratio, the percent current use of maximum demand and business class. These variables are also specified in the model as intercept and/or slope shifters to account for the interaction among these characteristics. The model is specified as for day $\mathrm{t}$ and firm $\mathrm{f})^{23}$

$$
\begin{aligned}
& \sigma_{\mathrm{tf}}=\alpha+\beta_{1}\left[\mathrm{p}_{\mathrm{pt}, \mathrm{f}} / \mathrm{p}_{0 \mathrm{t}, \mathrm{f}}\right]+\beta_{2} \operatorname{Man}^{*}\left[\% \operatorname{MaxD}_{\mathrm{t}, \mathrm{f}}\right]+\beta_{3} \operatorname{Man} *\left[\mathrm{p}_{\mathrm{pt}, \mathrm{f}} / \mathrm{p}_{0 \mathrm{tt}, \mathrm{f}}\right] \\
& +\beta_{4} \text { Gov/Ed* }\left[\% \mathrm{MaxD}_{\mathrm{t}, \mathrm{f}}\right]+\beta_{5} \mathrm{Gov} / \mathrm{Ed}^{*}\left[\mathrm{p}_{\mathrm{pt}, \mathrm{f}} / \mathrm{p}_{0 \mathrm{t}, \mathrm{f}}\right]+\beta_{6} \mathrm{PW}^{*}\left[\% \mathrm{MaxD}_{\mathrm{t}, \mathrm{f}}\right] \\
& +\beta_{7} \mathrm{PW}^{*}\left[\mathrm{p}_{\mathrm{ptt}, \mathrm{f}} / \mathrm{p}_{0 \mathrm{t}, \mathrm{f}}\right]+\beta_{8} \mathrm{C} \& \mathrm{R}^{*}\left[\% \mathrm{MaxD}_{\mathrm{t}, \mathrm{f}}\right]+\beta_{9} \mathrm{C} \& \mathrm{R}^{*}\left[\mathrm{p}_{\mathrm{pt}, \mathrm{f}} / \mathrm{p}_{0 \mathrm{t}, \mathrm{f}}\right]+ \\
& \mathrm{u}_{\mathrm{tf}} \text {, }
\end{aligned}
$$

where $\left[p_{p t, f} / p_{0 t, f}\right]=$ ratio of peak to off-peak electricity prices on day $t$ for firm $f$; Man $=$ $0-1$ variable -1 for manufacturing firms, 0 otherwise; $\mathrm{Govt} / \mathrm{Ed}=0-1$ variable -1 for government/education firms, 0 otherwise; $\mathrm{PW}=0-1$ variable -1 for public works firms, 0 otherwise; $\mathrm{C} \& \mathrm{R}=0-1$ variable -1 for commercial and retail firms, 0 otherwise; $\% \mathrm{MaxD}_{\mathrm{t}, \mathrm{f}}=\%$ peak use on day $\mathrm{t}$ for firm $\mathrm{f}$ is of maximum demand for firm $\mathrm{f}$ in the year for which day $t$ is an observation; and $\mathrm{u}_{\mathrm{tf}}$ is a random error term.

\section{B.3.4.1 Interpreting the Coefficients}

The important hypotheses about the effects on the elasticity of substitution of electricity of the ratio of peak to off-peak prices and firm characteristics are reflected in the expected signs of the coefficients for each of the variables in equation (20). These

\footnotetext{
${ }^{23}$ In the empirical analysis, a first-order autoregressive process is incorporated into the model to correct for autocorrelation of the residuals. The reason for this correction is discussed in the previous section in conjunction with estimating the GL demand model.
} 
specific hypotheses are discussed along with the empirical results below. In this section, we instead discuss in more general terms how to interpret the coefficients.

In general, the interpretation of the estimated coefficients in equation (20) is consistent with those in any linear regression model. For continuous variables, such as the peak to off-peak price ratio, the regression coefficient, $\beta_{1}$, reflects the marginal change in the elasticity of substitution, $\sigma$, due to a unit increase in the variable (e.g., an increase in the peak to off-peak price ratio from 1.5 to 2.5$)$. Formally, we have:

$$
\partial \sigma_{\mathrm{tf}} / \partial\left[\mathrm{p}_{\mathrm{pt}, \mathrm{f}} / \mathrm{p}_{0 \mathrm{t}, \mathrm{f}}\right]=\beta_{1}
$$

Since there are some categorical 0-1 variables used to identify any systematic differences in price responsiveness among firms in various categories, such as business class, the coefficient $\beta_{1}$ actually measures the effect of changes in the price ratio on the elasticities of substitution for a reference group of customers. In our model, this reference group of firms contains firms in the health care industry. By including these categorical variables as interaction terms with the price ratio, the effects of the price ratio on the elasticities of substitution are allowed to differ for other groups of customers from that of the reference group. for manufacturing firms, for example, the elasticity of substitution differs from that of the reference group of firms (e.g. firms in the health care industry in our case) by an amount $\beta_{2}$. For government/education firms the elasticity of substitution differs from that of the reference group of firms (e.g. firms in the health care industry in our case) by an amount $\beta_{5}$.

Since some of the variables in the model are formulated by multiplying a $0-1$ categorical variable by a more conventional, continuous variable, it is perhaps useful to highlight the interpretation of the coefficients associated with these variables. We can illustrate by considering the combined effect of the peak to off-peak price ratio and the percent peak use is of maximum peak demand on the elasticity of substitution, $\sigma$, for manufacturing firms. These combined effects are captured in the following three terms. That is, the elasticity of substitutions for manufacturing firms differ from that of the reference group (e.g., firms in the health care industry) by an amount equal to:

$$
\beta_{2} \operatorname{Man} *\left[\% \operatorname{MaxD}_{\mathrm{t}, \mathrm{f}}\right]+\beta_{3} \operatorname{Man} *\left[\mathrm{p}_{\mathrm{pt}, \mathrm{f}} / \mathrm{p}_{0 \mathrm{t}, \mathrm{f}}\right]
$$

To determine the total amount by which $\sigma$ for manufacturing firms differs from other firms, one need only evaluate expression $(22)$ for $(\mathrm{Man}=1)$ and the appropriate values of $\left[\% \mathrm{MaxD}_{\mathrm{t}, \mathrm{f}}\right]$ and $\left[\mathrm{p}_{\mathrm{pt}, \mathrm{f}} / \mathrm{p}_{0 \mathrm{t}, \mathrm{f}}\right]$ for the day of interest, $\mathrm{t}$, and manufacturing firm of interest, $\mathrm{f}$. Normally, these combined effects are summarized by calculating expression (22) at the mean and the extremes of these two continuous variables. Expression (22) also reveals the changes in $\sigma$ due to marginal changes in both $\left[\% \mathrm{MaxD}_{\mathrm{t}, \mathrm{f}}\right]$ and $\left[\mathrm{p}_{\mathrm{pt}, \mathrm{f}} / \mathrm{p}_{0 \mathrm{t}, \mathrm{f}}\right]$. That is, the $\sigma$ for manufacturing firms is also increased by an amount $\beta_{2}$ as peak electricity use increases by $1 \%$ relative to maximum peak demand and by an amount $\beta_{3}$ as the ratio of peak to off-peak price increases by one unit. For Man $=1$, these two relationships are derived formally by: 


$$
\begin{aligned}
& \partial \sigma_{\mathrm{tf}} / \partial\left[\% \mathrm{MaxD}_{\mathrm{t}, \mathrm{f}}\right]=\operatorname{Man} * \beta_{2}, \text { and } \\
& \partial \sigma_{\mathrm{tf}} / \partial\left[\mathrm{p}_{\mathrm{pt}, \mathrm{f}} / \mathrm{p}_{0 \mathrm{t}, \mathrm{f}}\right]=\beta_{1}+\operatorname{Man} * \beta_{3}{ }^{24}
\end{aligned}
$$

We can isolate the differences in the elasticity of substitution for government and educational firms $(\mathrm{Govt} / \mathrm{Ed}=1)$ in a similar way by examining the coefficients in the following expressions:

$$
\begin{aligned}
& \beta_{4} \operatorname{Gov} / \operatorname{Ed}^{*}\left[\% \mathrm{MaxD}_{\mathrm{t}, \mathrm{f}}\right]+\beta_{5} \operatorname{Gov} / \mathrm{Ed}^{*}\left[\mathrm{p}_{\mathrm{pt}, \mathrm{f}} / \mathrm{p}_{0 \mathrm{t}, \mathrm{f}}\right] \\
& \partial \sigma_{\mathrm{tf}} / \partial\left[\% \mathrm{MaxD}_{\mathrm{t}, \mathrm{f}}\right]=\mathrm{Govt} / \mathrm{Ed} * \beta_{4}, \text { and } \\
& \partial \sigma_{\mathrm{tf}} / \partial\left[\mathrm{p}_{\mathrm{pt}, \mathrm{f}} / \mathrm{p}_{0 \mathrm{t}, \mathrm{f}}\right]=\beta_{1}+\mathrm{Govt} / \mathrm{Ed} * \beta_{5 .}{ }^{25}
\end{aligned}
$$

Summarily, we can isolate the differences in the elasticity of substitution for public works firms $(\mathrm{PW}=1)$ by examining the coefficients in the following expressions:

$$
\begin{aligned}
& \beta_{6} \mathrm{PW}^{*}\left[\% \mathrm{MaxD}_{\mathrm{t}, \mathrm{f}}\right]+\beta_{7} \mathrm{PW}^{*}\left[\mathrm{p}_{\mathrm{pt}, \mathrm{f}} / \mathrm{p}_{0 \mathrm{t}, \mathrm{f}}\right] \\
& \partial \sigma_{\mathrm{tf}} / \partial\left[\% \mathrm{MaxD}_{\mathrm{t}, \mathrm{f}}\right]=\mathrm{PW} * \beta_{6}, \text { and } \\
& \partial \sigma_{\mathrm{tf}} / \partial\left[\mathrm{p}_{\mathrm{pt}, \mathrm{f}} / \mathrm{p}_{0 \mathrm{t}, \mathrm{f}}\right]=\beta_{1}+\mathrm{PW}^{*} \beta_{7 .}{ }^{26}
\end{aligned}
$$

Finally, we can isolate the differences in the elasticity of substitution for commercial and retail firms $(C \& R=1)$ by examining the coefficients in the following expressions:

$$
\begin{aligned}
& \beta_{8} \mathrm{C} \& \mathrm{R}^{*}\left[\% \mathrm{MaxD}_{\mathrm{t}, \mathrm{f}}\right]+\beta_{9} \mathrm{C} \& \mathrm{R} *\left[\mathrm{p}_{\mathrm{pt}, \mathrm{f}} / \mathrm{p}_{0 \mathrm{t}, \mathrm{f}}\right] \\
& \partial \sigma_{\mathrm{tf}} / \partial\left[\% \mathrm{MaxD}_{\mathrm{t}, \mathrm{f}}\right]=\mathrm{C} \& \mathrm{R}^{*} \beta_{8}, \text { and } \\
& \partial \sigma_{\mathrm{tf}} / \partial\left[\mathrm{p}_{\mathrm{pt}, \mathrm{f}} / \mathrm{p}_{0 \mathrm{t}, \mathrm{f}}\right]=\beta_{1}+\mathrm{C} \& \mathrm{R} * \beta_{9 .}{ }^{27}
\end{aligned}
$$

\footnotetext{
${ }^{24}$ The coefficient $\beta_{1}$ is in this equation for the marginal effect of price to reflect the effect of the price ratio on the elasticity of substitution for health care firms, the reference group. The coefficient $\beta_{3}$ measures the differential effect of the price ratio for the manufacturing group, but the combined effect is the sum of the two coefficients.

${ }^{25}$ The coefficient $\beta_{1}$ is in this equation for the marginal effect of price to reflect the effect of the price ratio on the elasticity of substitution for health care firms, the reference group. The coefficient $\beta_{5}$ measures the differential effect of the price ratio for the government/education group, but the combined effect is the sum of the two coefficients.

${ }^{26}$ The coefficient $\beta_{1}$ is in this equation for the marginal effect of price to reflect the effect of the price ratio on the elasticity of substitution for health care firms, the reference group. The coefficient $\beta_{7}$ measures the differential effect of the price ratio for the public works group, but the combined effect is the sum of the two coefficients.

${ }^{27}$ The coefficient $\beta_{1}$ is in this equation for the marginal effect of price to reflect the effect of the price ratio on the elasticity of substitution for health care firms, the reference. The coefficient $\beta_{9}$ measures the differential of the price ratio for the manufacturing group, but the combined effect is the sum of the two coefficients.
} 


\section{B.3.5 Average Elasticity of Substitution Regression Specification}

The regression specified in equation (20) is designed to test some important hypotheses about the effect of the prices and relative usage on firms' elasticities of substitution. However, although the GL model allows for elasticities of substitution for a firm to vary by day, we are also interested in how firm characteristics affect the average ability of firms to respond to price. We can accomplish this by again by pooling data for the average elasticities of substitution across firms, and regressing the averages on individual firm characteristics, particularly those derived from the survey. The model has the form: MON-F $+\beta_{7} \mathrm{SCR}+\beta_{10}$ GEN $+\beta_{11}$ ELECT-INCR $+\beta_{12}$ Avg-P-NP-KW $+\mathrm{u}_{\mathrm{tf}}$,

where, $C \& R=0-1$ variable -1 for commercial and retail firms, 0 otherwise. Man $=0-1$ variable -1 for manufacturing firms, 0 otherwise; Govt/Ed $=0-1$ variable -1 for government/education firms, 0 otherwise; Health $=0-1$ variable -1 for health care firms, otherwise; EDRP = 0-1 variable--1 for firms in EDRP, 0 otherwise; $\mathrm{SCR}=0-1$ variable-1 for firms in SCR, 0 otherwise; EMCS $=0-1$ variable-- 1 for firms with EMCS equipment, 0 otherwise; MON-F $=0-1$ variable--1 for firms that monitor load frequently, 0 otherwise; EDRP $=0-1$ variable--1 for firms with on-site generation, 0 otherwise; ELECT-INCR $=0-1$ variable--1 for firms indicating that electricity usage has risen over the sample period, 0 otherwise; EDRP $=$ a continuous variable for the average peak to off-peak load.

\section{B.4 Aggregate Demand Response}

The theoretical discussion and mathematical and empirical models in this appendix relate primarily to methods by which one can estimate a customer's load reduction in response to changes in the ratio of peak to off-peak electricity prices. Other models are specified to identify the effect of customer characteristics on both average levels of price responsiveness and day-to-day changes in price responsiveness. From the information generated using these methods, it is also possible to estimate the aggregate demand response. This aggregate demand response has important policy significance, as it provides an indication of the response forthcoming from the entire group of customers during times of high prices, which are also often coincident with those times when the system is near capacity.

To generate this aggregate demand response, we begin by estimating each firm's peak period load reduction for a change in the peak period price of electricity by using that firm's average estimated elasticity of substitution. As shown in Footnote Error!

Bookmark not defined., the "adding up" conditions on the Allen partial elasticities of substitution that are required of a well-behaved indirect GL cost function allow one to derive an estimate for the own-price elasticity of demand for constant output and other 
input price levels. For a given percentage change in the peak price relative to its average level (the term in [ ] ), the firm f's peak period load reduction, $\mathrm{DR}_{\mathrm{p}, \mathrm{f}}$, would be:

$$
\mathrm{DR}_{\mathrm{p}, \mathrm{f}}=\left\{\left(\sigma_{\mathrm{f}} * \mathrm{~S}_{0, \mathrm{f}}\right) *\left[\left(\mathrm{p}_{\mathrm{p}, \mathrm{f}} * \text { Avg. } \mathrm{p}_{\mathrm{p}, \mathrm{f}}\right) / \text { Avg. } \mathrm{p}_{\mathrm{p}, \mathrm{f}}\right]\right\} * \text { Avg. } \mathrm{k}_{\mathrm{p}, \mathrm{f}}
$$

where $\sigma_{\mathrm{f}}$ is firm f's average elasticity of substitution for peak and off-peak electricity usage, $\mathrm{S}_{0, \mathrm{f}}$ is firm f's share of total electricity cost spent on off-peak electricity, and Avg. $\mathrm{k}_{\mathrm{p}, \mathrm{f}}$ is firm f's average peak electricity usage.

To derive an aggregate level of demand response, we sum each firm's level of demand response for the same change in the peak price. By simulating each firm's demand response over a wide range of peak period prices, it is possible to create an aggregate demand response curve that indicates the estimated amount of demand response that the analyzed SC-3A customers would provide during the peak period for any given level of peak price. 


\section{References}

Allen, R. G. D. (1938). Mathematical Analysis for Economists. New York, St. Martin's Press, Inc., reprinted in 1964.

Berndt, E. R. (1991). The Practice of Econometrics: Classic and Contemporary. Reading MA: Addison-Wesley Publishing Company.

Boisvert, R. N. (1992). "The Translog Production Function: Its Properties, Its Several Interpretations and Estimation Problems," Department of Agricultural Economics, A.E. Res. 82-28, Cornell University, September.

Boisvert, R. N., P. Cappers, B. Neenan, and B. Scott (2003). Industrial and Commercial Customer Response to Real Time Electricity Prices, Unpublished Manuscript at Neenan Associates, Syracuse, NY.

Braithwait, S. (2000). "Residential TOU Price Response in the Presence of Interactive Communication Equipment," in A. Faruqui and K. Eakin. (eds.) Pricing in Competitive Electricity Markets. Boston: Kluwer Academic Publishers.

Cappers, P. (2003). “ An Evaluation of Demand Response in New York State's Wholesale Electricity Markets", unpublished MS thesis, Cornell University.

Caves, D. and L. Christensen (1980a). "Global Properties of Flexible Functional Forms", American Economic Review 70: 422-432.

Caves, D. and L. Christensen (1980b). "Residential Substitution of Off-Peak for Peak Electricity Usage under Time of Use Prices", Energy Journal, 1:85-142.

Caves, D. and L. Christensen (1980c). "Econometric Analysis of Residential Time-ofUse Pricing Experiments", Journal of Econometrics, 14:287-306.

Caves, D., L. Christensen and J. Herriges (1984). "Consistency of Residential Response in Time of Use Pricing Experiments", Journal of Econometrics 26:179-203.

Caves, D., L. Christensen and J. Herriges (1987). "The Neoclassical Model of Consumer Demand with Identically Priced Commodities: An Application to Time-of-Use Electricity Pricing", The Rand Journal of Economics 18: 564-580.

Chambers, Robert G (1988). Applied Production Analysis: A Dual Approach. Cambridge: Cambridge University Press.

Charles River Associates (2004). "Statewide Pricing Pilot: Summer 2003 Impact Analysis" Report to the California Energy Commission, Draft, January 16. 
Diewert, W. E. (1974). “Applications of Duality Theory,” in M. D. Intriligator and D. A. Kendrick (eds.) Frontiers of Quantitative Economics, vol. 2 (Amsterdam: NorthHolland).

Ferguson, C. E. (1969). The Neoclassical Theory of Production and Distribution. Cambridge: Cambridge University Press.

Goldberger, A. (1991). A Course in Econometrics. Cambridge, MA: Harvard University Press.

Goldman, C., N. Hopper, O. Sezgen, M. Moezzi, R. Bharvirkar, B. Neenan, R. Boisvert, P. Cappers, D. Pratt. (2004). Lawrence Berkeley National Laboratory and Neenan Associates (2004). "Customer Response to Day-ahead Wholesale Market Electricity Prices: Case Study of RTP Program Experience in New York”, Final Report. Prepared for the California Energy Commission by Lawrence Berkeley National Laboratory Neenan Associates, June.

Greene, W. H. (1990). Econometric Analysis. New York: MacMillan Publishing Company.

Gujarati, D. (1995). Basic Econometrics. $3^{\text {nd }}$ edition, (New York: McGraw-Hill Book Company).

Ham, J., D. Mountain, and M. Chan (1997). "Time-of-Use Prices and Electricity Demand: Allowing for Selection Bias in Experimental Data", RAND Journal of Economics, 28: s113-s140.

Herriges, J., S. Baladi, D. Caves, and B. Neenan (1993). "The Response of Industrial Customers to Electric Rates Based Upon Dynamic Marginal Costs," The Review of Economics and Statistics,75(20): 446-54.

King, K. and P. Shatrawka (1994). "Customer Response to Real-Time Pricing in Great Britain," ACEEE 1994 Summer Study on Energy Efficiency in Buildings, Panel 2 Demand and Load Shapes, pp. 2194-2203.

Patrick, R. (1990). "Rate Structure Effects and Regression Parameter Instability Across Time-of-Use Electricity Pricing Experiments", Resources and Energy 12:180195.

Patrick, Robert H. and Frank A. Wolak (2001). "Estimating the Customer-Level Demand for Electricity Under Real-Time Market Prices”, National Bureau of Economic Research (NBER) Working Paper 8213, April.

Miller, M. N. Whittlesey, and T. Barr (1975). "The Constant Elasticity of Substitution Production Function and Its Application in Research," Technical Bulletin Agricultural Research Center, Washington State University, August. 
Moroney, J. R. (1972). The Structure of Production in American Manufacturing. Chapel Hill, NC: The University of North Carolina Press.

Mountain, D. and C. Hsiao (1986). "Peak and Off-Peak Demand for Electricity: The Hopkinson Rate in Ontario, Canada", The Energy Journal, 7:149-68.

Neenan Associates (2002). NYISO Price-Responsive Load Program Evaluation: Final Report, Prepared for the New York Independent System Operator, Albany, NY.

Neenan, B., D. Pratt, P. Cappers, J. Doane, J. Anderson, R. Boisvert, C. Goldman, O. Sezgen, G. Barbose, R. Bharvirkar, M. Kintner-Meyer, S. Shankle and D. Bates (2003). "How and Why Customers Respond to Electricity Price Variability: A Study of NYISO and NYSERDA 2002 PRL Program Performance" report to the New York Independent System Operator (NYISO) and New York State Energy Research and Development Agency (NYSERDA), prepared by Neenan Associates and CERTS, January.

Schwarz, P. M., T. N. Taylor, M. Birmingham and S. L. Dardan (2002) "Industrial Response to Electricity Real-Time Prices: Short Run and Long Run" Economic Inquiry 40(4): 597-610.

Shepherd, R. (1970). Theory of Cost and Production Functions. Princeton N.J.: Princeton University Press.

Taylor, T. N. and P. M. Schwarz (1990). "The Long-Run Effects of a Time-of-Use Demand Charge", The Rand Journal of Economics 21(3): 431-445.

Taylor, T. N., P. M. Schwarz and J. E. Cochell (2005), "24/7 Hourly Response to RealTime Pricing with up to Eight Summers of Experience", Journal of Regulatory Economics 27(3): 235-262.

SAS Institute, Inc. (1985). SAS User’s Guide: Statistics, Version 5 Edition, Gary, NC. 


\section{Appendix C. Empirical Estimates of NMPC's SC-3A Customers' Response to Day- Ahead Market Electricity Prices}

In this Appendix, we present the full set of empirical results from this study of SC-3A customers' price response. The main findings are also included and discussed in Chapter 3 of the main report and policy implications are discussed in Chapter 5. For those interested in additional detail, this appendix provides it.

There are three primary sets of empirical results that correspond to the three estimated equations described in Appendix B. The first involves estimates of substitution elasticities between peak and off-peak electricity use derived from separate demand models estimated for each customer. The second and third sets of results are derived from heuristic regression models. The first regresses daily elasticities against prices, price ratios and load conditions to answer questions about the character of price response. The second regresses customer-average elasticities against customer-level characteristics and circumstances.

A detailed breakdown of the customer accounts included in the three stages of this study is provided in Table 1. While load and price information were available for $146 \mathrm{SC}-3 \mathrm{~A}$ accounts, only the 119 accounts that were known to have faced hourly varying prices were included in the analysis (see Appendix B for the rationale behind this decision). Of these 119 accounts, only 55 answered the survey and could be included in the second regression model.

Table 1. SC-3A Customer Accounts, 2000-2004

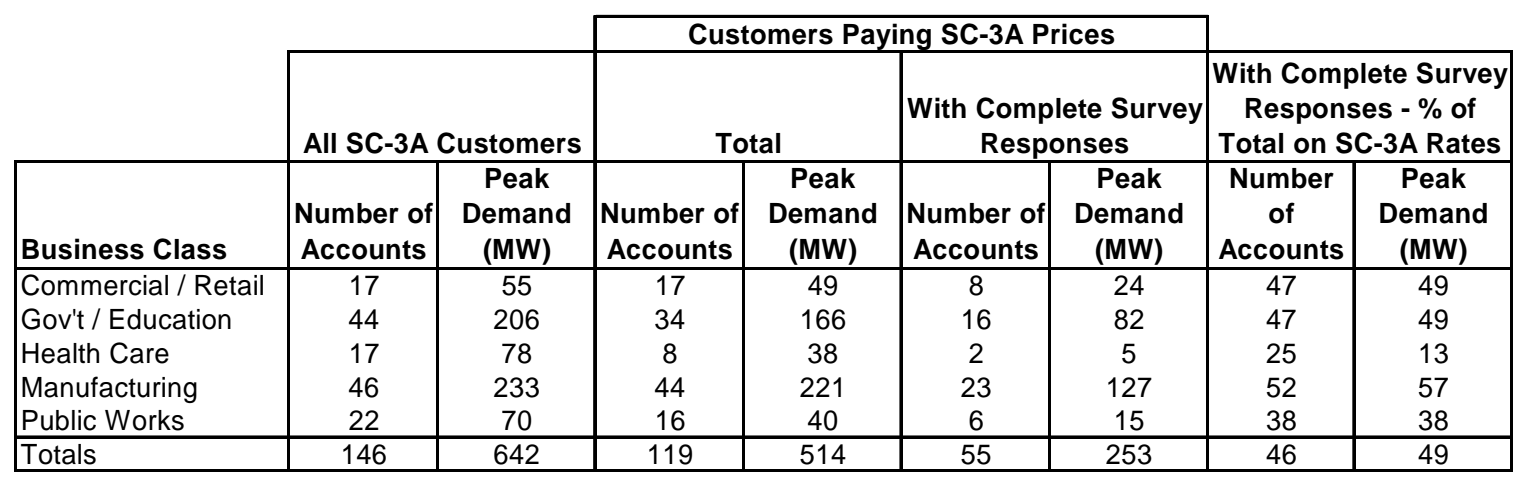

\section{C.1 Estimates of Customer Price Responsiveness}

We analyzed the price response behavior of NMPC's RTP customers by estimating the GL demand model (from equations (19) and (16) in Appendix B) for several alternative specifications of the peak period that differ in length and by time of day. We focused on summer weekdays, and initially defined six separate peak periods, as follows:

- two five-hour peaks, 11:00 a.m. to 4:00 p.m. and 12:00 noon to 5:00 p.m.;

- two four-hour peaks, 12:00 noon to 4:00 p.m. and 1:00 p.m. to 5:00 p.m.; and

- two three-hour peaks, 1:00 p.m. to 4:00 p.m. and 2:00 p.m. to 5:00 p.m. 
The load-weighted average and range in firm-level elasticities of substitution of peak for off-peak electricity for the 119 accounts are provided in Table 2; the firms are grouped according to business class. Recall that the elasticity of substitution is defined as the percentage change in the ratio of peak to off-peak electricity usage due to a one percent change in the ratio of off-peak to peak prices.

Table 2. Load-Weighted Elasticities of Substitution of Off-Peak for Peak Electricity by Customer Class and Peak-Period Definition

\begin{tabular}{|c|c|c|c|c|c|c|c|c|c|c|}
\hline \multirow[b]{3}{*}{ Business Class } & \multirow{3}{*}{$\begin{array}{l}\text { Number of } \\
\text { Accounts }\end{array}$} & \multicolumn{9}{|c|}{ Peak Periods } \\
\hline & & \multicolumn{3}{|c|}{ 11:00 a.m. to 4:00 p.m. } & \multicolumn{3}{|c|}{ 12:00 noon to $4: 00$ p.m. } & \multicolumn{3}{|c|}{ 1:00 p.m. to $4: 00$ p.m. } \\
\hline & & Min & Avg & $\operatorname{Max}$ & Min & Avg & $\operatorname{Max}$ & Min & Avg & $\operatorname{Max}$ \\
\hline Commercial / Retail & 17 & 0.01 & 0.02 & 0.02 & 0.06 & 0.07 & 2.06 & 0.05 & 0.07 & 1.93 \\
\hline Gov't / Education & 34 & 0.01 & 0.02 & 0.03 & 0.04 & 0.06 & 2.99 & 0.06 & 0.08 & 1.75 \\
\hline Health Care & 8 & 0.00 & 0.01 & 0.01 & 0.03 & 0.03 & 0.03 & 0.03 & 0.03 & 0.03 \\
\hline Manufacturing & 44 & 0.00 & 0.07 & 0.09 & 0.12 & 0.12 & 0.13 & 0.12 & 0.12 & 0.14 \\
\hline Public Works & 16 & 0.00 & 0.09 & 4.63 & 0.01 & 0.02 & 0.02 & 0.01 & 0.01 & 0.02 \\
\hline All Accounts & 119 & 0.01 & 0.04 & 0.35 & 0.07 & 0.08 & 1.33 & 0.07 & 0.09 & 0.88 \\
\hline
\end{tabular}

\begin{tabular}{|c|c|c|c|c|c|c|c|c|c|c|}
\hline \multirow[b]{3}{*}{ Business Class } & \multirow{3}{*}{$\begin{array}{l}\text { Number of } \\
\text { Accounts }\end{array}$} & \multicolumn{9}{|c|}{ Peak Periods } \\
\hline & & \multicolumn{3}{|c|}{$12: 00$ noon to $5: 00$ p.m. } & \multicolumn{3}{|c|}{ 1:00 p.m. to 5:00 p.m. } & \multicolumn{3}{|c|}{ 2:00 p.m. to 5:00 p.m. } \\
\hline & & Min & Avg & $\operatorname{Max}$ & Min & Avg & $\operatorname{Max}$ & Min & Avg & $\operatorname{Max}$ \\
\hline Commercial / Retail & 17 & 0.01 & 0.03 & 0.04 & 0.05 & 0.06 & 1.43 & 0.05 & 0.06 & 1.49 \\
\hline Gov't / Education & 34 & 0.00 & 0.04 & 0.05 & 0.07 & 0.08 & 1.21 & 0.09 & 0.10 & 0.42 \\
\hline Health Care & 8 & 0.00 & 0.04 & 0.05 & 0.03 & 0.04 & 0.04 & 0.03 & 0.04 & 0.04 \\
\hline Manufacturing & 44 & 0.00 & 0.07 & 0.09 & 0.12 & 0.12 & 0.14 & 0.15 & 0.16 & 0.18 \\
\hline Public Works & 16 & -0.04 & 0.01 & 0.01 & 0.01 & 0.01 & 0.01 & 0.01 & 0.02 & 0.02 \\
\hline All Accounts & 119 & 0.00 & 0.05 & 0.06 & 0.08 & 0.09 & 0.63 & 0.10 & 0.11 & 0.38 \\
\hline
\end{tabular}

Note:Firm-level individual elesticities of substitution summarized here are estimated from demand model (equation (19)) and equation (16).

There are several important patterns to note. For the 119 customers as a group, the average price responsiveness is remarkably similar regardless of the peak period. The load-weighted average elasticity of substitution ranges between 0.04 and 0.09 in all but one of the peak periods. For the $2-5$ p.m. peak period, the average elasticity of substitution is slightly higher $(0.11)$. On average and regardless of the definition of the peak period, differences by business class are more pronounced. They are generally highest for manufacturing, ranging from a low of 0.07 for manufacturing for the 11:00 a.m. to 4:00 p.m. peak to 0.16 for the $2-5$ p.m. peak. The elasticities for the government/education sector range from a low of 0.02 to a high of 0.10 for these same peak periods. On average, the price responsiveness of commercial/retail customers is somewhat below that for government/education customers. This difference is largest for the $2-5$ p.m. peak period (average elasticity is 0.06 vs. 0.10 ).

There are, however, also some systematic differences as the length of the peak period increases (Table 2 and Figures 1 and 2). First, there is quite a bit of consistency in the elasticities of substitution for peak periods of 3 and 4 hours in length, regardless of when the peak ends, although the elasticities are generally nearly the same or somewhat lower for all business classes for the 4-hour peak. With the exception of healthcare (for the peak 
periods ending at 5:00 p.m.), and public works (for the peak ending at 4:00 p.m.), price response in all other sectors falls dramatically in moving from the 3-or 4-hour peak to the 5-hour peak. As the peak period expands in length, there are fewer adjacent hours in which to shift load to minimize the effect on output.

For all subsequent analyses and results, the 2-5 p.m. peak period was used.

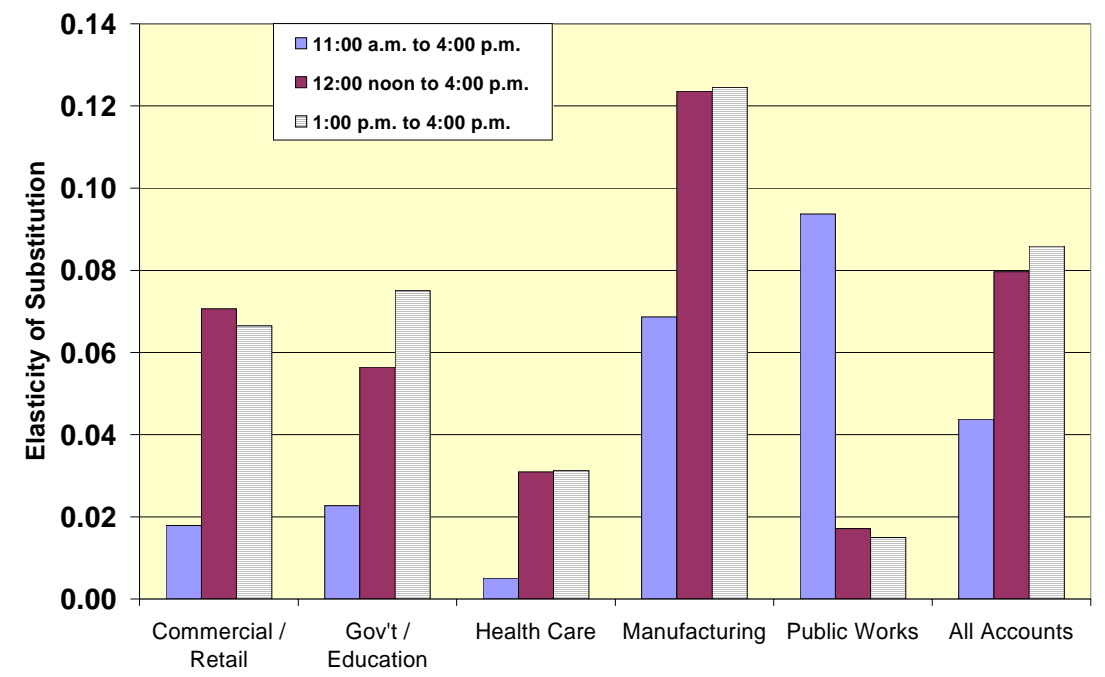

Figure 1. Average Elasticities of Substitution for Peak Periods Ending at 4:00 p.m.

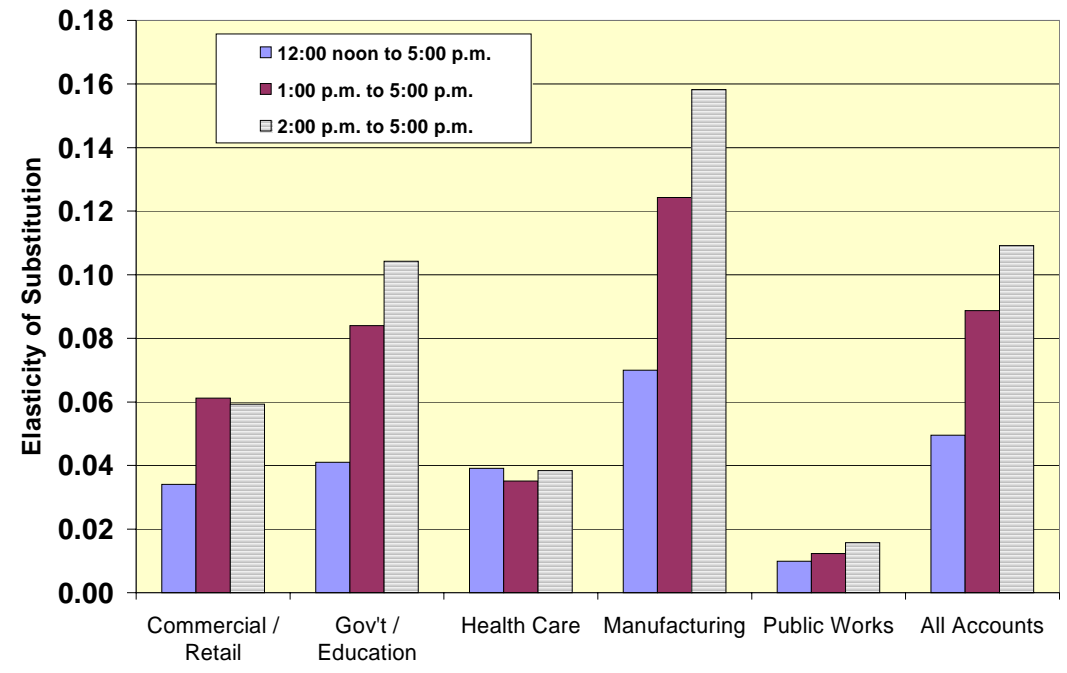

Figure 2: Average Elasticities of Substitution for Peak Periods Ending at 5:00 p.m.

Among the strengths of the GL demand model are its ability to accommodate variations in elasticities across firms and days and its ability to identify customers that are completely non-responsive (zero elasticities). As evidenced by the ranges in the load- 
weighted elasticities of substitution by business class and peak period (Table 2), the differences among customers' elasticities are substantial.

The distribution of customers' average elasticities are shown by customer account and non-coincident peak load in Figures 3 and 4. Thirty-two of the 119 firms (about 28\%) have zero elasticities of substitution (e.g. they have rectangular constant output curves and are not price responsive, Case 2 in Appendix B). Another nine customers (about 8\%) have elasticities averaging less than 0.01 , and 33 (about 28\%) have elasticities of substitution between 0.01 and 0.05 . Just under $20 \%$ (33 firms) have elasticities of substitution between 0.05 and 0.10 . The remaining $18 \%$ are quite price-responsive, with elasticities of substitution above $0.10 .{ }^{28}$ It is the firms in these final two groups that account for the vast majority of SC-3A customers' aggregate price response. ${ }^{29}$

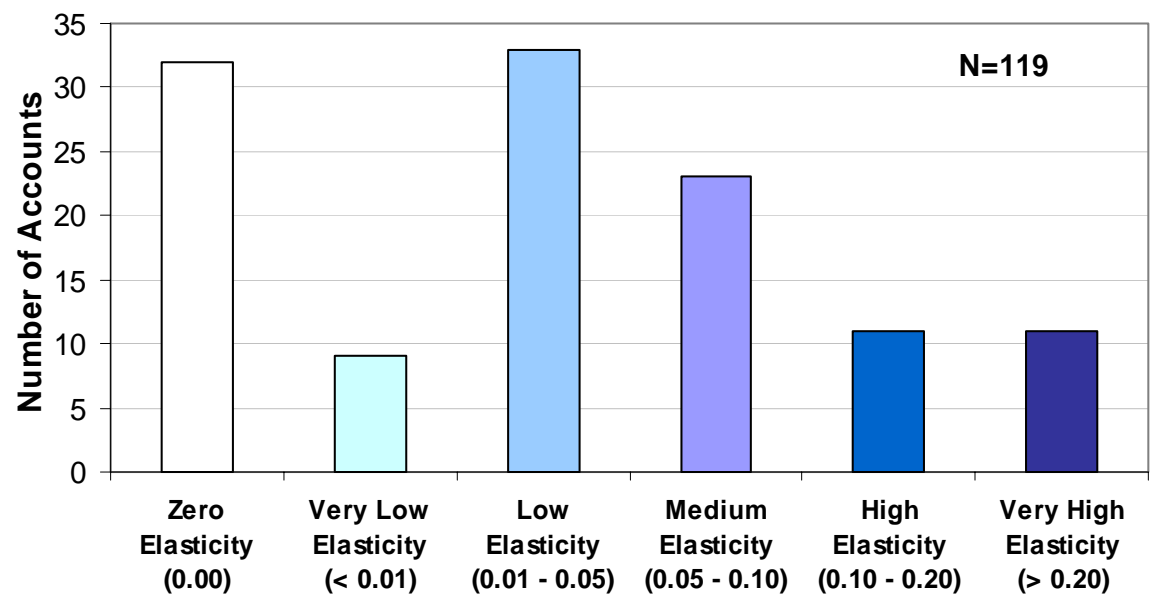

\section{Figure 3. Distribution of Accounts by Elasticity of Substitution}

As emphasized in Appendix B (Case 3), it is through the use of this GL methodology that we are also able to identify firms, perhaps with on-site generation, where peak electricity may well be "priced out of the market" at very high peak prices. Of the 119 customers, we found four government/education and one commercial/retail customer with this characteristic. The ratios of peak to off-peak prices at which their usage of peak electricity is "priced out of market" range from lows of 7 and 15, to highs of 95 and well over 100. As might be expected, all five of these customers have on-site generation, and they are among the 11 customers with elasticities of substitution greater than 0.20 (Figure 3).

Firms with zero elasticities of substitution account for about $24 \%$ (87 MW) of the 119 SC-3A customers' combined non-coincident maximum demand (Figure 4). Those with

\footnotetext{
${ }^{28}$ Because of the flexibility of the GL model, it is necessary to check to see if estimated demand functions are well-behaved at each data point for all firms that have something other than rectangular isoquants.. Using procedures discussed in Section A.2.2.6, we performed these checks and found that at each data point the estimated cost function is monotonically increasing and strictly quasi-concave in input prices. ${ }^{29}$ To identify firm characteristics that are related to an ability to respond to price and to the lack of an ability to do so, we do not eliminate non-price responsive firms from the subsequent analysis.
} 
elasticities of substitution between zero and 0.01 represent $6 \%$ (23 MW) of maximum demand. Another $34 \%$ (124 MW) is accounted for by firms with elasticities of substitution between 0.01 and 0.05 . The remaining $18 \%$ (65 MW) of maximum demand is accounted for by the final two groups of relatively price responsive customers (elasticities of substitution above 0.10 ). Firm electricity usage is thus distributed over these price response categories in proportions similar to firm numbers. This is contrary to the notion that price response is positively related to the firm's usage level.

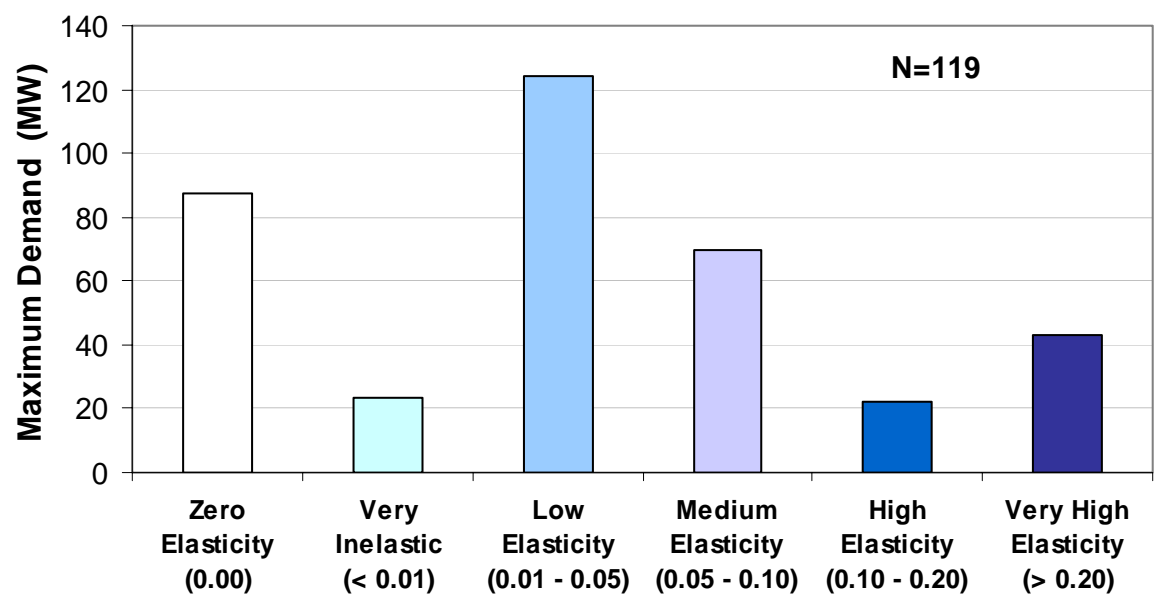

Figure 4. Distribution of Load by Elasticity of Substitution

Some subject customers, in addition to facing daily prices, were enrolled in NYISO demand response programs, which offer inducements to reduce load on very short (twohour) notice. Figure 5 displays the distribution of NYISO program participants and nonparticipants by substitution elasticity category. ${ }^{30}$ Not surprisingly, the firms with the highest elasticities of substitution show disproportionately high levels of participation. However, some customers with relatively low elasticities of substitution (under 0.05 ) or even zero elasticities participated in the NYISO programs. This apparent anomaly is discussed in Chapters 3 and 5.

\footnotetext{
${ }^{30}$ Beginning in 2001, the NYISO demand response programs have been offered every summer. Customers generally enroll for six-month terms.
} 


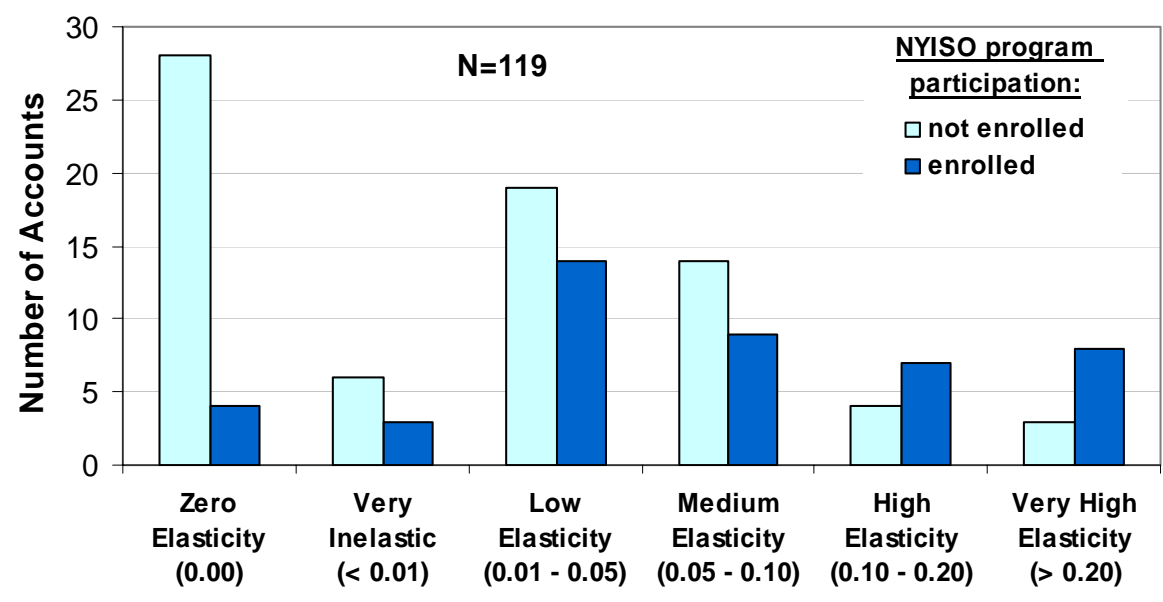

Figure 5. Distribution of Accounts by Elasticity of Substitution and NYISO DR Program Participation

To control for the effects of weather on electricity use and price responsiveness, two variables were included in the GL demand model (equation (19) in Appendix B). Table 3a shows the number of customers in each business category for which the coefficients on these two weather variables are significantly different from zero, along with the number of firms with "significant" coefficients that are positive and negative. Overall, the weather intercept shifter was significant for 58 (49\%) of the 119 firms but the slope shifter, which indicates a direct effect of weather on price response, was significant for only $32(27 \%)$ of the 119 firms. Including the intercept weather effect, to measure the coincidence of high prices and high peak to off-peak loads, was critical as it provided a "correction" for almost half of the firms. The coefficient was positive and significant for 52 of these 58 firms. For them, the ratio of peak to off-peak load is higher during hot days than on cool days. For six firms, the coefficient was negative and significant, indicating that the ratio of peak to off-peak usage was lower during hot days. This particular effect of weather on peak to off-peak usage also differs substantially across business sectors. This effect was statistically significant for a larger percentage of firms for those sectors wherein firms conduct service businesses from office buildings or in a campus setting. The coefficients on the intercept terms are significant for more than $65 \%$ of firms in the healthcare, government/education, and commercial/retail sectors. In contrast, less than $25 \%$ of the manufacturing and $40 \%$ of the public works firms appear to be sensitive to weather in the sense that there is a change in peak to off-peak usage during hot days. 
Table 3a. Weather Variables Included in GL Model

\begin{tabular}{|c|c|c|c|c|c|c|}
\hline \multirow[b]{3}{*}{ Business Class } & \multicolumn{3}{|c|}{ Weather Intercept } & \multicolumn{3}{|c|}{ Weather Slope } \\
\hline & \multicolumn{2}{|c|}{ Statistically Sig. } & \multirow{2}{*}{$\begin{array}{l}\text { Statistically } \\
\text { Insig. }\end{array}$} & \multicolumn{2}{|c|}{ Statistically Sig. } & \multirow{2}{*}{$\begin{array}{l}\text { Statistically } \\
\text { Insig. }\end{array}$} \\
\hline & Positive & Negative & & Positive & Negative & \\
\hline Commercial/Retail & 12 & 1 & 4 & 3 & 4 & 10 \\
\hline Government/Education & 22 & 1 & 11 & 0 & 8 & 26 \\
\hline Health Care & 6 & 0 & 2 & 1 & 3 & 4 \\
\hline Manufacturing & 7 & 3 & 34 & 2 & 7 & 35 \\
\hline Public Works & 5 & 1 & 10 & 0 & 4 & 12 \\
\hline Totals & 52 & 6 & 61 & 6 & 26 & 87 \\
\hline
\end{tabular}

The effect of weather on price response intensity is both less extreme and less diverse across business sectors. For only two sectors (commercial/retail and healthcare) do more than $40 \%$ of the firms have statistically significant "slope" variable coefficients. A quarter or less of firms in the other sectors exhibit a relationship between weather and price response. Although weather appears to be an important factor affecting price response for these firms, the signs on these estimated parameters cannot be interpreted directly. In some cases, the average elasticity is higher for firms for which this particular weather variable is statistically significant, and lower for others.

Although it is impossible to disentangle the separate effects of these two weather variables on the estimated elasticities of substitution, the net effect of both can be determined by calculating the average elasticities of substitution for each firm for both "hot" and "cool" days (i.e. the weather intercept is set at its daily value, but "hot" days are defined as those days when the binary slope variable for weather takes on a value of "1";"cool" days are when this variable takes on a value of "0"). Table $3 \mathrm{~b}$ shows the loadweighted average elasticities of substitution for hot and cool days by business class.

\section{Table 3b. Impact of Weather on Price Response by Business Sector}

\begin{tabular}{ccc} 
& \multicolumn{2}{c}{$\begin{array}{c}\text { Avg. Elasticity of } \\
\text { Substitution }\end{array}$} \\
\cline { 2 - 3 } Business Class & Cool & Hot \\
\hline Commercial / Retail & 0.05 & 0.10 \\
Government / Education & 0.10 & 0.12 \\
Health Care & 0.04 & 0.04 \\
Manufacturing & 0.16 & 0.15 \\
Public Works & 0.02 & 0.02 \\
\hline Total & $\mathbf{0 . 1 0 9}$ & $\mathbf{0 . 1 1 3}$
\end{tabular}

It is evident that the inclusion of these weather variables in the GL model specification has a definite effect on the elasticities of substitution. The difference in the overall load weighted average elasticities of substitution across all firms is relatively small -0.113 for hot days compared to 0.109 on cool days. However, this is not true across all business classes. For example, when comparing hot days with cool days, the sectors with heavy reliance on cooling loads (commercial/retail and government/education) exhibit a marked 
increase in their elasticities of substitution. Manufacturing firms, on the other hand, appear to become less price responsive on hot days, but only slightly so. There is no appreciable difference in average elasticities of substitution for the other two business classes for hot and cool days.

\section{C.2 Factors Affecting Price Response}

This section discusses the results of two additional regression equations that investigate factors that affect daily and customer-average elasticities. The first includes all 119 customers that have faced SC-3A rates sometime during the study period. In contrast, the second regression uses data collected from the survey as explanatory variables and therefore includes only the 55 customers for which survey responses are available. For purposes of comparison, and in an attempt to understand how general our results are, we also estimate the first regression using data from only the 55 customers.

Table 4. Characteristics of Modeled Customers

\begin{tabular}{|l|c|c|c|c|c|c|}
\cline { 2 - 7 } \multicolumn{1}{c|}{} & \multicolumn{2}{c|}{ Customers Paying SC-3A Prices } & \multicolumn{2}{c|}{ With Complete Survey Responses } \\
\cline { 2 - 7 } \multicolumn{1}{c|}{ Bumber of } & $\begin{array}{c}\text { Peak } \\
\text { Demand } \\
\text { Bums }\end{array}$ & $\begin{array}{c}\text { Load-Wgt. } \\
\text { Avg. } \\
\text { Elasticity }\end{array}$ & $\begin{array}{c}\text { Number of } \\
\text { Accounts }\end{array}$ & $\begin{array}{c}\text { Peak } \\
\text { Demand } \\
\text { (MW) }\end{array}$ & $\begin{array}{c}\text { Load-Wgt. } \\
\text { Avg. } \\
\text { Elasticity }\end{array}$ \\
\hline Commercial / Retail & 17 & 49 & 0.06 & 8 & 24 & 0.03 \\
Gov't / Education & 34 & 166 & 0.10 & 16 & 82 & 0.13 \\
Health Care & 8 & 38 & 0.04 & 2 & 5 & 0.05 \\
Manufacturing & 44 & 221 & 0.16 & 23 & 127 & 0.06 \\
Public Works & 16 & 40 & 0.02 & 6 & 15 & 0.01 \\
\hline Totals & 119 & 514 & 0.11 & 55 & 253 & 0.07 \\
\hline
\end{tabular}

Table 4 contains information about the 119 firms and the sub-set of 55 firms. This sub-set represents about $46 \%$ of the 119 firms, and about $49 \%$ of the peak demand. The healthcare and public works sectors are under represented in the sub-set of 55. The loadweighted average elasticities of substitution for the sub-sample are $36 \%$ lower than the larger group's average, and the sub-sample exhibits significantly lower average elasticities for the commercial/retail and manufacturing sectors, and higher elasticities for the government/education sector than the respective larger samples.

\section{C.2.1 Factors Affecting Daily Elasticities of Substitution}

The first of the two regression equations uses the price ratio and the firm's usage as a percentage of maximum demand as variables to explain day-to-day differences in the estimated firm-level elasticities of substitution. By including interactive terms made up of the product of the price ratio and the business sector and the demand percentage, the effects of these factors on price response by business activity are estimated. The definitions of the variables used in this regression are presented in Table 5. Although this discussion (and the discussion in Chapter 3) focus on the results of the regression model based on data for all 119 firms, a model based on data from the 55 firms is also reported in Table 6. 
Table 5. Definitions of Explanatory Variables

\begin{tabular}{|c|c|}
\hline Variable & Definition \\
\hline Intercept & \\
\hline Public Works & $0-1$ Variable, 1 if firm is in Public Works, 0 otherwise \\
\hline Comm/Retail & $0-1$ Variable, 1 if firm is Commercial or Retail, 0 otherwise \\
\hline Manufacturing & $0-1$ Variable, 1 if firm is in Manufacturing, 0 otherwise \\
\hline Gov/Ed & $0-1$ Variable, 1 if firm is in Government or Education, 0 otherwise \\
\hline Public/Health & $0-1$ Variable, 1 if firm is in Public Health, 0 otherwise \\
\hline$\%$ Max Dmnd & $\begin{array}{l}\text { Daily peak electricity usage as \% of corresponding year's max } \\
\text { demand }\end{array}$ \\
\hline Price Ratio & Ratio of Peak to Off-Peak Prices \\
\hline Event & 0-1 Variable, 1 if an NYISO EDRP event was declared, 0 otherwise \\
\hline EDRP & 0-1 Variable, 1 if firm participates in NYISO's EDRP, 0 otherwise \\
\hline SCR & $\begin{array}{l}0-1 \text { Variable, } 1 \text { if firm participates in NYISO's ICAP/SCR program, } 0 \\
\text { otherwise }\end{array}$ \\
\hline Increased Energy & $\begin{array}{l}0-1 \text { Variable, } 1 \text { if survey respondent said energy use increased } \\
\text { over the } 2000-2004 \text { period, } 0 \text { otherwise }\end{array}$ \\
\hline Monitor Prices Freq. & $\begin{array}{l}0-1 \text { Variable, } 1 \text { if survey respondent said the firm monitors } \\
\text { electricity prices frequently }\end{array}$ \\
\hline Use EMCS & $\begin{array}{l}0-1 \text { Variable, } 1 \text { if survey respondent said the firm uses its EMCS } \\
\text { equipment, } 0 \text { otherwise }\end{array}$ \\
\hline Have On-Site Gen & $\begin{array}{l}0-1 \text { Variable, } 1 \text { if survey respondent said the firm has on-site } \\
\text { generation, } 0 \text { otherwise }\end{array}$ \\
\hline
\end{tabular}

For each sample there are two regressions shown in Table 6, labeled "GLS" (generalized least squares) and "GMM" (generalized method of moments) models. Ultimately, it is the "GMM" models that are of interest, because they include a correction for autocorrelation. In effect, we can think of the estimation process as involving two steps. The first is to estimate the "GLS" model. This model includes an AR(1) process to deal with the autocorrelation that was apparent from examining the data and is due to a time-dependent persistence of similar elasticities of substitution from one day to the next. The high degree of fit, as measured by the $\mathrm{R}^{2}$ values for both the "GLS" models are the result of this correction for autocorrelation Once this correction has been done, any variations around this strong persistent trend due to the explanatory variables in the model are reflected in the resulting parameter estimates.

Table 6. Estimated Daily Elasticity of Substitution Regression Model Results

\begin{tabular}{|c|c|c|c|c|c|c|c|c|}
\hline \multirow[b]{3}{*}{ Variable } & \multicolumn{4}{|c|}{ Survey Sub-Sample (55) } & \multicolumn{4}{|c|}{ Full Sample (119) } \\
\hline & \multicolumn{2}{|c|}{ GLS Model } & \multicolumn{2}{|c|}{ GMM Model } & \multicolumn{2}{|c|}{ GLS Model } & \multicolumn{2}{|c|}{ GMM Model } \\
\hline & $\begin{array}{l}\text { Parm. } \\
\text { Est. }\end{array}$ & t-Stat & $\begin{array}{l}\text { Parm. } \\
\text { Est. }\end{array}$ & t-Stat & Parm. Est. & t-Stat & $\begin{array}{l}\text { Parm. } \\
\text { Est. }\end{array}$ & t-Stat \\
\hline Pk Off-Pk Price Ratio (PR) & -0.0034 & -0.69 & -0.0040 & -5.49 & -0.0025 & -1.06 & -0.0028 & -8.92 \\
\hline Commercial/Retail * PR & 0.0004 & 0.07 & 0.0005 & 0.63 & 0.0184 & 6.15 & 0.0199 & 4.22 \\
\hline Manufacturing * PR & 0.0018 & 0.35 & 0.0023 & 2.27 & 0.0014 & 0.55 & 0.0016 & 2.34 \\
\hline Gov't/Education * PR & 0.0162 & 3.13 & 0.0185 & 3.90 & 0.0228 & 8.69 & 0.0241 & 3.44 \\
\hline Public Works * PR & 0.0014 & 0.25 & 0.0019 & 2.30 & 0.0009 & 0.31 & 0.0010 & 2.80 \\
\hline Daily $\%$ of Max Demand (MD) & -0.0680 & -13.79 & -0.0702 & -1.92 & -0.0375 & -10.29 & -0.0513 & -1.99 \\
\hline Commercial/Retail * MD & 0.0621 & 6.55 & 0.0651 & 1.79 & 0.0511 & 8.00 & 0.0646 & 2.43 \\
\hline Manufacturing * MD & 0.0659 & 11.42 & 0.0674 & 1.85 & 0.0352 & 8.74 & 0.0487 & 1.89 \\
\hline Health Care * MD & 0.0692 & 3.66 & 0.0718 & 1.97 & 0.0378 & 3.44 & 0.0514 & 2.00 \\
\hline Public Works * MD & 0.0676 & 9.29 & 0.0695 & 1.91 & 0.0373 & 6.95 & 0.0509 & 1.97 \\
\hline $\operatorname{AR}(1)$ & 0.4348 & 56.04 & 0.4341 & 5.48 & 0.4674 & 87.62 & 0.4657 & 8.82 \\
\hline R-Squared & 0.98 & & 0.98 & & 0.99 & & 0.99 & \\
\hline Durbin Watson Statistic & 2.14 & & 2.14 & & 2.13 & & 2.13 & \\
\hline White's Test Statistic & 5,516 & & & & 13,022 & & & \\
\hline
\end{tabular}


While the results of the "GLS" models looked extremely encouraging, we were, as suggested in Appendix B, concerned about heteroskedasticity of the error structure because of the wide variation in daily elasticities of substitution for some firms. Thus, we performed a White's test for heteroskedasticity and found the White's statistic to be significantly different from zero in both "GLS" Models. The second step of the estimation, therefore, was to correct for this problem of heteroskedasticity by reestimating the model using the generalized method of moments (hence the "GMM" name on the second models). While the procedure correcting for heteroskedasticity does generally change the estimated coefficients, the effect is often expected to be minor. This proved to be the case in both models. However, the primary purpose in correcting for heteroskedasticity is to ensure that the standard errors on the coefficients (and therefore the t-statistics) are unbiased. Based on this correction, most of the t-ratios increased, while some others declined. In the fnal "GMM" models, all but one estimated coefficient (for the sample of 55) are all significantly different from zero. It is also encouraging that the corresponding estimated coefficients for each of the "GMM" models have the same sign and are of similar magnitude. The overall performance of the "GMM" model for the sample of 119 does slightly outperform the one for the sample of 55, particularly in terms of the size of the t-ratios. One possible interpretation of these results is that by including more firms in the sample, we are able to measure the effects of the variables on price responsiveness with greater statistical precision.

Since many of the variables are interaction terms, an effective way to interpret the results is to estimate the changes in the elasticities of substitution for a particular change in one of the explanatory variables - in this case the price ratio and the percent of maximum demand. Using the estimated coefficient for the "GMM" model for the 119 customers from Table 6 , the effects of changes in the price ratio and in usage relative to maximum demand are summarized in Table 7 for the full sample of 119 customers and in Table 8 for the sub-set of 55 survey respondents.

\section{Table 7. Marginal Changes in Elasticities of Substitution by Business Class: 119 Customer Sample}

\begin{tabular}{|c|c|c|c|c|c|c|}
\hline & & & Elastici & $\begin{array}{r}\text { ty of Substit } \\
\text { Chan }\end{array}$ & $\begin{array}{l}\text { ution for a } \\
\text { ge in: }\end{array}$ & Marginal \\
\hline & & & $\begin{array}{r}\text { Peak to Of } \\
\mathrm{Ra} \\
\end{array}$ & $\begin{array}{l}\text { f-peak Price } \\
\text { tio }^{\text {a }}\end{array}$ & $\begin{array}{r}\text { Proporti } \\
\text { Max D } \\
\end{array}$ & $\begin{array}{l}\text { on Use of } \\
\text { emand }^{b}\end{array}$ \\
\hline Business Class & $\begin{array}{l}\text { Number of } \\
\text { Accounts }\end{array}$ & $\begin{array}{l}\text { Average } \\
\text { Elasticity }\end{array}$ & Elasticity & $\begin{array}{l}\% \text { Change } \\
\text { from Avg. }\end{array}$ & Elasticity & $\begin{array}{l}\text { \% Change } \\
\text { from Avg. }\end{array}$ \\
\hline Commercial/Retail & 17 & 0.115 & 0.132 & $14.8 \%$ & 0.116 & $1.2 \%$ \\
\hline Gov't/Education & 34 & 0.159 & 0.180 & $13.4 \%$ & 0.154 & $-3.2 \%$ \\
\hline Health Care & 8 & 0.035 & 0.032 & $-8.1 \%$ & 0.035 & $0.0 \%$ \\
\hline Manufacturing & 44 & 0.087 & 0.086 & $-1.4 \%$ & 0.087 & $-0.3 \%$ \\
\hline Public Works & 16 & 0.018 & 0.017 & $-9.5 \%$ & 0.018 & $-0.2 \%$ \\
\hline Total & 119 & & & & & \\
\hline
\end{tabular}

${ }^{\text {a }}$ A marginal change in the peak to off-peak price is having the price ratio change from 2 to 3.

${ }^{\mathrm{b}}$ A marginal change is use increasing from say 0.6 of maximum demand to 0.7 of maximum demand 
Table 8. Marginal Changes in Elasticities of Substitution by Business Class: 55 Customer Sub-Sample

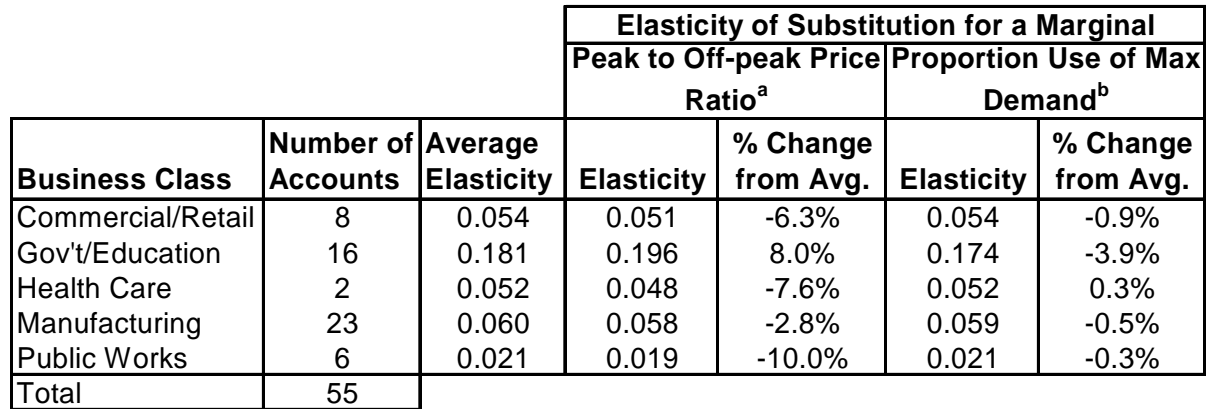

${ }^{a}$ A marginal change in the peak to off-peak price is having the price ratio change from 2 to 3.

${ }^{\mathrm{b}}$ A marginal change is use increasing from say 0.6 of maximum demand to 0.7 of maximum demand

For each business sector, the number of accounts and the un-weighted average the elasticity of substitution values are reported by sector in the left-hand part of the Table 7 . To the right of these values, Table 7 is separated into two sections. The first section provides for each sector the impact on that sector's average elasticity of substitution (and the $\%$ change for the average) for a unit increase in the price ratio, say from a ratio of $2: 1$ to $3: 1$. This provides an indication of the extent to which elasticities of substitution larger for higher peak prices than for lower ones. ${ }^{31}$ A positive percentage change indicates that price response increases as the peak price increases; a negative percentage change indicates that price responsiveness falls as the peak price increases.

The commercial/retail and government/education sectors both exhibit increased price responsiveness at higher peak prices: the former increases by $14.8 \%$ and the latter by $13.4 \%$ in response to a $50 \%$ increase in the peak price (holding the off-peak price constant). These firms can be expected to decrease peak usage more at very high market prices than at moderately high prices. Healthcare and public works customers, on the other hand, show the opposite result; their price response drops by $8.1 \%$ and $9.5 \%$, respectively, as the price ratio increases in our example by $50 \%$. The manufacturing sector's price response appears to be nearly immune to changes in the nominal peak price. $^{32}$

\footnotetext{
${ }^{31}$ Although it is the price ratio that is changing, one can still use these results to infer something about changes in price responsiveness as the peak price changes, ceteris paribus. This is due to the fact that the price ratio can increase when the peak price increases while there is no change in the off-peak price. To illustrate, one might use an example of off-peak price at $\$ 0.05 / \mathrm{kwh}$ and a peak price of $\$ 0.10 / \mathrm{kwh}$. This gives a price ratio of 2 . If the peak price increases to $\$ 0.15 / \mathrm{kwh}$, then the price ratio goes from $2: 1$ to $3: 1$. The same would be true of initial prices of $\$ 0.10 / \mathrm{kwh}$ off peak and $\$ 0.20 / \mathrm{kwh}$ on peak, with a peak price increase up to $\$ 0.30 / \mathrm{kwh}$.

${ }^{32}$ The data in Table 8 can be interpreted in a manner similar to those in Table 7. It is encouraging that with the exception of the commercial/retail sector, the signs and the relative magnitudes of the percentage changes in the elasticities of substitution are quite similar to those from Table 7. It is important to note that the sign of the effects differ between the two samples only for the commercial/retail sector, and this is the one sector in which there is a statistically insignificant coefficient on one interaction term involving the
} 
The remaining section of Table 7 shows the impact on the sector's average elasticity of substitution of a $10 \%$ increase in the amount of load a customer uses on a given day relative to its maximum (summer) peak demand. A positive value indicates that the ability to reduce load in response to increases in the peak to off-peak price ratio increases as the firm approaches its summer peak demand. A negative percentage change suggests the opposite - that customers are less able to reduce load in response to relative increases in peak price as they approach their peak demand.

The impact of the size of the firm's load relative to its peak usage level on the response elasticity is very small for all sectors but the government/education sector. In that sector, firms reduce their ability to respond to relative price increases by just over $3 \%$ as their load increases from $60 \%$ to $70 \%$ of their peak summer demand. ${ }^{33}$

\section{C.2.1.1 Impact of Nominal Prices on Daily Elasticities}

In specifying the regression models displayed in Table 6, the daily elasticities of substitution for all firms were regressed on the peak-to-off peak price ratio and the proportion of maximum demand at which the firm was operating on a given day. By specifying this equation in terms of the price ratio, we maintain consistency with the GL functional form used to estimate the elasticities of substitution. This model specification essentially constrains the size of the effect on the elasticity of substitution from a change in the peak price to be the same as for a change in the off-peak price, but one effect is the inverse of the other. In so doing, the marginal effects reported in Tables 7 and 8 in a pure sense reflect changes in the elasticities of substitution as the price ratio changes.

However, these marginal changes could also be interpreted in terms of changes in just the peak price, if one assumes that the off-peak price remained unchanged. Even though this is, from a technical point of view, also a correct interpretation, it is sometimes difficult to convey the equivalence of a change in the price ratio if it is due only to a change in the peak price. Therefore, a model that relates daily differences in the elasticities of substitution directly to the peak prices was also estimated. Results from these regressions and their marginal effects are reported for both customer samples in Tables 9, 10, and 11 . The relative performances of the four models in Table 9 are very similar to those in Table 6 in the sense that those based on data for the 119 customers are slightly more robust than for the sample of 55 customers. Furthermore, the correction for heteroskedasticity improves these results as well. Therefore, it is sufficient to focus this discussion on fourth model in Table 9: the "GMM" model for the full, 119 customer sample.

price ratio. This insignificant coefficient appears in the model based on the sub-sample of 55 firms. Thus, by being able to include more firms in this regressions, we were able to isolate this effect with greater statistical precision.

${ }^{33}$ Taken in aggregate, these results seem counterintuitive in that government/education customers are more responsive on hot days and as prices rise, but are less responsive as they approach their maximum demand. This can be rationalized by observing the lack of coincidence of high prices, hot days, and high loads for these customers - a finding that runs counter to conventional wisdom for this class of customers. 
Table 9. Estimated Daily Elasticity of Substitution Regression Results Using Nominal Peak Prices

\begin{tabular}{|c|c|c|c|c|c|c|c|c|c|}
\hline & & \multicolumn{4}{|c|}{ Survey Sub-Sample (55) } & \multicolumn{4}{|c|}{ Full Sample (119) } \\
\hline & \multirow[b]{2}{*}{ Variable } & \multicolumn{2}{|c|}{ GLS Model } & \multicolumn{2}{|c|}{ GMM Model } & \multicolumn{2}{|c|}{ GLS Model } & \multicolumn{2}{|c|}{ GMM Model } \\
\hline & & Parm. Est. & t-Stat & Parm. Est. & t-Stat & Parm. Est. & t-Stat & Parm. Est. & $\mathrm{t}$-Stat \\
\hline & Peak Price $(\mathrm{PR})$ & -0.0034 & -0.69 & -0.0068 & -2.36 & -0.0052 & -0.46 & -0.0060 & -4.25 \\
\hline & Commercial/Retail * PR & 0.0004 & 0.07 & 0.0000 & -0.01 & 0.0231 & 1.74 & 0.0272 & 3.25 \\
\hline & Manufacturing * PR & 0.0018 & 0.35 & 0.0012 & 0.39 & 0.0024 & 0.20 & 0.0034 & 1.79 \\
\hline & Gov't/Education * PR & 0.0162 & 3.13 & 0.0424 & 2.92 & 0.0803 & 6.60 & 0.0886 & 2.40 \\
\hline & Public Works * PR & 0.0014 & 0.25 & 0.0006 & 0.18 & 0.0010 & 0.08 & 0.0014 & 0.83 \\
\hline \multirow{9}{*}{ Daily } & $\%$ of Max Demand (MD) & -0.0680 & -13.79 & -0.0708 & -1.92 & -0.0396 & -10.81 & -0.0534 & -2.04 \\
\hline & Commercial/Retail * MD & 0.0621 & 6.55 & 0.0649 & 1.76 & 0.0573 & 8.92 & 0.0719 & 2.65 \\
\hline & Manufacturing * MD & 0.0659 & 11.42 & 0.0680 & 1.84 & 0.0373 & 9.22 & 0.0509 & 1.93 \\
\hline & Health Care * MD & 0.0692 & 3.66 & 0.0697 & 1.88 & 0.0388 & 3.54 & 0.0523 & 1.99 \\
\hline & Public Works * MD & 0.0676 & 9.29 & 0.0702 & 1.90 & 0.0394 & 7.31 & 0.0530 & 2.02 \\
\hline & $\operatorname{AR}(1)$ & 0.4348 & 56.04 & 0.4365 & 5.50 & 0.4693 & 88.08 & 0.4675 & 8.84 \\
\hline & R-Squared & 0.98 & & 0.98 & & 0.99 & & 0.99 & \\
\hline & Dubin Watson Statistic & 2.14 & & 2.14 & & 2.13 & & 2.13 & \\
\hline & White's Test Statistic & 5,516 & & & & 14,012 & & & \\
\hline
\end{tabular}

In comparing this model with the corresponding one in Table 6 , we see that the signs on the corresponding terms are the same across both. Since the peak price is in the numerator of the price ratio, the direction of change in the elasticity of substitution is the same for a change in each corresponding variable containing a price term. The same is true for each of the variables containing a "Max Demand" component. It is only the magnitude of the effects that differ. These differences are best seen by comparing the results from Tables 7 and $10 .{ }^{34}$ The differences in the magnitudes of the effects of the "Max Demand" variables across models are very small. However, this is not true for the variables containing the price ratio (from Table 7) and the peak price (from Table 10). Although the direction of the change is the same, the magnitudes of the effects are generally smaller in the model that includes only the peak price (Table 10).

\section{Table 10. Marginal Changes in Elasticities of Substitution for Peak Price Regression: 119 Customer Sample}

Elasticity of Substitution for a Marginal Change in:

\begin{tabular}{|c|c|c|c|c|c|c|}
\hline \multirow[b]{2}{*}{ Business Class } & \multirow[b]{2}{*}{$\begin{array}{c}\text { No.of } \\
\text { Accounts }\end{array}$} & \multirow[b]{2}{*}{$\begin{array}{l}\text { Average } \\
\text { Elasticity }\end{array}$} & \multicolumn{2}{|c|}{ Peak Price $^{\mathrm{a}}$} & \multicolumn{2}{|c|}{$\begin{array}{c}\text { Proportion Use of Max } \\
\text { Demand }^{\text {b }}\end{array}$} \\
\hline & & & Elasticity & $\begin{array}{l}\% \text { Change } \\
\text { from Avg. }\end{array}$ & Elasticity & $\begin{array}{l}\% \text { Change } \\
\text { from Avg. }\end{array}$ \\
\hline Commercial/Retail & 17 & 0.115 & 0.117 & $1.8 \%$ & 0.117 & $1.6 \%$ \\
\hline Gov't/Education & 34 & 0.159 & 0.241 & $5.2 \%$ & 0.154 & $-3.4 \%$ \\
\hline Health Care & 8 & 0.035 & 0.029 & $-1.7 \%$ & 0.035 & $-0.3 \%$ \\
\hline Manufacturing & 44 & 0.087 & 0.084 & $-0.3 \%$ & 0.087 & $-0.3 \%$ \\
\hline Public Works & 16 & 0.018 & 0.014 & $-2.5 \%$ & 0.018 & $-0.2 \%$ \\
\hline Total & 119 & & & & & \\
\hline
\end{tabular}

\footnotetext{
${ }^{34}$ Similar comparisons, for the sub-sample of 55 customers, can be made by examining the results in Tables 8 and 11. Since these results are included primarily for purposes of completeness, there is no need to discuss them in detail.
} 
Table 11. Marginal Changes in Elasticities of Substitution for Peak Price Regression: 55 Customer Sub-Sample

\begin{tabular}{|c|c|c|c|c|c|c|}
\hline \multirow[b]{2}{*}{ Business Class } & \multirow[b]{2}{*}{$\begin{array}{c}\text { No.of } \\
\text { Accounts }\end{array}$} & \multirow[b]{2}{*}{$\begin{array}{l}\text { Average } \\
\text { Elasticity }\end{array}$} & \multicolumn{2}{|c|}{ Peak Price $^{a}$} & \multicolumn{2}{|c|}{$\begin{array}{c}\text { Proportion Use of Max } \\
\text { Demand }^{\mathrm{b}}\end{array}$} \\
\hline & & & Elasticity & $\begin{array}{l}\% \text { Change } \\
\text { from Avg. }\end{array}$ & Elasticity & $\begin{array}{l}\% \text { Change } \\
\text { from Avg. }\end{array}$ \\
\hline Commercial/Retail & 8 & 0.054 & 0.053 & $-1.3 \%$ & 0.054 & $-1.1 \%$ \\
\hline Gov't/Education & 16 & 0.181 & 0.185 & $2.0 \%$ & 0.174 & $-3.9 \%$ \\
\hline Health Care & 2 & 0.052 & 0.051 & $-1.3 \%$ & 0.052 & $-0.2 \%$ \\
\hline Manufacturing & 23 & 0.060 & 0.059 & $-0.9 \%$ & 0.059 & $-0.5 \%$ \\
\hline Public Works & 6 & 0.021 & 0.020 & $-2.9 \%$ & 0.021 & $-0.3 \%$ \\
\hline Total & 55 & & & & & \\
\hline
\end{tabular}

${ }^{\text {a }}$ A marginal change in the peak price from say $\$ 0.20 / \mathrm{kWh}$ to $\$ 0.30 / \mathrm{kWh}$.

${ }^{\mathrm{b}}$ A marginal change is use increasing from say 0.6 of maximum demand to 0.7 of maximum demand

There are several possible explanations for this result, but the most plausible is that the models in Table 9 are actually mis-specified. Since peak and off-peak electricity use can be viewed as substitute inputs in production processes, economic theory suggests that any model that attempts to explain relative changes in electricity use between these two inputs should include the prices of both inputs. We find that when the peak price rises, off-peak prices also rise, but by a smaller amount. Because of this correlation, the coefficients on the variables involving peak price terms in the models in Table 9 are biased because the models exclude a term that is correlated with peak price. ${ }^{35}$ Thus the effect of the change in the peak price reflected in Tables 7 and 8 dominates the offsetting effect of a relatively smaller increase in the off-peak price. Because there is no way to control for the relative changes in peak to off-peak prices in the model in Table 9, the true effect of changes in the peak price is somewhat understated. For these reasons, we argue that the correct model specifications and measures of marginal effects on the elasticities of substitution are in Tables 6, 7 and 8, even though the interpretation of the results in terms of changes in the peak price are not as straightforward as in the models in Tables 9, 10 , and 11 .

\section{C.2.3 Factors Affecting Customer-Average Elasticities of Substitution}

In the third empirical model, we identify key customer characteristics that affect average elasticities of substitution by firm. ${ }^{36}$ We do so by regressing these average elasticities on a variety of variables that describe customer circumstances. Since a number of these variables were obtained through the survey, the sample of firms included in this analysis is limited to the 55 customers that provided answers to the appropriate survey questions. A comparison of this subset of firms with the 119 used to estimate the other two equations indicates that, with the exception of healthcare and public works, other sectors are proportionally represented both in terms of customer numbers and maximum demand.

\footnotetext{
${ }^{35}$ See Goldberger 1990, p. 189-90, for a discussion of omitted variable bias.

${ }^{36}$ See Table 5 for the definitions of the variables.
} 
Table 12 presents the estimated parameters for the third equation designed to identify systematic differences in average elasticities across firms associated with firm characteristics and circumstances. The $\mathrm{R}^{2}$ indicates that the explanatory variables included in this equation account for about a third of the variation in the average elasticities of substitution for the 55 firms. White's statistic indicates that the errors terms do not exhibit heteroskedasticity, so no correction was required.

\section{Table 12. Customer-Level Elasticities of Substitution Regression Results}

\begin{tabular}{|l|c|c|}
\hline \multicolumn{1}{|c|}{ Variable } & Parm. Est. & t-Stat \\
\hline Intercept & 0.1976 & 0.88 \\
Commercial/Retail & 0.1640 & 1.34 \\
Manufacturing & 0.0155 & 0.17 \\
Gov't/Education & 0.1227 & 1.09 \\
Health Care & 0.0590 & 0.37 \\
EDRP Participant & 0.1794 & 2.53 \\
SCR Participant & -0.0610 & -0.63 \\
Installed EMCS & -0.1489 & -2.46 \\
Monitor RTP Frequently & 0.0579 & 0.52 \\
Installed On-Site Gen & 0.0262 & 0.45 \\
Increased kWh & 0.0811 & 1.34 \\
Avg. Pk. Off-Pk. Load Ratio & -1.3114 & -0.94 \\
R-Squared & 0.31 & \\
White's Test Statistic & 52 & 0.10 \\
\hline
\end{tabular}

In general, the estimated parameters values do yield some insight into the factors that explain differences in customers' average ability to reduce peak load in response to price. While many of the coefficients are of the expected sign, only two effects are statistically different from zero( $t>2)$. Rather than suggesting that these other factors have no effect, the low t-statistics could also be due to the relatively small sample size and the resulting limited variation in the level of the explanatory variables. In this case, the low t-ratio means that we are measuring the effect with very little precision, a situation that might well have been avoided if these variables had been available for all 119 customers.

The estimated coefficient for the EMCS variable is negative, indicating that firms with these systems are less able to shift load in response to higher relative peak prices, on average, than firms that do not have them. This result, has been consistent throughout this study, and comports with previous studies of price response among customers throughout New York participating in NYISO demand response programs.

The coefficients on the variables for participation in NYISO's two demand response programs are of different signs. The coefficient for participation in the Emergency Demand Response Program is positive, and significant, indicating that such participation results in a higher average ability to be price responsive. This would seem to be an intuitively correct result. But the estimated coefficient on the ICAP/SCR participation variable is negative, and insignificant. In other words, the specification finds no (or at best a weak) relationship between the imposition of a high penalty prices and price response in the case of SCR, in contrast to the EDRP case. This counter-intuitive result is discussed in more detail in Chapter 3 of this report. 


\section{C.3. Aggregate Load Response}

To obtain some sense of the overall impact on the shift in peak to off-peak usage at various peak to off-peak electricity price ratios, the elasticities of substitution for individual firms were used to simulate the peak load reduction as the price ratio changes (see Appendix B for more details, particularly the discussion surrounding equation (35)). These results are illustrated in Figures 6 and 7.

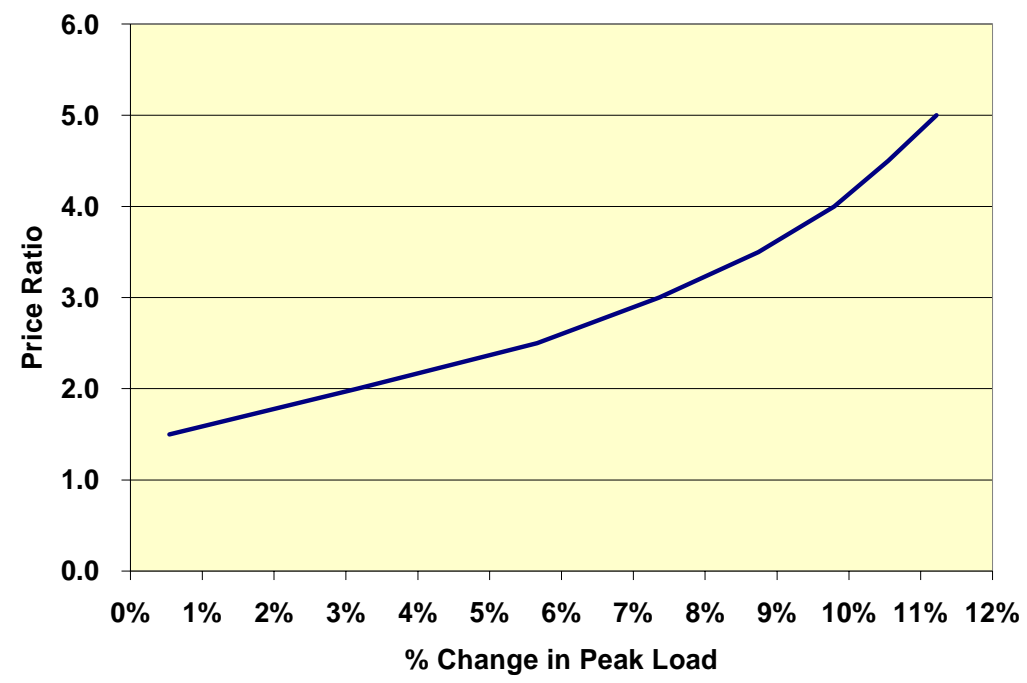

Figure 6. Percentage Reduction in 119 SC-3A Customers’ Peak Demand

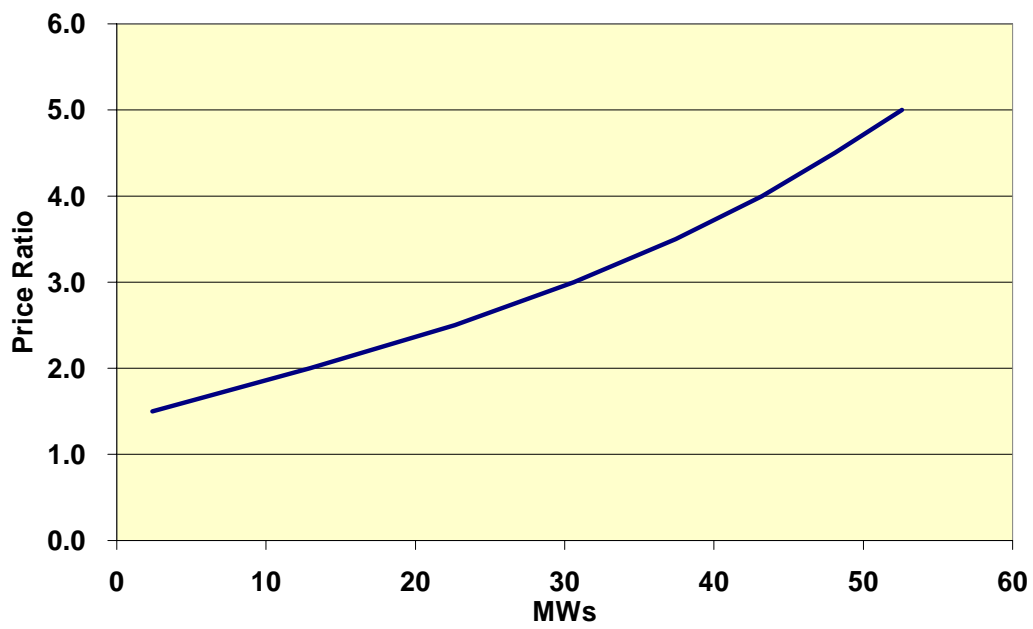

\section{Figure 7. Reduction in 119 SC-3A Customers’ Peak Demand}

At the highest peak to off-peak price ratio observed in the SC-3A price data $-5: 1$ - the 119 modeled customers are estimated to reduce their peak-period usage by about $50 \mathrm{MW}$, a 10\% reduction from their typical usage. SC-3A customers' aggregate load response is non-linear - it increases as the price ratio increases but at a decreasing rate, especially at 
ratios above $3: 1$. This occurs primarily because the relationship between price ratios and the elasticity of substitution is negative for $\sim 57 \%$ of the customers (see Table 7 ). As the price ratio increases, the elasticity of substitution decreases modestly among manufacturing, healthcare, and public works customers. The overall level of load response therefore increases for higher price ratios, but the rate of change for higher and higher price ratios becomes smaller and smaller. 